(1) Nordic Council of Ministers

\title{
Baltic Energy Technology Scenarios 2018
}

wasto th

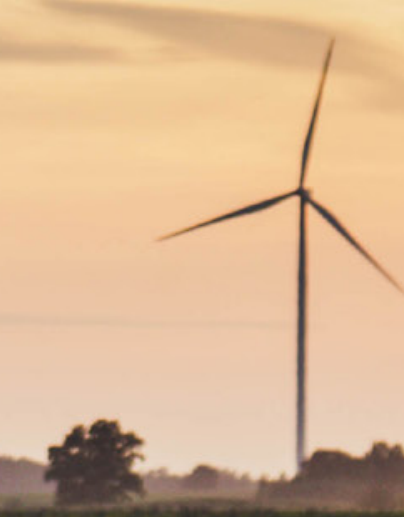

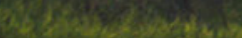

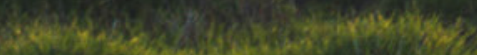

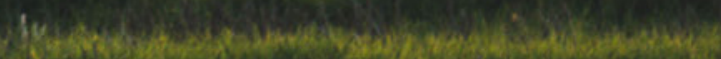

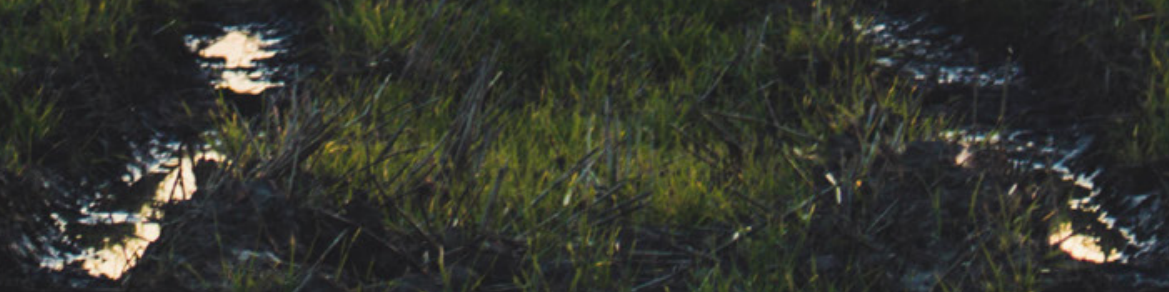

Whes
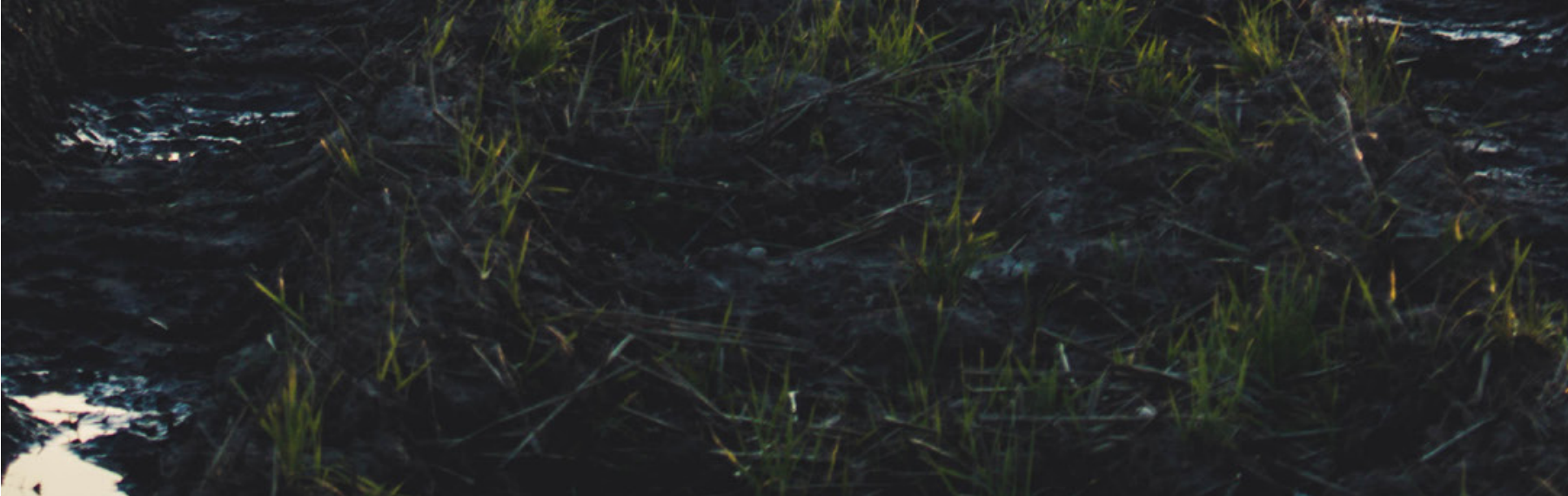



\section{Baltic Energy Technology Scenarios 2018}

Tomi J. Lindroos, Antti Lehtilä and Tiina Koljonen (VTT team).

Anders Kofoed-Wiuff, János Hethey, Nina Dupont and

Aisma Vitina (Ea Energy Analyses team).

TemaNord 2018:515 


\section{Baltic Energy Technology Scenarios 2018}

Tomi J. Lindroos, Antti Lehtilä and Tiina Koljonen (VTT team). Anders Kofoed-Wiuff, János Hethey, Nina Dupont and Aisma Vitina (Ea Energy Analyses team).

ISBN 978-92-893-5457-8 (PRINT)

ISBN 978-92-893-5458-5 (PDF)

ISBN 978-92-893-5459-2 (EPUB)

http://dx.doi.org/10.6027/TN2018-515

TemaNord 2018:515

ISSN $0908-6692$

Standard: PDF/UA-1

ISO 14289-1

(c) Nordic Council of Ministers 2018

Cover photo: Tautvydas Lapūnas

Photo: p 19/MKstudio; p 30/Capitanoseye; p 48/Egert; p 82/Alex Tihonovs; p 110/A. Aleksandraviciuss

Print: Rosendahls

Printed in Denmark

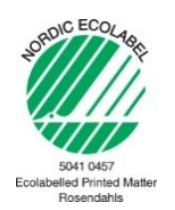

Disclaimer

This publication was funded by the Nordic Council of Ministers. However, the content does not necessarily reflect the Nordic Council of Ministers' views, opinions, attitudes or recommendations.

Rights and permissions

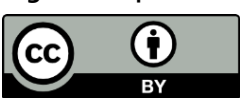

This work is made available under the Creative Commons Attribution 4.0 International license (CC BY 4.0) https://creativecommons.org/licenses/by/4.0.

Translations: If you translate this work, please include the following disclaimer: This translation was not produced by the Nordic Council of Ministers and should not be construed as official. The Nordic Council of Ministers cannot be held responsible for the translation or any errors in it.

Adaptations: If you adapt this work, please include the following disclaimer along with the attribution: This is an adaptation of an original work by the Nordic Council of Ministers. Responsibility for the views and opinions expressed in the adaptation rests solely with its author(s). The views and opinions in this adaptation have not been approved by the Nordic Council of Ministers. 
Third-party content: The Nordic Council of Ministers does not necessarily own every single part of this work. The Nordic Council of Ministers cannot, therefore, guarantee that the reuse of third-party content does not infringe the copyright of the third party. If you wish to reuse any third-party content, you bear the risks associated with any such rights violations. You are responsible for determining whether there is a need to obtain permission for the use of third-party content, and if so, for obtaining the relevant permission from the copyright holder. Examples of third-party content may include, but are not limited to, tables, figures or images.

Photo rights (further permission required for reuse):

Any queries regarding rights and licences should be addressed to:

Nordic Council of Ministers/Publication Unit

Ved Stranden 18

DK-1061 Copenhagen K

Denmark

Phone +4533960200

pub@norden.org

\section{Nordic co-operation}

Nordic co-operation is one of the world's most extensive forms of regional collaboration, involving Denmark, Finland, Iceland, Norway, Sweden, and the Faroe Islands, Greenland and Åland.

Nordic co-operation has firm traditions in politics, economics and culture and plays an important role in European and international forums. The Nordic community strives for a strong Nordic Region in a strong Europe.

Nordic co-operation promotes regional interests and values in a global world. The values shared by the Nordic countries help make the region one of the most innovative and competitive in the world.

The Nordic Council of Ministers

Nordens Hus

Ved Stranden 18

DK-1061 Copenhagen K, Denmark

Tel.: +4533960200 www.norden.org

Download Nordic publications at www.norden.org/nordpub 



\section{Contents}

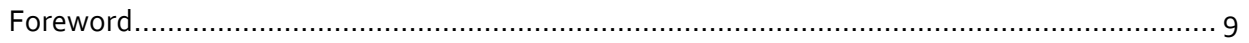

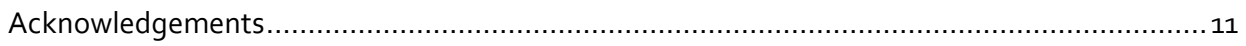

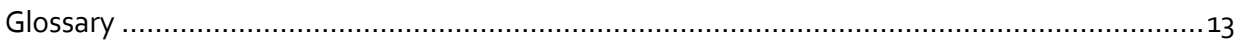

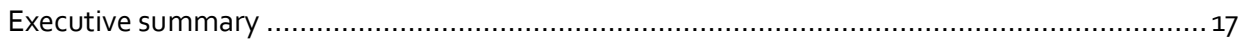

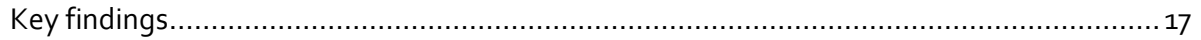

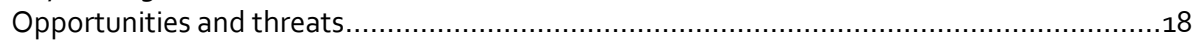

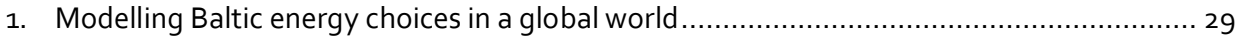

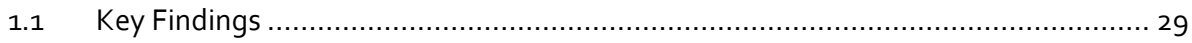

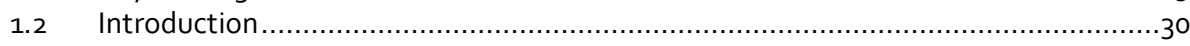

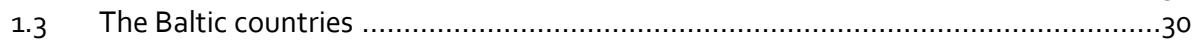

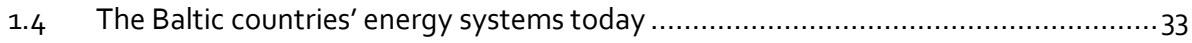

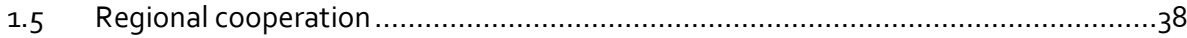

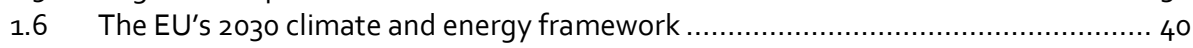

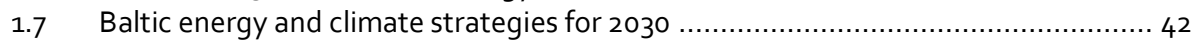

1.8 The scenario and modelling framework ........................................................ 44

2. Growing demands, increasing efficiency, and electrification ...................................47

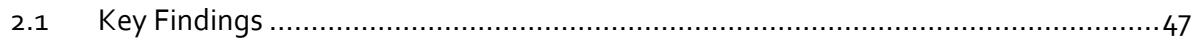

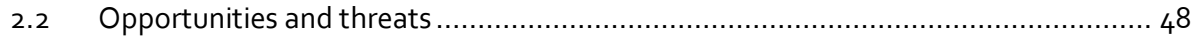

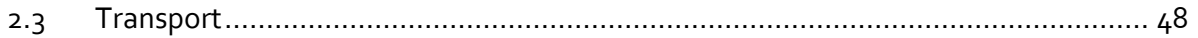

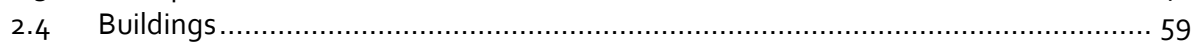

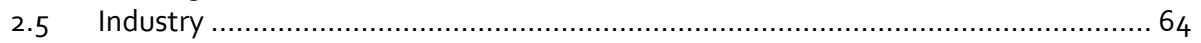

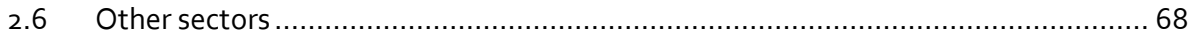

2.7 Electricity consumption increasing due to assumed growth and electrification ........76

3. Towards renewable and low-carbon electricity and district heating .............................. 81

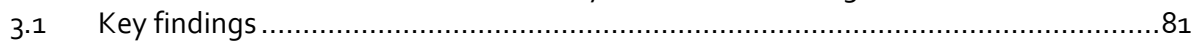

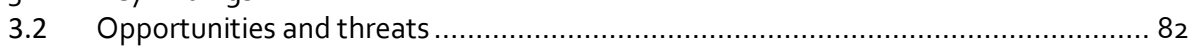

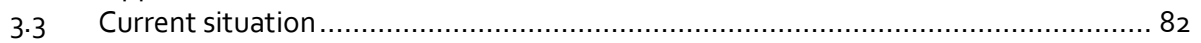

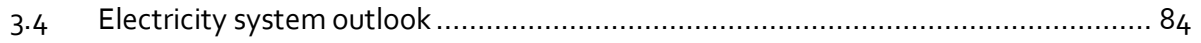

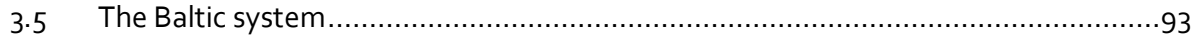

4. Progressing towards low-carbon and renewable energy systems ...............................109

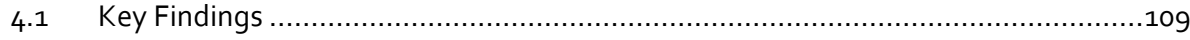

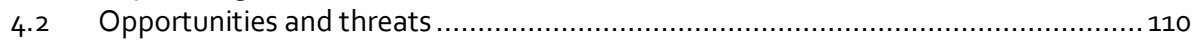

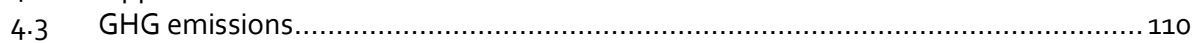

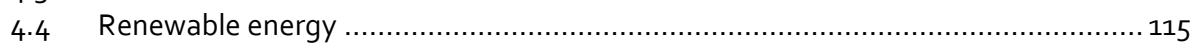

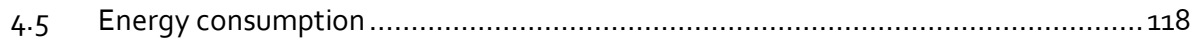

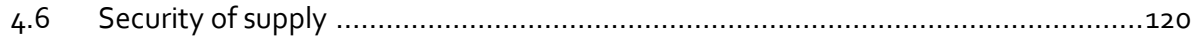

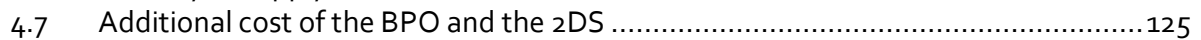

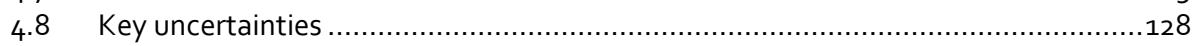

4.9 Things to improve in further studies ....................................................... 130

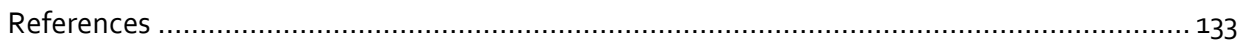

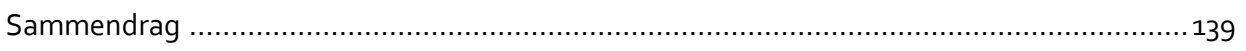




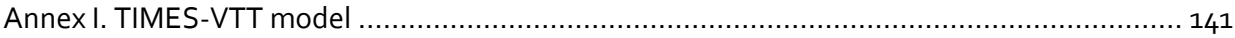

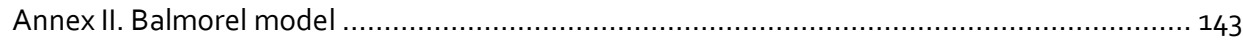

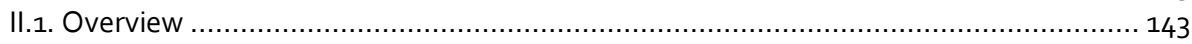

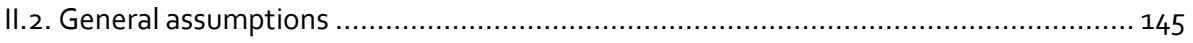

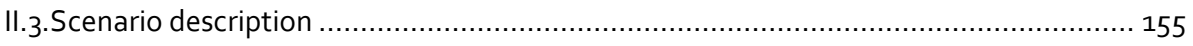

Annex III. Energy system modelling in Estonia .....................................................

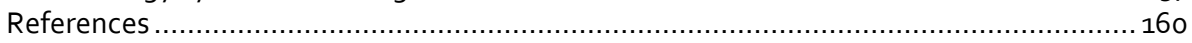

Annex IV. Energy system modelling in Latvia.......................................................... 161

Annex V. Energy system modelling in Lithuania ..................................................... 163

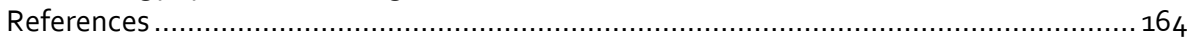




\section{Foreword}

Nordic Energy Research (NER) have since its inception worked closely with the Baltic countries. Baltic researchers have been involved in several research projects we have initiated and funded. NER have participated and organised numerous workshops in the Baltics and also had the pleasure of hosting several Baltic visits to Nordic capitals. We have also benefited from Baltic researchers and officials when formulating our new strategy.

The Nordic countries and the three Baltic countries share some common energy challenges and opportunities. Similar climatic conditions, rich bioenergy resources, ample wind-energy potential and hydropower. The Baltics are also major trading partner with the Nordics and integrated to the Nordic Electricity Market.

Nordic Energy Technology Perspectives (NETP) was the largest IEA collaborative analytical effort looking at regional long-term low-carbon technology pathways. The report applied the global energy scenarios of the IEA Energy Technology Perspectives (ETP) to the Nordic countries, utilising rich national data and addressing opportunities and challenges specific to the Nordic countries.

NETP has become a key point of reference for various subsequent analyses from Nordic governments, industry and civil society. After completing two editions of Nordic Energy Technology Perspectives (NETP) we considered it a natural next step to conduct a similar exercise for the Baltic countries. BENTE builds on the second edition of the report from 2016 and provides an analysis that explores the anticipated changes in the Baltic countries' energy systems. What would be required for the Baltic countries to meet their climate and energy targets in 2030, and what development would lead the Baltics towards a 2-degree pathway?

I am very encouraged by the interest and support we have experienced from Baltic researchers as well as senior officials from the Baltic capitals when we embarked on this project. Their involvement and sharing of insights was instrumental in making BENTE possible. I would also like to express my gratitude to Kevin Johnsen (NER) who has worked tirelessly on this project.

For Baltic policymakers, the scenarios in this report identify both challenges and opportunities on the road towards the ambitious national climate targets of the region. We hope that this report can provide valuable insights for each country on how to respond and fulfil the proposed EU-targets expressed in the so-called "winter package". It is my hope that this fruitful co-operation will continue and be extended to other projects as well.

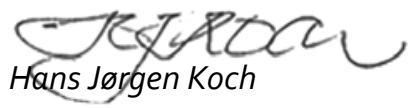

Director, Nordic Energy Research 



\section{Acknowledgements}

Baltic Energy Technologies Scenarios 2018 (BENTE) is a collaborative project between VTT Technical Research Centre of Finland, Ea Energy Analyses, Baltic research institutions and Nordic Energy Research - an intergovernmental organisation under the Nordic Council of Ministers.

Kevin Johnsen at Nordic Energy Research was the coordinator of the project.

Tomi J. Lindroos at VTT Technical Research Centre of Finland Ltd. was the analytical project manager and had overall responsibility for the design and implementation of the study.

Anders Kofoed-Wiuff led the analysis at Ea Energy Analyses.

\section{Nordic Energy Research team}

Kevin Johnsen, Svend Søyland and Hilde Marit Kvile.

\section{VTT team}

Tomi J. Lindroos, Antti Lehtilä, Tiina Koljonen.

\section{Ea Energy Analyses team}

Anders Kofoed-Wiuff, János Hethey, Nina Dupont and Aisma Vītiṇa.

\section{Baltic Researchers}

The report would not have been possible to make without the contributions from the Baltic researchers:

- Jānis Rekis and Gaidis Klāvs (Institute of Physical Energetics, Latvia).

- Arvydas Galinis, Egidijus Norvaisa, Vaclovas Miskinis, Vidas lekavicius, Inga Konstantinaviciute and Eimantas Neniskis (Lithuanian Energy Institute).

- Dagnija Blumberga, Jeḷena Ziemele and Diāna Žalostība (Riga Technical University).

- Hardi Koduvere (Tallinn University of Technology). 


\section{Steering group}

The work was guided by the Steering group, consisting of:

- Madis Laaniste (The Ministry of Economic Affairs and Communications, Estonia).

- Jānis Patmalnieks and Andrejs Apanuus (The Ministry of Economics, Latvia).

- Ilze Prūse (Ministry of Environmental Protection and Regional Development, Latvia).

- Daumantas Kerezis and Ilona Pintuke (The Ministry of Energy, Lithuania).

- Stasile Znutienè (Ministry of Environment of the Republic of Lithuania).

- Svend Søyland and Kevin Johnsen (Nordic Energy Research).

The individuals and organisations that contributed to this study are not responsible for any opinions or judgements contained in this study.

\section{Contact}

Comments and questions are welcome and should be addressed to:

- Kevin Johnsen, Nordic Energy Research, e-mail: kevin.johnsen@nordicenergy.org

- Tomi J. Lindroos, VTT Technical Research Centre of Finland Ltd, e-mail: Tomi.J.Lindroos@vtt.fi

For enquiries regarding the presentation of results or distribution of the report, contact Nordic Energy Research.

Additional materials, press coverage, presentations etc can be found at www.nordicenergy.org. 


\section{Glossary}

- $2 D S$

2 Degrees Scenario. A scenario where global warming is limited to 2 degrees and EU reduces $\mathrm{GHG}$ emissions by $80 \%$ by 2050 . See chapter 1.7 for details.

- $4 D S$

4 Degrees Scenario. A scenario where global warming reaches 4 degrees. See chapter 1.7 for details.

- Baltic countries

Estonia, Latvia, and Lithuania. Also known as the Baltic States, Baltic republics, or simply, the Baltics.

- $B P O$

Baltic Policies Scenario. This is the same as $4 \mathrm{DS}$, except that we assume additional GHG and renewable energy targets for the Baltic countries. See chapter 1.7 for details.

- $\mathrm{CH}_{4}$ Methane.

- $\mathrm{CO}_{2}$

Carbon dioxide.

- Dispatchable generation

Sources of electricity that can be dispatched (controlled) both up and down at the request of operators.

- $D H$

District heating.

- $G H G$

Greenhouse gas. $\mathrm{CO}_{2}, \mathrm{CH}_{4}, \mathrm{~N}_{2} \mathrm{O}$, and fluorinated-gases (F-gases), sometimes also called Kyoto gases.

- Energy dependence

The extent to which an economy relies on imports in order to meet its energy needs. Calculated as total net imports of electricity and fuels (solid, liquid, gaseous) as a share of primary energy consumption.

- $E S D$

Effort Sharing Decision (ESD) sets EU Member state specific caps to GHG emissions from Effort Sharing Sector (ESS) from 2013 to 2020. 
- $\quad E S R$

Effort Sharing Regulation (ESR) is an updated and continued version of the ESD covering the period from 2021 to 2030 . ESR is currently a proposal by European Commission.

- $\quad$ ESS

Effort Sharing Sector (ESS) covers GHG emissions from transport, buildings, agriculture, waste management, industry not included to the EU ETS, electricity and heat production not included to the EU ETS, and F-gases. Country specific emission cap to ESS is set in the ESD from 2013 to 2020 and in proposed ESR from 2021 to 2030.

- EUETS

EU's Emission Trading Scheme (EU ETS) covers $\mathrm{CO}_{2}$ emissions and some other GHG emissions from heavy energy-using installations (power stations and industrial plants).

- $E V$

Electric Vehicle. Uses only electricity as fuel. Some sources use Battery Electric Vehicle (BEV).

- F-gases

Fluorinated-gases. GHG emissions from various groups of gases that are used as coolants and in industrial processes. F-gases can stay in the atmosphere for centuries and have a strong warming effect.

- Final energy consumption

Final energy consumption covers all energy supplied to final consumers (transport, buildings, industry, and agriculture) excluding energy used in industry's energy transformation (CHP, steam generation, etc). In the case of e.g. industry steam, the steam is considered industry final energy. The fuel to produce the steam is classified to energy transformation.

- $F L H$

FLH (Full Load Hours) are used to compare annual operation times. If a plant operates at $50 \%$ capacity all year, it has $8760 * 0.5=4380 \mathrm{FLH}$. If a plant operates 6 months with $100 \%$ capacity, $50 \%$ for 5 months, and is shut down for a month, it has $8760 *(6 / 12+0.5 * 5 / 12)=5292.5 \mathrm{FLH}$.

- $\quad$ LULUCF Land Use, Land-Use Change, and Forestry

- MSW

Municipal solid waste

- $\mathrm{N}_{2} \mathrm{O}$

Nitrous oxide 
- Normal year

Used in modelling of variables that have a large natural variability between years, e.g. precipitation for hydropower, heating degree days (HDD) for buildings, and wind. Statistics are based on actual years, but the modelling is based on normal years.

- PaMs

The policies and measures (PaMs) outlined in an EU directive require all member states to report their GHG projections and planned mitigation measures.

- Plug-in hybrid

Plug-in hybrid Electric Vehicle. Often also called PHEV. Uses electricity and petrol/diesel as fuels.

- Primary energy supply

Total Primary Energy Supply (TPES) calculates the total of production, net imports, and storage changes of all fuels. Electricity is primary energy only when traded. Produced electricity is a secondary product from power and heat generation.

- PRIMES

Energy system model used in the European Commission's impact analysis for the $\mathrm{EU}$ and EU member states.

- $R E D / R E D 2$

EU's Renewable Energy Directive (RED). RED is in effect until 2020, after which it should be replaced with the new version, called RED2, for the period from 2021-2030.

- $R E F / R E F 2016$

Reference scenario used in PRIMES modelling by EU commission. Very similar to the $4 \mathrm{DS}$ in this report. The latest reference scenario is the EU Reference Scenario 2016 (EC, 2016a).

- $R E$

Renewable Energy, also often referred to as RES (Renewable Energy Sources).

- $R E S-E$

EU method to calculate electricity generation from renewable energy sources (RES-E). Imported electricity is counted as non-renewable. The current method includes normalizing the annual variations of renewable energy production and cannot be calculated directly from produced electricity.

- $R E S-H$

EU method to calculate heat generation from renewable energy sources (RES-H). This includes district heating and heat generated in buildings.

- $R E S-T$

EU method to calculate transport energy from renewable energy sources (RES-T). Current EU methodology until 2020 includes multiplication factors for advanced biofuels and electricity and cannot be directly calculated from the transport final energy shares. 
- RES target

Usually defined as a certain share of final energy from renewable energy sources.

- VRE

Variable Renewable Energy is a subcategory of renewable energy. It primarily refers to wind, solar, and run-of-river hydroelectricity that fluctuate.

- WAM

The WAM (with additional measures) scenario describes the effects of climate and energy policy measures and is used in the EU policies and in the PaMs report.

- WEM

The WEM (with existing measures) scenario is used in the EU policies and in the PaMs report. 


\title{
Executive summary
}

\author{
Key findings
}

- GHG reductions should be led by the electricity and district heating sectors, followed by transport, buildings and other sectors. End-use sectors can reduce GHG emissions and increase the RE share through electrification only if the supplied electricity is $\mathrm{CO}_{2}$-free and renewable.

- The Baltic countries do not reach their Effort Sharing Sector(ESS) targets in the 4 Degree Scenario (4DS). Especially Latvia will need additional reductions or flexibility measures. The most cost-effective measures to reduce ESS emissions are to decrease oil consumption in ESS (most importantly in transport, buildings, and industrial plants that are not included in EU ETS) and to reduce fossil fuel use in smaller district heating plants that are not included in EU ETS.

- The Baltic countries could achieve the proposed renewable energy targets using domestic resources. Energy efficiency measures, wind power, biomass, heat pumps, and solar power and heating are estimated to be the most cost-effective ways to increase the renewable energy share.

- Electricity consumption is projected to increase due to growing demands and electrification. The largest increase would come from electric vehicles (EVs), followed by industry due to assumed growth of production, heat pumps in buildings and district heat production, and other transportation. Based on the assumptions of this study, the growth could be $17 \%$ to $27 \%$ by 2030 compared to 2015 , and $60 \%$ to $65 \%$ by 2050 .

- Renewable energy is becoming the cheapest option for new electricity generation and European electricity systems will undergo a transformation to very high renewable shares in the coming decades. In the absence of sustainable policies to facilitate cost-effective local renewable energy generation, the Baltic countries will become large net importers of electricity.

- The deployment of renewable energy would reduce the import dependency of the Baltic countries and provide an effective hedge against high electricity prices.

Additional interconnection capacity to the Nordic countries is likely to become economical.

- The estimated additional energy system net costs of the Baltic Policies Scenario (BPO) and 2 Degree Scenario (2DS) are reasonably small. The additional costs compared to the 4DS range from $0 \%$ to $0.3 \%$ of GDP in 2030 and from $0.1 \%$ to $0.5 \%$ in 2050 . The BPO results in higher additional costs at 2030 than the $2 \mathrm{DS}$. 


\section{Opportunities and threats}

- The Baltic power systems offer good opportunities for integration of wind and solar power. The most important integration measures are local hydro power, largescale pumped hydro storage, interconnectors to the hydropower dominated Nordic power system, and flexible thermal power plants. In the longer term, power to heat solutions, i.e. electric boilers and large-scale heat pumps, could also play a key role in the integration of variable generation.

- Heat pumps could provide a cost-competitive option for the supply of district heating in an energy system with high shares of wind and solar power. However, further studies are required to substantiate the realistic potential and socioeconomic impacts of large heat pumps in the Baltic countries.

- Energy efficiency measures can save money, reduce GHG emissions, increase the RE share, and improve energy independence in the Baltic countries. Some of the costsaving energy efficiency measures are not implemented due to other barriers, such as conflicting interests between building owners and the people who benefit from the measures.

- The Baltic countries can avoid becoming large net importers of electricity. Modelled subsidy levels about 10 EUR/MWh for all domestic generation were sufficient to reduce annual net imports to zero by 2030 in a situation where wholesale power prices would be approx. 40 EUR/MWh. Wind and solar power provide the most cost-efficient way of reducing import dependency.

- Electricity consumption may increase less than projected if sectoral demands (transport volumes, industry production, floor areas, etc.) grow less than expected or if the electrification of sectors is delayed. This would help to achieve domestic generation targets and reduce costs.

- The economic sustainability of the existing gas-fired capacity in the Baltic countries is being challenged by low-priced imports. Further analyses are necessary to examine if this poses a threat to the security of supply in these three countries.

- Biomass is an important cross-cutting issue, as it can provide renewable energy and $G H G$ reductions to all energy-consuming sectors. There is strong competition for biomass resources both domestically and as an export product, but proposed EU LULUCF and RED 2 directives may change the classification of sustainable biomass and alter the available amounts and prices.

\section{Setting the scene}

In recent years, technological advancements in the energy sector have moved at a very fast pace. Renewable energy technology prices have dropped to a level where they are now outcompeting fossil fuels as a long-term solution. Battery prices depict a similar plunge, and it now seems realistic that total costs of electric vehicles will reach the total costs of diesel and gasoline cars within the next 5 to 15 years. EVs will be more expensive to buy, but cheaper to use and maintain. 


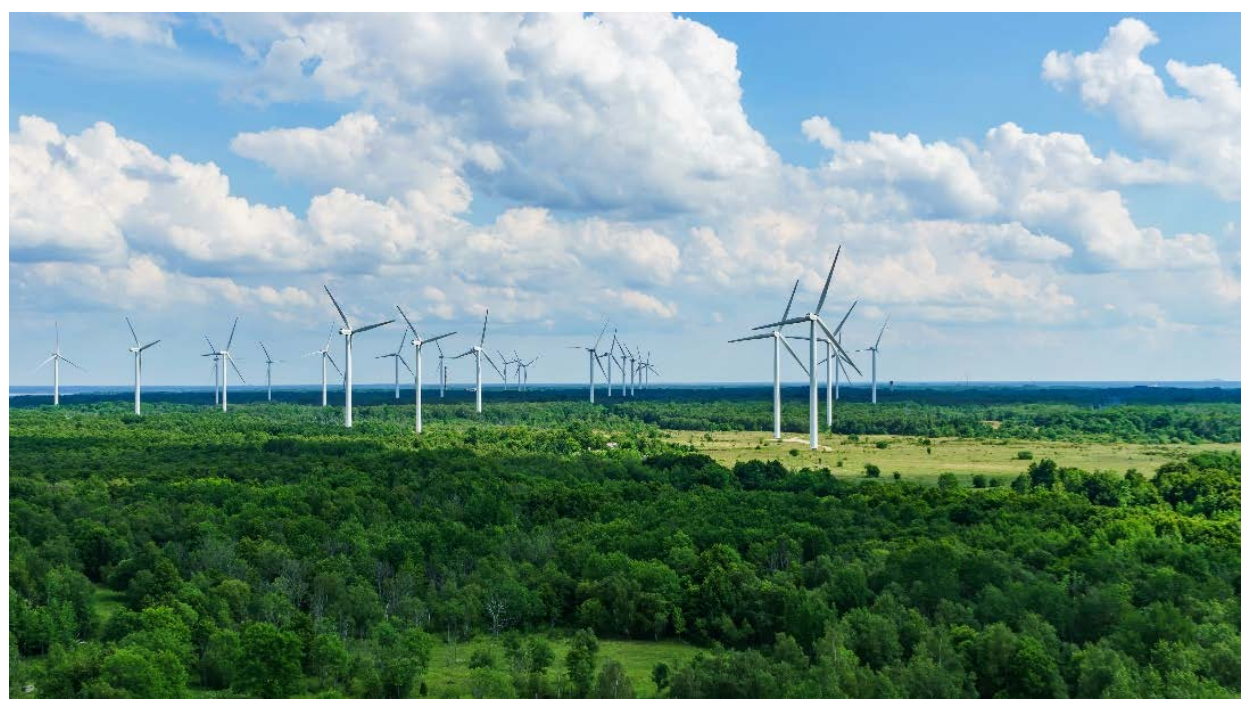

The three Baltic countries used to be so-called "energy islands" with no electricity or gas interconnectors to the rest of Europe. But this situation has changed with the establishment of electricity interconnectors to Finland, Sweden and Poland. At the same time, the opening of a LNG terminal in Lithuania has improved security of gas supplies and the bargaining power in gas price negotiations with Russia. Additionally, gas interconnectors to Finland and Poland are under construction.

Against this backdrop, the BENTE project explores the energy outlook for the three Baltic countries: Estonia, Latvia and Lithuania. The purpose of BENTE is to contribute to the Baltic countries' efforts to renew and update their energy and climate strategies, with a particular focus on how each country could achieve their proposed EU 2030 targets and suggested national additional targets for 2030, and on providing a perspective towards 2050.

There are no decisions yet, but the most important proposals for our energy systems modelling are:

- Effort Sharing Sector's (ESS) targets, proposed by the EC (Estonia -13\%, Latvia -6\%, and Lithuania $-9 \%$ by 2030 compared to 2005 ).

- Renewable energy targets, proposed by the Baltic countries (50\% Estonia, 50\% Latvia, and 45\% Lithuania.).

- Energy efficiency targets, proposed by the Baltic countries (both sectoral and general targets, see chapter 1.6 for details).

- Targets for domestic electricity and district heat generation, proposed by the Baltic countries (see chapter 1.6 for details).

The chosen targets have a high influence on the results and it remains to be seen how many of these targets will actually be adopted and if the ambition level will be the same than assumed here. 


\section{Analytical framework}

Three core scenarios have been created, providing the analytical framework for the project. The scenarios have been designed with a view to describing realistic consequences of future possible climate policies and to assessing what measures will be required in the Baltic countries to comply with EU climate and energy obligations:

- 4 Degrees Scenario (4DS) presents a world with moderate ambitions for climate change mitigation. The EU will go forward with its 2030 targets. We assume also that the emission cap of both EU ETS and ESS will keep tightening towards 2050, but not enough to reach the $80 \%$ target. The Baltic countries will achieve their 2020 targets, but will not adopt any new targets thereafter. In this scenario, Baltic countries might not achieve proposed 2030 targets, e.g. ESS targets.

- Baltic Policies Scenario (BPO) is comparable to the $4 D S$, but in the BPO we assumed that the Baltic countries' comply with proposed 2030 ESS targets and national targets to increase their RE shares. In BPO, we assume also that 2050 ESS targets for Baltic countries will be implemented similarly than for the other EU in 4DS (Estonia -39\%, Latvia -34\%, and Lithuania -36\%).

- 2 Degrees Scenario (2DS) models a cost-optimal pathway to achieving the global two degree target, where the EU complies with its ambition of $80 \%$ reduction by 2050. The high price of $\mathrm{CO}_{2}$ is the main driver for the low-carbon transition in this scenario. In 2DS, we do not include Baltic countries' RE targets for 2030 to be able to study if those are in line or more ambitious than in the 2DS pathway.

We use two energy system models to study the impacts of Baltic energy choices. TIMES-VTT includes all energy production, consumption, and Kyoto GHGs excluding LULUCF. The Balmorel model is much more detailed in the electricity and district heating sector. These two models are linked in this study. Balmorel provides detailed analysis of electricity and district heating and TIMES-VTT gives overall projections of energy demand, energy supply, renewable energy, and integrated results.

\section{Greenhouse gas emissions}

GHG reductions should be led by electricity and district heating sectors, followed by transport, buildings, and other sectors (Figure 1). GHG emissions from electricity and district heating peaked around 2010 and were at 30\% lower levels in 2015.

The trend continues across the scenarios, because electricity and district heating provide the most cost-effective options to reduce GHG emissions and to increase the renewable energy share. The Baltic power systems hold good opportunities for integration of wind and solar power. The most important integration measures are local hydropower - including large-scale pumped storage - interconnectors to the hydropower dominated Nordic power system and flexible thermal power plants. In the longer term, the widespread district heating schemes could also play a key role, through power to heat solutions, i.e. electric boilers and heat pumps. 
Energy demand sectors can reduce GHG emissions and increase the RE share through electrification only if they are supplied with $\mathrm{CO}_{2}$-free and renewable electricity.

Figure 1: GHG emissions by sector in the Baltic countries in the BPO

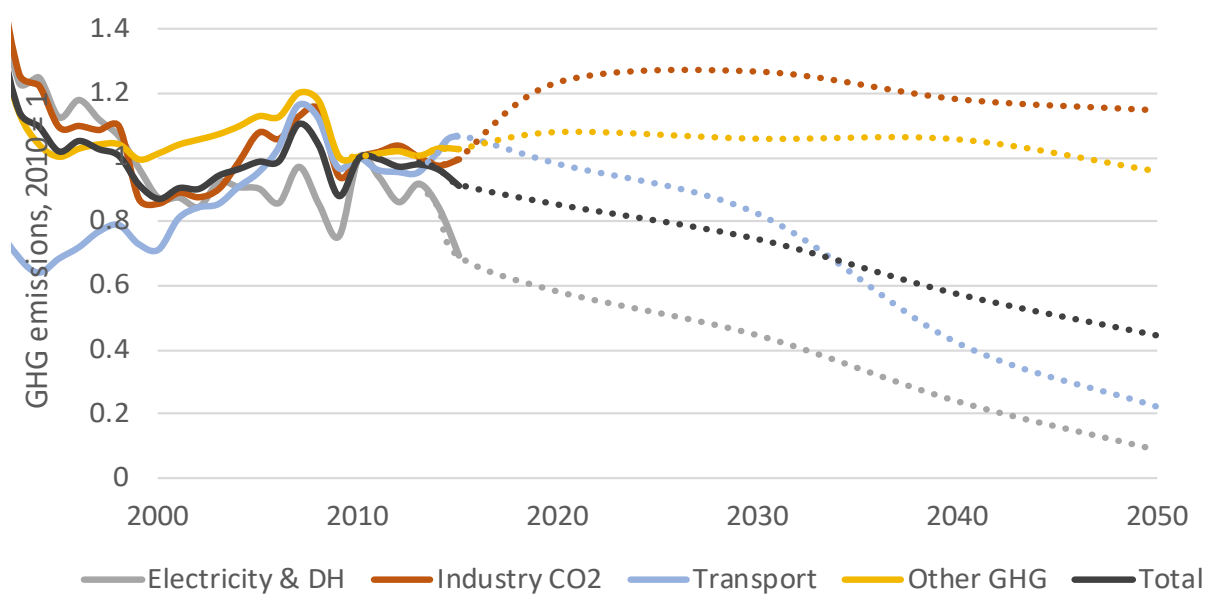

Key point(s): Electricity and district heating should reduce emissions first, followed by buildings and transport.

Note: $\quad$ Contrary to these results, Lithuania's national projections show a growing trend in transport emission. See Chapter 2.1 for comparison between these and national results.

The ESS target is very important, especially for Latvia. Estonia and Lithuania are close to achieving their 2030 ESS target in the $4 \mathrm{DS}$, but Latvia needs to reduce ESS emissions by more than $10 \%$ to reach the 2030 target for 4 DS (Figure 2 ).

The most cost-effective measures to reduce ESS emissions by 2030 are to reduce fossil fuel use in small district heating plants that are not included in EU ETS, and to reduce oil consumption in ESS (most importantly transport, buildings, and industries not included in EU ETS). In the long term, EVs will reach price parity with combustion engine vehicles and drive down transport sector emissions.

The Baltic countries produce a large share of non- $\mathrm{CO}_{2}$ emissions (agriculture, industry processes, waste management), which are much more difficult to reduce than $\mathrm{CO}_{2}$ emissions from energy use. In the $\mathrm{BPO}$, the share of non- $\mathrm{CO}_{2}$ emissions will increase from $25 \%$ in 2015 to $50 \%$ in 2050. 
Figure 2: Effort Sharing Sector (ESS) emissions of Baltic countries in the 4DS and BPO compared to national target pathways from 2013 to 2020 and from 2021 to 2030

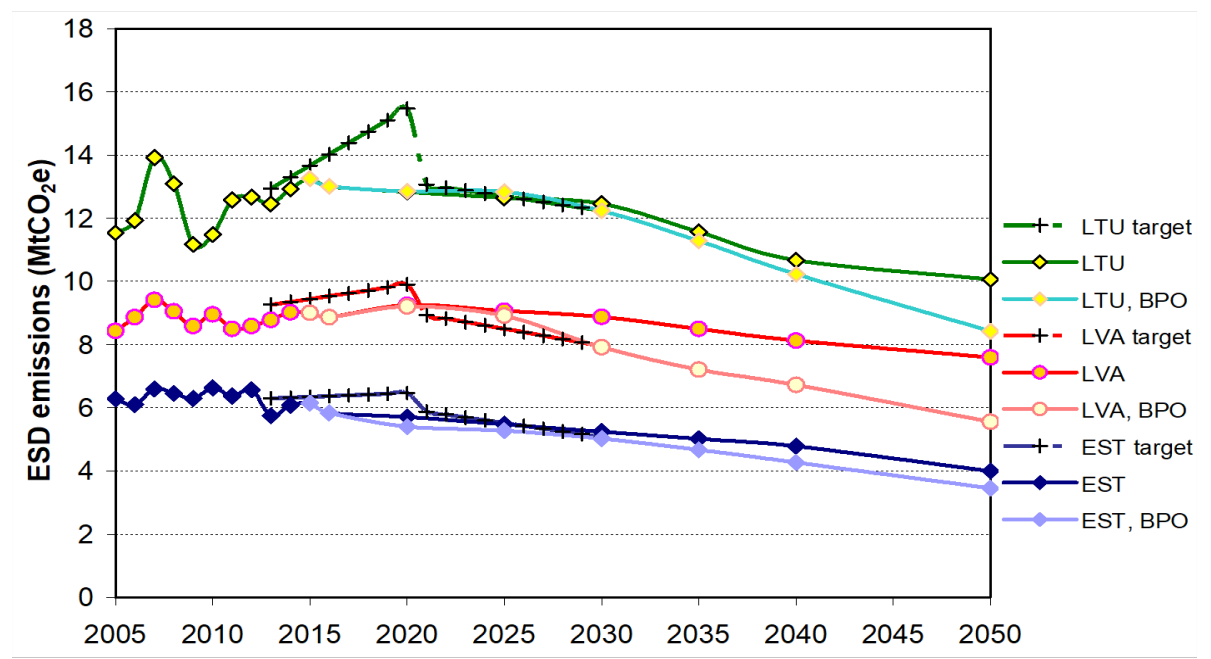

Key point(s): The Baltic countries do not reach their 2030 ESS targets in the 4 DS. Especially Latvia needs additional emission reductions.

\section{Renewable energy}

The Baltic countries' renewable energy share was between the RE shares of the EU and Nordic countries at 2015 (Figure 3). The projected development increases the RE shares of all three regions in all scenarios.

The Baltic countries' renewable energy targets would take them to the 2 degrees pathway in 2030 , reaching $50 \%$ in the BPO compared to $42 \%$ in the $4 \mathrm{DS}$. The increase from 2015 to 2020 is due to adopted 2020 targets, but the development would stall without additional targets and measures. Similarly, in the BPO, the Baltic countries will fall behind the 2DS pathway after 2030 unless additional targets and measures are adopted. 
Figure 3: Renewable energy share of final consumption in the Baltic countries, Nordic countries, and EU

\section{$100 \%$}

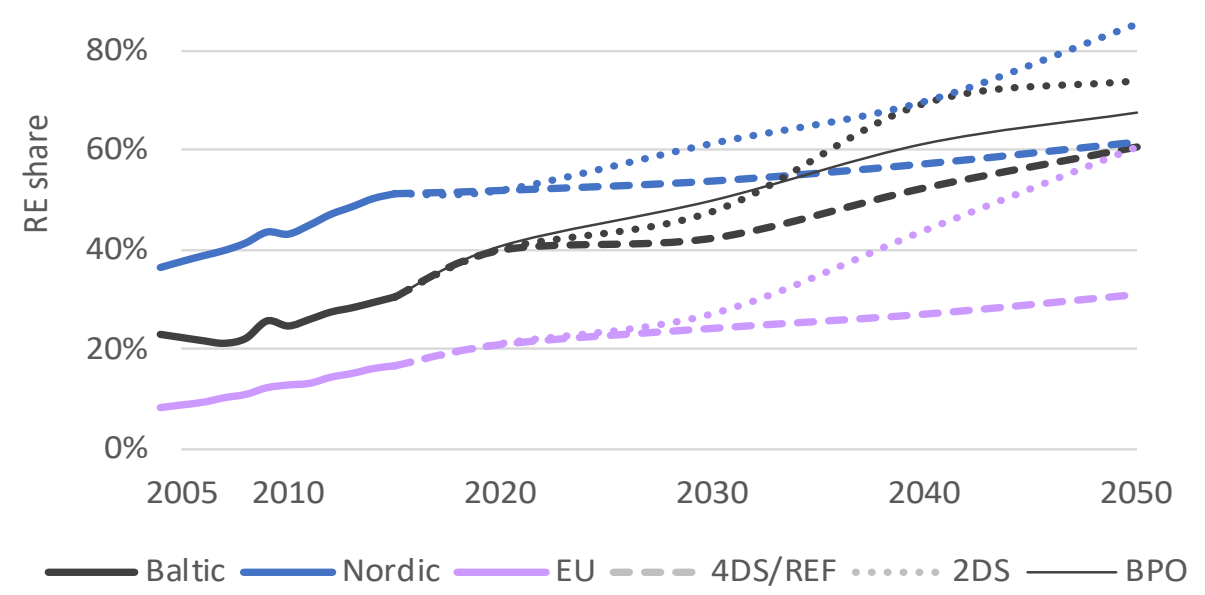

Key point(s): The Baltic countries' renewable energy targets take them to the 2 degrees pathway, but more targets are needed towards 2050 to remain on the 2DS pathway.

The Baltic countries' renewable energy targets can be achieved with domestic resources. Energy efficiency measures, wind power, heat pumps, biomass, and solar are estimated to be the most cost-effective ways to increase the renewable energy share. Especially the amounts of renewable electricity and renewable district heating increase in the scenarios (Figure 4).

Biomass utilisation is an important cross-cutting issue, since biomass can provide renewable energy and GHG reductions to all energy-consuming sectors. Hence, there is strong competition for biomass resources, both domestically and as an export product. Proposed EU LULUCF and RED2 directives may change the classification of sustainable biomass and alter the available amounts and their prices. In the scenarios, the consumption of biomass increases, but the use shifts from direct use to biofuel refining and district heating.

Heat pumps could provide a cost-competitive option to produce district heating and increase the RE share; however further studies are required to substantiate the realistic potential. 
Figure 4: Renewable energy in the Baltic countries by renewable energy source and consuming sector. In this figure, other sectors include commercial buildings and agriculture energy use

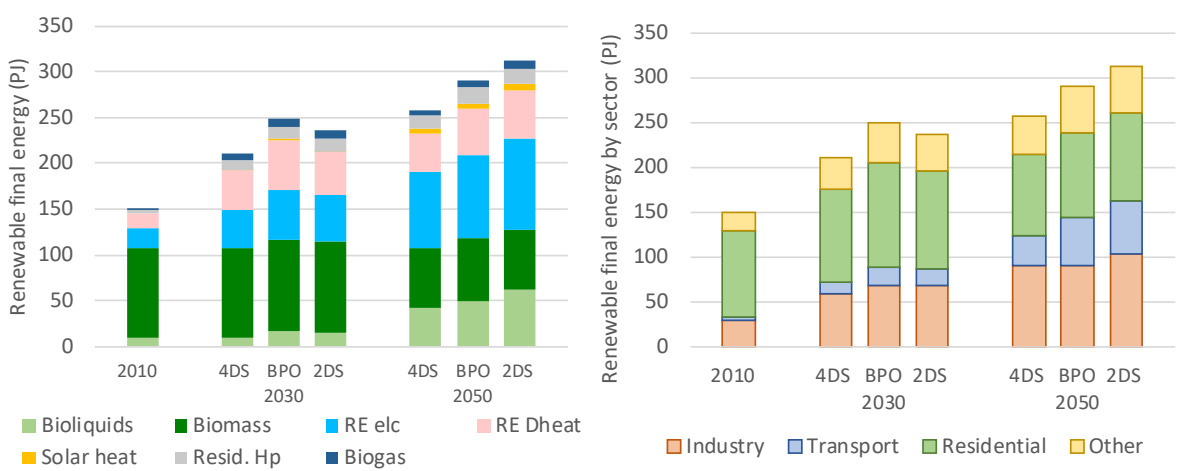

Key point(s): Renewable electricity and renewable heating provide the largest increase from renewable energy sources.

\section{Electricity consumption}

Electricity consumption increases in the scenarios due to assumed growth in demands and modelled electrification. The largest increase in electricity consumption would be in the transport sector due to electric vehicles (EVs), in industry due to assumed growth of production, from heat pumps for district heating, and from increasing building stock and heat pumps in buildings (Figure 5 ).

Based on the assumptions of this study, the growth could be $17 \%$ to $27 \%$ by 2030 compared to 2015 , and $60 \%$ to $65 \%$ by 2050 . When compared to national estimates, this is in line with Estonian estimates, higher than Latvian estimates, and smaller than Lithuanian estimates.

Electricity consumption may increase less than in these scenarios if demand does not grow as assumed or if electrification of sectors is delayed. This would help to achieve domestic generation targets and reduce costs.

Figure 5: Electricity's share of sectoral final energy consumption (left) and the total electricity consumption in the Baltic countries (right)
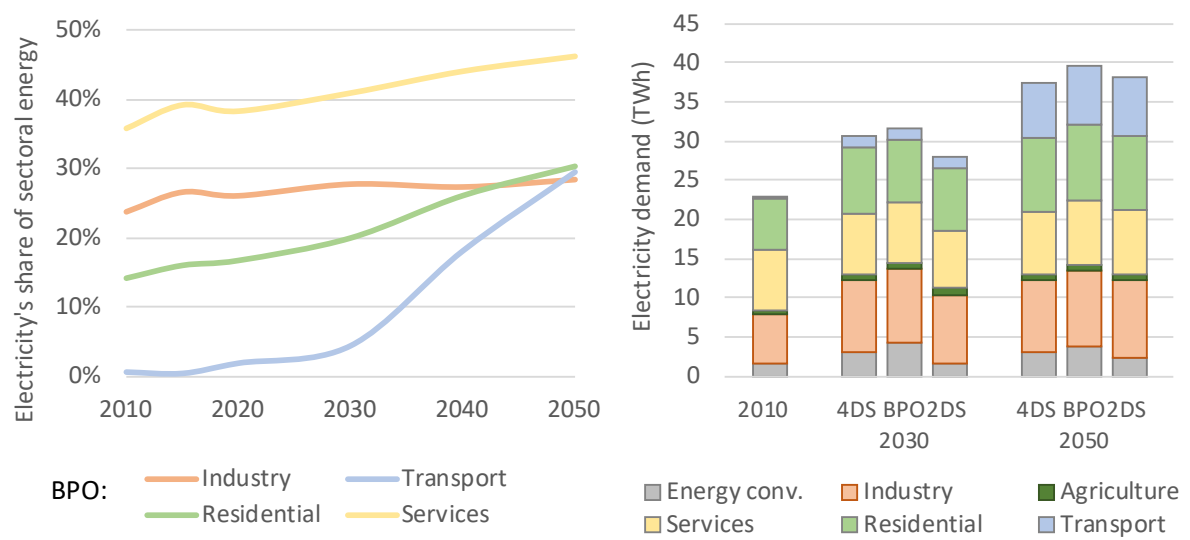

Key point(s): Electricity consumption increases due to both assumed growth in demand and modelled electrification. 


\section{System outlook for the electricity sector}

Measured by their levelized cost of energy (LCOE) generation, wind and solar power are becoming the cheapest option for new electricity generation. This new price relationship will frame the development of European power systems, which will undergo a transformation to very high renewable shares in the coming decades. This is even the case in the $4 \mathrm{DS}$, in spite of quite moderate incentives for decarbonisation. Renewables will gradually take over the market, merely because they provide the cheapest electricity.

On the European level* (*i.e. countries included in the simulation), renewable energy will cover $67 \%$ of the demand by 2030 in the $4 \mathrm{DS}$ and $85 \%$ by 2050 . In the $2 \mathrm{DS}$, the higher $\mathrm{CO}_{2}$ price pushes the RE shares up to $68 \%$ and $86 \%$ respectively (Figure 6 ).

Figure 6: Annual electricity generation development by power source in the modelled region for the 4DS and $2 \mathrm{DS}$

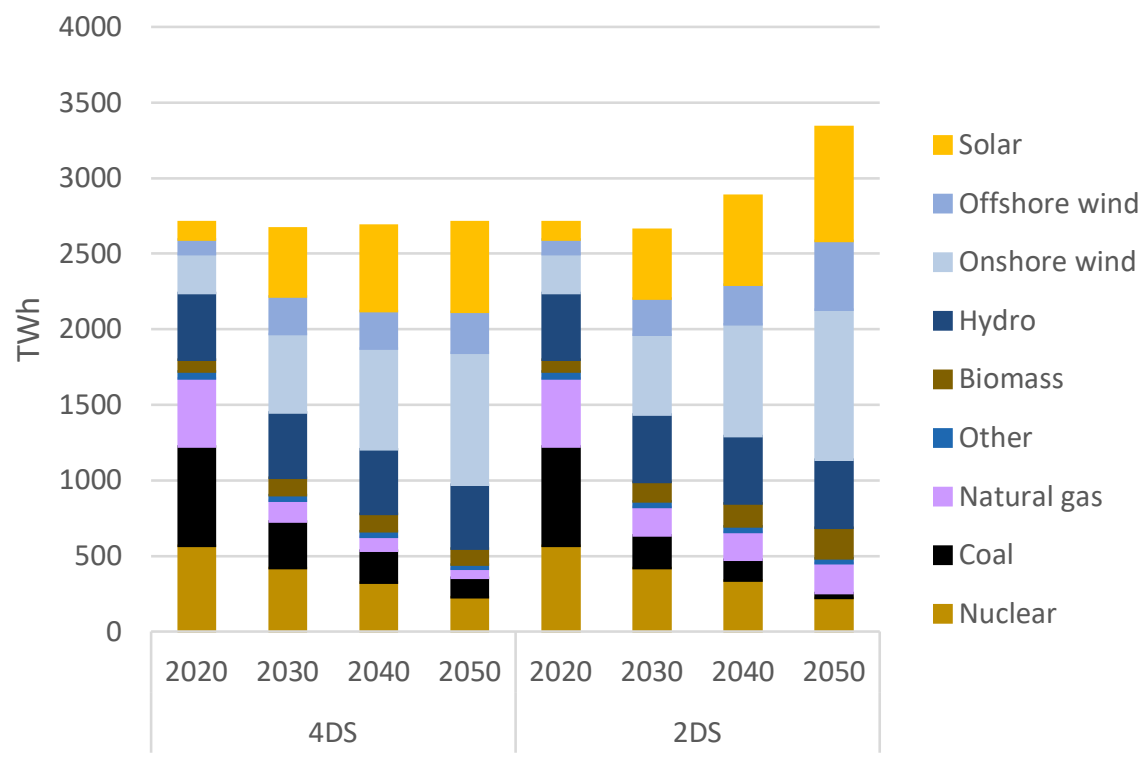

Key point(s): European electricity generation will be decarbonised in the coming decades.

The Baltic countries are importers in all three scenarios: $4 \mathrm{DS}, \mathrm{BPO}$ and 2DS. The lowest generation levels are observed in the $4 \mathrm{DS}$ where more than half of the electricity demand is served by imports from 2030 onwards. The production from oil shale-fired power plants gradually declines from 2020 in accordance with the scheduled phase-out plans. In the 2DS, oil shale generation is reduced to less than 2 TWh by 2040 as a result of the high $\mathrm{CO}_{2}$ price, which makes oil shale generation uncompetitive. The $2 \mathrm{DS}$ on the other hands sees the strongest increase in renewable generation. Wind power generation almost quadruples between 2020 and 2030, and considerable additional investments are made in solar and wind power capacity towards 2050.

Biomass-based power generation could play an increasing role in the Baltic energy system if $\mathrm{CO}_{2}$ prices increase sufficiently, as in the 2DS (Figure 7). Biomass 
provides also an option to build dispatchable generation to help in balancing varying solar and wind power.

Figure 7: Annual power generation development by power source in the Baltic countries for the 4DS, BPO and 2DS

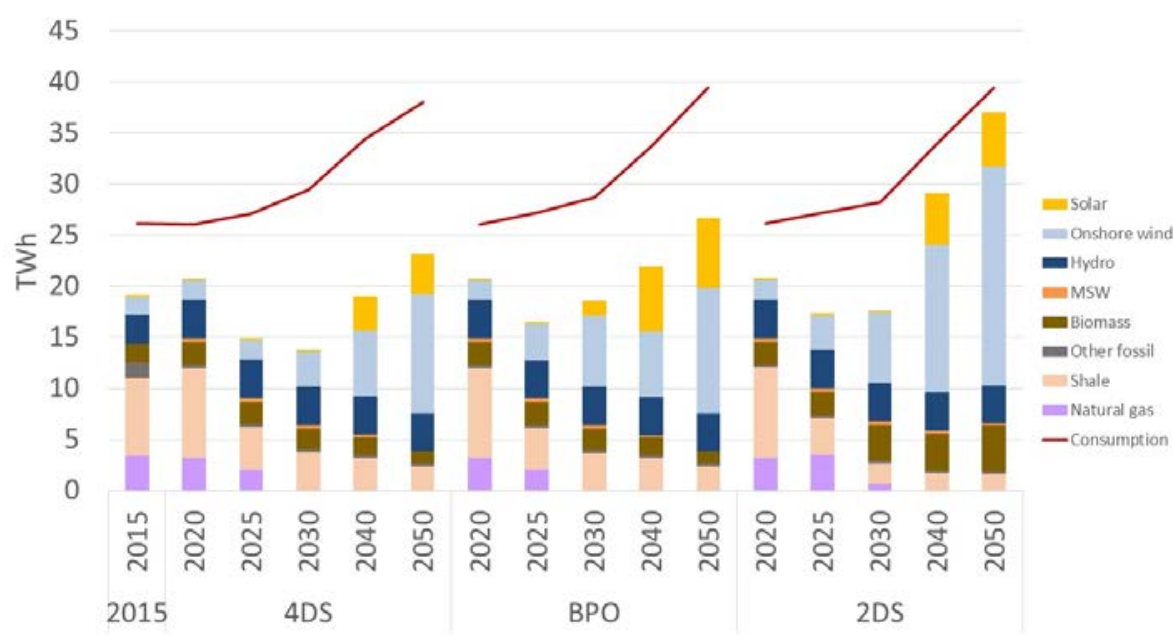

Key point(s): Wind and solar will become the cheapest source of new capacity after 2030, but domestic generation is at risk of declining before that.

Electricity prices are likely to remain higher in the Baltic countries compared to the Nordic countries. The simulations show that further interconnector capacity between the two regions would be economical, particular in the $4 \mathrm{DS}$, where Baltic imports are highest. Additional transmission capacity would allow generation from the Nordic countries to replace more expensive Baltic electricity generation or Polish imports.

Natural gas used to be the dominant fuel for district heating in the Baltic countries, but high gas prices and a political will to reduce import dependency have prompted a move towards local biofuel in the last 5 to 10 years. Today, around $50 \%$ of the heating demand in the Baltic countries is served by biomass, mainly locally produced wood chips and wood waste. Towards 2030, the scenarios predict that the natural gas share is further reduced and replaced by biomass, municipal solid waste and electric heat pumps.

Heat pumps could potentially meet about $50 \%$ of the demand for district heating by 2050 . However, the Baltic countries have very limited experience with heat pumps in district heating applications and further investigations are required to uncover the realistic potential, possible socio-economic impacts, etc.

\section{Security of supply}

The security of supply has multiple dimensions, including annual energy dependency and momentary production capacity. Energy import dependency is a very top-level indicator measuring the ratio of domestic versus imported energy. 
Most measures that reduce emissions, increase renewable energy or improve energy efficiency, also improve (reduce) energy import dependency in the Baltic countries. The most notable exception is reducing the use of shale oil in Estonia, because this is the only large-scale domestic fossil energy source in the Baltic countries. Energy import dependency improves for the Baltic countries in all three scenarios, contrary to the current trend in the EU (Figure 8). Low-carbon scenarios would turn the trend, also in the EU.

Figure 8: Energy import dependency of the Baltic countries and EU

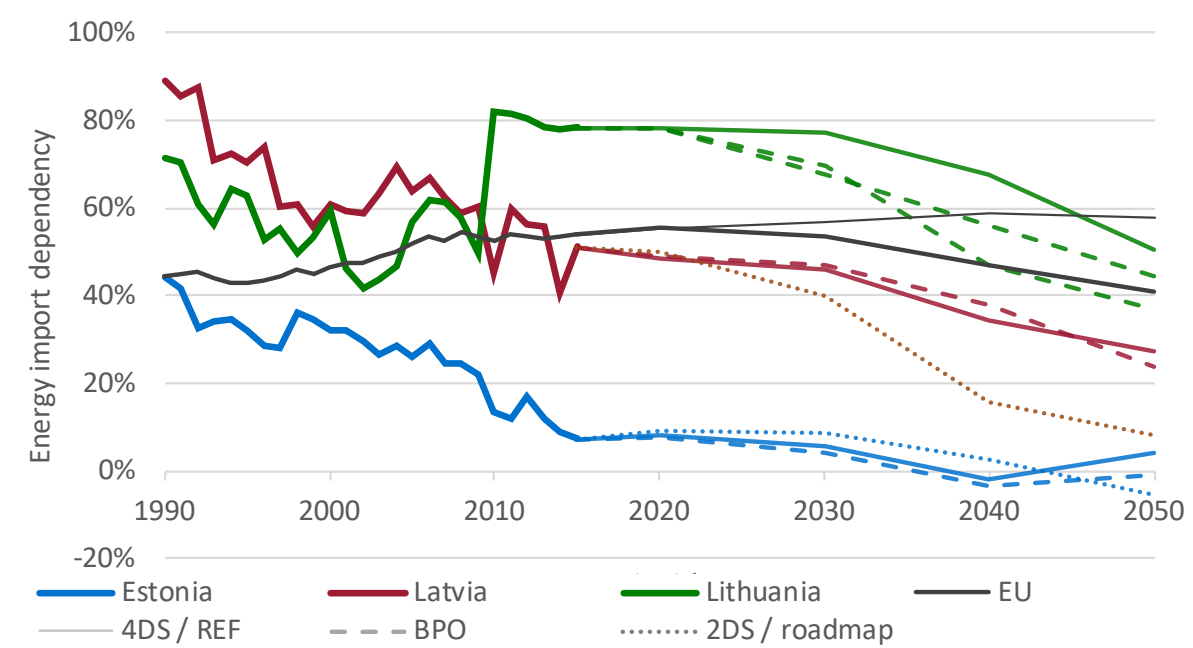

Key point(s): Energy independence improves mostly through the same measures required to reduce GHG emissions, increase the RE share, or improve energy efficiency.

The Baltic countries have increased the transmission capacity to Central Europe and the Nordic countries and intend to synchronise to the Central European grid to improve security of supply.

In the absence of sustainable policies to facilitate cost-effective local renewable energy generation, the Baltic countries will become large net importers of electricity. This development will result from three main factors:

- The phasing out of oil shale-based power plants in Estonia in accordance with existing policies.

- Increasing electricity demand in the Baltic countries as a consequence of economic growth and electrification.

- Increasing electricity imports to Baltic countries from the Nordic countries, which have beneficial political framework conditions for renewable energy and extensive resources.

The Baltic countries are not only importing electricity in the scenarios, their capacity balances are also gradually becoming negative. In the $4 \mathrm{DS}$, literally all existing gas-fired generation capacity will be shut down towards 2030 either due to existing retirement expectations or due to model optimised decommission, as capacity becomes 
uncompetitive. In both the $4 \mathrm{DS}$ and $2 \mathrm{DS}$, the Baltic countries will rely on imports to supply peak demand from 2030. Whereas solar and wind power provide the cheapest options for delivering energy security, re-investments in natural gas-fired capacity and shale oil capacity appear to be the most cost-effective measures to ensure a positive electricity balance in the Baltic countries. On that note, it is important to underline that dedicated reliability analyses of security of supply, based on stochastic modelling, have not been undertaken as part of this project.

Additional policy measure are required if the Baltic countries should not become net importers of electricity. Modelled subsidy levels about $10 \mathrm{EUR} / \mathrm{MWh}$ to all local generation were sufficient to reduce annual net imports to zero by 2030 in the $4 \mathrm{DS}$ where wholesale power prices would be approx. 40 EUR/MWh. Wind and solar power provide the most cost-efficient way of reducing import dependency. The required subsidy levels are sensitive to electricity prices, wind and solar power costs, the $\mathrm{CO}_{2}$ price, and assumed policies. 


\section{Modelling Baltic energy choices in a global world}

\section{$1.1 \quad$ Key Findings}

- The Baltic countries (Estonia, Latvia and Lithuania) had a population of 6.1 million and a GDP of billion euros 85 in 2016. Lithuania is the largest Baltic country in terms of population (2.8 million) and GDP (billion EUR 39), but Riga, the capital of Latvia, is the largest city with 0.64 million inhabitants. Estonia has the highest GDP per person (euros per inhabitant approximately 16,000).

- The Baltic countries used to be so-called "energy islands" with no electricity or gas interconnectors to the rest of the EU, but this situation has changed with the establishment of electricity interconnectors to Finland, Sweden and Poland.

- At the same time, the opening of an LNG terminal in Lithuania has improved the security of gas supplies and the bargaining power in gas price negotiations with Russia. Additionally, gas interconnectors to Finland and Poland are under construction.

- In 2015 , the main energy sources for the Baltic countries were oil products (48\%), biomass and waste (22\%), and natural gas (21\%). Biomass has replaced fossil fuels in electricity and heat generation, but the share of oil has remained at $48 \%$ due to increasing transport volumes.

- Both the European Commission and the Baltic countries' governments have proposed 2030 climate and energy targets for the Baltic countries. The targets are currently proposals or visions and the modelling in this project aims to give information about their possible impacts.

- The most important proposals for our energy systems modelling are to increase the renewable energy share (proposed by the Baltic countries: $50 \%$ for Estonia and Latvia, $45 \%$ for Lithuania), EU Effort Sharing Decision targets proposed by the EC (Estonia -13\%, Latvia -6\% and Lithuania -9\% compared to 2005), energy efficiency targets and targets for domestic electricity and district heating. See chapter 1.6 for details. 


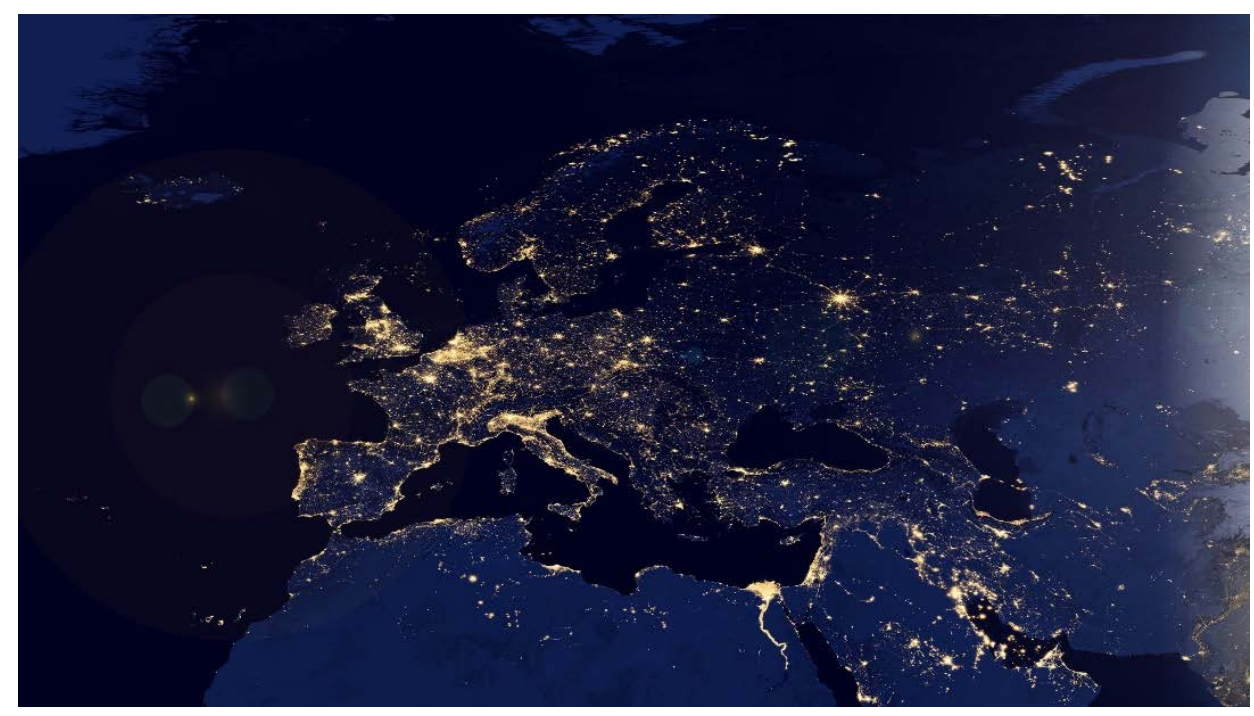

\subsection{Introduction}

This report studies Baltic Energy Technology Perspectives and models the long-term development of the Baltic countries' energy systems towards 2050. We have paid special attention to the 2030 mid-term targets, as they will significantly influence the energy and climate strategies being designed and evaluated by the Baltic countries at the time of producing this report.

The report is divided into four chapters, of which the first one introduces the report, the Baltic countries, and the modelling approach. The second chapter analyses end-use sectors, such as transport, buildings and industry; presents the available data; and shows the modelling results from those sectors. Chapter 3 focuses on electricity and district heating. And the fourth chapter summarises the results.

\subsection{The Baltic countries}

The Baltic countries, Estonia, Latvia, and Lithuania, are located on the east coast of the Baltic Sea (see map in Figure 9). The Baltic countries are members of the European Union, Eurozone and NATO. Estonia and Latvia are members of the OECD while Lithuania is a candidate country. Estonia is the only Baltic country that is a member of the IEA (International Energy Agency). These memberships are important, both politically and in terms of available statistics. 
Figure 9: Map of the Baltic countries and the countries in the Baltic region. Indicative illustration of regions' electricity transmission grid and natural gas grid are presented in the figure

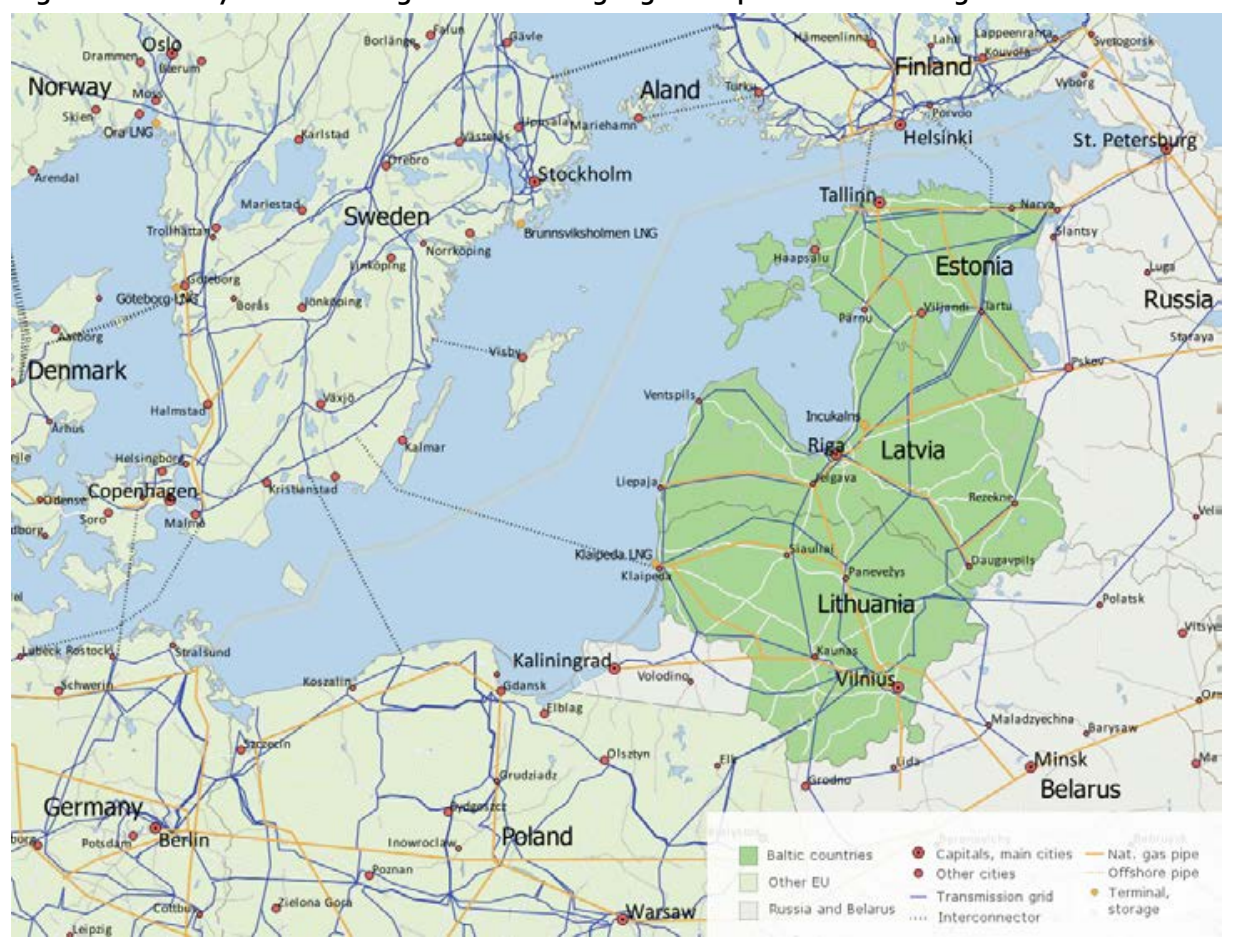

Key point(s): Electricity interconnectors from the Baltic countries to the Nordic countries have been built in recent years; gas interconnectors are under construction.

The Baltic countries had a combined population of 6.1 million and a GDP of 85 billion euros in 2016 (Table 1). These figures correspond to $1.2 \%$ and $0.6 \%$ of the EU's population and GDP, respectively. Riga, the capital of Latvia, is the largest city in the Baltic countries. Approximately every second Latvian resident lives in the metropolitan area of the Riga. The average GDP (nominal) per person in the Baltic countries is roughly half of the EU's average (euros per person in 2016, 28,000).

\section{Table 1: Quick facts about the Baltic countries}

\begin{tabular}{llll} 
& Estonia & Latvia & Lithuania \\
\hline Flag & & & \\
Population (2016) & 1.3 million & 2.0 million & 2.8 million \\
Area (\% of water) & $45,300 \mathrm{~km}^{2}(4.4 \%)$ & $64,600 \mathrm{~km}^{2}(1.6 \%)$ & $65,300 \mathrm{~km}^{2}(1.3 \%)$ \\
GDP (2016) & 21 Billion euros & 25 Billion euros & 39 Billion euros \\
GDP per capita & EUR 16,100 & EUR 12,700 & EUR 13,500 \\
Capital & Tallinn & Riga & Vilnus \\
Population of the capital & 440,000 & 640,000 & 550,000 \\
\hline
\end{tabular}

Key point(s): Lithuania is the largest Baltic country measured by population and GDP, Riga is the largest city, and Estonia has the highest GDP per person.

Source: $\quad$ GDP data: IMF 2017. Population data: Ministry of Interior of Estonia (2017), Central Statistics Bureau of Latvia (2017a), Statistics Lithuania (2017a). 
The ten largest cities in the Baltic countries accommodate over $40 \%$ of the population in the Baltic countries (Table 2), but the proportion varies greatly depending on whether the population is calculated based on city limits or on the total metropolitan regions. The size decreases relatively fast after the ten largest cities; and the 2oth largest city, Rèzekne in Latvia, has 30,000 inhabitants. Fifty per cent of the population live in small cities with less than 30,000 inhabitants and in the countryside.

Table 2: The largest cities in the Baltic countries, their population, and their share of the population in the Baltic countries

\begin{tabular}{|c|c|c|c|c|c|}
\hline Rank & City & Country & Population 2017 & $\begin{array}{r}\text { Share of the population } \\
\text { in Baltic countries }\end{array}$ & $\begin{array}{r}\text { Cumulative share of } \\
\text { population }\end{array}$ \\
\hline 1 & Riga & Latvia & 640,000 & $11 \%$ & $11 \%$ \\
\hline 2 & Vilnius & Lithuania & 550,000 & $9 \%$ & $19 \%$ \\
\hline 3 & Tallinn & Estonia & 440,000 & $7 \%$ & $27 \%$ \\
\hline 4 & Kaunas & Lithuania & 290,000 & $5 \%$ & $31 \%$ \\
\hline 5 & Klaipèda & Lithuania & 150,000 & $2 \%$ & $34 \%$ \\
\hline 6 & Šiauliai & Lithuania & 101,000 & $2 \%$ & $36 \%$ \\
\hline 7 & Tartu & Estonia & 97,000 & $2 \%$ & $37 \%$ \\
\hline 8 & Panevèžys & Lithuania & 90,000 & $1 \%$ & $39 \%$ \\
\hline 9 & Daugavpils & Latvia & 85,000 & $1 \%$ & $40 \%$ \\
\hline 10 & Liepāja & Latvia & 69,000 & $1.1 \%$ & $41 \%$ \\
\hline
\end{tabular}

Key point(s): The ten largest cities in the Baltic countries accommodate over $41 \%$ of the population in the Baltic countries.

Source: Ministry of Interior of Estonia, Central Statistics Bureau of Latvia, Statistics Lithuania.

The population of the Baltic countries has decreased from 8 million in 1990 to 6.1 million in 2017. The GDP (constant in 2010 euros) has seen the opposite growth, increasing from billion euros 32 (2010 euros) in 1995 to 74 billion euros (2010 euros) in 2016. In today's money, the GDP is $14 \%$ higher (billion euros 84.7), but the real increase in GDP is more evident when looking at the constant prices. The GDP per person has been increasing faster ( $+180 \%$ from 1995 to 2016 ) than the overall GDP ( $+130 \%$ from 1995 to 2016). In 2016, the employment rate in the Baltic countries was a few per cent higher than the EU average (Eurostat 2017).

Figure 10: Population, age dependency (share of the population aged 15-64), and share of employed population
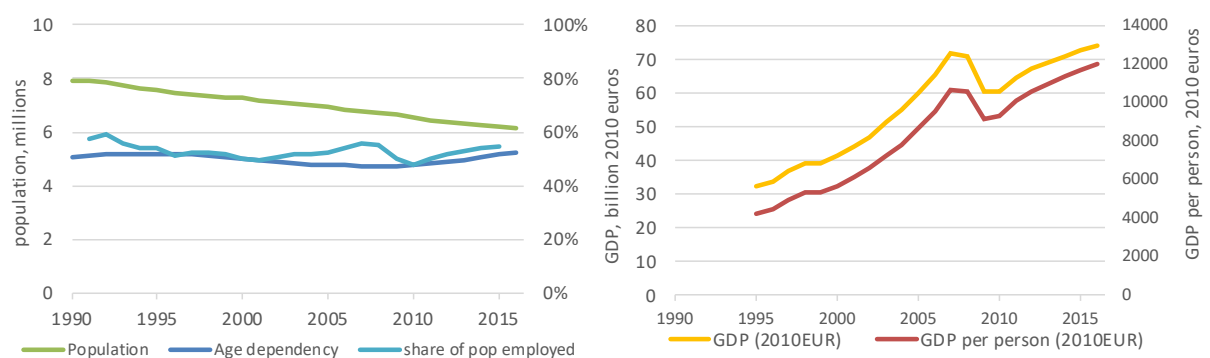

Key point(s): The population of the Baltic countries has decreased by $20 \%$ from 1995 to 2016 , but the GDP and GDP per person have increased three-fold.

Source: World Bank (2017). 


\subsection{The Baltic countries' energy systems today}

The main energy sources for the Baltic countries in 2015 were oil ( $26 \%$ of primary energy), biomass (22\%), oil shale (22\%), and natural gas (21\%). Lithuania has a large oil refinery located near the Latvian border in the western part of the country. The refinery feedstock is currently supplied through the Būtinge oil terminal in Lithuania. Estonia burns oil shale for electricity and district heating, and refines oil shale to shale oil, which is used to replace heavy oil in maritime transport and exported, see shale oil info box below. Latvia has the highest share of biomass in the primary energy supply and a notable share of hydro power.

Figure 11: Primary energy supply of the Baltic countries from 1990 to 2015 and country-level snap shots from 2010 and 2015

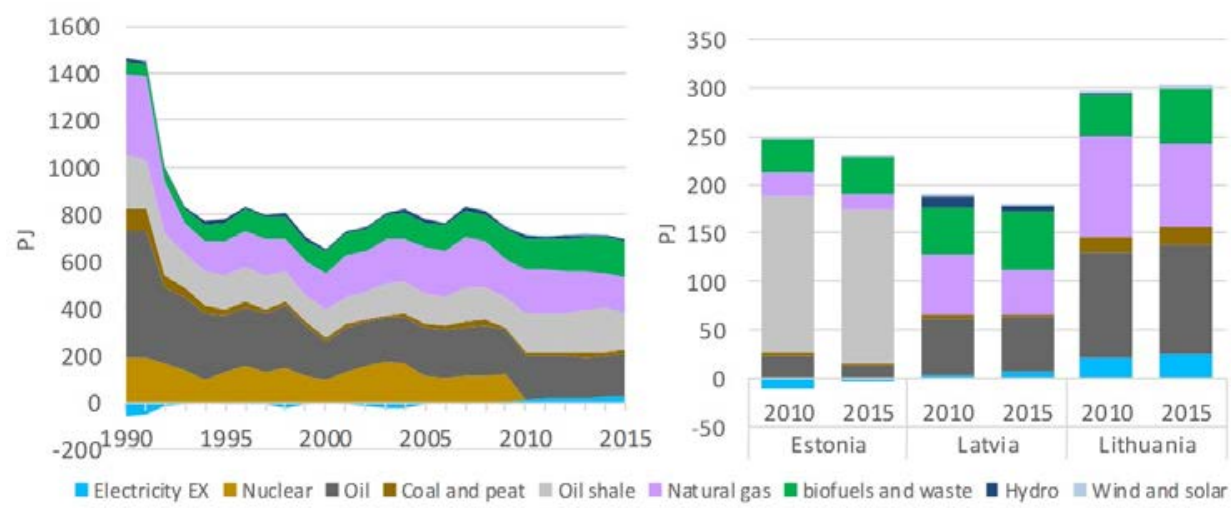

Key point(s): Shutting the Ignalina nuclear power plant at the end of 2009 increased the consumption of oil products and electricity imports.

Note: $\quad$ Only electricity net imports are included in primary energy. Estonia refines a part of the oil shale to oil products. Certain share of these oil products are exported and reduced from the oil primary energy supply. For this reason, the oil primary energy consumption is very small in Estonia.

Source: $\quad$ IEA Energy Balances (IEA, 2017)

The Baltic countries have historically received all their natural gas from Russia. Latvia has the Inčukalns natural gas storage facility, which has a $2.3 \mathrm{Gm} 3$ capacity (1.5 times the annual demand), allowing Latvia to buy cheaper gas when there is less demand in the summer and use the gas throughout the year. Stored gas can be transported to Lithuania. To diversify the supply options, Lithuania completed the Klaipeda LNG station (see map from Figure 2) in 2014. In addition, two gas interconnectors to the Baltic countries are under construction, one from Poland to Lithuania, which is expected to be completed in 2021, and another from Estonia to Finland, which is expected to be completed in 2020 . 
The Baltic countries supplied $22 \%$ of their primary energy demand ( $145 \mathrm{PJ}$ of $710 \mathrm{PJ}$ in 2015) from biomass and net exported 50 PJ of biomass in 2015. The largest consumers of biomass are the residential sector $(55 \mathrm{PJ})$, electricity and district heating $(50 \mathrm{PJ})$, and industry (20 PJ) where it is mostly used to generate electricity and steam for processes.

\section{Oil shale}

Oil shale is an organic-rich sedimentary rock containing kerogen. Oil shale resources around the world are plentiful, although only a small fraction of them are economically feasible to utilise. The largest deposits are found in the USA, China, Israel and Russia. However, Estonia remains the largest utiliser of oil shale resources in the world, using roughly 15 million tonnes of the resource annually.

Extracted oil shale is rich in mineral content and when the organic part is utilised (burned or extracted via heating), a large volume of mineral ash remains (Figure 12).

Oil shale is used in electricity generation, liquid fuel production, and in the chemical industry. Oil shale currently plays a dominant role in the Estonian power system and while the share of electricity produced from oil shale power plants is declining, it has still exceeded $75 \%$ of the total annual generation between 2010 and 2016. However, electricity generation from oil shale is related to high $\mathrm{CO}_{2}$ costs, and Eesti Energia, which owns the power plants, has reported $\mathrm{CO}_{2}$ emissions of roughly $1200 \mathrm{gCO}_{2}$ per $\mathrm{kWh}$ of electricity produced. This can be compared to the overall $\mathrm{CO}_{2}$ intensity of electricity generation in Estonia $(760 \mathrm{gCO} / \mathrm{kWh})$, Poland $(670 \mathrm{gCO} / \mathrm{kWh})$, and the $\mathrm{EU}(270$ $\mathrm{gCO} 2 / \mathrm{kWh}$ ) in 2014 (EEA 2017a).

Oil shale can also be processed into liquid fuel - shale oil (Figure 13). Oil shale is similar to conventional oil products, but has a higher sulphur content, making it hard to utilise directly. It can be mixed with conventional oil for maritime use. Shale oil production results in by-products that can be used for electricity generation: semicoke and shale gas. The oil refining process is much more efficient than burning oil shale in condensation power plants, but the overall financial and environmental cost of liquid fuel production is still higher than conventional oil extraction.

Other uses of oil shale include various chemical products that can be used in the pharmaceutical, cosmetic and wood industries or in other advanced products as components in paints. Currently, the vast majority of extracted oil shale in Estonia is used for electricity generation, but the focus appears to be slowly shifting towards products providing more added value, chemical products and liquid fuels. Furthermore, in 2025 a significant portion of the oil shale power generation units in Estonia will be shut down due to environmental restrictions related to air quality. Several other oil shale power generation units are also based on old technologies. After 2030, only three oil shale power generation units are expected to be running, with a total net capacity of around $650 \mathrm{MW}$. The future of the shale oil industry, however, depends largely on crude oil prices. With the current low prices, no significant investment in shale oil refineries will be made. Existing capacities will be utilised until the end of their exploitation period, however. 


\section{Figure 12: Contents of 1 ton of extracted oil shale}

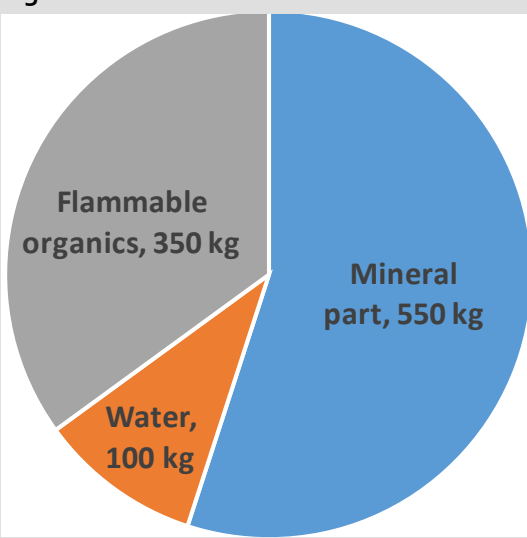

Key point(s): Oil shale is solid fuel as its mineral content is roughly $55 \%$ from the weight.

Figure 13: Energy flows of shale oil refining

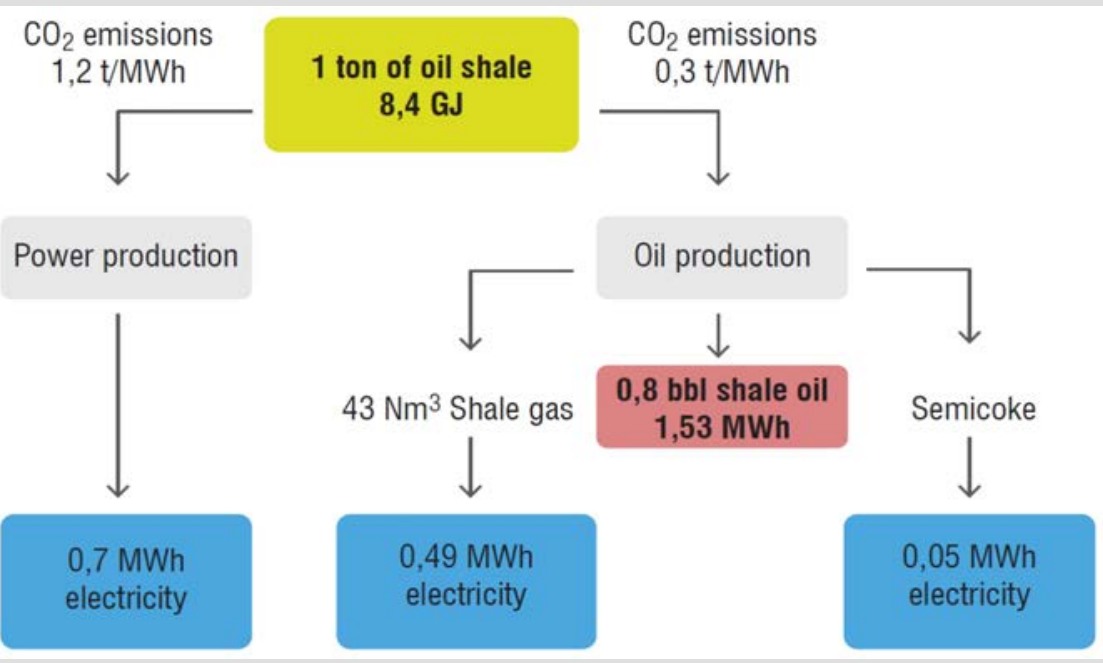

Key point(s): Main products of oil shale refining are shale oil, electricity, and shale gas which is also used to generate electricity currently.

\section{Future}

The transport sector consumed the largest share of the final energy in the Baltic countries in $2015(32 \%)$, followed by the residential sector (30\%), industry (21\%), and other sectors (commercial, public, agriculture energy use) that together account for $18 \%$ of the final energy consumption. The sectoral distribution of the energy consumption is very similar across the Baltic countries, although transport consumed a slightly higher share in Lithuania (36\%) compared to the other Baltic countries (28\%). The reasons for this are discussed in chapter 2.1. 
Oil products were the most common energy carrier with a $36 \%$ share of the final energy demand. Eighty-four per cent of the oil was consumed by the transport sector, where demand increased from $100 \mathrm{PJ}$ in 2000 to $150 \mathrm{PJ}$ in 2015 . After oil products, the most common fuels used in the final energy consumption were biomass (20\%), electricity (17\%), and district heating (15\%). The fuels used in the production of electricity and heating are not included in the final energy consumption.

Figure 14: Final energy consumption by sector and by fuel in the Baltic countries

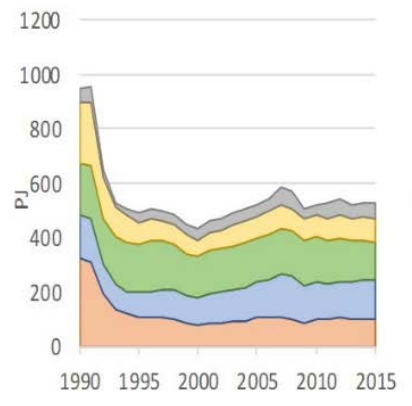

घnon-energy use $\square$ Other $\square$ Residential 口Transport $\square$ Industry

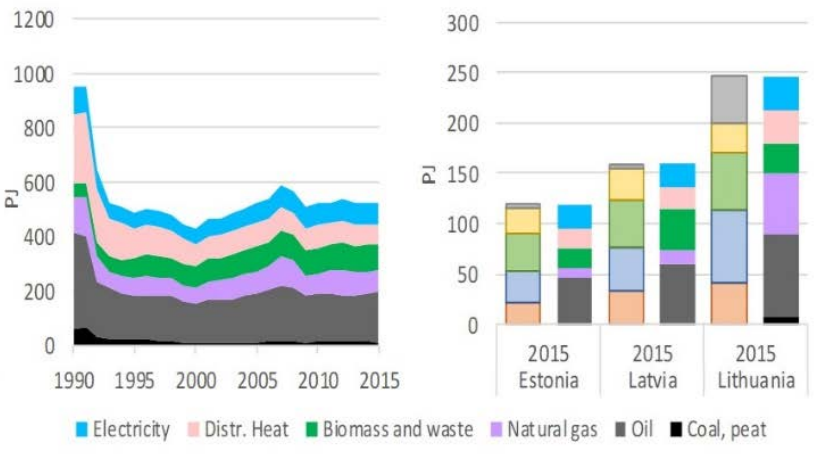

Key point(s): Growing transport demand has increased the oil consumption in the Baltic countries.

Note: $\quad$ All oil shale is used in transformation sector (electricity and district heat, and refining) and there's no oil shale in the final energy consumption.

Source: $\quad$ IEA Energy Balances. Notes: Other sectors are commercial buildings, public buildings, and agriculture energy use.

The largest sources of greenhouse gas (GHG) emissions in the Baltic countries are public electricity and district heating (32\% at 2015), transport (21\%), industry (18\% when counting both energy and process emissions), and agriculture (17\%). The remaining $12 \%$ are emitted from buildings, the waste management sector, and other energy use. These calculations exclude emissions from international aviation and maritime, and from Land Use, Land-Use Change, and Forestry (LULUCF).

Figure 15 shows that emissions from public electricity and heating are the primary source of emissions in Estonia. Most of these are classified under the EU ETS, which corresponds to $66 \%$ of the national GHG emissions in Estonia. The EU ETS's share is much smaller in Lithuania (34\%) and Latvia (20\%). 
Figure 15: GHG emissions in the Baltic countries in 2015 split by sector and EU ETS / ESS classification

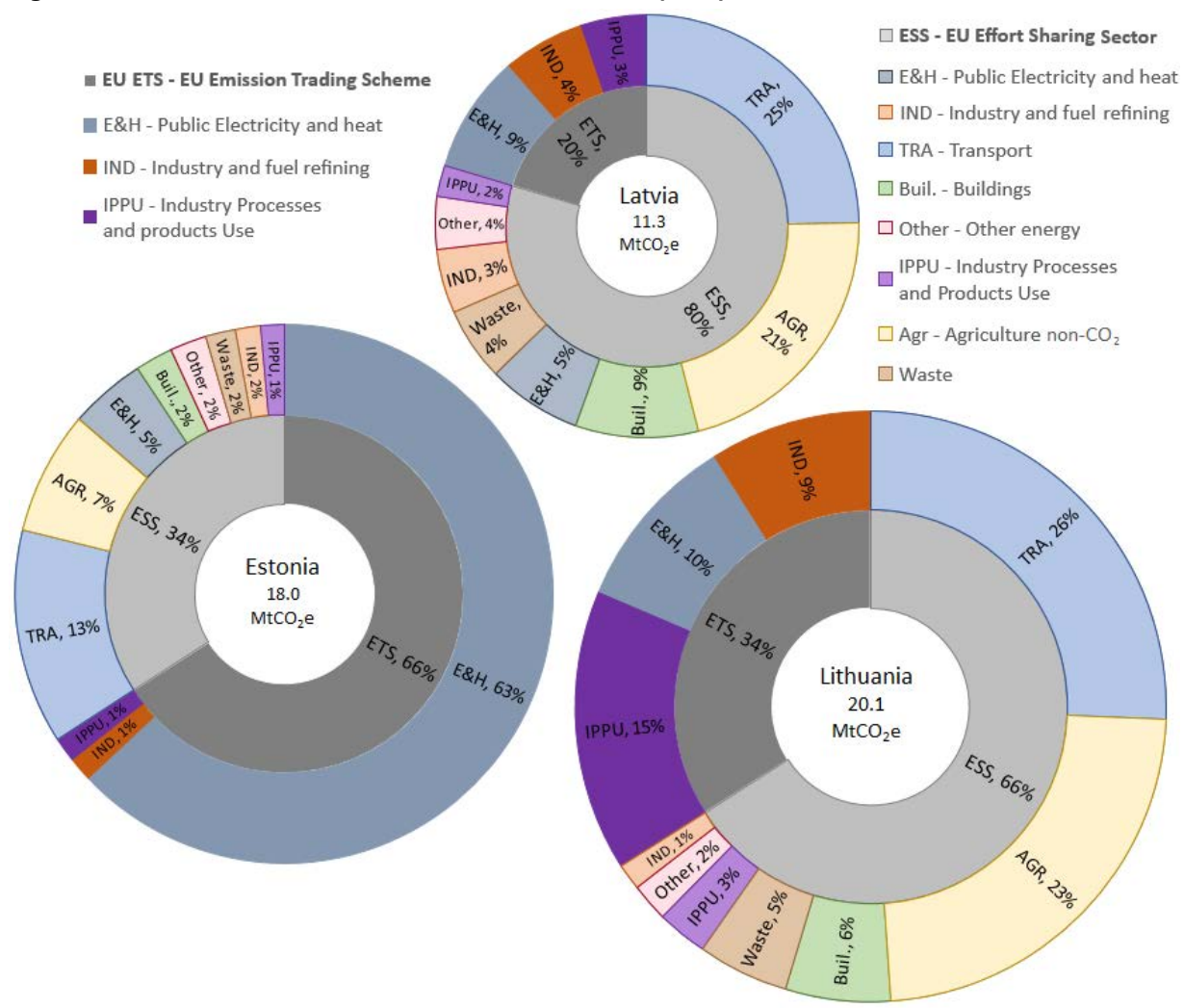

Key point(s): Effort Sharing Sector (ESS) emissions formed the majority of Latvia's (80\%) and Lithuania's (66\%) GHG emissions in 2015, but a smaller share of Estonia's GHG emissions (34\%).

Source: $\quad$ ESS total emissions from EEA (2017), GHG total emissions from UNFCCC (2017a), and sectoral split of emissions from national PaMs reports (Ministry of the Environment of Estonia 2017, Ministry of the Environment of Latvia 2017, and Ministry of the Environment of Lithuania 2017).

The Baltic countries' electricity systems are currently operated in parallel with the Integrated/Unified Power System (IPS/UPS) of Russia and Belarus. The Baltic countries have interconnectors to the synchronous grid of Central Europe (Lithuania - Poland) and to the Nordic power system (Lithuania - Sweden and Estonia - Finland). The current political target is to desynchronize the Baltic countries from the IPS/UPS and synchronize the Baltic countries' electricity grid to the Central European synchronous grid. See the "Desynchronisation from Russia" info box in Chapter 3 for more information.

Estonia's electricity generation capacity is based on oil shale and shale gas, which forms the bulk of the generation capacity (1650 MW / $2250 \mathrm{MW}$ ). Some of these plants are old and they would need retrofitting to comply with new air quality limits set for 2026. But it is likely that retrofitting will be too costly and operating companies will not upgrade the plants. This also affects the generation of district heating, but Estonia had 
a larger share of district heating produced from biomass (48\%) and natural gas (26\%) at 2015 (IEA, 2017).

Latvia has three large hydropower plants (880 MW, $400 \mathrm{MW}$, and $260 \mathrm{MW}$ ) which formed $53 \%$ of the total capacity and supplied $33 \%$ of Latvia's electricity in 2015 (IEA, $2017)$. The annual variation in the hydropower generation has been high $( \pm 30 \%)$ ranging from the $3700 \mathrm{GWh}$ at 2012 to $1860 \mathrm{GWh}$ at 2015 while the average from 2000 to 2016 has been $2830 \mathrm{GWh}$ per year. The remaining electricity generation capacity is mostly natural gas (40\%) supplemented with biomass and biogas. District heating in Latvia is derived from natural gas and biomass. The amount of district heating produced with biomass has increased from $4 \mathrm{PJ}$ in 2010 to $9.5 \mathrm{PJ}$ in 2015 (IEA energy balances) and Latvia has further plans to replace fossil fuel-based district heating with biomass.

Lithuania has substantial natural gas generation capacity (2700 MW), but electricity imports have increased since Ignalina nuclear power plant shut down at the end of 2009. Lithuania has $120 \mathrm{MW}$ of hydropower and $900 \mathrm{MW}$ of pumped hydro that can be used to balance short term variability in the power system. Industry generated $25 \%$ of the district heat in Lithuania which is significantly higher than in Latvia and Estonia (7\% each). The public district heat was produced with biomass $(61 \%)$ and natural gas $(36 \%)$ at 2015 (IEA, 2017). The amount of biomass used for electricity and district heating has increased in recent years and Lithuania would like to further increase the share of biomass.

At the end of 2016, the amount of installed wind power in the Baltic countries was $918 \mathrm{MW}$, equalling $150 \mathrm{~W}$ per person. This is below the EU's average $300 \mathrm{~W}$ per person, but close to countries like France ( $170 \mathrm{~W}$ per person) and on a par with Italy ( $150 \mathrm{~W}$ per person). Estonia has more installed wind power per capita, whereas Latvia only has 35 W per person, which is the 6th lowest in the EU (EurObserv'ER, 2017). The amount of installed solar power is still relatively low in the Baltic countries. Estonia had $2 \mathrm{MW}$ solar PV installed at 2015, Latvia 1 MW, and Lithuania 3 MW.

\subsection{Regional cooperation}

The Baltic countries cooperate closely with each other and with other European regions, most importantly the Nordic countries (Iceland, Denmark, Norway, Sweden and Finland) and Poland that is part of the Visegrád country group (Poland, Czech Republic, Slovakia and Hungary).

The Baltic countries have formed the Baltic Assembly, which provides a forum for interparliamentary cooperation and attempts to find common ground on many international issues. The Baltic Council of Ministers (BCM) is the forum for intergovernmental cooperation. The most important areas of cooperation have been security policy, defence, energy and transport.

The Baltic countries have agreed that chairmanship rotates at the beginning of each calendar year. Latvia held the chairmanship in 2016, Estonia in 2017, and Lithuania will be the chairing country in 2018. Estonia had the following priorities for the Baltic cooperation during 2017 (Ministry of Foreign Affairs of Estonia, 2017): 
- Strengthening of security, enhancement of security and defence co-operation.

- Developing regional energy markets.

- Developing transport connections.

The main focus areas in 2017 included energy markets, low-carbon economy and transport infrastructure (Baltasam, 2017).

Cooperation between the Nordic and Baltic countries is regarded as one of the closest in the world. The Nordic governments were among the earliest supporters of Baltic independence, and political and civil cooperation between the regions has been strong ever since. The regions' cooperation on energy has been growing steadily since relations were formalised in the early 1990s. Through initiatives like the Nordic-Baltic Eight (NB8, consisting of 5 Nordic countries and 3 Baltic countries), the Nordic Council of Ministers' cooperation with the Baltic countries, BASREC (Baltic Sea Region Energy Cooperation), BEMIP (Baltic Energy Market Interconnection Plan), Baltic integration in the Nord Pool market, and other initiatives, the link between the Nordics and Baltics has continued to solidify over the years.

BEMIP plans to link the energy markets and networks of Germany, Denmark, Sweden, Finland, Poland and the Baltic countries (EC 2017a). BEMIP aims to build both gas and electricity interconnectors. For the Baltic countries, plans include:

- Electricity interconnector for Estonia-Finland (Estlink 2, 650 MW, completed in 2014).

- Electricity interconnector for Sweden-Lithuania (NordBalt, $700 \mathrm{MW}$, completed in 2016).

- Strengthening electricity grid between Estonia and Latvia (with 3rd interconnector, 600 MW).

- Gas interconnection between Poland and Lithuania (GIPL, $2.3 \mathrm{Bm}^{3}$ per year with the possibility of doubling the capacity).

- Natural gas pipeline between Estonia and Finland (Baltic Connector, 2 Bm³ per year).

- Strengthening natural gas network between Estonia and Latvia.

The most notable cooperation on transport infrastructure is Via Baltica (route E67) running from the Czech Republic to Tallinn and extending to Helsinki by ferry. Rail Baltica is a railway project that aims to link the rail network in Germany to the Baltic countries and possibly to Finland via a tunnel. The construction work from Germany to Tallinn is scheduled to be completed by 2030.

The Baltic Sea has huge offshore wind power potential. The Baltic countries could invest in joint projects, including additional interconnectors through offshore wind power sites. The Baltic Sea Declaration, which seeks to accelerate offshore wind cooperation in the Baltic Sea region, was approved in 2017 (BSOWF, 2017). 


\subsection{The EU's 2030 climate and energy framework}

The EU climate and energy framework outlines three key targets for the year 2030 (EC 2017b):

- At least 40\% reduction in GHGs from 1990 to 2030.

- At least $27 \%$ renewable energy share of final consumption by 2030 .

- At least $27 \%$ (or 30\%) improvement in energy efficiency.

The framework builds on the principles of the 2020 climate and energy package and furthers many of the initiatives adopted in the previous package. GHG emissions reductions are divided into three categories, EU ETS (EU Emissions Trading Scheme), ESS (Effort Sharing Sector), and LULUCF (Land Use, Land-Use Change and Forestry). The EU tried to integrate emissions from international transport into the EU's climate and energy framework, but those negotiations are currently the remit of international forums.

EU ETS sets a cap on emissions from domestic flights and approximately 11,000 power stations and manufacturing plants in the $28 \mathrm{EU}$ member states, Norway, Iceland, and Liechtenstein. The EU ETS covered approximately $42 \%$ of the EU's GHG emissions in 2015 (EEA 2017, UNFCCC2017). Countries can trade emissions allowances (EU EUA) and EUA futures with each other. The current price is 7 euros per $\mathrm{CO}_{2}$ tonne and 2020 futures reach the price of 7.2 euros per $\mathrm{CO}_{2}$ tonne (ICE, 2017). The cap to reduce emissions decreases by $1.74 \%$ per year, but the European Commission has proposed increasing the annual decrease to $2.2 \%$ from 2021 onwards. According to the Commission's proposal, the EU ETS cap would be $43 \%$ less in 2030 compared to 2005 (EC, 2017C).

ESS covers emissions from smaller power stations and manufacturing plants, transport, agriculture, waste management, buildings, and other energy use. EU Member states have country-level targets which are the responsibility of the national governments. Emission cap to ESS is set by Effort Sharing Decision (ESD) from 2013 to 2020 and by Effort Sharing Regulation (ESR) from 2021 to 2030. In this report, we use ESS to speak about the sector and both ESD and ESR.

The 2020 ESS targets allowed some Eastern European member states to increase their emissions, while wealthier Western European countries adopted stricter targets, up to a $20 \%$ reduction by 2020 compared to 2005 . According to the Commission's proposal for the period 2021-2030, these country-levels targets would become tighter while the reasoning behind the effort sharing would remain much the same. Norway and Iceland have agreed to participate in the ESS for the period 2021-2030. The EU member states can trade ESS emission allocations and use flexibility mechanisms, e.g. from the land use sector (EC, 2017d).

Renewable energy targets were set at the national and sectoral level in the 2020 climate and energy package. Each member state is required to reach a specific target on overall renewable final energy and renewable energy in transport. Country-specific 
targets were not adopted in the EU's 2030 climate and energy framework, but the EU level has been allocated a target of $27 \%$ and the European Commission will observe the level of renewable energy in biannual progress reports (EC, 2017e). Also, the renewable energy directive allowed RE units to be statistically transferred between member states to fulfil national targets. Estonia and Lithuania have sold renewable energy units to Luxembourg (EC 2017f, EC 2017m).

The proposal for a new renewable energy directive includes proposed updated sustainability criteria for solid biomass, biofuels, and gaseous biofuels (EC, 2017g). The EU has directed that biofuels must achieve at least 50\% GHG reductions compared to fossil fuels, that biofuels cannot be grown "in areas converted from land with previously high carbon stock such as wetlands or forests," and that biofuels cannot be produced using raw materials from land with high biodiversity. The suggested new rules might limit the use of some currently-used feedstocks, but the rules are under negotiation in the EU and a final version of the proposal will likely be published in 2018.

The main impact of the Energy Efficiency Directive comes from a set of binding measures. Energy should be saved at all stages of the energy chain, from production to final consumption. The Energy Efficiency Directive includes numerous separate measures, for an example $3 \%$ of public building stock must carry out energy efficiency renovations, energy audits are organized for industry, and EU has adopted energy efficiency labelling of appliances, buildings, and cars (EC, 2017h). Member states have set their own indicative national energy efficiency targets. Depending on country preferences, these targets can be defined as primary/final energy consumption, primary/final energy savings from baseline, or energy intensity. Member states have finalised their National Energy Efficiency Action Plans and report their progress annually (EC, 2017i).

Land use and forestry proposal would integrate the LULUCF sector with the EU climate and energy framework as a third pillar alongside the EU ETS and ESS. The Commission's proposal sets a binding commitment to each member state that their land use emissions would be compensated by at least similar sinks, known as the "no debit rule" (EC, 2017j). The 2030 "no debit level" should not be higher than the reference level of each member state. If a country has calculated emissions from the LULUCF sector, then they should be compensated in the ESS. If a country has a net-sink of emissions in the LULUCF sector, part of it can be calculated as emissions reductions in the ESS. LULUCF emissions and links to the ESS are not included in the BENTE modelling.

European Commission aims to create a new governance system for a transparent and dynamic government process to "help deliver the Energy Union" (EC, 2017b). The Commission aims to achieve higher investments, more coherent legislation and markets, and to integrate the markets further. 


\subsection{Baltic energy and climate strategies for 2030}

The Baltic countries are undergoing processes to update their existing 2020 energy and climate strategies for the period from 2021 to 2030.

Estonia's government approved the Estonian Energy Development Plan until 2030 (ENMAK) in October 2017 (MKM, 2017). The general targets are:

- A working, independent, subsidy-free and open fuel and electricity market.

- Domestic electricity generation capacity is adequate, when $\mathrm{N}-1-1$ criterion is fulfilled.

- Renewable energy $50 \%$ of final consumption by 2030 .

- $50 \%$ RES-E by 2030.

- $80 \%$ RES-H by 2030.

- Energy efficiency, especially in buildings and transport.

- Synchronisation with the Central European grid.

- The average total yearly time of power cuts in a distribution network (SAIDI) does not exceed go minutes per place of consumption.

The "General Principles of Estonian Climate Policy until 2050" were approved in the Estonian Parliament in April 2017 (Parliament of Estonia, 2017). The approved legislation outlines the general framework and sectoral development principles for both mitigation and adaptation. It also defines long term targets to reduce GHG emissions by $70 \%$ by 2030 and by $80 \%$ by 2050 , compared to 1990 . And it requires a report on the preparation and implementation of cross-sectoral and sectoral strategies every 4 years, starting from 2019.

Latvia's "Long-Term Energy Strategy of Latvia 2030" gives a vision how the 2030 could look like, but the proposed targets are not officially adopted by the government (Ministry of Economics Latvia, 2013). The energy system modelling in this project are carried out assuming the vision in the Long-Term Energy Strategy of Latvia 2030.

The strategy includes more general notes, such as that the energy sector should have a favourable impact on the economy, and should become more secure and sustainable. More practical suggestions include increasing the renewable energy share to $50 \%$ of final consumption by 2030 , reaching $50 \%$ energy dependency by 2030 , and reducing energy use for heating by $50 \%$ by 2030 compared to the current average level of $200 \mathrm{kWh} / \mathrm{m}^{2}$ (202 $\mathrm{kWh} / \mathrm{m}^{2}$ in 2009, $304 \mathrm{kWh} / \mathrm{m}^{2}$ in 1990).

The Long-Term Energy Strategy is linked to a broader "Sustainable Development Strategy of Latvia until 2030" that covers areas like culture, education, the environment and innovation (Parliament of Latvia, 2010). The Sustainable Development Strategy of Latvia is a long-term development planning document that outlines the key objective for the energy sector as being to ensure energy independence by using domestic resources and integrating with EU energy networks. 
Lithuania's Government proposed an update to the National Energy Independence Strategy in 2017. The proposal has many specific targets for the year 2030 (Ministry of the Energy of Lithuania, 2017). The most important targets for modelling in BENTE are:

- Renewable energy $45 \%$ of final consumption by 2030 .

- $90 \%$ RES-H by 2030.

- $15 \%$ RES-T by 2030.

- $45 \%$ RES-E by 2030.

- $70 \%$ domestic generation of electricity by 2030 .

- Energy intensity would be 1.5 times lower in 2030 compared to 2017. This is estimated to correspond a final energy demand to decrease $-13 \%$ from baseline, which is projected to be 5.3-5.7 Mtoe of final energy in 2030.

The previous National Energy Independence Strategy (Parliament of Lithuania, 2012) presented several concrete mid-term targets for 2020 and laid down guidelines for the development of Lithuania's energy sector towards 2030 and 2050. Concrete mid-term targets for the power sector included integration of electricity markets, building new interconnectors, and building a new nuclear power plant (which was later turned down in a public vote). For the residential sector, the strategy aimed to increase energy efficiency, support renewables in the residential sector, and increase market liberalisation. The strategy also included building the Klaipeda LNG terminal and a pipeline to Poland, as well as gas market liberalisation. It also aimed to ensure low oil product prices for consumers, to increase the share of renewables in electricity generation (biomass and wind), district heating from biomass, and biofuels for transportation.

All Baltic countries report their energy and climate policies and measures to the EU in a PaMs report. The most recent reports have been submitted in 2017 (Ministry of the Environment of Estonia 2017, Ministry of the Environment of Latvia 2017, Ministry of the Environment of Lithuania 2017) and they describe 149 individual policy measures that have either been implemented or are planned. Described policy measures range from the very specific, such as "Investment Support Programmes in Public Sector Energy Efficiency," to the very general, such as "Improvement of road infrastructure" or "Renovation of heat networks" (EEA, 2017c).

The Baltic countries have listed 96 implemented, 25 adopted, and 17 planned policies and measures. The remaining 9 have expired. We have not specifically modelled the effects of these PaMs. Of the non-expired PaMs, 29 focus on energy supply and mostly aim to increase the renewable energy share or energy efficiency. Renewable energy is modelled through potentials, technology development and targets (see chapter 1.7). Transport sector emissions are addressed by $28 \mathrm{PaMs}$ (chapter 2.1.), while $20 \mathrm{PaMs}$ are aimed at the agriculture sector (chapter 2.4), 12 are for waste management (chapter 2.4), 27 cover energy consumption, mostly in connection with energy efficiency measures for buildings (chapter 2.2), 3 address industrial processes 
(chapter 2.3), and 20 are aimed at LULUCF, which is not included in the modelling in this project.

\subsection{The scenario and modelling framework}

We use two energy system models to study the impacts of Baltic energy choices. TIMES-VTT includes all energy production, consumption and Kyoto GHGs (excl. LULUCF). The Balmorel model is much more detailed in the electricity and district heating sector. These two models are linked in this study, as illustrated in Figure 16. TIMES-VTT models the Nordic and Baltic countries as separate regions, and the remaining EU as Western and Eastern Europe. TIMES-VTT also includes the rest of the world in 10 global regions.

Balmorel models EU electricity and heat markets in more detail. Each country is represented by electricity market areas (one for each Baltic country) and multiple heat areas per country (20 DH areas in the Baltic countries in total). Balmorel matches the consumption and supply in each of these areas.

Figure 16: A schematic of the models and how they are linked together

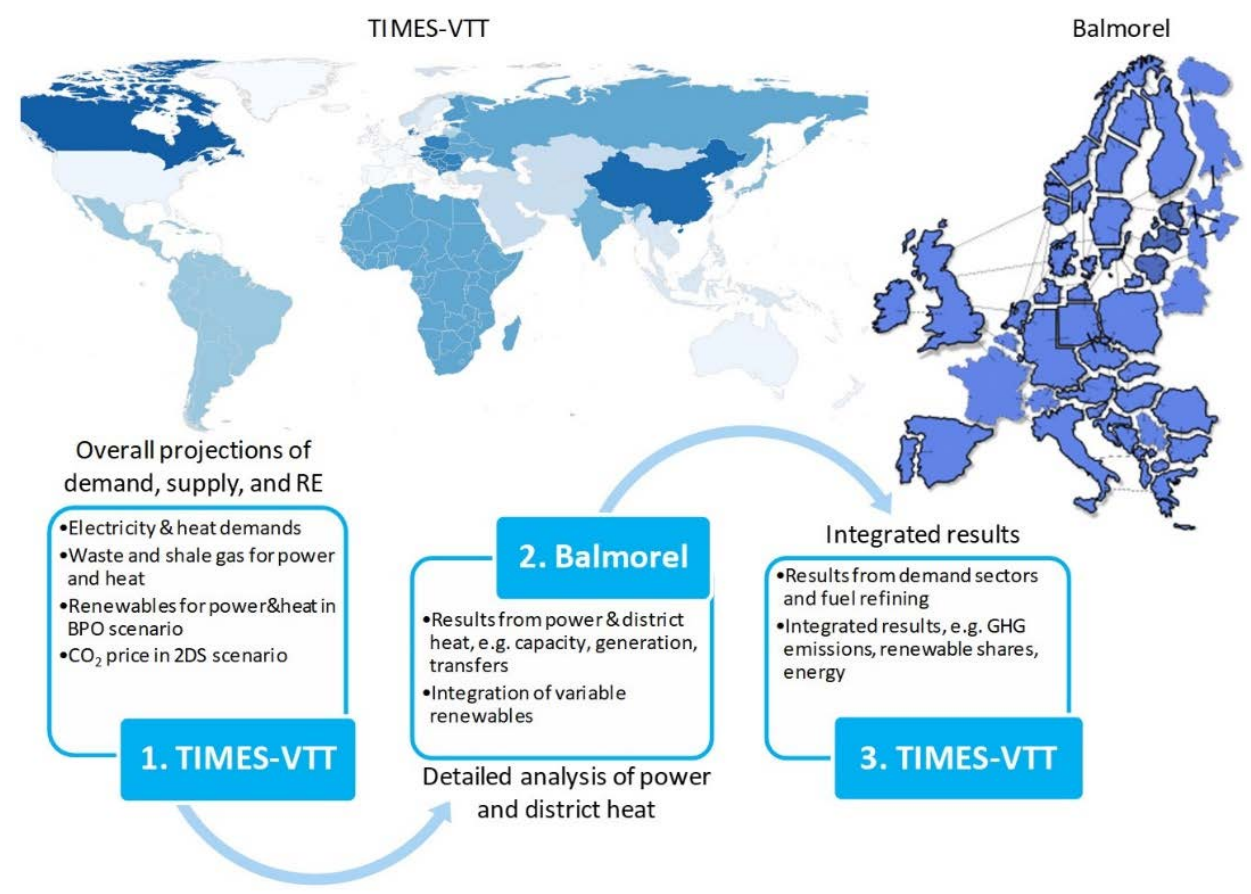

Key point(s): Balmorel models electricity and district heating in detail. TIMES-VTT models integrated results and overall projections for energy demand, energy supply, and renewable energy.

The sectors and emissions covered are slightly different to other comparable studies. BENTE modelling covers all the same $\mathrm{CO}_{2}$ emissions as IEA's ETP studies, but also incorporates the non- $\mathrm{CO}_{2}$ emissions that are crucial for the modelling of ESS and 
national ESS targets. The European Commission's modelling includes LULUCF, but not $\mathrm{CO}_{2}$ from international aviation (EC, 2016a).

Table 3: Modelled sectors and emissions

\begin{tabular}{l|lll} 
GHG & BENTE European Commission modelling & IEA ETPs
\end{tabular}

$\mathrm{CO}_{2}$ from energy (domestic)

$\mathrm{CO}_{2}$ from international transport

$\mathrm{CH}_{4} \mathrm{~N}_{2} \mathrm{O}$, F-gases

LULUCF

$\mathrm{x}$

Key point(s): BENTE covers all Kyoto gases ( $\mathrm{CO}_{2}, \mathrm{CH}_{4}, \mathrm{~N}_{2} \mathrm{O}$, F-gases) except $\mathrm{CO}_{2}$ from LUULCF.

We have modelled three main scenarios to study development without additional actions in the Baltic countries, impacts of the Baltic countries' 2030 policies, and an ambitious 2 Degree Scenario. We use the following abbreviations for our scenarios throughout the report:

- 4DS-4 Degrees Scenario.

- BPO - Baltic Policies Scenario.

- 2DS-2 Degrees Scenario.

$4 D S$ presents a world that lacks ambition to mitigate climate change. The EU will go forward with 2030 targets and will continue the gradual decrease of EU ETS and ESS caps, but will not reach the $80 \%$ reduction and the price of carbon stays relatively low increasing to $40 \mathrm{EUR} / \mathrm{tCO}_{2}$ by 2050 . The emissions trajectory starts like the more ambitious 2DS, but falls behind when agreed 2050 targets are not implemented.

In this scenario, the Baltic countries will achieve 2020 targets, but will not adopt any new targets thereafter. The Baltic countries will have the same $\mathrm{CO}_{2}$ price than the rest of the EU due to common EU ETS. This methodology is similar to the EU WEM (With Existing Measures) scenarios that the Baltic countries have modelled for their PaMs reports. This framework is also required to compare the changes and costs of other scenarios.

In the $B P O$, we add expected Effort Sharing Sector (ESS) targets and proposed national targets for the RE share of final energy for 2030 for the Baltic countries. After 2030, the EU ETS cap decreases in all EU as in 4 DS and the carbon price increases as in the $4 \mathrm{DS}$. After 2030, the assumed 2050 ESS targets for Baltic countries will be implemented similarly than for the other EU in $4 \mathrm{DS}$ (Estonia -39\%, Latvia $-34 \%$, and Lithuania -36\%).

The rest of the world is defined in the same way as in the $4 \mathrm{DS}$, but the changes in the Baltic countries modelling can slightly impact the other regions. This approach is similar to the EU WAM (With Additional Measures) scenarios that the Baltic countries have modelled for their PaMs reports.

The biggest difference between our and national PaMs scenarios is that we did not include all the targets suggested by the Baltic countries. Most importantly, we did not include targets for domestic generation in the main scenarios, because we wanted to 
study what kind of an impact the renewable and ESS targets would have on the domestic generation. Impacts and costs of specific domestic generation targets are studied in the Chapter 4.4 .

$2 D S$ is an ambitious scenario which achieves the global two degrees target. We included $2030 \mathrm{GHG}$ targets for the EU and Baltic countries, but did not include separate targets for renewable energy. After 2030, the EU will reduce GHG emissions by $80 \%$ by 2050, but there will be no specific GHG targets for any EU member state for 2040 or 2050. The Baltic countries' GHG reductions will be modelled as part of the EU. The Baltic countries' own 2030 targets are not included in the 2DS. This allows us to analyse how well the proposed national targets align with the 2DS pathway.

More detailed assumptions about the scenarios and sectoral modelling are presented in later chapters, in the modelling annexes 1 and 2, and in the supplementary Excel files. 


\section{Growing demands, increasing efficiency, and electrification}

\subsection{Key Findings}

- Energy efficiency plays a key role in the decarbonisation of transportation and buildings. Both sectors go through significant energy efficiency improvements in the scenarios and the total energy consumption decreases despite increasing transport demands and floor areas.

- Electrification offers the possibility of reducing emissions and increasing renewable energy in all sectors.

- The transport sector starts to gradually shift to EVs between 2020 and 2030 when EVs reach cost parity, but the big changes in the scenarios happen after 2030. National policies can change the situation fast, and political push will likely be needed for the infrastructure investments.

- Biofuels are needed to decarbonise heavy trucks, airplanes and ships unless companies succeed in developing electric alternatives to these modes of transport.

- Building energy efficiency improvements will likely lead to a reduced consumption of district heating and residential biomass. Heat pumps, solar electricity and solar heating in buildings become more common in the scenarios.

- Industry sectors' energy consumption, electricity consumption and emissions increase due to assumed growth in production. These scenarios include only minor structural changes or fuel switching in industry, and the potential would likely be larger.

- Electricity consumption is projected to increase due to growing demands and electrification. The largest increase would come from electric vehicles (EVs), followed by industry due to assumed growth of production, heat pumps in buildings and district heat production, and other transportation. Based on the assumptions of this study, the growth could be $17 \%$ to $27 \%$ by 2030 compared to 2015 , and $60 \%$ to $65 \%$ by 2050 . 


\subsection{Opportunities and threats}

- Energy efficiency improvements will help to achieve 2030 targets in all scenarios and they have a good chance of delivering a return, if planned well. Successful energy efficiency measures also reduce the need for investment in additional energy production capacity (e.g. electricity and biofuels).

- Electricity consumption may increase less than in these scenarios, if the economy grows less than assumed or if the electrification of sectors is delayed. This would help to achieve domestic generation targets and reduce costs.

- Scenarios suggest relatively quick changes in the energy consuming sectors. However, infrastructure improvements (such as improved energy efficiency in buildings and deployment of EV charging points) and consumer behaviour could change slower in real life.

- The industry sector could become locked into fossil fuel use unless specific measures are outlined. These will likely require plant-specific assessments. On the other hand, increasing costs for the industry sector could result in decreased competitiveness, especially for products and processes that compete in global markets.

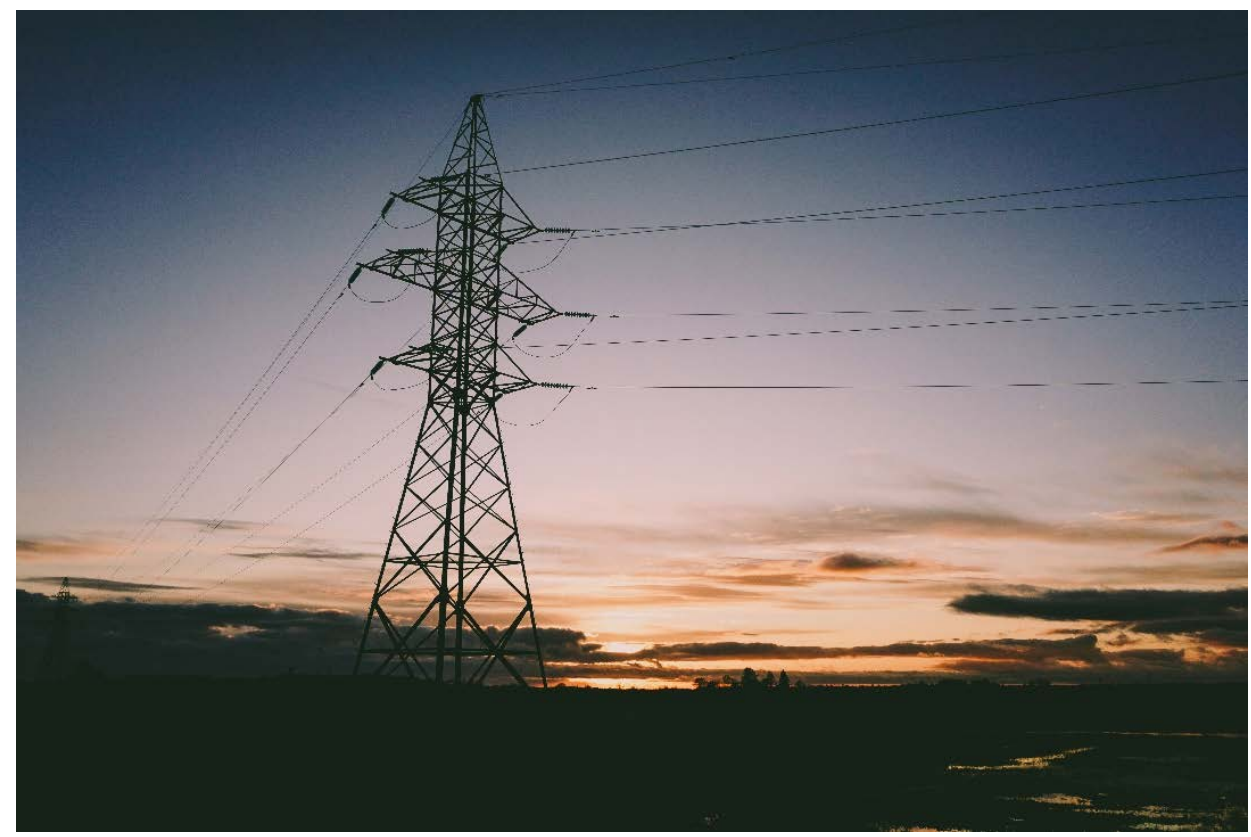

\subsection{Transport}

Domestic transport consumed $31 \%$ of the final energy and produced $21 \%$ of the GHG emissions in the Baltic countries in 2015. The largest transport modes are private cars and trucks, which consumed $90 \%$ of the total energy for domestic transportation. 
When adding international aviation and maritime to domestic transport, the transport sector's GHG emissions increase from $10.6 \mathrm{MtCO}_{2} \mathrm{e}$ to $13.2 \mathrm{MtCO}_{2} \mathrm{e}$. International maritime produced significantly more emissions in the Baltic countries (2.0 $\mathrm{MtCO}_{2} \mathrm{e}$ in 2015) than international aviation ( $0.65 \mathrm{MtCO}_{2} \mathrm{e}$ ).

Modelling road transport is trickier in small countries that have a large share of international road transport. According to the European Commission's statistical pocketbook, Lithuania and Luxembourg have the highest share of international road freight transport in the entire EU ( $90 \%$ of the total road freight in 2015) when measured based on where Lithuania's and Luxembourg's trucks are driving (EC, 2017k). Latvia and Estonia also have high shares of their trucks driving in other countries, $80 \%$ and $70 \%$ of the total tonne-kilometre of the total freight transport, respectively.

To be able to model national emissions, we need to estimate the amount of transport within the borders of each country. For freight, we took our estimates from the European Commission's statistical pocketbook, which gives estimates both for "Haulage by vehicles registered in the reporting country" and for "Haulage performed within the territory of each country by any Vehicle." The latter should correlate better to the amount of fuel consumed within the country. The energy intensity calculated from the latter also gives more logical values for the Baltic countries, see Table 4.

Table 4: Energy consumption and transport demand for trucks and cars and motorcycles in the Baltic countries and EU

\begin{tabular}{|c|c|c|c|c|c|c|c|c|}
\hline & \multicolumn{2}{|c|}{ Estonia } & \multicolumn{2}{|c|}{ Latvia } & \multicolumn{2}{|c|}{ Lithuania } & \multicolumn{2}{|c|}{$\mathrm{EU}_{28}$} \\
\hline & $\begin{array}{r}\text { Cars, } \\
\text { motorc. }\end{array}$ & Trucks & $\begin{array}{r}\text { Cars, } \\
\text { motorc. }\end{array}$ & Trucks & $\begin{array}{r}\text { Cars, } \\
\text { motorc. }\end{array}$ & Trucks & $\begin{array}{r}\text { Cars, } \\
\text { motorc. }\end{array}$ & Trucks \\
\hline Energy consumption, PJ, 2015 (UNFCCC, 2017b) & 19.5 & 10.7 & 23.2 & 17.0 & 42.6 & 26.9 & 7,622 & 4,572 \\
\hline Cars + motorcycles, billion passenger-km, 2015 & 12.3 & & 16.8 & & 25.8 & & 4,719 & \\
\hline Calculated MJ/passenger-km & 1.58 & & 1.38 & & 1.65 & & 1.62 & \\
\hline Calculated passenger-km/person & 9,400 & & 8,500 & & 8,900 & & 9,300 & \\
\hline $\begin{array}{l}\text { Haulage by vehicles registered in the reporting } \\
\text { country, billion tonne-km, } 2015\end{array}$ & & 6.3 & & 14.7 & & 26.5 & & 1,151 \\
\hline Calculated MJ/tonne- $\mathrm{km}$ & & 1.69 & & 1.16 & & 1.01 & & 3.97 \\
\hline Calculated tonne- $\mathrm{km} /$ person & & 4,800 & & 7,400 & & 9,100 & & 2,300 \\
\hline $\begin{array}{l}\text { Haulage performed within the territory of each } \\
\text { country by any vehicle, billion tonne-km, } 2015\end{array}$ & & 2.80 & & 4.80 & & 7.30 & & 1,722 \\
\hline Calculated MJ/tonne- $\mathrm{km}$ & & 3.81 & & 3.55 & & 3.68 & & 2.66 \\
\hline Calculated tonne- $\mathrm{km} /$ person & & 2,100 & & 2,400 & & 2,500 & & 3,400 \\
\hline
\end{tabular}

Key point(s): Transport modelling should only include transport within country borders, because that corresponds better with the fuel sold.

Source: $\quad$ Energy consumption from (UNFCCC 2017b). Demand for cars and motorcycles for Estonia and Lithuania (EC, 2017k) and for Latvia (IPE, 2017). Energy consumption and demand (haulage) for trucks for all Baltic countries (EC, 2017k). 
The Baltic countries have a slightly older car stock than the EU on average, but this is not directly visible from the calculated energy intensity of cars ( $\mathrm{MJ} /$ passenger-km). Especially Latvia has a lower energy intensity, but this might be due to the higher average number of passengers per car. More detailed studies of the Baltic countries' car stocks (Road administration Estonia 2017, Central Statistics Bureau of Latvia 2017b, Statistics Lithuania 2017b) could facilitate better understanding of these numbers in the further work.

In the Baltic countries, the sale of alternative fuel vehicles was around 100 vehicles in 2016 when including EVs, plug-in EVs and other alternative fuels (ACEA, 2017). In the first half of 2017, sales totalled 50 in Estonia, 110 in Latvia and 80 in Lithuania. The numbers are still very small compared to the total car fleet. Latvian municipal transport company Rigas Satiksme (Riga Transport) decided to invest to 10 hydrogen buses in 2017 and construct the required infrastructure (LSM, 2018).

The modelling in BENTE is based on average vehicle fleets, demands for each vehicle type, energy consumption of each vehicle type, and assumed future technologies for each vehicle type. The modelling input data for the Baltic countries does not include a detailed car fleet database, such as vehicle age, type, and annual driving distances.

The Baltic countries are assumed to experience a swift increase in transport demand for both passenger transport and freight transport. According to national estimates, the Baltic countries will reach the EU average demand for passenger transport by 2030 (Figure 17). The growth is projected to continue, and the Baltic countries' demand for passenger transport is expected to be slightly higher than the EU average by 2050 .

Figure 17: Demand for passenger transport

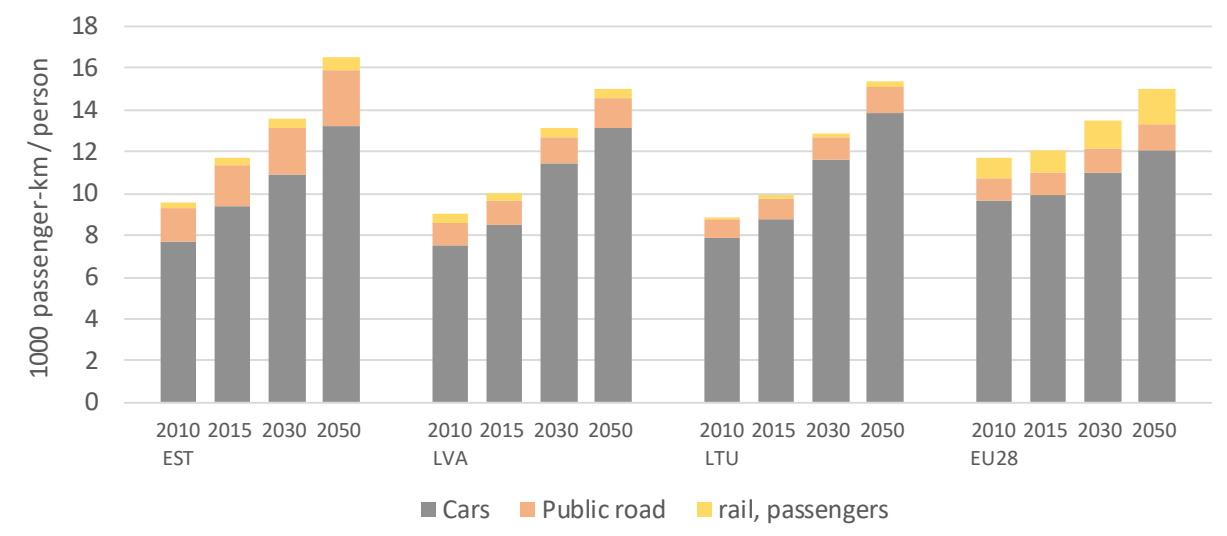

Key point(s): Demand for passenger transport in the Baltic countries will reach the EU average by 2030.

Source: Demand for car and motorcycle transport in 2010 and 2015 for Estonia and Lithuania (EC, $2017 \mathrm{k}$ ). Other data and growth rates for Estonia and Lithuania from 2015 to 2050 (MKM and LEI, respectively). Transport demands for Latvia 2010 to 2050 (IPE, 2017). See supplementary file about input data for more details.

The assumed increase in the demand for freight transport is much higher than for passenger transport (Figure 18). Freight transport is projected to grow much faster in 
Latvia and Lithuania than in the EU and Nordic countries. The growth trends are input data from the Baltic countries that are applied to the "Haulage performed within the territory of each country by any vehicle" starting point (EC, 2017k). Assumed transport demands for the Baltic countries are documented in the supplementary Excel files.

Figure 18: Demand for freight transport

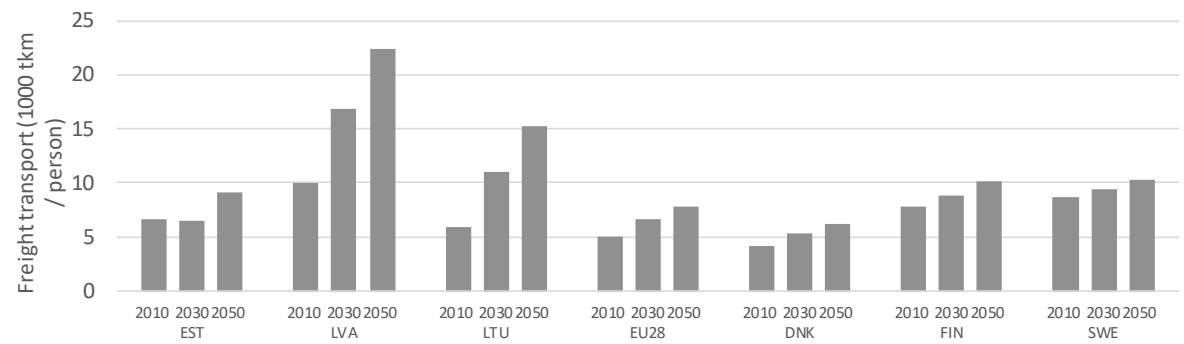

Key point(s): Assumed transport growth rates in Latvia and Lithuania are very high compared to the EU average and the Nordic countries.

Source: $\quad$ Truck transport statistics in 2010 (EC, 2017k). Growth rate for the EU and Nordic countries (EC, 2017k). Growth rate for the Baltic countries (MKM, IPE, and LEI). See supplementary file about input data for more details.

The high share of international freight transport means that the Baltic countries' transport emissions are strongly influenced by both domestic policies and policies in neighbouring countries. Cooperation with other EU member states and EU-level policies are required to achieve better results on freight transport mitigation measures.

The technological development in transport sector depends mostly on EU-level policies and trends. The price of electric private cars and vans are decreasing fast, but how much and for how long prices will drop remains uncertain. We have used data from an economic assessment of low-carbon vehicles (Cambridge Economics, 2013) to project prices to 2050. According to these estimates, Electric Vehicles (EVs) will become cheaper than combustion engine vehicles between 2020 and 2030 (Figure 19). Natural gas vehicles are estimated to be the cheapest type of car already at the moment, but their sales figures are quite modest in most EU countries, except Italy where fuel taxes are among the highest in the EU. 
Figure 19: Estimated total life-cycle costs of private vehicles by technology. Estimate is based on 17000 kilometres driven per year

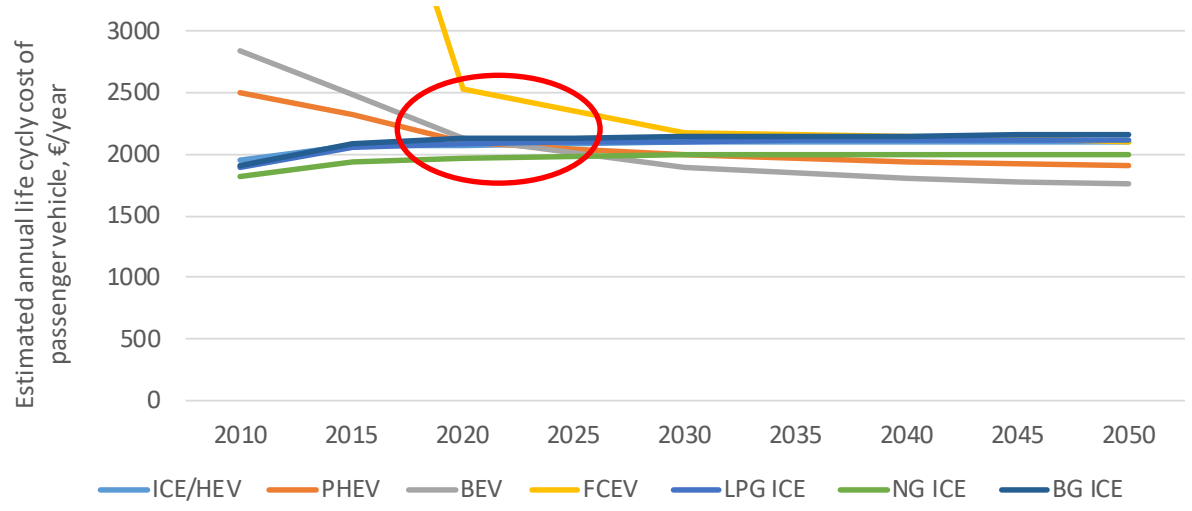

Key point(s): EVs will reach cost parity with petrol and diesel vehicles at some point between 2020 and 2030, depending on assumptions.

The above estimates show the costs from the consumer's perspective, since the consumer ultimately makes the decision. In the BENTE modelling, we also consider the costs of additional infrastructure, which increases the overall costs of EVs with O\&M costs of $10 \mathrm{EUR} / \mathrm{MWh}$ of electricity to transport.

National policies, taxes and other subsidies highly affect prices and EV markets. EV sales have increased quickly in Norway, for example, after monetary support and nonmonetary support (e.g. permission to drive on bus lanes) were established. Many countries and cities are planning bans on diesel vehicles and some have proposed bans on all combustion engines. At least the following countries are planning to implement either bans or heavy restrictions on selling and/or manufacturing combustion engine vehicles (CleanTechnica 2017, Independent 2017):

- Norway by 2025.

- Netherlands by 2025.

- India by 2030.

- Germany by 2030.

- France by 2040.

- UK by 2040.

Many EV manufacturers are pushing a range of new models to consumers. This could lead EVs gaining the benefits of scale, which, in turn, could result in prices decreasing faster than assumed here. Some research results have indicated that vehicle manufacturers might have to start pushing EVs to their markets to avoid fines from existing and future $\mathrm{EU} \mathrm{CO}_{2}$ emissions limits (PAN Consulting, 2017). 


\section{Why Norway leads the world in sales of electric vehicles}

Thanks to aggressive policy measures, Norway has the world's highest per-capita share of electric vehicles (EVs). The total EV stock reached 96,000 in 2016 (SSB, 2017). In 2017, 33\% of new private cars were battery electric vehicles (BEVs) and plug-in hybrid electric vehicles (PHEVs). In the month of December 2017, combined sales of BEVs and PHEVs reached $51 \%$ of total car sales. There were 36,000 $\mathrm{BEV}$ registrations and $23,000 \mathrm{PHEV}$ registrations in 2017 , and EVs made up approximately $6 \%$ of the total private car stock at the end of 2017.

High sales of EVs must be seen in the context of Norway's high taxes on vehicle purchases and fuels. The country's high registration tax scheme incorporates four elements: $\mathrm{CO}_{2}$ emissions, $\mathrm{NO}_{x}$ emissions, weight $(\mathrm{kg})$ and engine size (horsepower) ( $\mathrm{Bu}, 2015)$. Registration taxes averaged USD 13,500 in 2015. In addition, value-added taxes (VAT) of 25\%, averaging USD 9500 for a new vehicle, are levied on new vehicle purchases.

The Norwegian support scheme for EVs began in 1990 with exemption from vehicle registration taxes, and was gradually strengthened until 2005 to include most of the important elements that it retains to date (Aasness, 2015). Those elements include zero VAT, reduced company car tax, road toll and congestion charge exemptions, free parking, free passage on car ferries, and access to dedicated bus lanes. To ensure that bus lane access for EVs does not compromise public transit operations, they are restricted in certain cases, such as during peak-hour traffic in Oslo.

The first coordinated, nationwide roll-out of public charging stations began in 2009-2010, during which time nearly 1,800 new charging points were installed ( $B U, 2015)$. Over the following years, national government subsidies for public charging installations and operations gradually became the responsibility of local authorities. A public, open-source database called "Open Charge Map" provides drivers with data on charging station locations and updates on the availability of charging points in real time. As of 2017, the Open Charge Map has over 113,000 charging stations in over 58,000 locations in Norway. Most of these are in private buildings or only available to members. The total number of publicly available charging points is estimated to be around 9,000, of which nearly 1,100 are fastcharging stations.

Despite the above policies being implemented for more than a decade, the significant growth in Norway's EV sales is a very recent, and unforeseen, phenomenon (Holthe, 2015). The long time lag between policy adoption and market penetration likely stems from an evolving vehicle offer profile (Figenbaum, 2017). Yet, continued policy support is important to build on initial developments, stimulating additional savings arising from technological developments. On the other hand, the EV policy support should not underestimate the potential effects on overall car travel and congestion or the impact on the quality of public transport services. Policymakers should also consider the oft-cited critique that the existing scheme has translated to an extremely high $\mathrm{CO}_{2}$ abatement cost (i.e. cost per unit of $\mathrm{CO}_{2}$ saved) (Holtsmark and Skonhoft, 2014).

The declining importance of fossil fuels following the successful deployment of EVs would also lead to significant changes in government revenues leveraged from vehicle and fuel taxation. This observation suggests that EVs may only become economically viable in the presence of a switch in the way governments seek revenue streams, such as an evolution towards charging for road usage, taking the wider social and environmental costs of transport into account (e.g. road damage, congestion and fossil fuel dependence), or other relevant fiscal reforms.

Our modelling includes electric cars, motorcycles, vans, light-duty trucks, heavy-duty trucks, and trains. We have not included electric airplanes and ships, because there is very little techno-economic data available for modelling. The first electric shortdistance ferries are already operating (Siemens, 2017). Their operating range is very short ( 10km) at the moment, but it will improve. Many companies are also developing 
electric airplanes, which may already be in use by the 2020 s if all goes well. The development is led by small companies, which are backed up by Boeing and Airbus, for example (Popular Mechanics 2017, Airbus 2017). This is one aspect to develop in further modelling work. In the current modelling, aviation emissions can be reduced using biofuels, and maritime emissions can be reduced through methane, hydrogen, and biofuels.

Our main scenarios reflect the actual development of EVs in the past years in the Baltic countries, but we have calculated a sensitivity analysis, where we assume a high share of EVs and study its impacts on electricity consumption and GHG emissions. In this scenario, the Baltic countries decide to push for a relatively high share of EVs and reach $10 \%$ of car stock from EVs and $30 \%$ from plug-in hybrids by 2030 and achieve $70 \%$ from EVs by 2050 . In addition, we assume that $10 \%$ of all buses will be electric by 2030 and $40 \%$ by 2050 . The share of electric vans will reach $20 \%$ by 2030 and $70 \%$ by 2050 , and the share of electric trucks will reach $5 \%$ by 2030 and $30 \%$ by 2050 . All this will require a significant share of sales to come from EVs from 2020 onwards, as only a minor amount of EVs are likely to appear in the Baltic countries' car stock before 2020. Other assumptions in this sensitivity analysis are the same as for the BPO.

The private car fleet starts to shift to plug-ins and EVs after 2030 without specific supporting policies in the $4 \mathrm{DS}$ (Figure 20). By 2030, the share of EVs and plug-ins reaches $7 \%$ in the $4 \mathrm{DS}$ and $14 \%$ in the $\mathrm{BPO}$, when the Baltic countries will need to reduce emissions in the transport sector. The modelled rate of change increases sharply from 2030 to 2050 , reaching shares of $77 \% \mathrm{EVs}$ and plug-in EVs in the ${ }_{4} \mathrm{DS}$ and $78 \%$ in the $2 \mathrm{DS}$ by 2050 . In addition, hydrogen cars gain a notable share in all scenarios, $14 \%$ in the 4 DS by 2050 and $11 \%$ in the BPO by 2050 .

EVs increase energy efficiency significantly and can provide more passenger kilometres using less energy. Although this depends on the vehicle model and assumed efficiency improvements of internal combustion engine vehicles, a typical improvement is from 2 to 2.5 times more kilometres using the same energy as demonstrated in Figure 18. Passenger car efficiency is estimated to improve from 1.4 $\mathrm{MJ} /$ passenger- $\mathrm{km}$ in 2015 to $1 \mathrm{MJ} /$ passenger- $\mathrm{km}$ in 2030 and to $0.4 \mathrm{MJ} /$ passenger- $\mathrm{km}$ in 2050 in the $4 \mathrm{DS}$. The improvement is both due to developing internal combustion engine and electrification. When combined with the shift from fossil fuels to electricity and biofuels, this results in a $30 \%$ decrease in specific $\mathrm{CO}_{2}$ emissions $\left(\mathrm{gCO}_{2} /\right.$ passenger$\mathrm{km}$ ) from 2015 to 2030 and a $95 \%$ decrease from 2015 to 2050. 
Figure 20: Passenger kilometres (left) and energy consumption (right) of private vehicles in the main scenarios (4DS, BPO and 2DS) and in an electric vehicle sensitivity analysis for the BPO (EV)
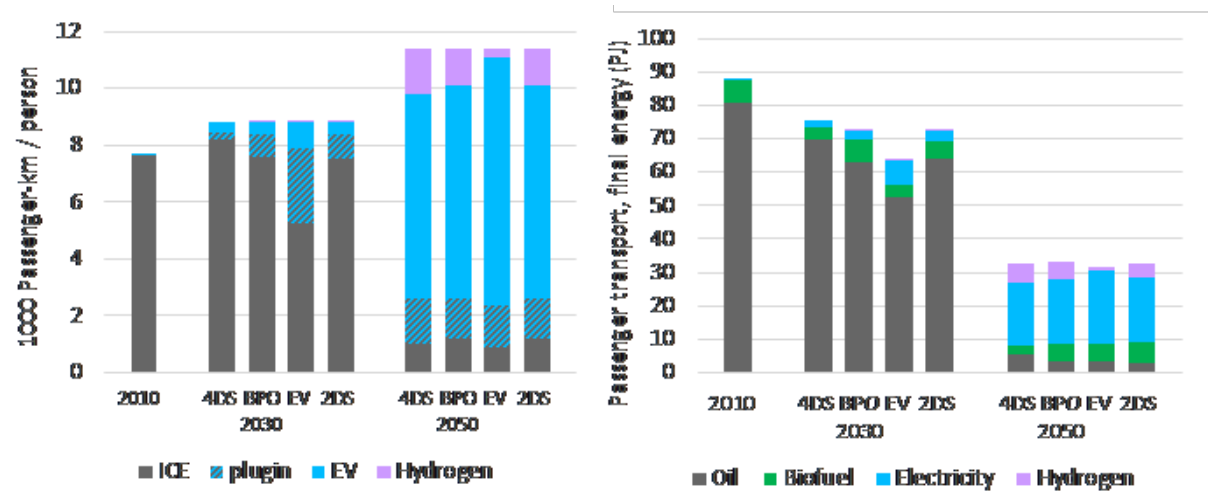

Key point(s): Electrification of the transport sector strongly decreases the total energy consumption.

Source:

IEA World Energy Balances for 2010.

The modelled rate of change from 2030 to 2050 might be hard to achieve in real life, because infrastructure changes tend to follow a slower pace than potential vehicle sales. The Baltic countries might need to implement supportive policies already before 2030 to be able to reach very high EV shares by 2050.

Trucks consume an increasingly large share of the transport energy towards 2050 (Figure 22). Electric vans reach price parity earlier than other EVs in the scenarios, reaching shares of $50 \%$ in 2030 . Heavy road transport is more difficult to electrify, but methane or hydrogen might provide another option to decarbonise trucks.

The railway transportation is electrified in the scenarios, but there would be room for additional ambition. In 2010, approximately $5 \%$ of the railway energy was supplied with electricity, but the share increases to $22 \%$ by 2030 and to $35 \%$ by 2050 . Further studies could study if further electrification of the railway transportation would be costefficient way to reduce emissions in the transport sector, because that largely depends on the infrastructure investment costs.

The amount of biofuels does not increase much in the $4 \mathrm{DS}$. But in the BPO and 2DS, biofuels are used to replace oil in all road transport from 2020-2030, and in heavy road transport between 2030 and 2050 (Figure 23). The Baltic countries do not have specific biofuel targets and the share is allowed to stay low in the scenarios despite the EU $10 \%$ RES-T target. In the $4 \mathrm{DS}$, the share of biofuels for the Baltic countries reaches between $5 \%$ (Lithuania) and 7\% (Estonia) by 2020.

Additional EVs decrease transport total energy consumption and emissions, but increase the electricity consumption. The total energy consumption of passenger cars is $13 \%$ less in the EV sensitivity scenario than in the BPO (Figure 21). The total energy consumption of the transport sector decreases by $6 \%$ and emissions decrease by $8 \%$ in the EV sensitivity scenario compared to the BPO by 2030. The difference in 2050 is smaller, when the total transport energy consumption decreases by $5 \%$. In the BPO, the electricity consumption in the transport sector is 1 TWh by 2030 and 5.5 TWh by 2050 
in the Baltic countries. In comparison, the consumption is 2.2 TWh by 2030 and 6.3 TWh by 2050 in the Baltic countries in the EV sensitivity scenario.

Figure 21: Final energy consumption for transport by type in the Baltic countries

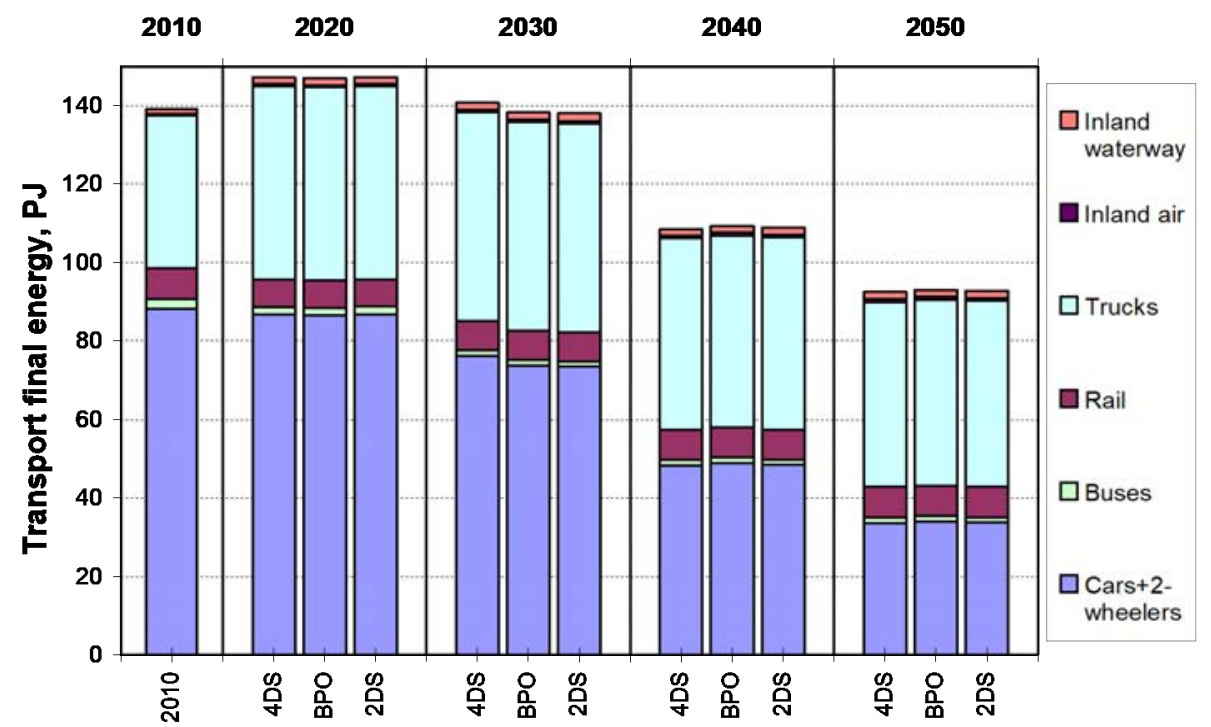

Key point(s): The trucks' share of the final energy consumption for transport in the Baltic countries increases from $30 \%$ in 2010 to $55 \%$ in 2050.

Figure 22: Final energy consumption for transport in the Baltic countries (excluding international aviation and maritime)

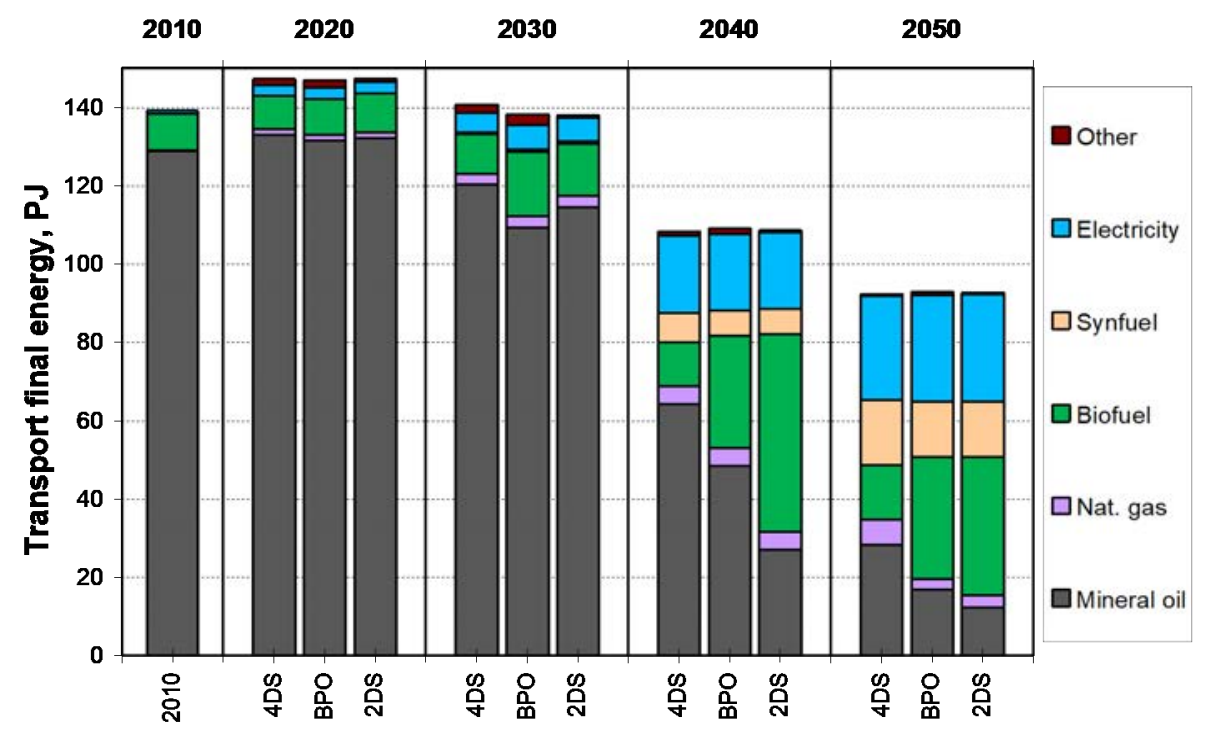

Key point(s): Mineral oil in transport is replaced with biofuels, electricity, hydrogen and methanol.

International transport energy consumption is projected to stay at the current level despite the doubling of aviation demand from 2010 to 2050, and international maritime transport is expected to increase by $33 \%$ from 2010 to 2050 . These sectors have two 
categories of emission reduction measures in the model: fuel switch (to methane and biofuels) and energy efficiency. In our scenarios, GHG emissions increase from 2010 to 2030 and then decrease below the 2010 level in the Baltic countries (Figure 23). Domestic aviation and domestic maritime are minor energy consumers in the Baltic countries (Figure 21). Emissions from international aviation are not included in the national totals in the EU policies.

Electricity could be a new option for aviation and maritime, but we did not include electric airplanes or ships in the scenarios, because there exists very limited technical information, which would be required for the modelling.

Figure 23: Final energy consumption and GHG emissions of international transport in the Baltic countries

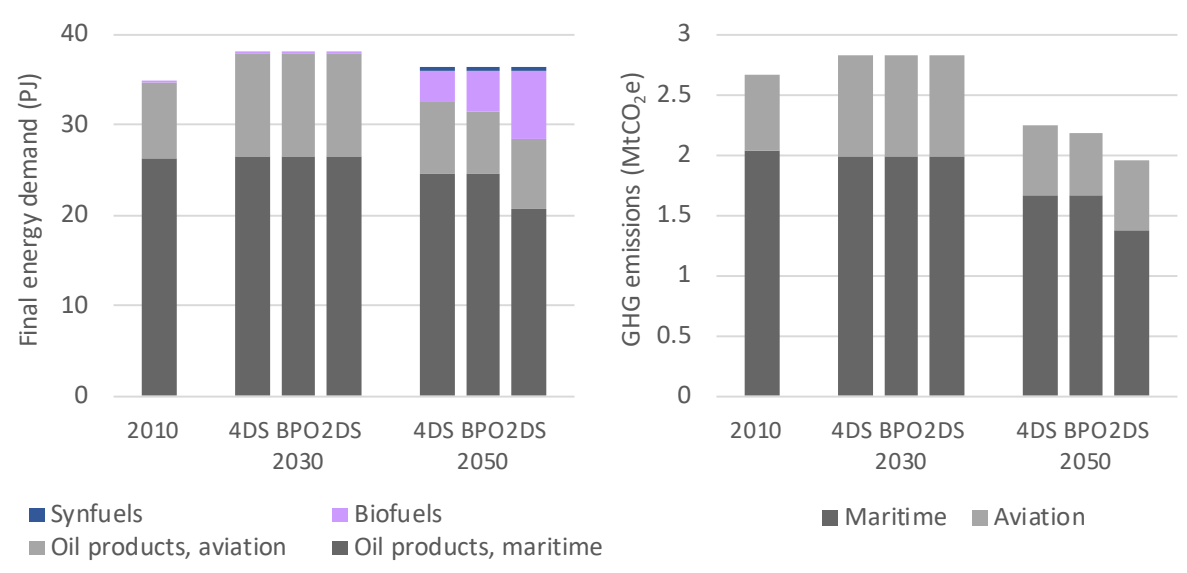

Key point(s): Energy consumption of international transport grows only slightly due to improvements in energy efficiency.

In general, the transport sector's GHG projections are lower than in national projections. The projections presented here largely agree with Estonian "With Additional Measures" (WAM) scenario and with Latvian scenarios up to 2020 (Figure 24). Lithuanian projections show much higher development of GHG emissions both in "With Existing Measures" (WEM) and WAM. After 2020, also the comparable Latvian scenarios show higher GHG emissions than $4 \mathrm{DS}$ and $\mathrm{BPO}$. 
Figure 24: Transport sector GHG projections in 4DS and BPO compared to national projections in "With Existing Measures" (WEM) and "With Additional Measures" (WAM) scenarios
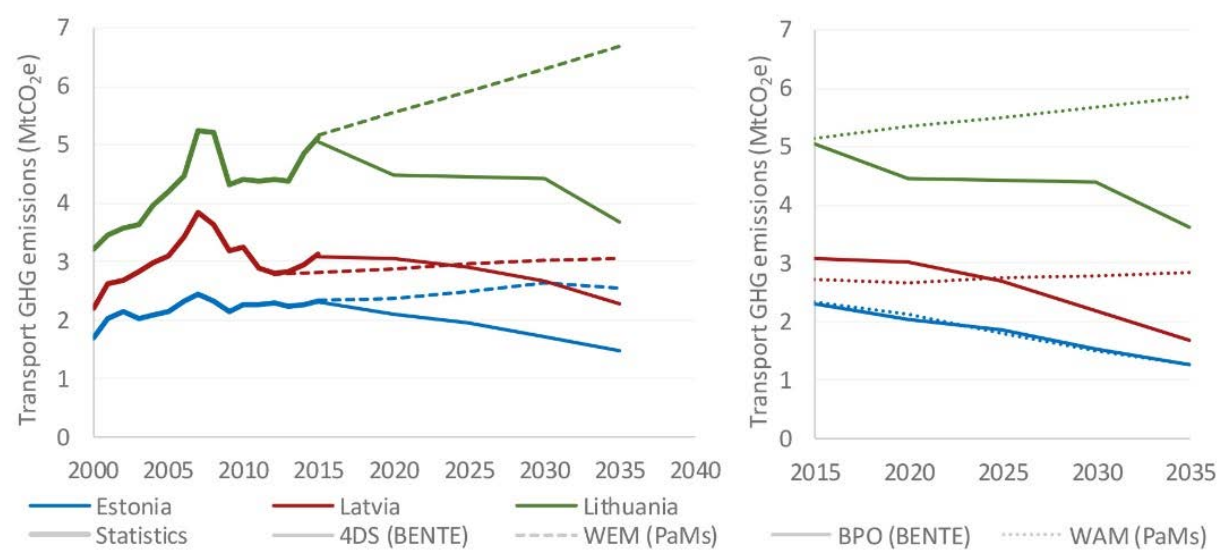

Key point(s): National scenarios project higher GHG emissions for transport sector compared to $4 \mathrm{DS}$ and BPO.

Source: $\quad$ Statistics from UNFCCC (2017). National projections from Ministry of the Environment of Estonia (2017), Ministry of the Environment of Latvia (2017), Ministry of the Environment of Lithuania (2017).

When all projections are compared, the projections of transport sector GHG emissions are at lower level in $4 \mathrm{DS}$ and BPO than in comparable national projections. Other results vary country by country: Lithuanian projections shows larger growth of GHG emissions than other scenarios, Estonian WAM shows very similar development than BPO, and Latvian WEM agrees with Estonia's WEM, but Latvia's WAM shows only minor additional reductions (Table 5). Results in ${ }_{4} \mathrm{DS}$ and $\mathrm{BPO}$ and similar across the Baltic countries while the variance is larger in national projections.

The main reason for differences are transport likely technology assumptions, which result to different efficiencies of car fleet and different fuel mixes between different projections. These differences should be explored further in the following projects.

There are likely some other unaccounted parameters, such as high annual variation in the transport demand due to up's and down's of the economy. The transport GHG emissions peaked in the Baltic countries at 2007 and 2008 and then stayed at the lower level from 2009 to 2013 . Annual variations have been the largest in Lithuanian and Latvia and smallest in the Estonia. Now transport GHG emissions are rising again in the Baltic countries with the recent positive economic development. All scenarios are projected with constant changes in the transport demand. 
Table 5: Change in transport sector's GHG emissions from 2015 to 2035 in 4DS, BPO and comparable national scenarios

\begin{tabular}{|c|c|c|c|}
\hline & & \multicolumn{2}{|c|}{ Change from 2015 to 2035 (\%) } \\
\hline & & 4DS / WEM & BPO / WAM \\
\hline \multirow[t]{2}{*}{ Estonia } & BENTE & $-37 \%$ & $-45 \%$ \\
\hline & PaMs & $+9 \%$ & $-45 \%$ \\
\hline \multirow[t]{2}{*}{ Latvia } & BENTE & $-26 \%$ & $-46 \%$ \\
\hline & PaMs & $+9 \%$ & $+4 \%$ \\
\hline \multirow[t]{2}{*}{ Lithuania } & BENTE & $-27 \%$ & $-29 \%$ \\
\hline & PaMs & $+29 \%$ & $+14 \%$ \\
\hline
\end{tabular}

Key point(s): Results in $4 \mathrm{DS}$ and BPO and similar across the Baltic countries while the variance is larger in national projections.

Source: $\quad$ PaMs scenarios from Ministry of the Environment of Estonia (2017), Ministry of the Environment of Latvia (2017), and Ministry of the Environment of Lithuania (2017).

\section{$2.4 \quad$ Buildings}

The building sector includes residential, commercial, and public buildings. The residential buildings consumed $30 \%$ of the final energy in the Baltic countries in 2015, but produced only $2 \%$ of the GHG emissions directly. Indirect emissions depend on the $\mathrm{CO}_{2}$ intensity of the electricity and district heating sector. If emissions from the production of electricity and district heating would be allocated to end-use sectors, the residential sector's share of GHG emissions would have been $18 \%$ in Estonia, $7 \%$ in Latvia and $2 \%$ in Lithuania.

Energy consumption in other buildings (e.g. commercial and public sector buildings) is almost as large as in the residential sector, reaching $18 \%$ of the total final energy consumption in the Baltic countries in 2015. Electricity and district heating supply a larger share of the energy consumption of commercial and public buildings than of residential buildings, because a larger share of commercial and public buildings are located in the cities.

The Baltic countries are experiencing trends of urbanisation and a decreasing population. The residential floor area per person has increased rapidly from the level of $25 \mathrm{~m}^{2}$ per person in 2000 to $30-40 \mathrm{~m}^{2}$ per person in 2015 (Figure 25). Floor area per person has increased $+20 \%$ in Latvia and Lithuania during the last 10 years, compared to only $10 \%$ increase in the Nordic countries and Estonia. The total floor area is assumed to increase by $12 \%$ in Latvia from 2015 to 2050 , but this means a $25 \%$ increase per person. For Estonia, the total increase is assumed to be $25 \%$ from 2015 to 2050 ( $44 \%$ increase per person) and $16 \%$ for Lithuania ( $37 \%$ increase per person). For reference, the floor area per person is assumed to increase by $7 \%$ in the Nordic countries from 2015 to 2050 (NER, 2016). 
Figure 25: Assumed population growth in the Baltic countries and residential floor area per person
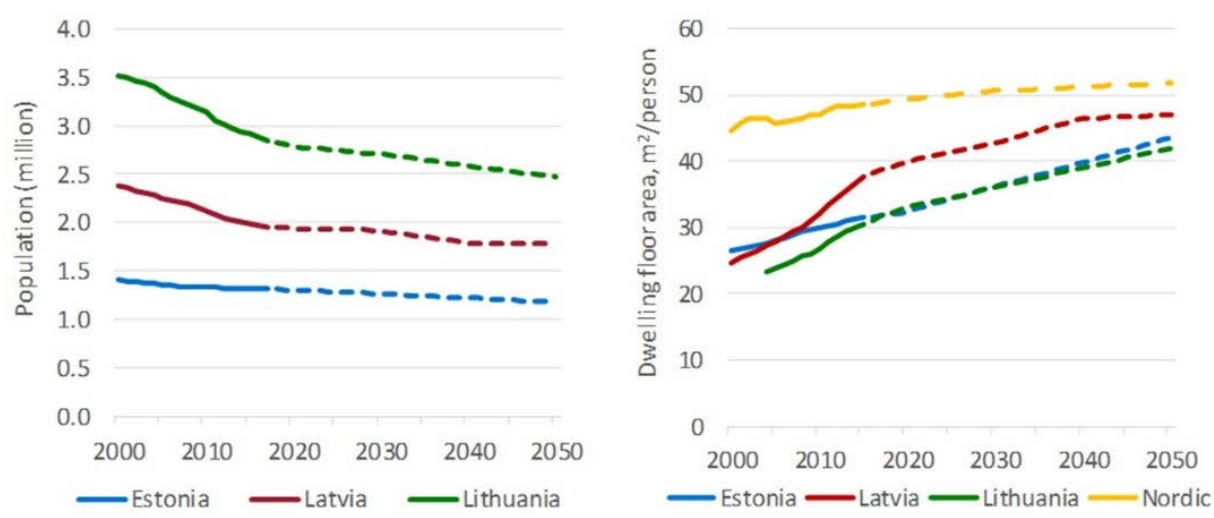

Key point(s): Decreasing population and slightly increasing floor area leads to relatively rapid growth in floor area per person in the Baltic countries (from a $70 \%$ to a $100 \%$ increase in 50 years).

Source: $\quad$ Population statistics (WB, 2017), floor area projections for the Baltic countries (MKM, IPE, and LEI, see supplementary input data file for additional details). Nordic statistics and projections from the NETP 2016 (NER, 2016).

Energy efficiency measures in the building sector are studied comprehensively in the Baltic countries. In Estonia, buildings consumed on average $53 \%$ of the total final energy from 2010 to 2015 . A recent study estimated that the final energy consumption of Estonian residential buildings could decrease $0 \%, 9 \%$ or $18 \%$ from 2010 to 2030 , depending on how ambitiously efficiency measures are applied (Kurnitski et al. 2014). The net costs over the lifetime of investments were estimated to be relatively low in each scenario, but the return will require some years.

In Lithuania, buildings consumed $43 \%$ of the total final energy in 2015 . Lithuania has many existing policies and programmes to improve energy efficiency in the building sector, which are estimated to reduce the final energy consumption of residential buildings by $3 \%$ from 2015 to 2020 and by $10 \%$ from 2015 to 2030 (Ministry of the Environment of Lithuania, 2017). If additional planned measures are implemented, the energy consumption of the residential sector is estimated to decrease by up to $30 \%$ from 2015 to 2030. The service sector also has energy efficiency programmes, but the final energy consumption is estimated to increase by $15 \%$ from 2015 to 2030 despite the existing energy policies. If all planned measures were to be implemented, the Lithuanian scenarios estimate a $15 \%$ reduction in the service sector's final energy consumption from 2015 to 2030 . For Latvia, see "Building sector energy efficiency measures in Latvia" info box.

Building sector energy efficiency measures in Latvia

In the National Real Estate Cadastre Information System, 1.35 million buildings are registered with a total area of 198 million $\mathrm{m}^{2}$, including various auxiliary buildings. Of the total number of 1.35 million buildings, approximately 400,000 buildings are heated, and 352,400 of these are residential buildings with a total floor area of 86.9 million $\mathrm{m}^{2}$. The largest number and share $(85 \%)$ is made up of single- 
dwelling buildings $(300,700)$. However, in terms of area, the share of single-dwelling buildings is only $39 \%$, while multi-dwelling (three and more dwellings) make up the largest share (58\%). The number and area of energy consuming buildings are presented in Table 6.

Table 6: Number and area of energy consuming residential and non-residential buildings

\begin{tabular}{lrr} 
Main type of utilisation & $\begin{array}{r}\text { Number, } \\
\text { thousand }\end{array}$ & $\begin{array}{r}\text { Area, } \\
\text { million } \text { m }^{2}\end{array}$ \\
\hline Residential buildings & & \\
Single-dwelling buildings & 300.7 & 33.9 \\
Two dwellings buildings & 12.4 & 2.5 \\
Three and more dwellings buildings & 38.6 & 50.4 \\
Buildings of various social groups & 0.7 & 0.1 \\
Total & 352.4 & 86.9 \\
Non-residential buildings & & \\
Wholesale and retail buildings & 11.4 & 6.1 \\
Office buildings & 7.3 & 6.6 \\
Hotel buildings and other temporary accommodation buildings & 4.8 & 2.3 \\
School, university and scientific research buildings & 3.9 & 6.6 \\
Communications buildings, stations, terminals and related buildings & 2.9 & 0.9 \\
Medical or health care institution buildings & 1.3 & 2.0 \\
Mass entertainment events buildings & 1.3 & 1.1 \\
Sports buildings & 1.0 & 1.1 \\
Museums and libraries & 0.5 & 0.3 \\
Total & 34.3 & 27.0 \\
\hline
\end{tabular}

Key point(s): In Latvia, single dwelling buildings form $85 \%$ of heated buildings by number, but only $39 \%$ by floor area.

Source: $\quad$ Ministry of Economy Latvia (2014).

The thermal characteristics of buildings depend on when they were constructed. Only $3 \%$ by number and $5 \%$ by area of the buildings were built after 2003 and may be considered to be compliant with the thermal engineering requirements applicable at the moment.

Figure 26: Breakdown of multi-apartment residential buildings by number (left pie chart) and area (right pie chart) by construction period

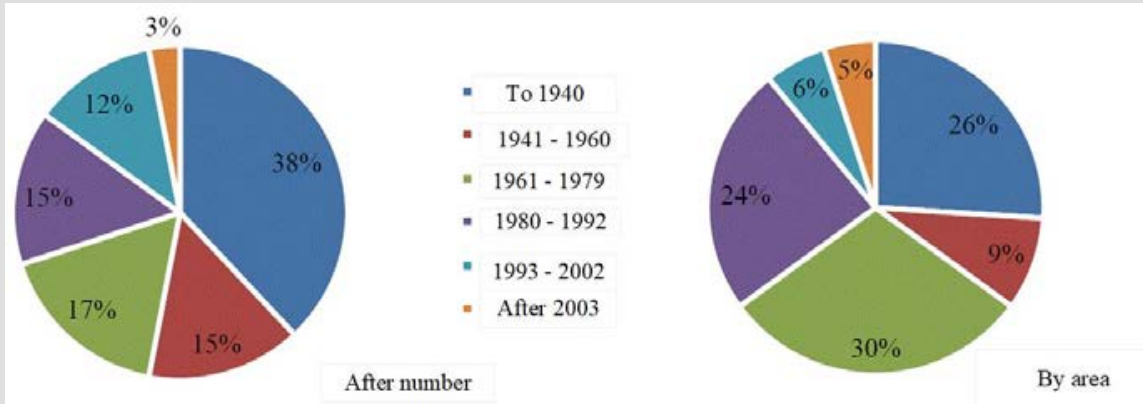

Key point(s): $70 \%$ of the multi-apartment buildings in Latvia have been built before 1980 .

Source: $\quad$ Ministry of Economy Latvia (2015).

Several objectives have been agreed to improve energy efficiency by 2020 : 
- Each year $3 \%$ of the public sector's building area (maximum forecast $-678460 \mathrm{~m}^{2}$ ) needs to be renovated (Cabinet of Ministers of Latvia, 2016). The objective is binding and outlined in the EU directive on energy efficiency 2012/27/ES9 (Regulation 383/2013 of Latvia).

- Decrease specific heat consumption for heating by households to $150 \mathrm{kWh} / \mathrm{m}^{2}$ per year by 2020 and to $100 \mathrm{kWh} / \mathrm{m}^{2}$ per year by 2030 (Ministry of Economics Latvia, 2013).

In accordance with the Regulation of the Republic of Latvia No 383 about buildings certification for energy efficiency, all new buildings owned by the State and in the possession of the institute of the country will meet nearly zero-energy building requirements already by 1 January 2019 (Table 7).

Table 7: A minimum level of energy performance of new buildings

$\begin{array}{lll}\begin{array}{l}\text { Building construction project } \\ \text { approval period }\end{array} & \begin{array}{l}\text { Minimum permissible level of energy efficiency for heating in new } \\ \text { buildings }\end{array} \\ & \text { Multi-dwelling residential buildings } & \text { Buildings owned by the State } \\ & \leq 60 \mathrm{kWh} / \mathrm{m}^{2} \text { per year } & \leq 90 \mathrm{kWh} / \mathrm{m}^{2} \text { per year } \\ 2017 & \leq 60 \mathrm{kWh} / \mathrm{m}^{2} \text { per year } & \leq 65 \mathrm{kWh} / \mathrm{m}^{2} \text { per year } \\ 2018 & \leq 50 \mathrm{kWh} / \mathrm{m}^{2} \text { per year } & \text { nearly zero-energy buildings } \\ 2019-2020 & \text { nearly zero-energy buildings } & \text { nearly zero-energy buildings } \\ \text { From 2021 onwards } & & \end{array}$

Key point(s): All new multi-apartment buildings and public buildings in Latvia should be nearly zero-energy buildings from 2021 onwards.

Source: $\quad$ Regulation $383 / 2013$ of Latvia.

These measures are expected to reduce the final energy consumption of the residential sector by $20 \%$ from 2015 to 2030, but the service sector's final energy consumption would increase by $1 \%$ with existing measures and decrease by $1 \%$ from 2015 to 2030 if additional planned measures were to be implemented (Ministry of the Environment of Latvia 2017).

We have modelled heat generation in buildings according to Technology Data for Individual Heating (DEA, 2016). With own generation of electricity and heating, buildings can become net-positive and produce surplus energy over the year. Building level energy production is supported by the EU Winter Package which outlines that consumers should be allowed to sell their excess production to the grid in all EU countries (Hancher et al., 2017).

Building level production is slightly problematic for the statistics, because it will make the real consumption more difficult to calculate. In this report, we always present the real consumption, not the net consumption. This might show slightly higher consumption figures towards 2050 than in studies that present the net consumption.

Another example of possible statistics problems in the near future are EVs that will increase the measured electricity consumption of the residential and service sectors. In this report, we have separated EVs from residential and commercial energy consumption and tried to keep the future numbers as comparable to current statistics as possible. 
The annual energy consumption of buildings varies significantly due to changing winter temperatures. In Baltic countries, 2010 was a particularly cold year with $12 \%$ more Heating Degree Days than average for 2010-2016, and 2015 was a particularly warm year with $10 \%$ less HDDs than average for 2010-2016 (Eurostat, 2017b). In 2015, area and water heating corresponded to $85 \%$ of the final energy consumption of the residential sector in Latvia and $80 \%$ in Lithuania (Eurostat, 2017b). See Figure 27 for annual variations. We have modelled the energy consumption based on a normal year with average Heating Degree Days, which is why 2020 has a higher energy consumption than 2015 .

Specific energy consumption $\left(\mathrm{kWh} / \mathrm{m}^{2}\right)$ of residential buildings in the Baltic countries decreases by $25 \%$ from 2010 to 2030 in the BPO, but the total energy consumption increases by $5 \%$ during the same period. This is due to increasing building stock (Figure 28) and because 2030 is modelled as a normal year compared to 2015 , which was warmer than average.

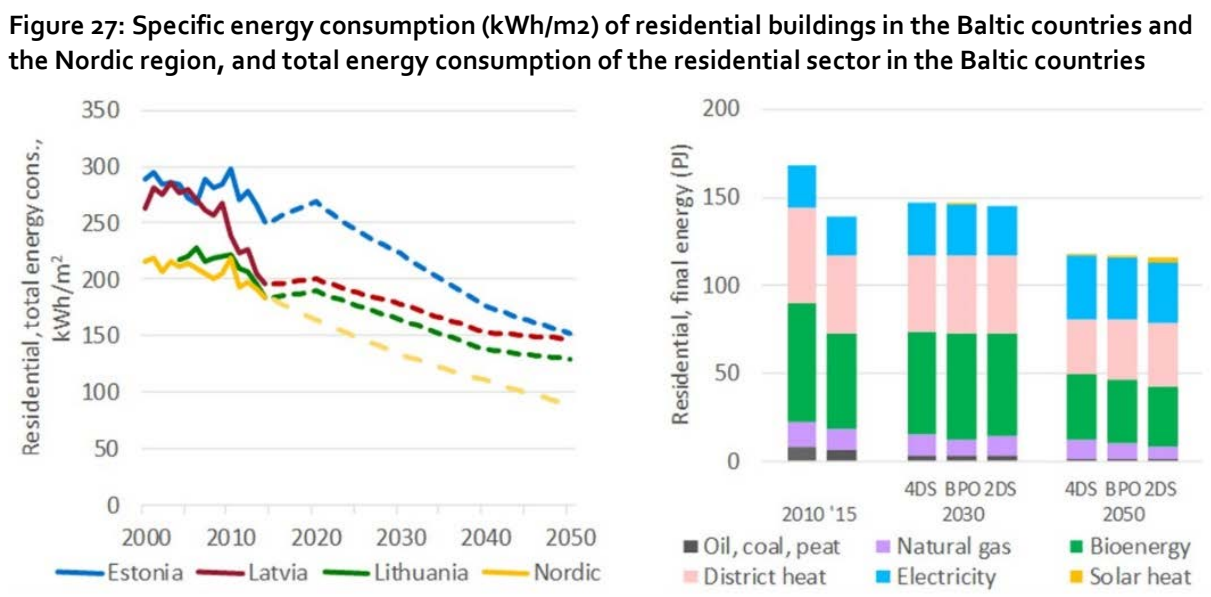

Key point(s): Specific energy consumption $(\mathrm{kWh} / \mathrm{m} 2)$ of residential buildings in the Baltic countries decreases, but the total energy consumption increases due to growing building stock. Annual variations due to warm and cold years are substantial.

Source:

Data for the Nordic region from NETP 2016 (NER, 2016).

The biomass consumption the residential sector increases from $55 \mathrm{PJ}$ in 2015 to $59 \mathrm{PJ}$ in 2030, but the share from the residential final energy remains in $40 \%$. This is due to difference between a warm statistical year (2015) and modelled normal year (2030). The amount and share of biomass in the residential sector final energy consumption decreases towards 2050 as older houses are renovated.

The share of electricity as an energy source in the residential sector increases due to improved energy efficiency and heat pumps. The actual potential and socioeconomic impacts of heat pumps in the residential sectors should be studied further.

For the previously mentioned reasons, district heating stays at the current level ( 50 PJ) until 2030, after which it starts to decline and reaches 30 PJ by 2050 . The current small share of heating oil ( $3 \%)$ is phased out in the scenarios. 
Much needs to be done to achieve these levels of efficiency improvements. The modelled rates of changes are lower than in the national PaMs reports (Ministry of the Environment of Estonia 2017, Ministry of the Environment of Latvia 2017, Ministry of the Environment of Lithuania 2017), but still very ambitious. It is crucial to address all real-life barriers that are not included in the modelling, such as the imbalance that the owner should pay for the energy efficiency improvements, but the tenant might get the savings.

The energy consumption of the other buildings decreases from the 2010 level of 68 PJ to 63 PJ by 2030 in all our main scenarios (Figure 20). The achieved efficiency increases are balanced by increasing building stock. We have modelled the building stock of other buildings based on roughly aggregated data and the modelling should be improved in further studies.

Figure 28: Final energy consumption of other buildings in the Baltic countries

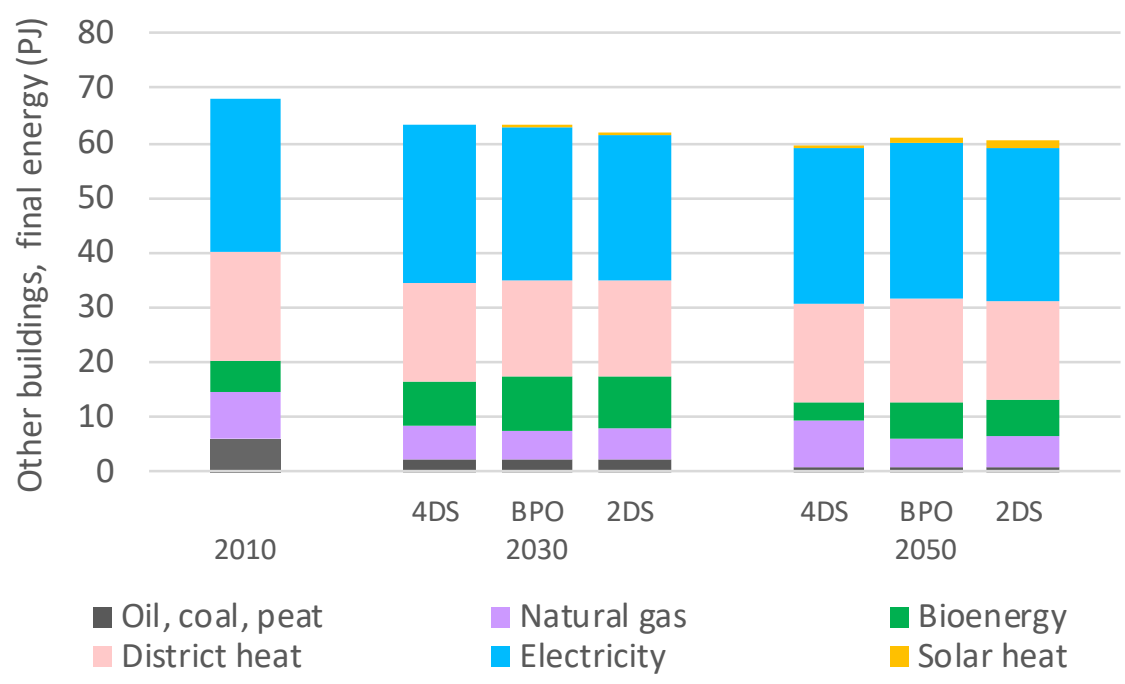

Key point(s): Oil heating in the service sector is replaced with district heating, heat pumps, and solar heating.

\subsection{Industry}

The industry sector accounted for $14 \%$ of the total Baltic GHG emissions in 2015 , and thus falls behind electricity and district heating, transport, and agriculture in GHG importance. Energy consumption accounted for $39 \%$, industrial process $\mathrm{CO}_{2}$ emissions $43 \%$, and non- $\mathrm{CO}_{2}$ emissions $18 \%$ of the total industrial sector GHG emissions. This means that industrial energy-related $\mathrm{CO}_{2}$ emissions contribute to only $6 \%$ of the total GHG emissions.

The drivers for the useful energy consumption in the industrial sectors were defined according to product-specific projections for the most important energy-intensive branches, and according to the volume indexes provided by the national teams for the output from the non-energy intensive sub-sectors. 
The presented drivers are for existing industry only. In addition, the modelling includes new industries for biofuel production in the Baltic countries. If any other new industries emerge, they are not included in the modelling and might have significant effect on industry sector's energy balance especially on the level of individual countries.

Major sources of process emissions are cement, ammonia and nitric acid production. Cement production is notable in all Baltic countries and is projected to increase by about $100 \%$ from 2010 to 2040 . Ammonia and nitric acid production are substantial in Lithuania, and are also estimated to increase (Table 8).

\begin{tabular}{|c|c|c|c|c|c|c|c|c|}
\hline Product & Unit & Country & 2010 & 2015 & 2020 & 2030 & 2040 & 2050 \\
\hline \multirow{4}{*}{$\begin{array}{l}\text { Cement } \\
\text { (clinker) }\end{array}$} & $1000 \mathrm{t}$ & EST & 577 & 754 & 1,131 & 1,131 & 1,131 & 1,131 \\
\hline & $1000 \mathrm{t}$ & LVA & 835 & 918 & 1,037 & 1,212 & 1,329 & 1,329 \\
\hline & $1000 \mathrm{t}$ & LTU & 536 & 963 & 1,498 & 1,498 & 1,498 & 1,498 \\
\hline & $1000 t$ & Total & 1,948 & 2,636 & 3,666 & 3,841 & 3,958 & $3,95^{8}$ \\
\hline Ammonia & $1000 \mathrm{t}$ & LTU & 527 & 1,064 & 1,194 & 1,194 & 1,194 & 1,194 \\
\hline Nitric acid & $1000 t$ & LTU & 936 & 1,195 & 1,200 & 1,200 & 1,200 & 1,200 \\
\hline \multirow[t]{4}{*}{ Sawn wood } & $1000 \mathrm{~m}_{3}$ & EST & 1,771 & 1,785 & 1,800 & 1,800 & 1,800 & 1,800 \\
\hline & $1000 \mathrm{~m}_{3}$ & LVA & 3,150 & 3,479 & 4,229 & 5,814 & 5,814 & 5,814 \\
\hline & $1000 \mathrm{~m}_{3}$ & LTU & 1,272 & 1,248 & 1,400 & 1,400 & 1,400 & 1,400 \\
\hline & $1000 \mathrm{~m}_{3}$ & Total & 6,193 & 6,513 & 7,429 & 9,014 & 9,014 & 9,014 \\
\hline \multirow[t]{4}{*}{ Wood-based panels } & $1000 \mathrm{~m}_{3}$ & EST & 338 & 495 & 500 & 500 & 500 & 500 \\
\hline & $1000 \mathrm{~m}_{3}$ & LVA & 918 & 1,270 & 1,300 & 1,300 & 1300 & 1,300 \\
\hline & $1000 \mathrm{~m}_{3}$ & LTU & 716 & 888 & 900 & 900 & 900 & 900 \\
\hline & $1000 \mathrm{~m}_{3}$ & Total & 1,973 & 2,654 & 2,700 & 2,700 & 2,700 & 2,700 \\
\hline
\end{tabular}

Source: Estimates provided by the national teams and own projections.

With respect to final energy consumption, the relative importance of the industrial subsectors differs substantially among the Baltic countries. Manufacturing of basic metals delivers an almost negligible contribution in all three countries. Non-metallic minerals, notably cement, however, contribute to about $14-17 \%$ of the total final energy consumption of industry in all Baltic countries (Figure 29). The chemical industry is very important in Lithuania and notable in Estonia, but not so in Latvia. Paper and pulp manufacturing is notable only in Estonia, where wood-based paper and pulp production is projected to remain competitive. On the other hand, mechanical wood processing industries appear to be very important in the Baltic countries - most notably in Latvia and Estonia, but also in Lithuania. One should note that the significant role of wood processing also contributes to the good prospects for maintaining the supply of bioenergy based on wood-based by-products and residues. Finally, foodstuff industries are quite important in Lithuania, even in terms of final energy. 
F-gas emissions are usually also mainly attributable to the industrial sector, and were all assumed to be so in the present study. The F-gas emissions baselines were defined according to national WEM projections, and the WAM measures from PaMs reports were forced in the BPO and 2DS. Consequently, Baltic F-gas emissions are assumed to decrease by $60 \%$ by 2030 already in the 4DS, in accordance with WEM projections of PaMs reports.

Figure 29: Shares of industrial sectors in the final energy consumption of industry in 2015 (excluding non-energy use)

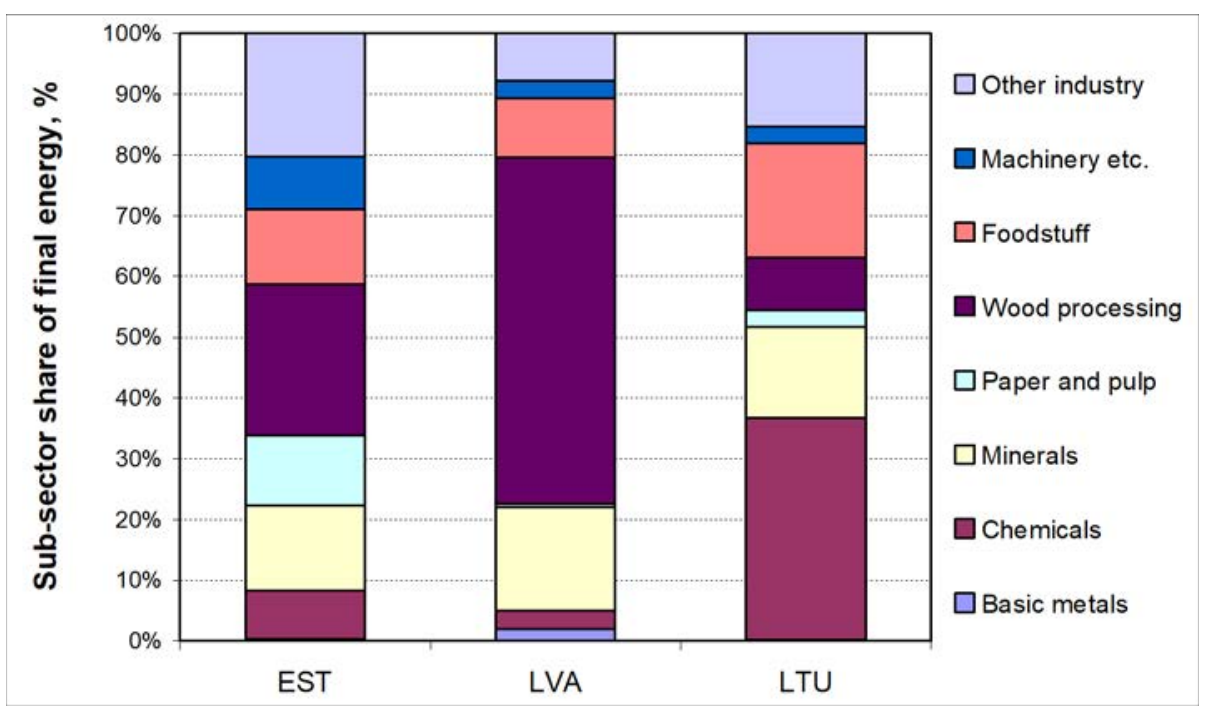

Key point(s): The industrial structure is quite different among the Baltic countries, but energy-intensive industries account for $60-80 \%$ of the final energy consumption.

In the scenarios, industrial final energy consumption tends to increase in line with production volumes, although energy efficiency improvements are, of course, included in the model and reduce the growth in final energy requirements. Total final energy increases by $17 \%$ from 2015 to 2030 and by $22 \%$ by 2050 (Figure 30). The consumption of fossil fuels, however, remains roughly at the 2015 level until 2030, and then starts declining already in the $4 \mathrm{DS}$. Among fossil fuels, the consumption of coal increases in all scenarios until 2030, mainly due to the increasing cement production volumes. But the consumption of mineral oil decreases gradually, reaching a $60-70 \%$ reduction by 2050. The consumption of natural gas remains stable until 2030 but then starts to decline. Bioenergy consumption increased substantially in the Baltic industry during $2010-2015$, and in the results, it increases further by $10-20 \%$ by 2030 and $50-60 \%$ by 2050. Biomass or waste is also used as a supplementary fuel in cement kilns, expanding most prominently in the $2 \mathrm{DS}$.

The role of industrial self-production of electricity has not been significant in the Baltic countries; it was only about 1.1 TWh in 2015. Most of the fossil fuel-based industrial CHP will be phased out by 2030, which in turn means that industrial process heating is to some extent shifting to steam-only plants. Industrial biomass-based CHP remain in the generation mix, and is even increasing in Latvia and Lithuania (Chapter 3). 
According to the results, industrial sector GHG emissions increase until 2030 and then turn to a declining trend, but further deep reductions would occur only with high $\mathrm{CO}_{2}$ prices that would make CCS and additional substitution of fossil fuels with bioenergy and electrification competitive (Figure 30). CCS contributes to a reduction of $2.6 \mathrm{MtCO}_{2}$ in the $2 \mathrm{DS}$, where total emissions are reduced by about $50 \%$ by 2050 .

Only in the $2 \mathrm{DS}$, where the $\mathrm{CO}_{2}$ price increases close to $100 \mathrm{EUR} / \mathrm{tCO}$, will there be investment in technologies that are not yet commercially viable for reducing industrial emissions. The most important of these technologies are related to CCS in cement and ammonia production. The role of other non-commercial technologies is not significant in the results, and may thus in fact be underestimated. Decarbonisation of industry could, in fact, be easier than estimated here if some of the new technologies turn out to be cheaper than expected. Nonetheless, the results are reasonably well in line with those of the IEA ETP, which also highlights the difficulty of achieving deep reductions in industrial emissions without CCS.

Figure 30: Development of final energy consumption in the industrial sectors

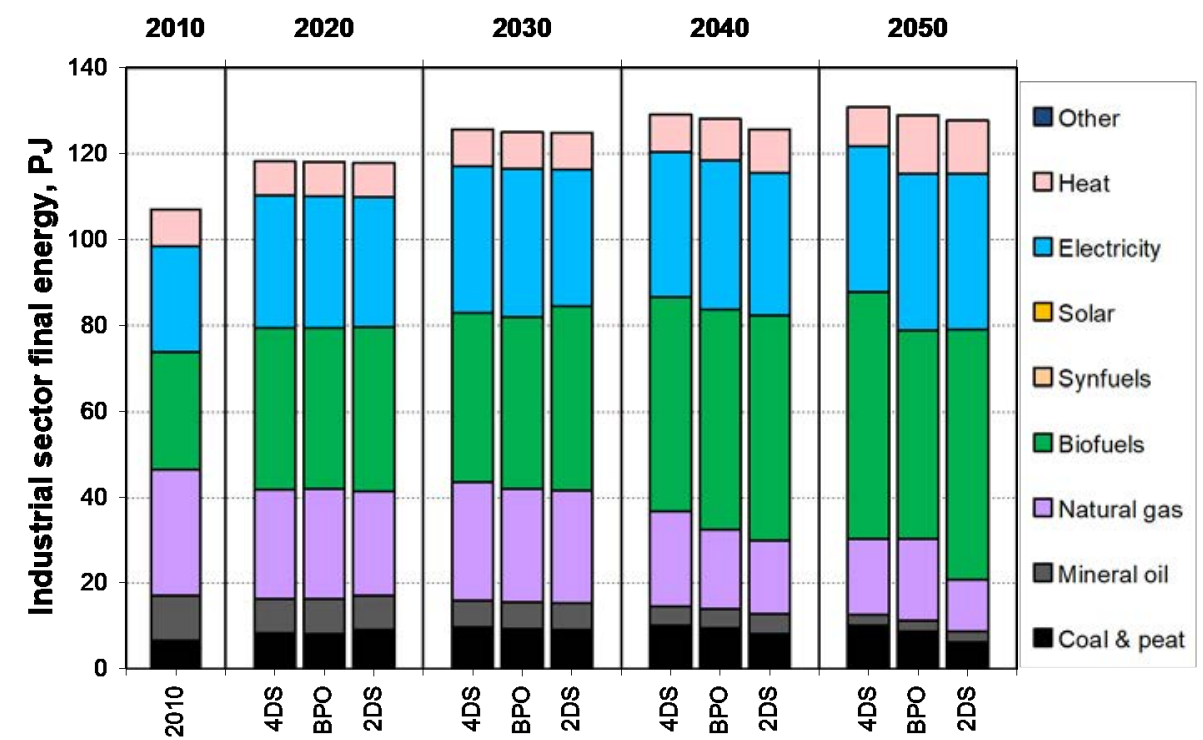

Key point(s): Final energy consumption in the industrial sector shifts from fossil fuels to biofuels and electricity, but more radically only after 2030 . 
Figure 31: Development of industrial sector GHG emissions by source category

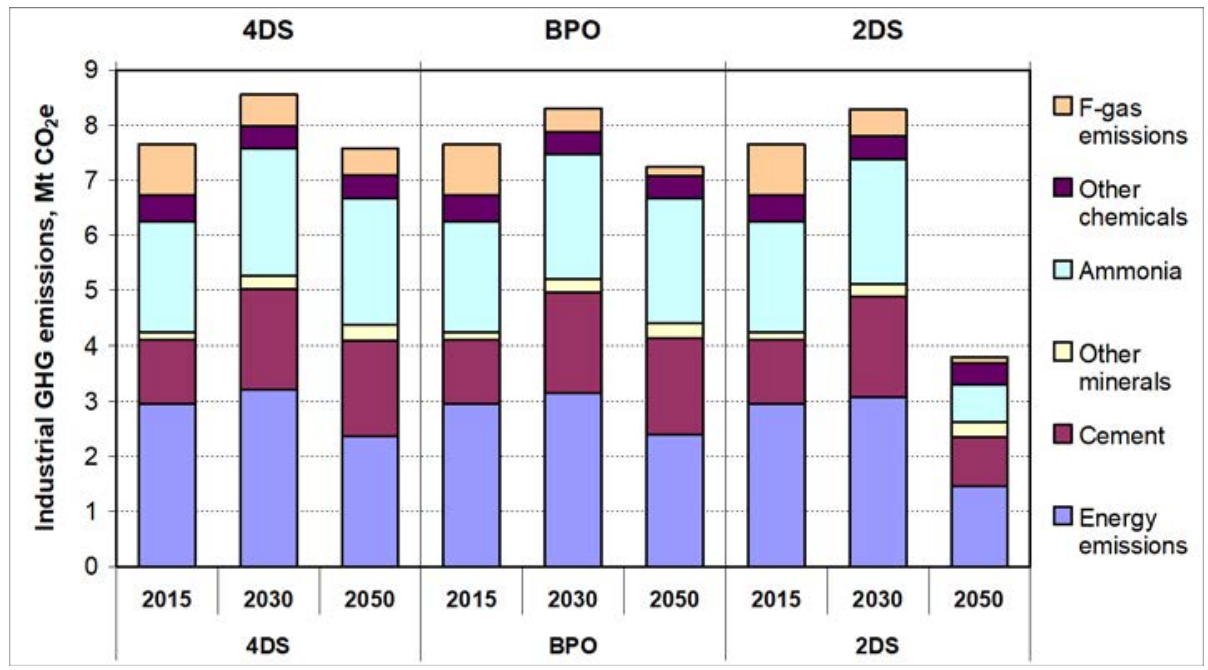

Key point(s): Industrial sector emissions tend to increase in the Baltic countries along with the projected growth in industrial output. CCS would be necessary for achieving deep reductions in process emissions, as realised in the 2DS after 2040 .

\subsection{Other sectors}

The remaining sectors distinguished here in view of the total GHG emissions balance are the fuel refining sector, agriculture and waste management. In total, these other sectors accounted for $28 \%$ of the total Baltic GHG emissions in 2015, amounting to 14.1 $\mathrm{MtCO}_{2} \mathrm{e}$ (Figure 32).

In comparison to the EU 28 as a whole, agricultural emissions are much more significant in the Baltics, while the contribution of waste management emissions is roughly the same in the two regions. However, among the Baltic countries, the significance of these other sectors differs considerably, as will be discussed in more detail below.

\subsubsection{Fuel refining}

Within the energy sector, fuel refining can be distinguished as a sector separate from electricity and district heat activities. Fuel refining makes a relatively small contribution to the overall GHG emissions in the Baltic countries, about $5 \%$ in 2015. In Latvia, fuel refining is currently almost negligible (no oil refining, no coking plants, only small-scale charcoal and peat refining plants). But in Estonia and Lithuania, the sector contributes to $7 \%$ of total GHG emissions, and about $10 \%$ of total $\mathrm{CO}_{2}$ emissions. In Estonia, most of the emissions are related to oil shale processing and refining, and in Lithuania to conventional oil refining. 
Figure 32: Greenhouse gas emissions from other sectors in the overall GHG balance (2015)

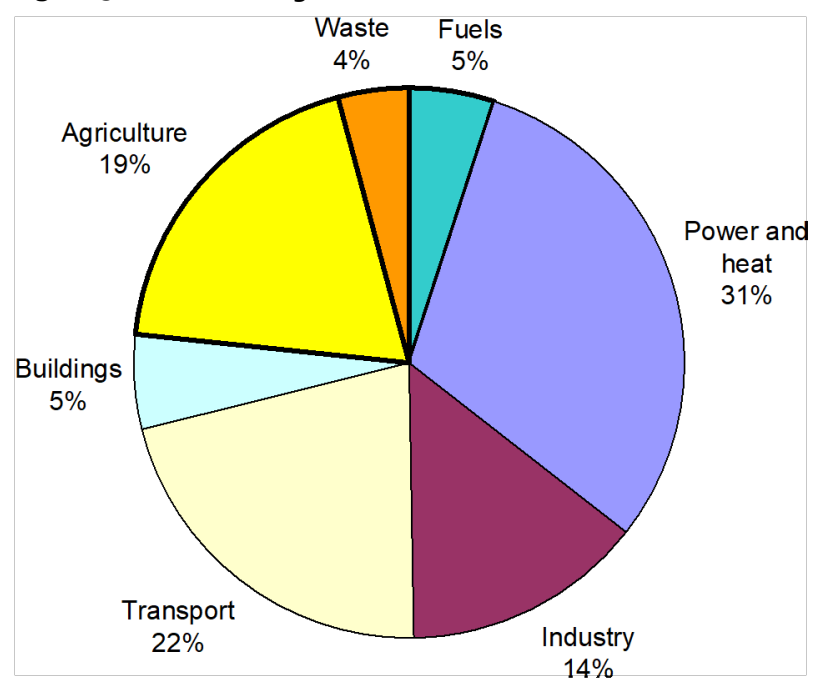

The oil shale industry in Estonia has been modelled using a rather simplified approach. Firstly, the mining of oil shale was assumed to stay at least at the level of 160 PJ until 2030 , but was then assumed to be allowed to decline linearly to 100 PJ by 2050 . The minimum level of oil shale mining was thus defined according to a fixed projection. The main options for utilising oil shale for energy include direct use as a fuel in electricity and district heat, and fuel conversion. As the utilisation in electricity and district heating was constrained according to the Balmorel model results, there was practically no room left for optimising the split between that and the use of oil shale for shale oil production.

The resulting trajectories for oil shale mining and shale oil production were thus practically identical in the three scenarios considered. The development of the production volumes is shown in Figure 33. In all scenarios, the utilisation of oil shale is shifting from use in electricity and district heating to the refining of shale oil, to the extent that all mined oil shale will be refined into shale oil by $2050 . \mathrm{CO}_{2}$ emissions from the refining process will also increase in line with increasing shale oil production, but due to the new plants being more efficient, the increase in emissions is projected to be about 50\% between 2015 and 2030.

The oil refining volume in Lithuania is assumed to remain at about $300 \mathrm{PJ}$ in 2030, with $\mathrm{CO}_{2}$ emissions of about $1.8 \mathrm{Mt}$, but is then allowed to decline by about $50 \%$ by 2050, in line with the declining consumption of oil in Europe. In the results, the oil refining volumes decline in the same way in all scenarios (Figure 36 ).

The supply of biofuels for transport in the Baltic countries is currently mainly based on domestic production. In 2015, about 7 PJ of biodiesel and 0.5 PJ of biogasoline were produced in Latvia and Lithuania. According to the results, domestic production of transport biofuels would increase only modestly by 2030 in all scenarios, but thereafter significant expansion into new production facilities would become competitive especially in the 2DS but also in the BPO scenario (Figure 37). 
Figure 33: Development of oil shale production and oil refining volumes

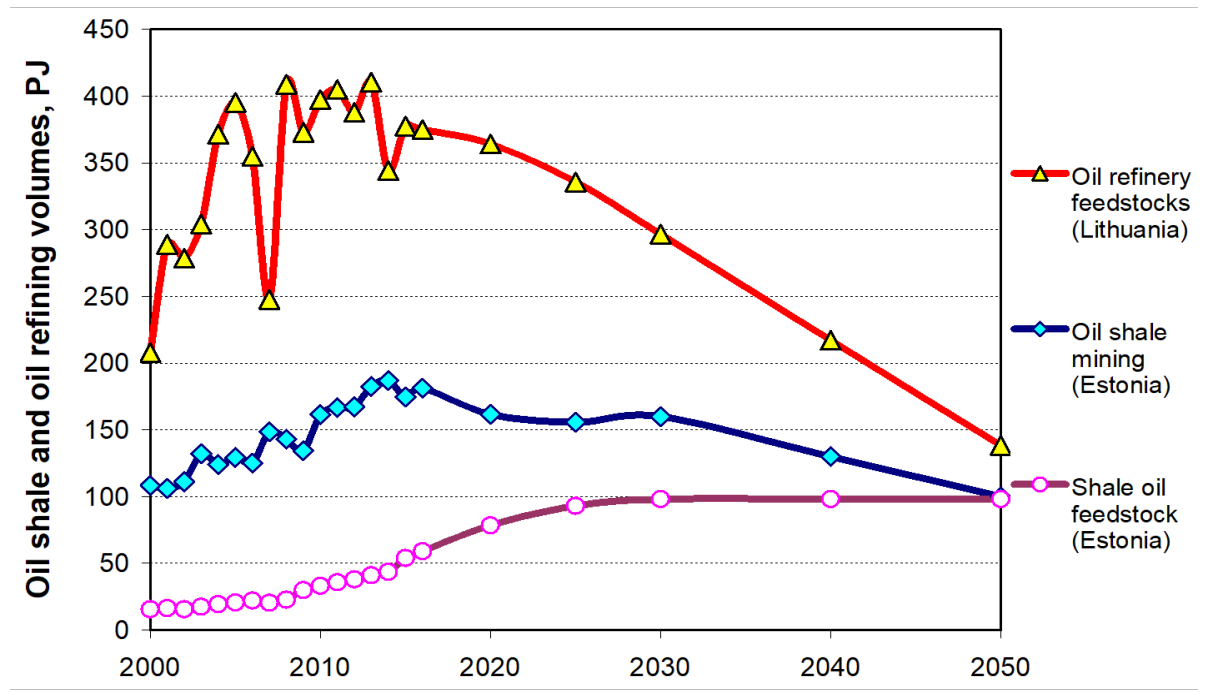

Key point(s): Oil shale mining and oil refining are notable energy industries in Estonia and Lithuania. Lithuanian oil refining is projected to decrease in volume, while oil shale refining will increase in Estonia.

Figure 34: Balance of transport biofuels in the Baltic countries

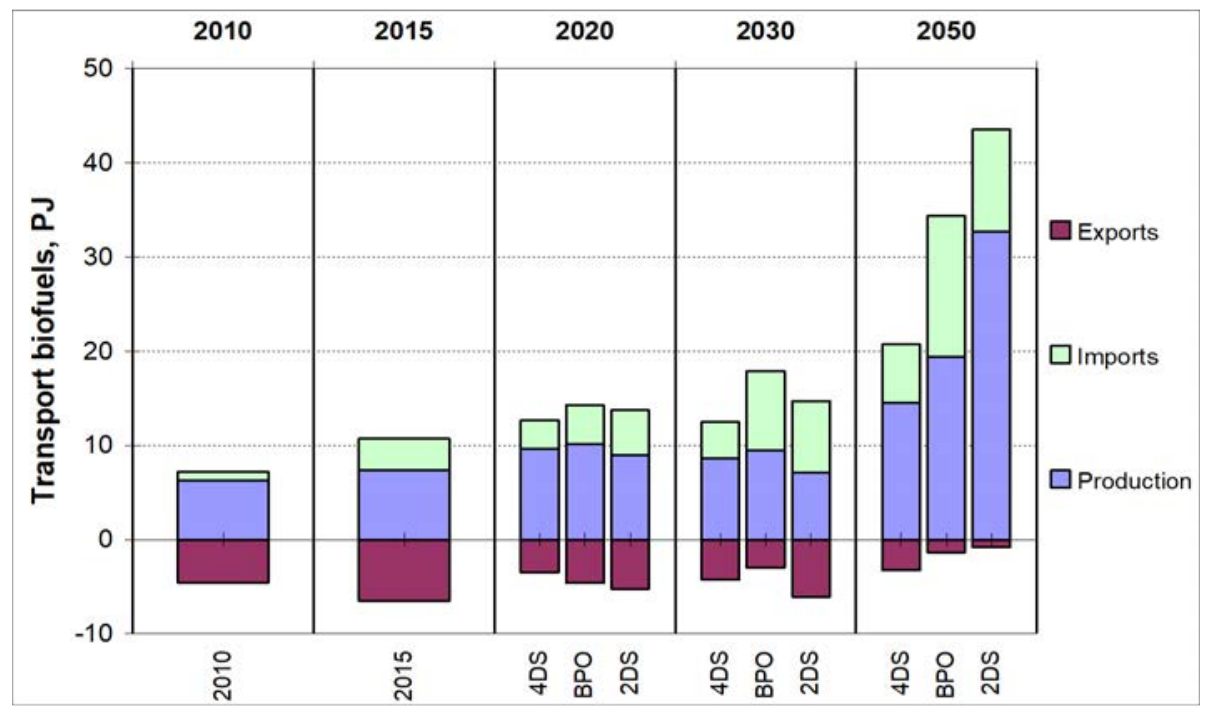

Key point(s): Until 2030, transport biofuels are expected to increase only a modest amount in the Baltic countries, but the more stringent emissions targets will require substantial imports and/or own production of liquid biofuels in the $2 \mathrm{DS}$ and $\mathrm{BPO}$.

\subsubsection{Agriculture}

Agriculture is a significant source of GHG emissions in the Baltic countries, contributing to about $19 \%$ of all Kyoto gas GHG emissions in 2015 . The share of all GHG emissions attributable to agriculture was highest in Latvia $(27 \%)$, followed by Lithuania $(23 \%)$ and 
Estonia (9\%). Total GHG emissions from agriculture were 9.5 $\mathrm{MtCO}_{2} \mathrm{e}$ in 2015 . Emissions from agriculture include $\mathrm{CO}_{2}$ from fuel combustion, $\mathrm{CH}_{41}$ emissions from enteric fermentation, $\mathrm{CH}_{4}$ and $\mathrm{N}_{2} \mathrm{O}$ from manure management and direct and indirect $\mathrm{N}_{2} \mathrm{O}$ and $\mathrm{CO}_{2}$ emissions from agricultural soils, including liming and urea application. The most important sources of emissions are agricultural soils (51\%) and enteric fermentation (32\%).

Note that the emissions from energy consumption in agriculture, forestry and fishing are included in this sector (as they are not considered elsewhere in this report). On the other hand, in the GHG inventories, all emissions from energy consumption are included in the "fuel combustion" category, which also contains the corresponding sectoral subcategory (1.A.4.c. Agriculture/Forestry/Fishing).

The historical development of agricultural GHG emissions in the Baltic countries is illustrated in Figure 35, together with the baseline projection according to the national WEM submissions extrapolated to 2050 by TIMES-VTT in the $4 \mathrm{DS}$. One can immediately see that agricultural activities underwent dramatic changes between 1990 and 2000 , whereby emissions decreased by as much as $60 \%$ in just one decade. Since 2000 , however, agricultural production has experienced a revival in the Baltic countries, and the baseline projections assume that emissions from this sector will increase slowly until 2040 in all main source categories. Despite the expected decrease in population, total agricultural emissions are thus projected to increase by about $14 \%$ by 2030 and by $19 \%$ by 2050 . The highest increase of agriculture emissions is projected for Latvia (15\%), followed by Lithuania (11\%), and Estonia (1\%) in 4DS by 2030 compared to 2015.

Figure 35: Historical and baseline development of GHG emissions from agriculture in the Baltic countries (national WEM projection extrapolated by TIMES-VTT to 2050)

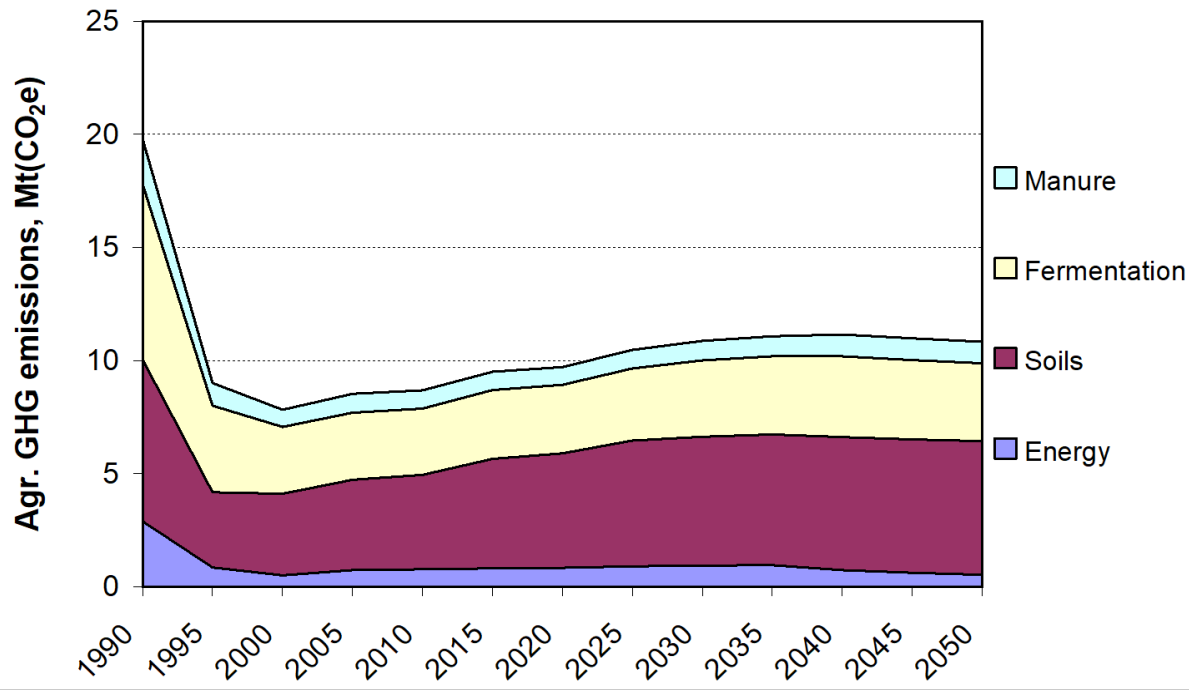

Key point(s): Baltic agriculture experienced a dramatic decline in 1990-2000, but the baseline emissions from agriculture are projected to increase until 2040 in line with increasing agricultural production and livestock numbers.

Note: $\quad$ Emissions from energy consumption in agriculture, forestry and fishing are included in this figure. 
Apart from energy consumption, emission reductions are, in general, rather complex to achieve in the agricultural sector. Most of the measures in the national PaMs were already included in the WEM scenarios and thus included in the modelled baseline. The impact of the national policies is relatively small in the national WEM and WAM scenarios until 2035. For Estonia and Lithuania, no impact was estimated, but for Latvia, a $10 \%$ reduction in methane emissions from enteric fermentation was assumed in the WAM scenario - leading to a reduction of about $2.6 \%$ in the total sector emissions according to the WEM projection.

The emissions from fuel combustion are modelled for buildings, grain dryers, and work machines, but make up only a small proportion of the total agricultural GHG emissions. According to the National Inventory Reports, they were most significant in Estonia, making up $21 \%$ of the total emissions in 2015 , while in Latvia they accounted for $11 \%$ and in Lithuania only $2 \%$ of the total. The very low figure for Lithuania indicates that some of the fuels consumed in this sector may not have been allocated correctly, since the total agricultural fuel consumption is given as only $3.3 \mathrm{PJ}$. In 2015 , total fuel consumption was reported to be about $15 \mathrm{PJ}$ in the Baltic countries, consisting of oil (74\%), gas (12\%), biomass (13\%) and coal/peat (1\%). The oil consumption (about $11 \mathrm{PJ}$ ) is mainly attributable to diesel oil for work machines (90\%). Therefore, the available emission reduction measures should concentrate to energy efficiency of machinery and buildings, mixing bio-components into the fuel, and optimising the use of machines. In total, the potential would thus be close to $100 \%$, by increasing the use of biodiesel. However, assuming that biodiesel would not be competitive for agricultural use, in the short term, the potential of the other options may be estimated to be below $20 \%$ by 2030 .

The emissions from agricultural soils consist mainly of $\mathrm{N}_{2} \mathrm{O}$ emissions from fertilizer uses, crop residues, histosols, and indirect $\mathrm{N}_{2} \mathrm{O}$ form leaching and deposition. Reducing fertilizer use is possible by, for example, restricting nitrogen usage per hectare, requiring strict fertilization plans, and adopting organic farming, but detailed estimates of the potentials were not available for this project. Increasing organic farming was not considered as an endogenous option in the modelling. The reduction options for soil emissions included in the model were thus limited to using nitrification inhibitors and a generic option of reduced fertilizer use, without any detailed national considerations. For methane emissions from enteric fermentation, generic options for improving the precision and quality of livestock feeding were included, albeit the total emission reduction potentials are again quite small. For manure management, additional farmscale anaerobic digestion technologies were included. The various options included in the model have a total additional reduction potential of about $20 \%$ by 2030 , and about $30 \%$ by 2050 , of total agricultural emissions.

In the Baltic policies scenario (BPO), the targets reflected in the national WAM projections have been included as fixed limits on the sector emissions. However, since there is also an overall ceiling for the ESS emissions, the model was free to implement even higher emission reduction measures, depending on their cost-efficiency, to reach the overall emissions targets. According to the results, total Baltic emissions will decrease by only $3.3 \%$ from the baseline ( 4 DS) by 2030 , and by $8.4 \%$ by 2050 (Figure 36 and Figure 40 ). It thus turns out that until 2030, reductions beyond the national WAM 
projections would not be cost-effective, but some additional measures would be implemented between 2030 and 2050, and would be distributed across all source categories. Most notable proportional reductions would occur in energy consumption, where results indicate $30 \%$ emission reductions from the $4 \mathrm{DS}$ by 2050 .

Figure 36: Development of agricultural and waste management emissions according to the national WAM scenarios, by country

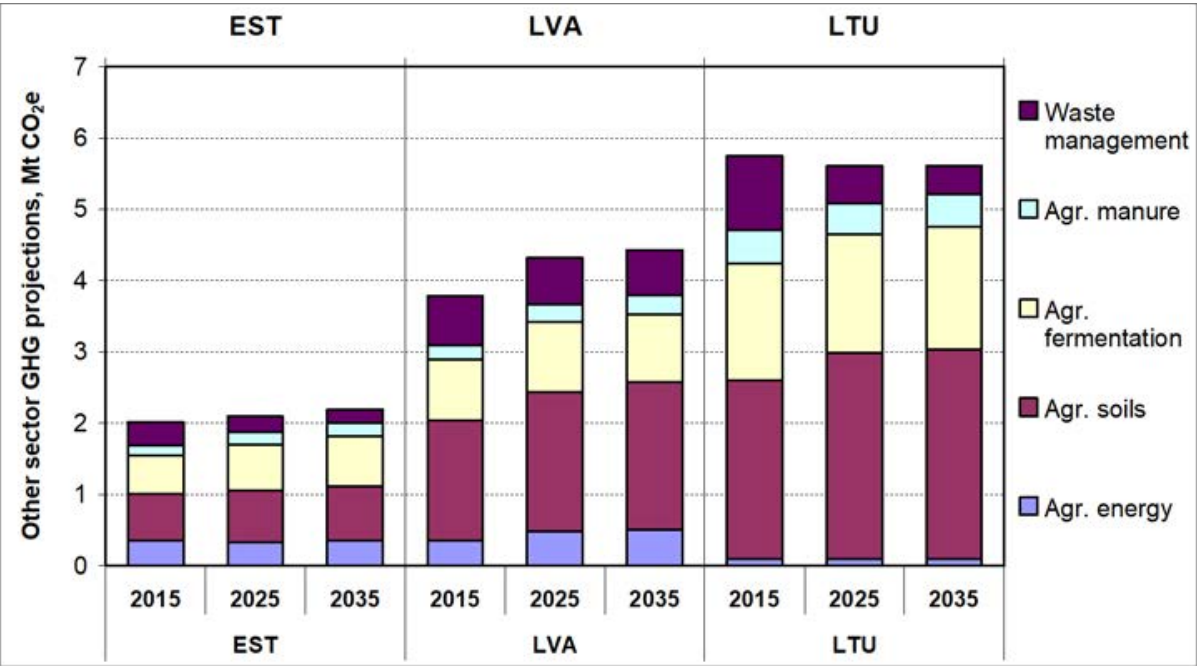

Key point(s): Emissions from the agriculture and waste management sectors are mostly methane and nitrous oxide. The national WAM scenarios only indicate considerable reductions in the waste management emissions.

Note: $\quad$ Emissions from energy consumption in agriculture, forestry and fishing are included in this figure.

Figure 37: Development of agricultural and waste management emissions in the Baltic countries in the TIMES scenarios

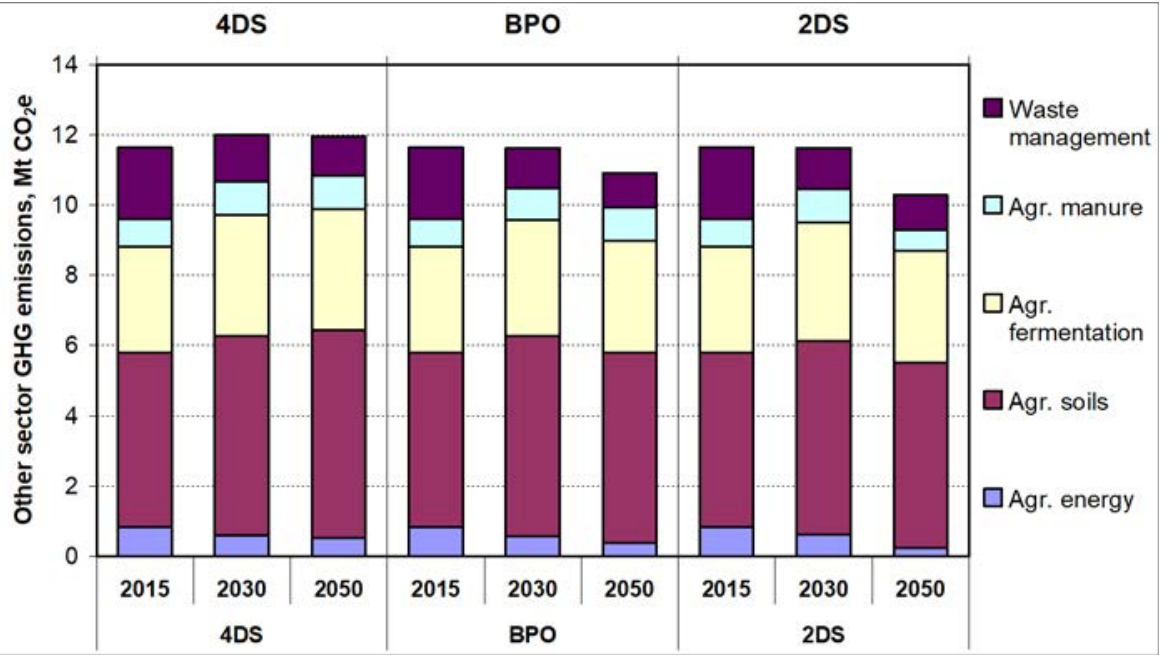

Key point(s): Non- $\mathrm{CO}_{2}$ emissions from agriculture are among the most difficult GHG emissions to reduce, and remain significant in the Baltic countries until 2050. 
Unlike the BPO scenario, national policies were not forced to be implemented in the $2 \mathrm{DS}$, but measures were more freely optimised. In the $2 \mathrm{DS}$, the total Baltic emissions decrease from the baseline by $3.6 \%$ by 2030 , and by $14 \%$ by 2050 (Figure 37 ). The reductions were thus almost identical in 2030, but more pronounced in 2050. Compared to 1990 levels, emissions have now been reduced by over 50\%. Again, the deepest reductions occur in energy consumption, by almost $60 \%$ compared to the $4 \mathrm{DS}$, but are also notable in manure management. However, even under the strict policies of the $2 \mathrm{DS}$, the reductions in this sector remain quite small, which is in line with the general viewpoint that agriculture has been identified as the sector that probably presents the most difficulties in efforts to achieve deep emission reductions.

\subsubsection{Waste management}

Waste management emissions account for $2 \%$ of the total GHG emissions in Estonia, and $5-6 \%$ of the total emissions in Latvia and Lithuania (Figure 36). Waste management practices have undergone a big transition in Europe during the past two decades, but the EU member states are to some extent at different stages of this transition.

In $2015,360 \mathrm{~kg}, 400 \mathrm{~kg}$ and $450 \mathrm{~kg}$ of municipal waste was generated per capita in Estonia, Latvia and Lithuania, respectively. The amounts are somewhat lower than in the Nordic countries, where the average was about $500 \mathrm{~kg}$ per capita in 2015. Estonia has already reduced the share of landfill waste to below $10 \%$. However, the share of landfill waste still accounted for about $62 \%$ in Latvia and about 54\% in Lithuania in 2015. Despite the differences, calculated on a per-capita basis, the Baltic emissions from waste management are roughly comparable to the average in the EU and Nordic countries (Figure 38 ).

Recycling, reusing and using waste for energy could nonetheless be increased considerably in Latvia and Lithuania, considering that the share of waste ending in landfills far exceeds the EU average. The baseline projection for Lithuania does indeed already assume a steep reduction in the emissions from solid waste management (Figure 39).

As to the options for reducing waste management emissions, the model includes options for reducing landfill waste by increasing the use of waste for energy, enhanced landfill gas recovery and utilisation, composting and anaerobic digestion of biodegradable waste, and more efficient anaerobic reactors in wastewater treatment plants. The generic technology data for these various options have been taken primarily from the ESTAP TIAM database, as there were insufficient resources to update them within the project to reflect the particular characteristics of the Baltic systems. 
Figure 38: GHG emissions from waste management per capita in 2015

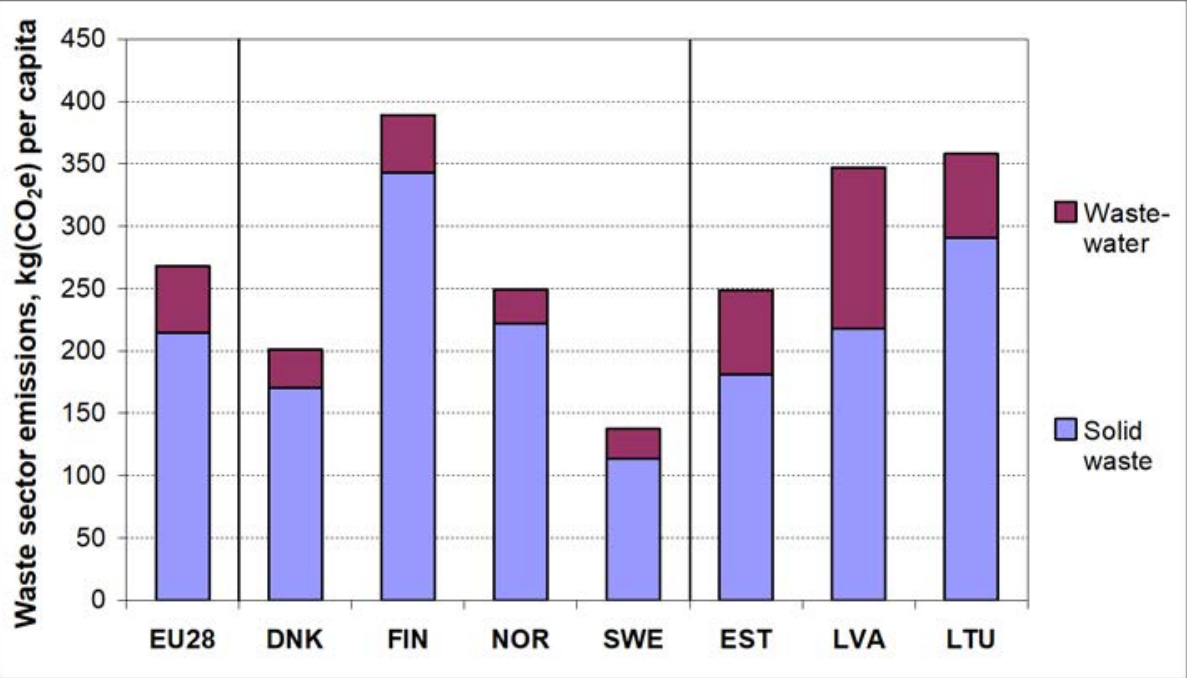

Key point(s): Overall emissions from the waste management sector in the Baltic countries are roughly in line with the EU 28. However, wastewater emissions are considerably higher in Latvia.

Figure 39: Baseline development of waste management emissions in the Baltic countries (national WEM projections extrapolated by TIMES to 2050)

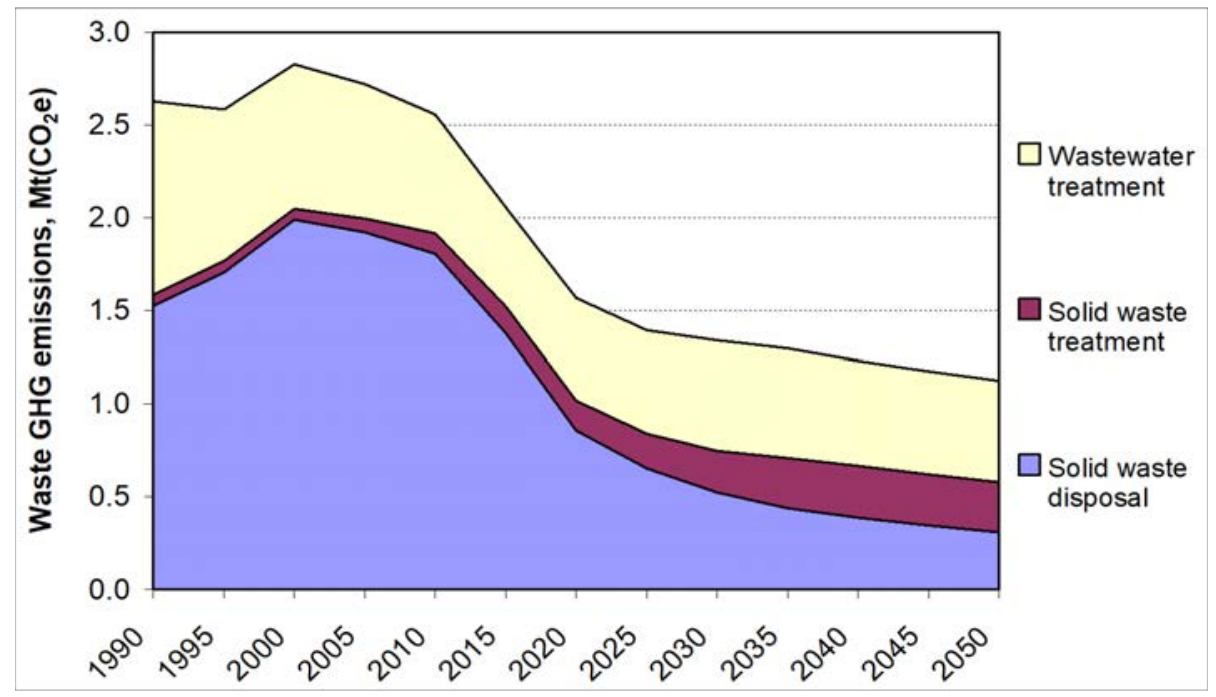

Key point(s): Emissions from waste management decrease by $45 \%$ by 2050 already in the baseline. The most significant additional reduction potential is to be found in wastewater treatment systems. 
Compared to 2015 levels, waste management emissions in the Baltic countries decrease already in the baseline by $35 \%$ by 2030 and by $45 \%$ by 2050 (Figure 39). Among the Baltic countries, the greatest reductions are projected for Lithuania, by $54 \%$ by 2035 , whereas Estonian emissions are projected to decrease by $43 \%$ and Latvian only about $10 \%$. The baseline projections reflect the differences in the stages of this transition, but the Latvian WEM projection can also be viewed as more conservative than the Lithuanian and Estonian.

As mentioned earlier, under the BPO, the targets reflected in the national WAM projections have been included, but the model may implement even higher emission reduction measures, depending on their cost-efficiency, in order to meet the overall ceiling for ESS emissions in 2030 and beyond. According to the results, total Baltic waste management emissions would decrease by $44 \%$ by 2030 and by $52 \%$ by 2050 (Figure 36 and Figure 37). By 2030, Estonian emissions would decrease by $47 \%$, Latvian by $23 \%$ and Lithuanian by $57 \%$, of which the Estonian and Latvian reductions are indeed higher than those included in the national WAM scenarios. The additional measures in Estonia and Latvia involve both solid waste management, with enhanced landfill gas recovery and an increase in anaerobic digestion, and digesters in wastewater management.

In the 2DS, where the national policies were not forcibly implemented, total Baltic waste management emissions would decrease by $42 \%$ by 2030 and $52 \%$ by 2050 . In other words, the results indicate that some of the measures included in the BPO were not deemed cost-effective by the model. In Latvia, reductions remained at the BPO level, but they were somewhat less ambitious in both Estonia and Lithuania. However, by 2050 the reductions converged to almost identical levels with the BPO, being $53 \%$ in Estonia, $37 \%$ in Latvia and $67 \%$ in Lithuania.

Increasing the reuse and recycling of waste materials was not explicitly considered in the scenarios, and the related PaMs were already included in the national "with existing measures" projection scenario.

\subsection{Electricity consumption increasing due to assumed growth and electrification}

Electricity consumption is projected to increase in all sectors despite the energy efficiency improvements, due to a) assumed growth of wealth, industry production, transport demand and floor areas, and b) electrification offers the possibility of reducing emissions and increasing renewable energy in all sectors - from transport to buildings and district heating. 
In industry, the main driver is the assumed increase in industrial production, as electricity's share of sectoral final energy remains approximately at the 2015 level until 2050 (Figure 40). In the residential and services sectors, growth in electricity consumption comes from increases in floor areas, number of appliances, and electrification such as heat pumps. In the transport sector, growth comes from a strong increase in assumed transport demand and intense electrification from 2030 onwards. The increase in energy conversion is due to large heat pumps for district heating.

Figure 40: Electricity's share of sectoral final energy in the BPO (left panel) and electricity consumption in the Baltic countries
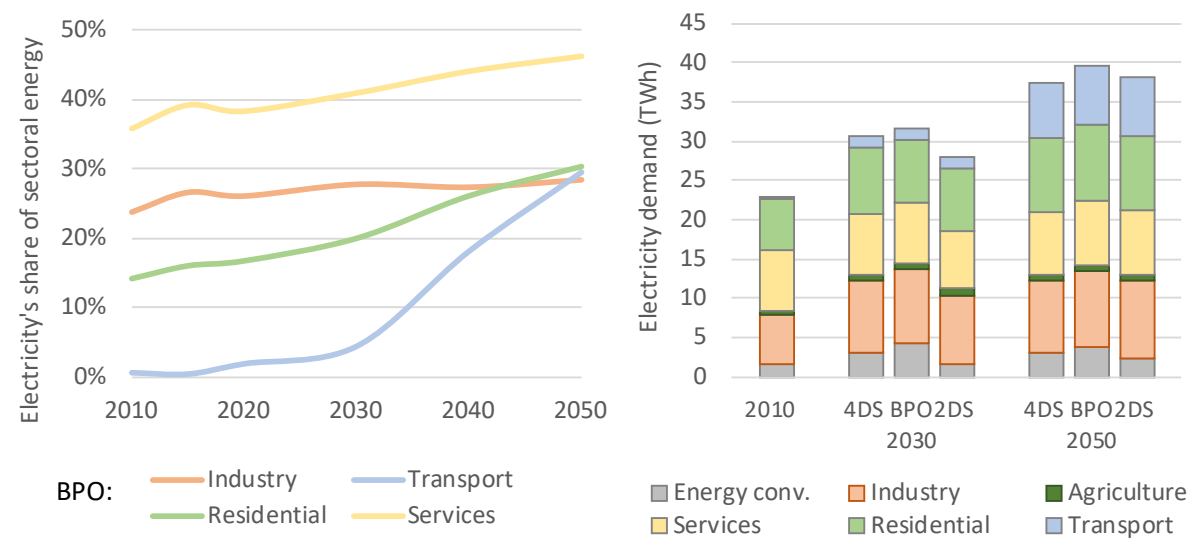

Key point(s): Electricity consumption increases due to assumed growth of industry production, transport demand and building floor areas, and modelled electrification.

Comparisons with other studies show that all of them expect electricity consumption to increase, but the BENTE results are at the high end of the scale. Figure 41 compares electricity consumption results for the Baltic countries from BENTE, national studies and the European Commission's PRIMES modelling. 
Figure 41: Comparison of electricity consumption projections presented by BENTE, PRIMES and national scenario studies
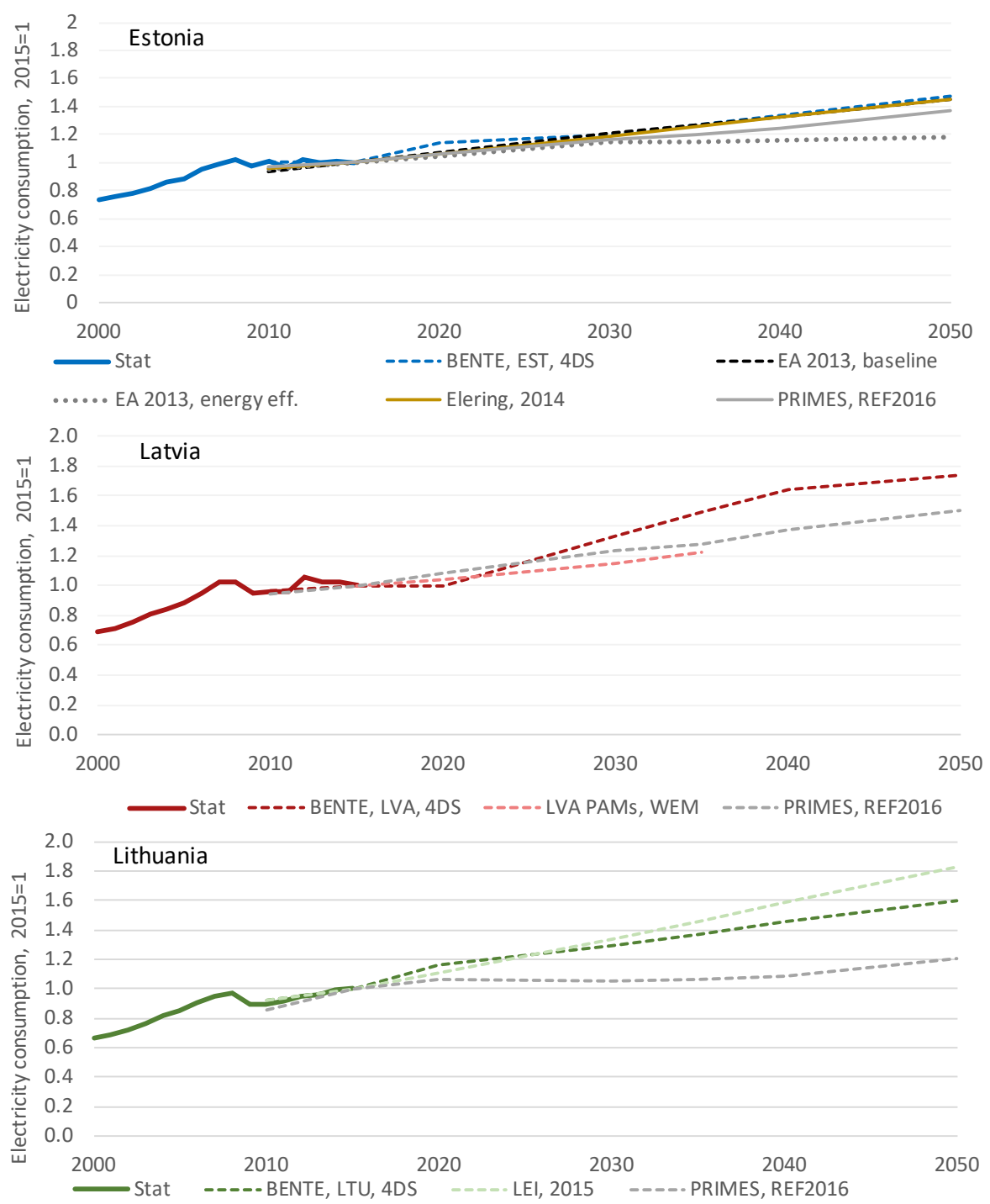

Key point(s): Electricity consumption projections are in line with Estonia's national projections, higher than Latvia's national projections, lower than Lithuania's national projections, and higher than PRIMES projections.

Note: $\quad$ Results are indexed because there were some differences in definitions, e.g. in losses, among the studies.

Source: $\quad$ Projections for Estonia from Elering (2014), Ea (2013). Projections for Latvia from Ministry of the Environment of Latvia (2017). Projections for Lithuania from LEI (2015). PRIMES projections from EC (2016a). 
If assumed growths, in industry production for example, do not come to fruition, the growth of electricity consumption will be smaller. In addition, if modelled electrification rates are not realised, electricity consumption may decrease due to efficiency improvements. If efficiency improvements are also not realised, electricity consumption could follow the status quo. All these assumption categories should be studied further.

If electricity consumption was to increase by less than projected here, the amount of imported electricity should decrease in the scenarios and it should be easier and cheaper to achieve domestic electricity generation targets. 



\section{Towards renewable and low- carbon electricity and district heating}

\subsection{Key findings}

- Renewable energy is becoming the cheapest option for new electricity generation and European electricity systems will undergo a transformation to very high renewable shares in the coming decades.

- In the absence of sustainable policies to facilitate cost-effective local generation, the Baltic countries are likely to become large net importers of electricity from the Nordic countries and Russia. This development will be instigated by three main factors:

- Increasing electricity consumption in the Baltic countries as a consequence of economic growth and electrification.

- Incentives to locate renewable energy generators in the Nordic countries, which provides plentiful resources and good political framework conditions, allowing net export of clean electricity to the rest of Europe, including the Baltic countries.

- Phasing out of oil shale-based power plants in Estonia in accordance with prevailing policies.

- Modest subsidies (or price guarantees) would incentivise renewable electricity generation in the Baltics countries. Without political support, the deployment of new domestic generation capacity might be limited before 2030 .

- Electricity use in heat pumps for district heating will become more and more competitive as the share of variable renewables in the power system increases. Further investigations are required to clarify the realistic and economically sustainable potential. 


\subsection{Opportunities and threats}

- Onshore wind power is already an attractive source of energy in the Baltic countries and with the cost of solar PV and offshore wind decreasing, projections show that these technologies could play a prominent role in the future Baltic electricity supply if proper framework conditions are provided.

- The Baltic countries possess large biomass resources, but the wind and solar price drops observed in recent years make it difficult for biomass to compete in the electricity sector.

- The deployment of renewable energy will reduce the import dependency of the Baltic countries and may provide a hedge against high electricity prices for consumers if the deployment of renewables is incentivised through contracts for difference (CFDs).

- The Baltic electricity systems hold good opportunities for integration of wind and solar power. The most important integration measures are local hydropower (including large-scale pumped storage) interconnectors to the hydropowerdominated Nordic electricity system and flexible thermal-based generators. In the longer term, the widespread district heating schemes could also play a key role, through power to heat solutions, i.e. electric boilers and heat pumps.

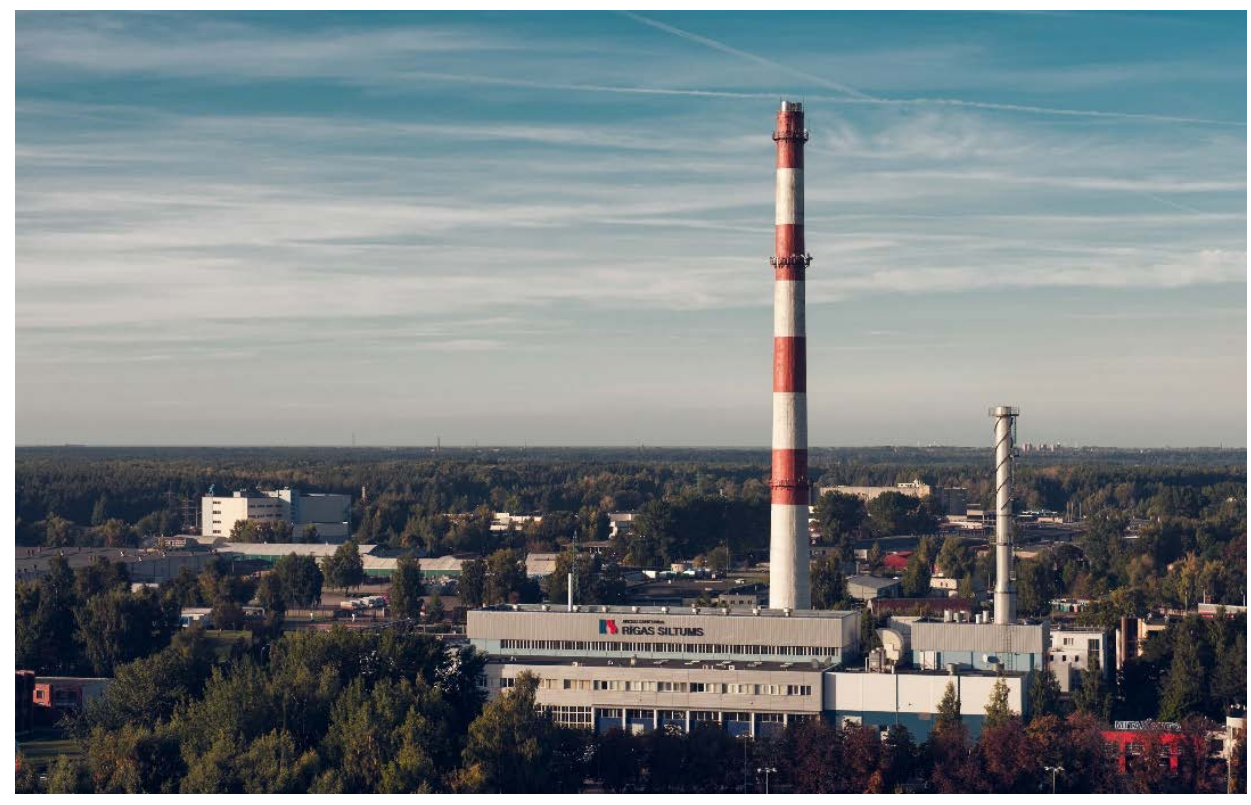

\subsection{Current situation}

The three Baltic countries used to be so-called "energy islands" with no electricity connections to the rest of Europe. In recent years, this situation has changed with the establishment of Estlink 1 and 2 connecting Estonia and Finland, the LitPol Link 
between Lithuania and Poland and the Nordbalt interconnector linking Sweden and Lithuania. All in all, these connections provide $2200 \mathrm{MW}$ of interconnection capacity between the Baltic countries and the rest of the EU. For comparison, the average load of all three Baltic countries was approximately $2800 \mathrm{MW}$ in 2016. The Baltic Energy Market Interconnection Plan (BEMIP) and EU infrastructure funds have been very instrumental to the development of the new interconnectors to the EU. In addition, the Baltic countries have connections to Russia of approx. $1000 \mathrm{MW}$ and to Belarus of approx. $1300 \mathrm{MW}$.

The sources of electricity generation are very different from country to country, but a common feature for all three Baltic countries is a very well-developed district heating network in most towns.

In Estonia, electricity generation mainly takes place at large oil shale power plants, located at the oil shale mines in the northern part of country. Oil shale is a cheap source of electricity production, but it is also polluting and has a high $\mathrm{CO}_{2}$ footprint. The city of Tallinn is mainly supplied with heat from biomass combined heat and power. The wind power capacity in Estonia has been growing steadily in recent years and amounted to $310 \mathrm{MW}$ by the end of 2016.

The Latvian electricity production is dominated by hydropower, which also represents more than half of the total installed power capacity. Most of the hydropower is produced by three power stations located along the river of Daugava. The hydropower plants have been designed for the provision of peak and intermediate loads, equipped with limited storage capacity sufficient to deal with intraday variations in electricity consumption. Other important generators are two relatively new combined cycle CHP units providing district heating for the city of Riga. Wind power plays a very limited role in Latvian electricity supply, providing less than $70 \mathrm{MW}$ of capacity.

Since the closure of the Ignalina nuclear power plant in 2009, Lithuanian electricity generation has been dominated by natural gas and large-scale imports of electricity from neighbouring countries. In 2016, imports covered about two-thirds of total consumption. Lithuania has several thermal gas/oil plants including thermal CHPs, some hydropower stations and one hydro storage plant. Lithuanian Power Plant (LPP) in Elektrenai is the largest thermal power station in the country and includes a new 455 MW combined cycle unit, which became operational in 2012. The Kruonis Pumped Storage Plant, with a power capacity of $900 \mathrm{MW}$, was originally established to provide back-up for the Ignalina nuclear power plant. In recent years, wind power capacity has been growing steadily and total capacity amounted to 509 MW by the end of 2016 . 
Figure 42: Electricity generation in Lithuania, Latvia and Estonia in 2016

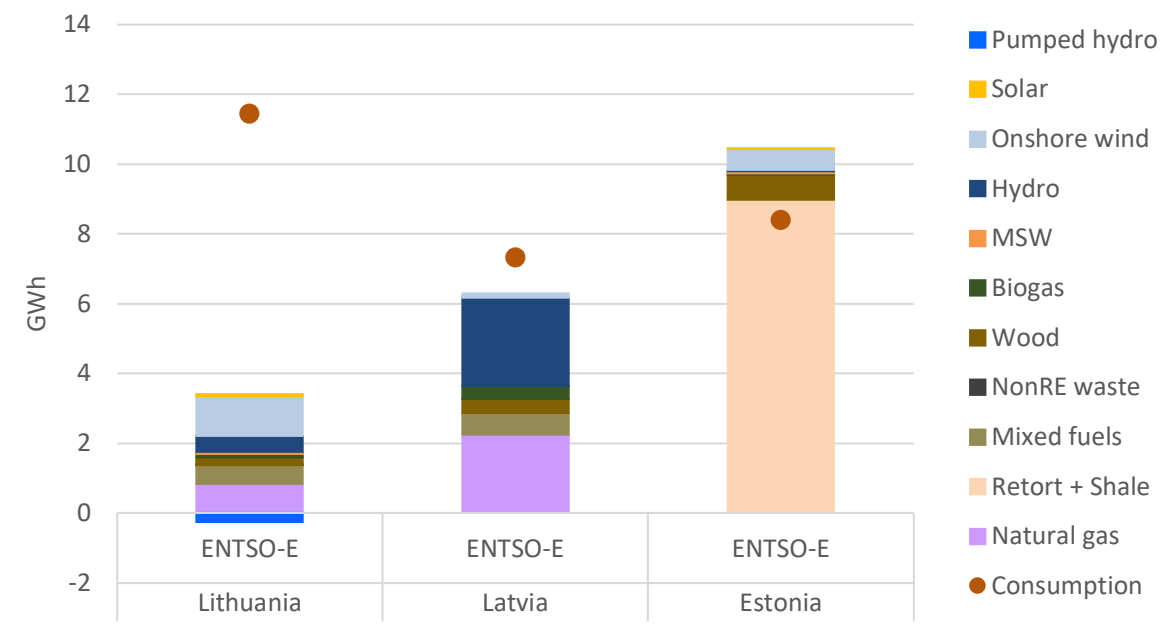

Key point(s): The Baltic countries display a diversified electricity generation portfolio. Lithuania is a significant importer and Estonia a small exporter.

Note: $\quad$ Pumped hydro shown as gross generation (electricity generation minus electricity consumption for pumping).

Source: $\quad$ ENTSO-E (2018).

All three Baltic countries are part of the Nord Pool market - Estonia since 2011, Lithuania since 2012 and Latvia since 2013. In 2015, electricity prices were significantly higher in the Baltic countries compared to the Nordic countries: +20 EUR/MWh in Latvia and Lithuania. But this difference has narrowed to approximately +10 EUR/MWh in 2016. The higher prices in the Baltic countries can be explained by the quite high shares of natural gas-fired capacity with comparatively high generation costs, whereas the convergence of prices between 2015 and 2016 may partly be ascribed to the commissioning of the two new interconnectors between Lithuania and Sweden (NordBalt) and Lithuania and Poland (LitPol) at the end of 2015.

\subsection{Electricity system outlook}

\subsubsection{Methodology}

The quantitative analyses have been made using Balmorel - a partial equilibrium model providing least cost solutions for dispatch and capacity expansion of the electricity system. Balmorel, which was originally developed with a focus on the countries in the Baltic Sea region, is particularly strong in modelling combined heat and power production.

The model is based on a detailed technical representation of the electricity system, i.e. electricity and heat generation facilities as well as the most important bottlenecks 
in the overall transmission grid. The geographical scope of electricity system modelling is the European system, though excluding the Iberian Peninsula and Balkan countries in order to limit calculation time.

The main result in this case is a least-cost solution for investments and dispatch of the electricity and district heating system.

\subsubsection{Key drivers}

The development of the European electricity system depends on a range of parameters, including the development of fuel prices, the level of ambition for achieving climate targets, technology costs, and regulations. The table below outlines the most important parameters for the electricity system modelling in the ${ }_{4} \mathrm{DS}$ and $2 \mathrm{DS}$ (Table 9).

Table 9: Key drivers for electricity system development in Europe

\begin{tabular}{|c|c|c|}
\hline Key parameter & 4DS & 2DS \\
\hline How will fuel prices develop? & $\begin{array}{l}\text { Current low forward prices for fossil } \\
\text { fuels will converge toward the IEA's } \\
\text { New Policies Scenario from World } \\
\text { Energy Outlook } 2016 .\end{array}$ & $\begin{array}{l}\text { Current low forward prices for fossil } \\
\text { fuels will converge toward the IEA's } \\
\text { 450ppm Scenario from World Energy } \\
\text { Outlook } 2016 \text {. }\end{array}$ \\
\hline Importance of EU ETS & $\begin{array}{l}\text { Moderate prices, reaching approx. } 15 \\
\text { EUR/t by } 2030 \text { and } 40 \text { EUR/t by } 2050 .\end{array}$ & $\begin{array}{l}\text { ETS becomes a main driver for the } \\
\text { green transition with prices of } 40 \\
\text { EUR/t by } 2030 \text { and } 100 \text { EUR/t by } 2050 \text {. }\end{array}$ \\
\hline $\begin{array}{l}\text { What climate targets will the EU and } \\
\text { its member states pursue for } 2030 \\
\text { and beyond? }\end{array}$ & $\begin{array}{l}\text { The EU will pursue an active climate } \\
\text { policy within electricity and heating } \\
\text { towards } 2030 \text {. European countries have } \\
\text { minimum RE targets until } 2030 \text { (based } \\
\text { on ENTSO-E scenarios) and will invest } \\
\text { in further RE, if beneficial at limited } \\
\text { subsidy of } 7.5 \text { EUR/MWh RE } \\
\text { (technology neutral). } \\
\text { Poland and the Czech Republic will be } \\
\text { less ambitious ( } 50 \% \text { of subsidy level) } \\
\text { Baltics: No RE targets }\end{array}$ & $\begin{array}{l}\text { The EU will pursue an active climate } \\
\text { policy, also beyond } 2030 \text {. However, } \\
\text { ETS will be the main driver, and no } \\
\text { minimum RE targets are required and } \\
\text { no subsidies implemented. }\end{array}$ \\
\hline $\begin{array}{l}\text { Will renewable energy technologies } \\
\text { mainly be supported through } \\
\text { subsidies or indirectly by means of a } \\
\text { carbon price? }\end{array}$ & $\begin{array}{l}\text { The future climate policy will involve a } \\
\text { combination of renewable energy } \\
\text { support and carbon pricing. Until 2030, } \\
\text { the importance of carbon pricing will } \\
\text { still be moderate. }\end{array}$ & $\begin{array}{l}\text { ETS will be the main driver for } \\
\text { deployment of renewable energy. }\end{array}$ \\
\hline $\begin{array}{l}\text { How will technological development } \\
\text { influence electricity markets? }\end{array}$ & $\begin{array}{l}\text { The investment cost of renewable } \\
\text { energy technologies will decrease to } \\
\text { the extent that their production profile } \\
\text { becomes the major barrier for further } \\
\text { market uptake. } \\
\text { New storage technologies and smart } \\
\text { grid technologies will not be deployed } \\
\text { extensively towards } 2030 \text {, but can gain } \\
\text { increasing importance towards } 2050 \text {. }\end{array}$ & $\begin{array}{l}\text { The investment cost of renewable } \\
\text { energy technologies will decrease to } \\
\text { the extent that their production profile } \\
\text { becomes the major barrier for further } \\
\text { market uptake. } \\
\text { New storage technologies and smart } \\
\text { grid technologies will not be deployed } \\
\text { extensively towards 2030, but can gain } \\
\text { increasing importance towards } 2050 \text {. }\end{array}$ \\
\hline
\end{tabular}

The BPO builds on the $4 \mathrm{DS}$, but includes national RE targets for electricity and district heating for the Baltic countries (Figure 43). The renewable energy targets for the BPO reflect national policies and only apply to Lithuania and Estonia, since there is currently 
no national RE target in Latvia. The targets for the energy and heating sector are a result of analyses using the TIMES model, showing how RE targets for the whole energy sector are most cost-effectively distributed between different sectors (chapter o).

Figure 43: Renewable energy targets for the energy and heating sector included in the BPO. There is currently no national RE target in Latvia. Full lines represent modelled minimum requirements on RE shares. Dotted lines with markers show the realised RE shares in the electricity and district heating simulations

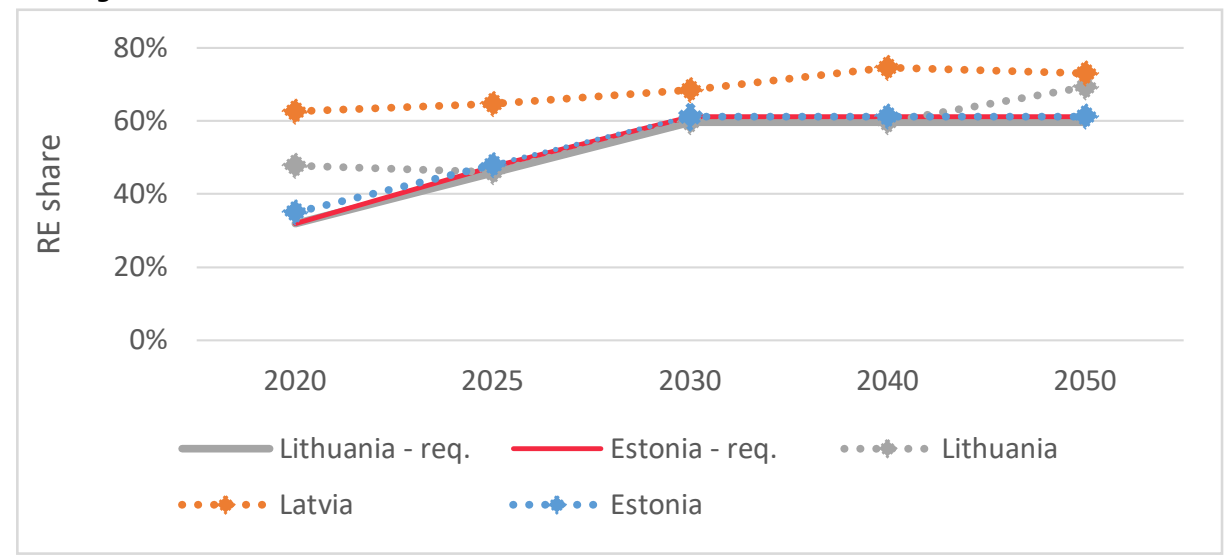

Key point(s): Estonia and Lithuania have strong targets for increasing the share of renewable energy.

\subsubsection{Cost of renewables and system price impacts}

In recent years, results from auctions of renewable energy around the world have indicated sharp declines in the cost of wind and solar power. These trends have been taken into account when estimating the cost of renewable energy (Annex II). As a result, renewable energy is the cheapest option when evaluating the socioeconomic cost for new generation capacity, as shown by the Levelized Cost of Energy (LCOE) for different technologies in Figure 44 . 
Figure 44: Socioeconomic LCOE for different options for new generation capacity with first year of operation in 2020

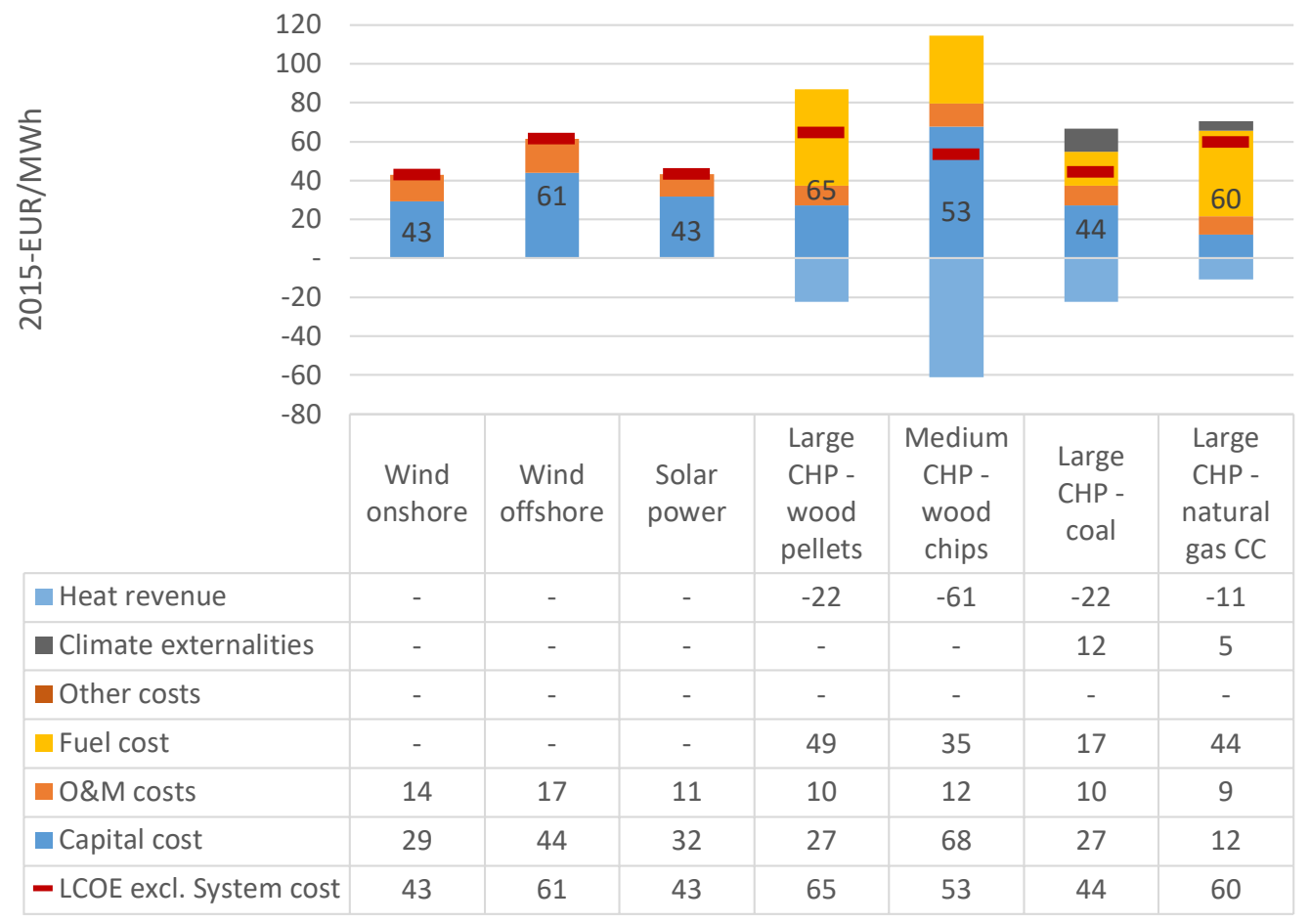

Key point(s): By 2020, wind and solar power are the cheapest option for new generation investments (without taking system effects into account)

Note: $\quad$ Full load hours for wind-based electricity in Latvia: 2140 for onshore, 3640 for offshore. Solar power: 959. Technical lifetime of individual technologies.4\% WACC. Value of heat set to 12 EUR/MWh. Climate externalities ( $\mathrm{CO}_{2}$ ) based on cost of $\mathrm{CO}_{2}$ of 20 EUR/ton. Wood pellets: 8.5 EUR/GJ. Wood chips: 7.4 EUR/GJ. Coal: 3.0 EUR/GJ. Natural gas: 8.9 EUR/GJ.

Source: $\quad$ Levelized Cost of Energy (LCOE) calculator, DEA2016a. Adjusted to own assumptions.

Especially wind and solar power are dependent on the local resource quality in terms of wind speed and solar irradiation. Figure 45 provides an overview of the resource quality in the Baltic countries. While the resource quality of solar power is comparable across a large region (but significantly better in the southern parts of Europe), wind resources show larger variations. Modelling of wind power is based on wind speed series provided by the Joint Research Centre (JRC) and assumptions about the future development of wind turbine technology and costs. 
Figure 45: Wind resources (left) and solar resources (right)

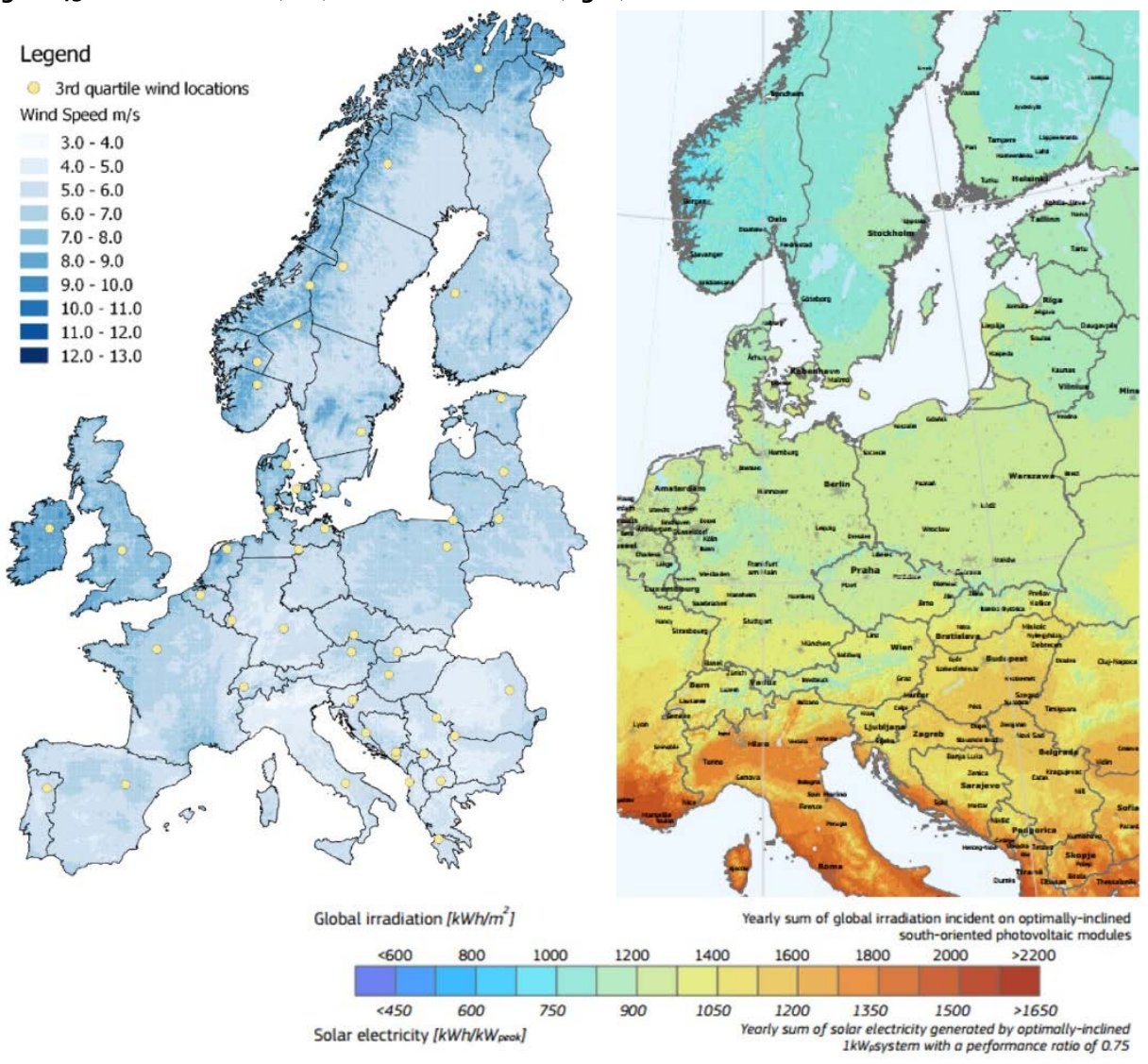

Key point(s): Wind and solar resources in the Baltic countries are mediocre.

Source: Wind data obtained from Global Wind Atlas 2.0, solar data from Šúri M. et al. (2007) and Huld Tet al. (2012).

The resulting number of full load hours ${ }^{1}$ for wind and solar power in the Baltic countries are shown in the table below. For solar power, the resource quality is comparable across the three countries. But for wind, Estonia demonstrates somewhat better resources than Latvia and Lithuania. At the same time, the estimated number of full load hours per year for onshore wind is lower than in the Nordic countries and large parts of Western Europe.

\footnotetext{
${ }^{1}$ Dividing the annual yield of a generation technology by its rated capacity gives the number of hours that the technology in question theoretically has to be operated at full capacity in order to achieve the annual energy yield. By standardising the capacity, these so-called full load hours enable a comparison between various sites or years.
} 
Table 10: Full load hours for wind and solar power

\begin{tabular}{lllll} 
& & 2020 & 2030 & 2050 \\
Onshore wind & Estonia & 2,700 & 2,950 & 3,200 \\
& Latvia & 2,150 & 2,350 & 2,600 \\
\multirow{3}{*}{ Offshore wind } & Lithuania & 2,100 & 2,300 & 2,550 \\
& Estonia & 3,750 & 3,900 & 4,000 \\
\multirow{3}{*}{ Solar power } & Latvia & 3,800 & 4,000 & 4,100 \\
& Lithuania & 3,800 & 3,900 & 4,000 \\
& Estonia, Latvia, & 960 & 990 & 1,020 \\
\hline
\end{tabular}

Key point(s): The Baltic countries show reasonable wind and solar resources. While solar resources are assessed to be of similar quality, wind power resources are best in Estonia.

Note: $\quad$ For solar power, full load hours are shown with respect to the installed panel capacity.

Source: $\quad$ Calculations based on sources for Figure 45 .

Figure 46 shows the development of Levelized Cost of Energy (LCOE) for wind and solar technologies in the Baltic countries. Offshore wind generation remains costlier than onshore wind and solar PV in the LCOE projection throughout the modelled years. The learning curve for solar power means that, from a pure LCOE perspective, solar power will be the cheapest option by 2030. The projections for LCOE do not take the value of the electricity generation into account, which is accounted for in the model optimisation below. When considering the value of electricity generation in the power market, prioritization between technologies can easily change, particularly in longer term as the shares of renewable energy increases and cannibalising effects in the power market become more dominating.

Technology cost projections are mainly based on the Technology Catalogue published by the Danish Energy Agency and the Danish national transmission system operator, Energinet. It should be stressed that the technology projections are subject to considerable uncertainty. The low prices derived from renewable auction results during 2016 and 2017 have proved previous expectations in the catalogue wrong and have led to downgrades of the catalogue's investment cost for solar PV and offshore wind of about $30 \% .^{2}$

2 The Danish Energy Agency Catalogues are available from the following website: https://ens.dk/en/ourservices/projections-and-models/technology-data, accessed 20-12-2017. 
Figure 46: LCOE development for onshore and offshore wind and solar

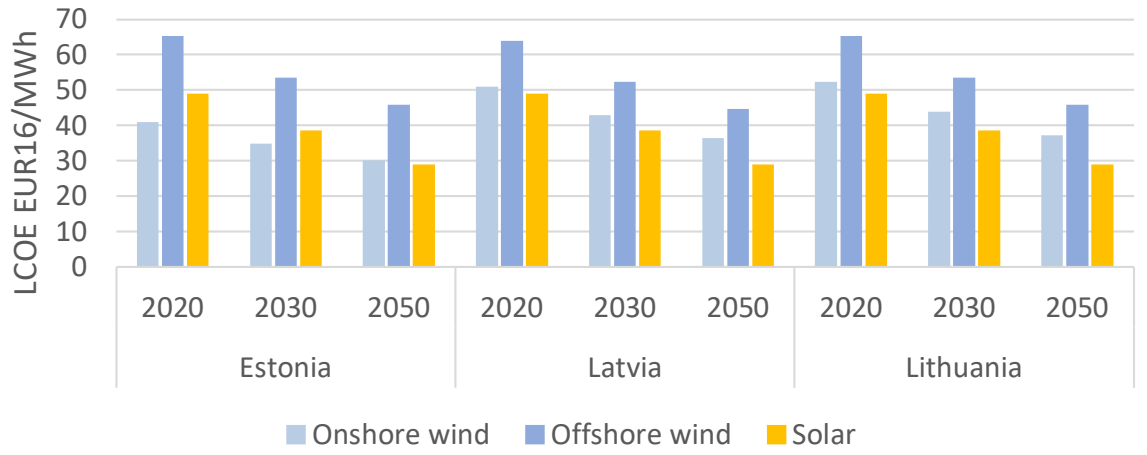

Key point(s): The cost of solar and wind power is projected to decrease substantially towards 2050.

\subsubsection{Annual electricity generation}

The European electricity system will undergo a substantial transformation towards 2030 and 2050 (Figure 47). The share of renewables in the electricity sector is about $67 \%$ by 2030 in the $4 \mathrm{DS}$ and $85 \%$ by 2050 . The higher $\mathrm{CO}_{2}$ price in the $2 \mathrm{DS}$ pushes the RE shares up to $69 \%$ and $86 \%$, respectively. In both scenarios, wind and solar contribute substantially to the generation mix. By 2050, around two thirds of electricity generation is provided by variable renewable energy in both the $2 \mathrm{DS}$ and the $4 \mathrm{DS}$.

Figure 47: Annual electricity generation development by fuel in the modelled region* for the 4DS and the 2DS. *The EU including Norway and the UK, excluding the Balkan countries and Iberian Peninsula

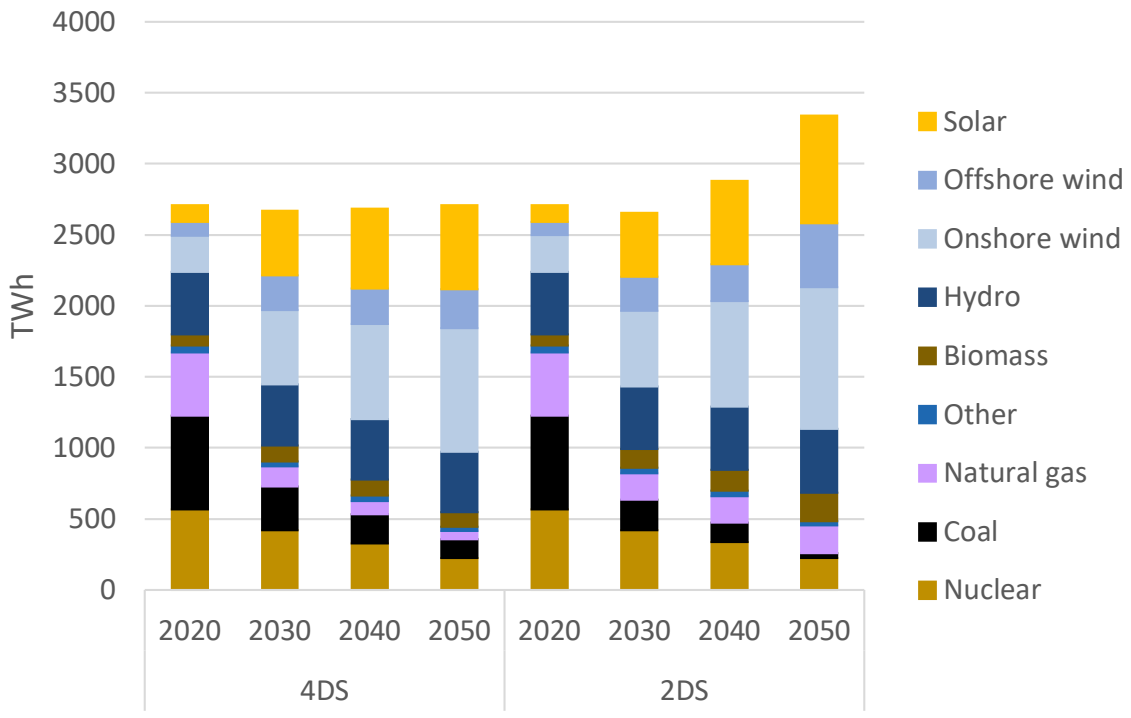

Key point(s): Renewable energy will dominate the future power markets. 


\subsubsection{Environmental impact: $\mathrm{CO}_{2}$ emissions}

Following the increasing shares of renewable generation, $\mathrm{CO}_{2}$ emissions are projected to decrease across Europe in all scenarios (Figure 48). By 2030, reductions in electricity and district heating will be around $65 \%$ compared to 2005 in the $4 \mathrm{DS}$. For comparison, according to the European Commission's climate roadmap from 2011, the electricity sector's emissions should decrease by $51-66 \%$ compared to 2005 , in order to achieve an overall reduction of $36-40 \%$. The higher $\mathrm{CO}_{2}$ price applied in the $2 \mathrm{DS}$ leads to further emission reductions compared to the $4 \mathrm{DS}$. By 2050 , emissions reductions will be around $89 \%$ in the $2 \mathrm{DS}$.

Figure 48: $\mathrm{CO}_{2}$ emissions for the modelled region (electricity and heating). Percentage figures indicate $\mathrm{CO}_{2}$ reductions since 2005 (Source 2005 emissions: EC, 2016)

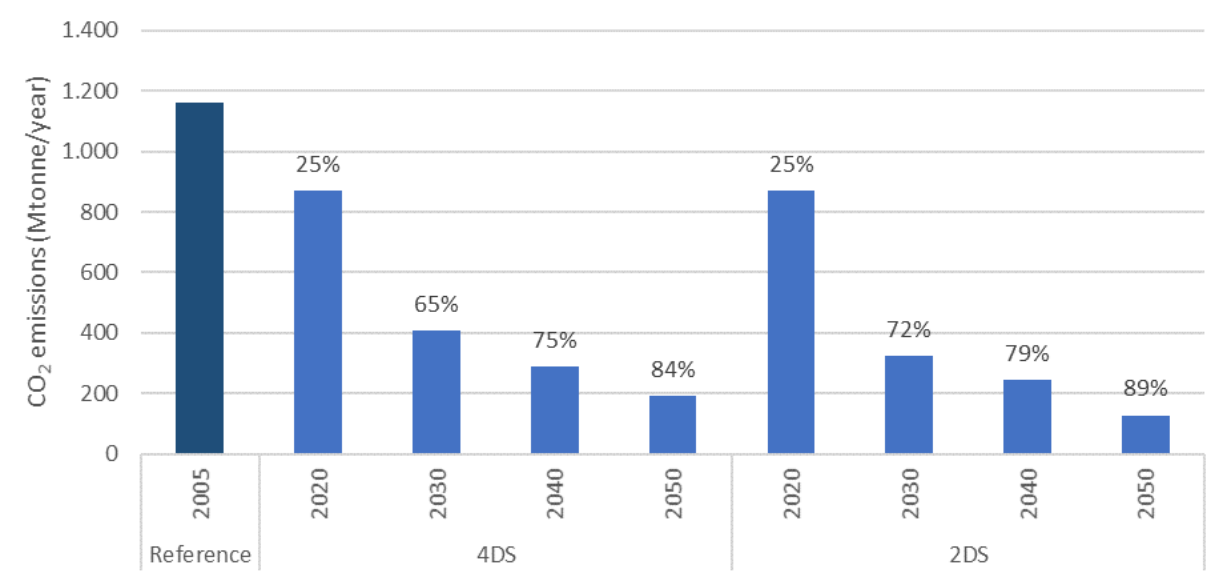

Key point(s): $\mathrm{CO}_{2}$ emissions are projected to decrease sharply in both the ${ }_{4} \mathrm{DS}$ and the $2 \mathrm{DS}$ as renewables deployment surges

\subsubsection{Electricity prices}

Electricity prices are expected to increase slightly towards 2030 and beyond across Europe in the $4 \mathrm{DS}$ (Figure 49). The main reasons are slight increases in fuel and emissions prices and the reestablishment of a balanced power market due to decommissioning of existing unprofitable power plants. Compared to the Nordic countries, the Baltic countries show higher electricity prices in the long term. The main explanation for this is a lower penetration of renewable energy and the strong connection to Continental Europe (through the reinforced LitPol interconnector), which exhibit higher electricity prices. Renewable energy resources, especially wind power, and balancing options are better in the Nordic countries compared to the Baltic countries and Continental Europa. Therefore, options for electricity import from the Nordic countries to the Baltic countries appear favourable in comparison to imports from Continental Europe. Similar options for export of electricity from the Nordic countries were highlighted in the Nordic Energy Research funded study on Nordic Energy Technology Perspectives (NER, 2016). 
The $2 \mathrm{DS}$ exhibits higher electricity prices than the $4 \mathrm{DS}$ in all parts of Europe as a result of the higher $\mathrm{CO}_{2}$ price levels, which increases the marginal cost of electricity generation of fossil fuel power plants.

Figure 49: Electricity price development for the Baltic countries, the Nordic countries and Germany in the $4 \mathrm{DS}$ and 2DS. Electricity prices in 2015 from statistics (sources: Nord Pool spot, 2018 and Fraunhofer, 2018)

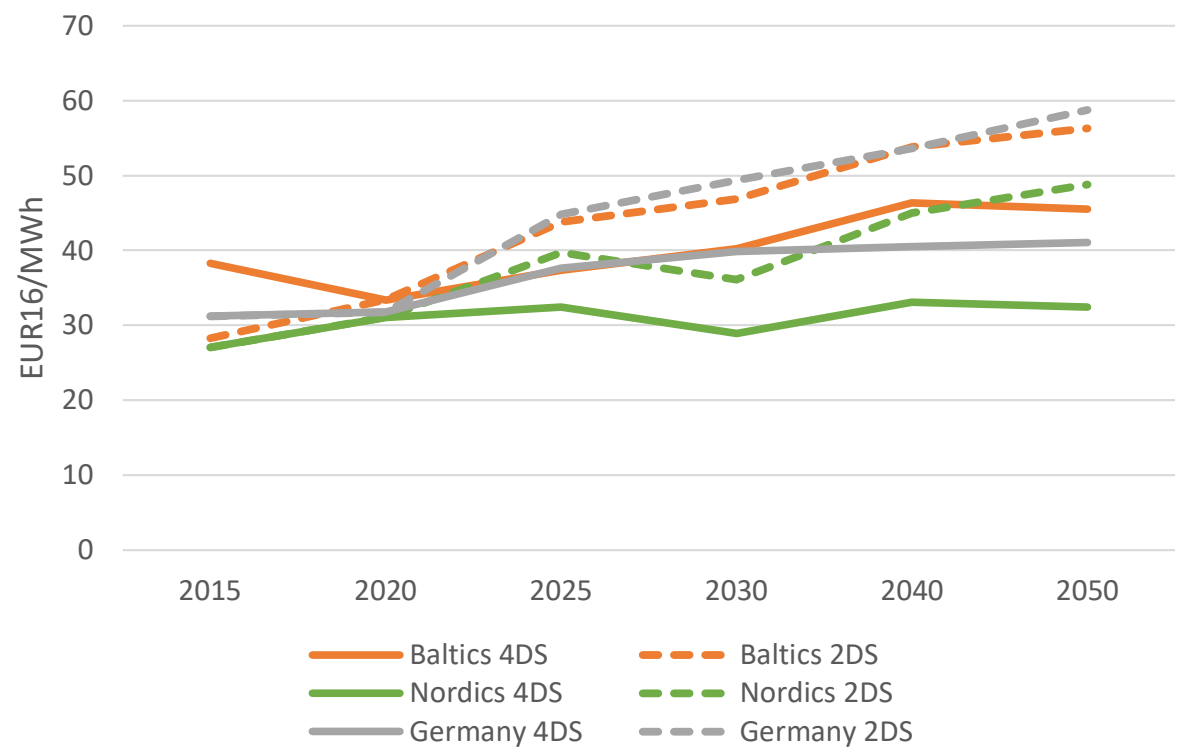

Key point(s): Average electricity prices are projected to increase, particularly in the 2DS.

Wind and solar power plants will bid in power spot markets at prices of around zero EUR per MWh. Due to the merit-order effect, this leads to a self-cannibalising effect on electricity prices. ${ }^{3}$ Consequently, as the shares of wind and solar power increase in the markets, their average selling price decrease relative to the average spot prices. In 2020, the self-cannibalising effect is more or less absent in the Baltic countries, but after 2030 it becomes substantial, particularly in the 2DS (Figure 50). This is particularly true for solar PV, which settles at a price close to half of the average market price by 2050. 
Figure 50: Average electricity prices, and captured electricity prices for wind and solar power (all prices as averages across the Baltic countries). Electricity prices in 2015 from statistics (source: Nord Pool Spot, 2018)

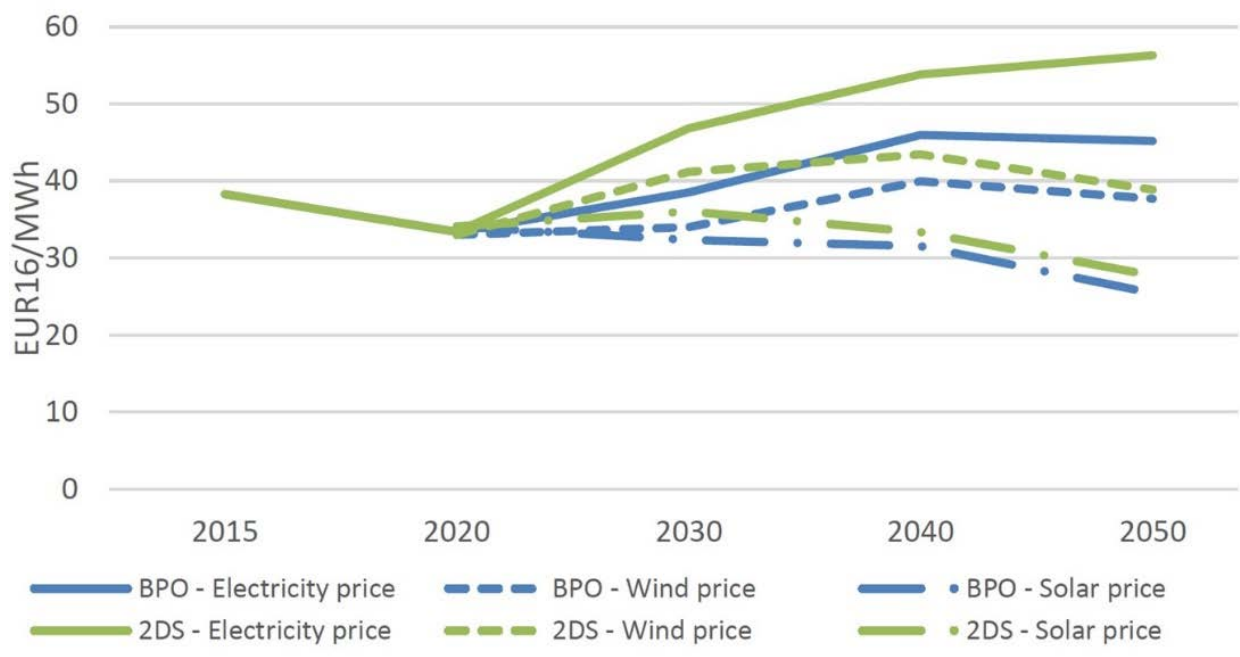

Key point(s): Increasing deployment of solar and wind power has a self-cannibalising effect on electricity prices.

\subsection{The Baltic system}

\subsubsection{Annual electricity generation}

The Baltic countries are importers in all three scenarios: $4 \mathrm{DS}, \mathrm{BPO}$ and 2DS. The lowest generation levels are observed in the $4 \mathrm{DS}$, where around half of electricity consumption is served by imports by 2030 . Production from oil shale-fired power plants is gradually reduced from 2020 in accordance with the scheduled phase-out plans.

In the 2DS, oil shale generation is reduced to less than 2 TWh by 2040 as a result of the high $\mathrm{CO}_{2}$ price, which makes the generation of oil shale uncompetitive. The $2 \mathrm{DS}$, on the other hand, sees the strongest increase in renewable generation. Wind power generation almost quadruples between 2020 and 2030 and very considerable additional investments are made in solar and wind power capacity in the subsequent decades. By 2050, wind and solar power cover close to two-thirds of the total consumption in the Baltic countries and net imports are narrowed down to 2-3 TWh. 
Figure 51: Annual electricity generation by fuel in the Baltic countries for the $4 \mathrm{DS}, \mathrm{BPO}$ and 2DS

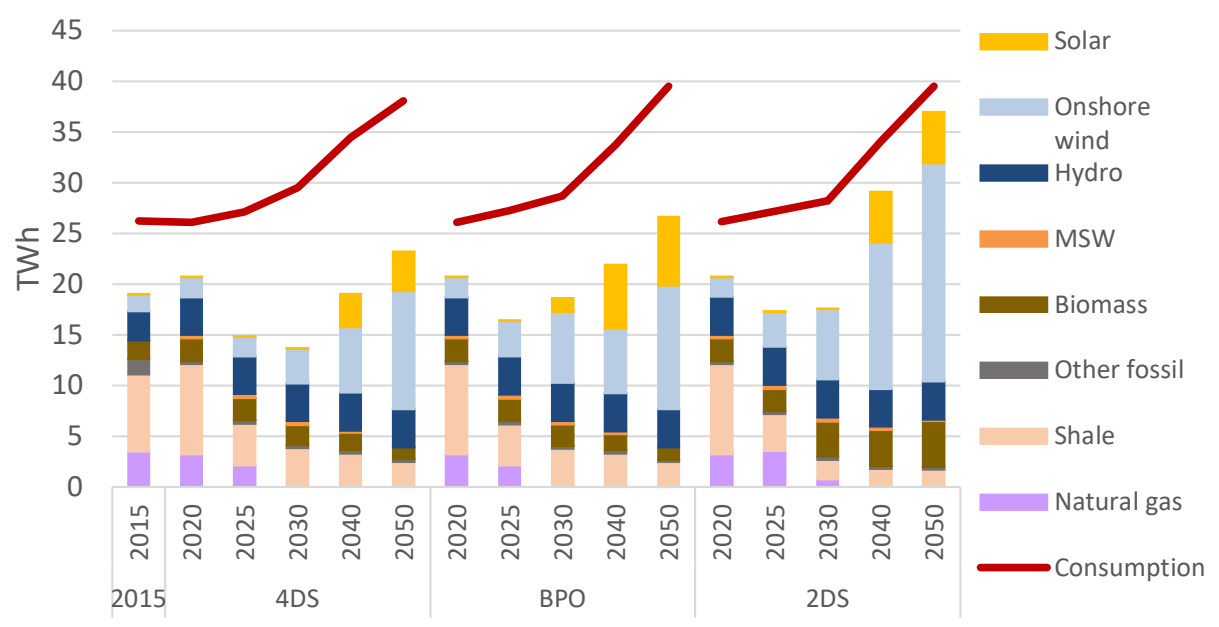

Key point(s): The Baltic countries are likely to remain net importers of electricity.

Source: $\quad$ Electricity generation from 2015 ENTSO-E (2018).

Figure 52: Electricity capacity by fuel in the Baltic countries for the $4 \mathrm{DS}, \mathrm{BPO}$ and 2DS

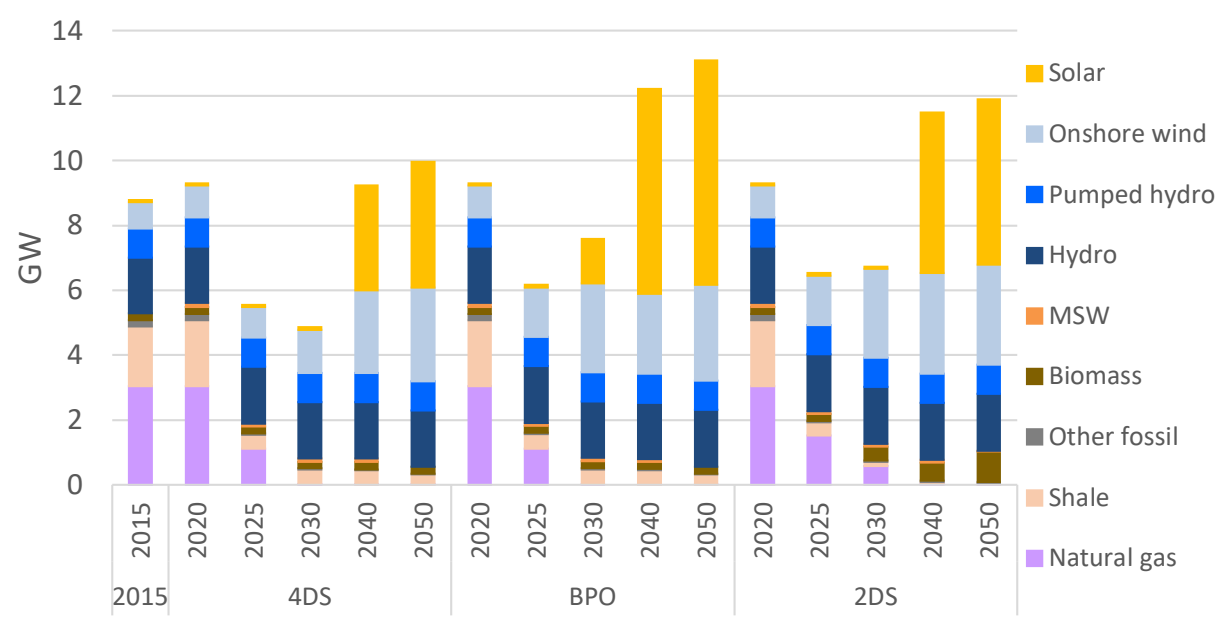

Key point(s): Without specific supporting policies, generation capacity tends to decline in the Baltic countries from 2015 to 2030. 
Figure 53: Annual electricity generation in 2030 for each Baltic country for the $4 \mathrm{DS}, \mathrm{BPO}$ and 2DS

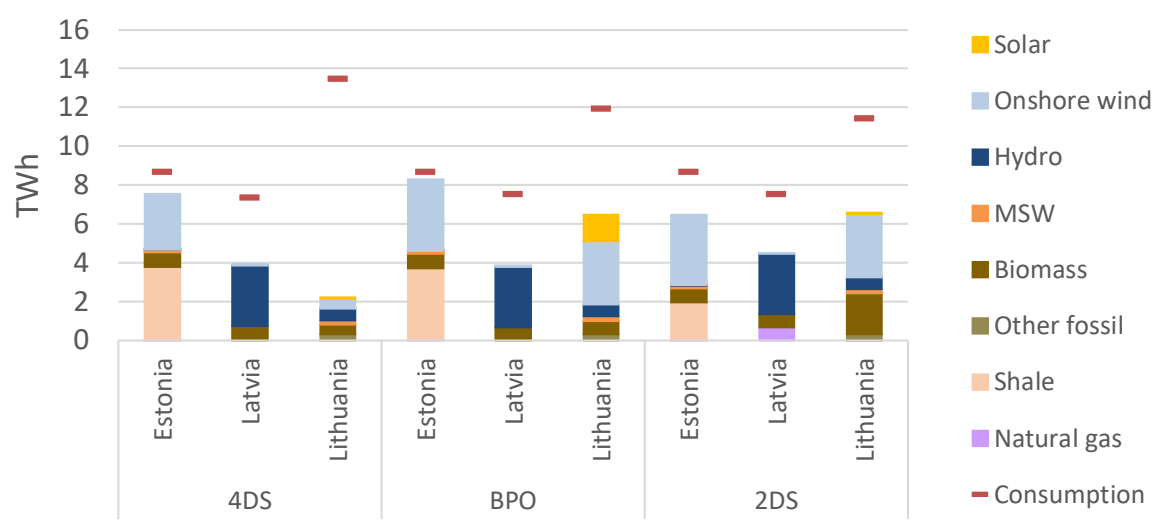

Key point(s): The deployment of renewables in the Baltic countries is substantially higher in the BPO and $2 \mathrm{DS}$ compared to the $4 \mathrm{DS}$.

\subsubsection{Interconnection of the Baltic region}

\section{Connections to Poland, Russia and Scandinavia}

Today, the Baltic countries are operated in parallel with the Integrated/Unified Power System (IPS/UPS) of Russia and Belarus, but it is a political objective of the Baltic countries governments to desynchronise from Russia and synchronise with the interconnected European system by 2025. The scenarios in the present report assume that the desynchronisation is in fact implemented by 2025 and, as a result, the interconnectors to Poland are strengthened, whereas the capacity between Lithuania and Belarus is reduced (see text box on desynchronisation with Russia).

\section{Desynchronisation from Russia}

The electricity system of the Baltic countries is operating in parallel with the Integrated/Unified Power System (IPS/UPS) of Russia and Belarus at the moment. The general aim is to continue integration of the Baltic countries to the rest of the EU and synchronise with power systems using the same technical standards and developing within the same European legal framework by 2025 .

Drivers for desynchronisation

It was identified that the cost-benefit analysis of the synchronisation is negative and there are no traditional technical or economic reasons that can justify a change of synchronisation from the present IPS/UPS system to the CE system (ENTSO-E, 2017). However, dependence on third parties like Russia and Belarus, which are not subject to EU legislation or policies, creates a legislative vacuum, disrupts market harmonisation and cannot fully guarantee security of the grids (Tuohy et al., 2017). So, the desynchronisation process has been started by the political decision due to the number of geopolitical, security, technical and other reasons (Litgrid, 2017a):

- High probability of geopolitical risks.

- Lack of information/security. The Baltic countries have limited information about the condition or development of the electricity infrastructure in the IPS/UPS system. 
- System frequency is controlled by the central dispatch centre in Moscow. In this system the Baltic countries are entirely dependent on Russia in terms of decision making.

How far is the project and what is the schedule?

The process started in 2007 when the Prime Ministers of the Baltic countries declared the strategic objective to join the European Continental Network synchronous area as soon as possible. The recent study by the European Commission's Joint Research Centre discovers that the most cost-effective and efficient option to synchronise the energy systems of the Baltic countries with the EU system is to utilise the LitPol Link interconnection with Poland. The investments were estimated to be $770-960$ million euros. Alternative synchronisation with Scandinavia would cost 1.36-1.41 billion euros (JRC, 2017). According to Gothia Power, a Swedish consultancy, 2025 could be a realistic year for this complex programme of synchronisation to be fulfilled. However, this will be very challenging, because the political agreements are essential to progressing the process. After the agreements, the next steps could be to obtain technical specifications and coordination with ENTSO-E, agreement with Russia and Belarus, preparation for trial operation of Baltic energy systems in isolated mode, etc. (Litgrid, 2017a). Due to these issues the exact schedule is unknown at the moment.

\section{What are the main technical challenges associated with the project?}

The technical, legal and economic options were examined in detail by a number of studies and no major technical obstacles were identified. But a number of issues (like local grid reinforcements, etc.) still needs to be resolved (Litgrid, 2017). However, the political issues could be the most challenging dimension of desynchronisation (Tuohy et al., 2017). As the first step, it requires political agreement between all parties involved (including Russia and Belarus).

Currently the main challenges are related to the issues involving the second line from Lithuania to Poland (Lit Pol Link 2). Latvia and Estonia have doubts about the possibility of synchronisation through only one existing line to Poland due to safety issues (Baltic course, 2017). According to Poland, building a second LitPol Link would be complicated due to environmental requirements (Energy central, 2017). In addition, a single line could mean significantly higher costs for the operation of the energy systems in the Baltic countries and a decline in the security of supplies (Financial observer, 2017).

How will net transfer capacities be affected?

The desynchronisation will affect the transfer capacities of intersystem lines connecting Lithuania with Poland and Belarus. The transfer capacities with Sweden, Latvia and Kaliningrad will not change (Table 11). For Latvia and Estonia, the net transfer capacity with Russia will be affected.

Table 11: Net transfer capacities in 2017 and 2026 (D. Virbickas 2017 CEO of Litgrid, Litgrid 2017b)

\begin{tabular}{lrrrrrrr} 
Line & LT-PL & LT-BL & LT-LV & LT-RU & LT-SE \\
MV & MV & MV & $\begin{array}{r}\text { LV-RU } \\
\text { MV }\end{array}$ & $\begin{array}{r}\text { EE-FI } \\
\text { MV }\end{array}$ \\
\hline 2017 & 500 & 1,300 & $1,200-1,500$ & $600-680$ & 700 & 300 & 1,000 \\
2026 & $1,080^{1}$ & $500^{2}$ & $1,200-1,500$ & $600-680^{2}$ & 700 & 300 & 1,000 \\
$2030^{3}$ & $2,400^{4}$ & 500 & 1,200 & 680 & 700 & 300 & 1,000 \\
\hline
\end{tabular}

Note: $\quad{ }^{1}$ Existing LitPol Link in synchronous mode, including only LitPol Link 1.

${ }^{2} 500 \mathrm{MW}$ converter station from LitPol Link will be reconnected to one line with Belarus. The capacity of other converters with Belarus and Russia will depend on negotiations and trade demands.

${ }^{3} 2030$ shows assumed capacities in model calculations for 2030 .

4 Including LitPol Link 2 
Figure 54 shows the transmission lines in the modelled region by 2030. Compared to the current situation, the interconnection to Poland is assumed to be increased from $500 \mathrm{MW}$ to $2400 \mathrm{MW}$, whereas the connection to Russia is reduced to $500 \mathrm{MW}$. These interconnections feed into the model and are based on the Ten-Year Network Development Plan (TYNDP) and input from the Baltic researchers.

Figure 54: Transmission capacity development in the 4DS, 2015 (left), 2030 (mid), 2050 (right). Blue: decrease in capacity. Red: increase in capacity. Exogenous expansion until 2030 (sources for 2015 and 2030: (ENTSO-E 2016) and own estimates)
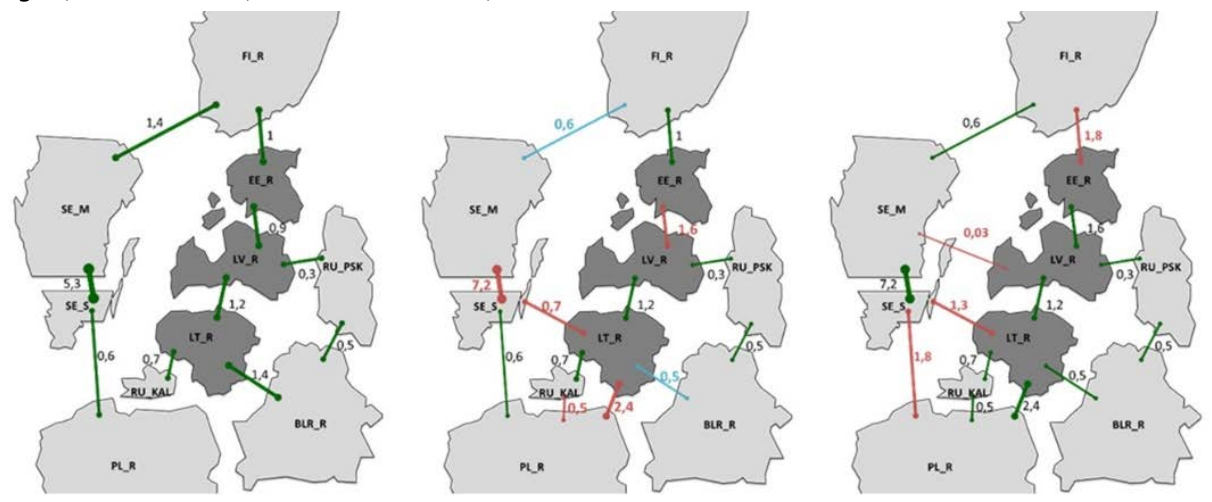

Key point(s): The analyses show that it is becoming increasingly attractive to strengthen interconnection capacities in the region.

Note: $\quad$ The reduction of capacity between Sweden and Finland is due to refurbishment plan for Fenno-Skan. Replacement capacity is expected to be established further north between SE2, north of SE-3 (shown as SE-M on map) and Finland (not shown on map). Values between 1 and $600 \mathrm{MW}$ indicate that an interconnection could be economically viable. However, small connections are rarely realisable due to disadvantages from economy of scale. Values above $600 \mathrm{MW}$ indicate that an interconnection is viable given the assumptions in the relevant scenario.

Model-based investments in transmission capacity are only allowed after 2030. Transmission expansions to neighbouring countries from 2030 to 2050 are summarised in Table 12. The annual net electricity flows for 2030 are shown in Figure 55 for the $4 \mathrm{DS}$ and 2DS. In all three scenarios, the Baltic countries are importers, with annual net import levels of about 15 TWh by 2030 in the $4 \mathrm{DS}, 9$ TWh in the BPO, and 10 TWh in the $2 \mathrm{DS}$. 
The large price difference of about 10-15 EUR/MWh between the Baltic countries and the Nordic countries in 2030 (Figure 49) indicates options for further transmission expansion connecting the two regions. It should be noted however, that the decisive factor for the value of additional transmission capacity is the absolute average price difference per hour, not the difference in average electricity prices, since flow and value of import/export is determined by the hourly prices. Until 2030, the model does not allow for additional capacity, but existing connection lines between the Nordic and Baltic countries are used with high capacity factors of about $75 \%$ in the $2 \mathrm{DS}$ and $85 \%$ in the $4 \mathrm{DS}$ - virtually all import to the Baltics. When the model allows investment in 2040, some $900 \mathrm{MW}$ of transmission is added to the Nordic region in the ${ }_{4} \mathrm{DS}$. In the BPO and 2DS, the deployment of renewables is greater in the Baltic countries and less Nordic import is needed. This also reduces the economic potential for new interconnectors (Table 12).

Table 12: Model-based transmission expansion (MW). Additions compared to 2030 levels

4DS

Lithuania <-> Sweden-S

Latvia $<->$ Sweden-M

Estonia <-> Finland

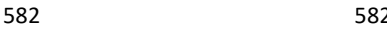

$30 \quad 30$

BPO

Lithuania <-> Sweden-S

Latvia <-> Sweden-M

82

Estonia $<->$ Finland

$\begin{array}{rr}22 & 22 \\ 80 & 80 \\ 277 & 873 \\ & \\ 0 & 167 \\ 0 & 5 \\ 197 & 442\end{array}$

Lithuania <-> Latvia

Latvia $<->$ Sweden-M

Estonia <-> Finland

Key point(s): The large price difference of about 10-15 EUR/MWh between the Baltic countries and the Nordic countries result further transmission expansion connecting the two regions.

Note: $\quad$ Values between 1 and $600 \mathrm{MW}$ indicate that an interconnection could be economically viable. Values above $600 \mathrm{MW}$ indicate that an interconnection is viable given the assumptions in the relevant scenario. 
Figure 55: Net transmission flows (TWh per annum, dark green) between the Baltic countries and neighbours and electricity prices (EUR/MWh, black) in 2030 for the $4 \mathrm{DS}$ (left) and the 2DS (right)
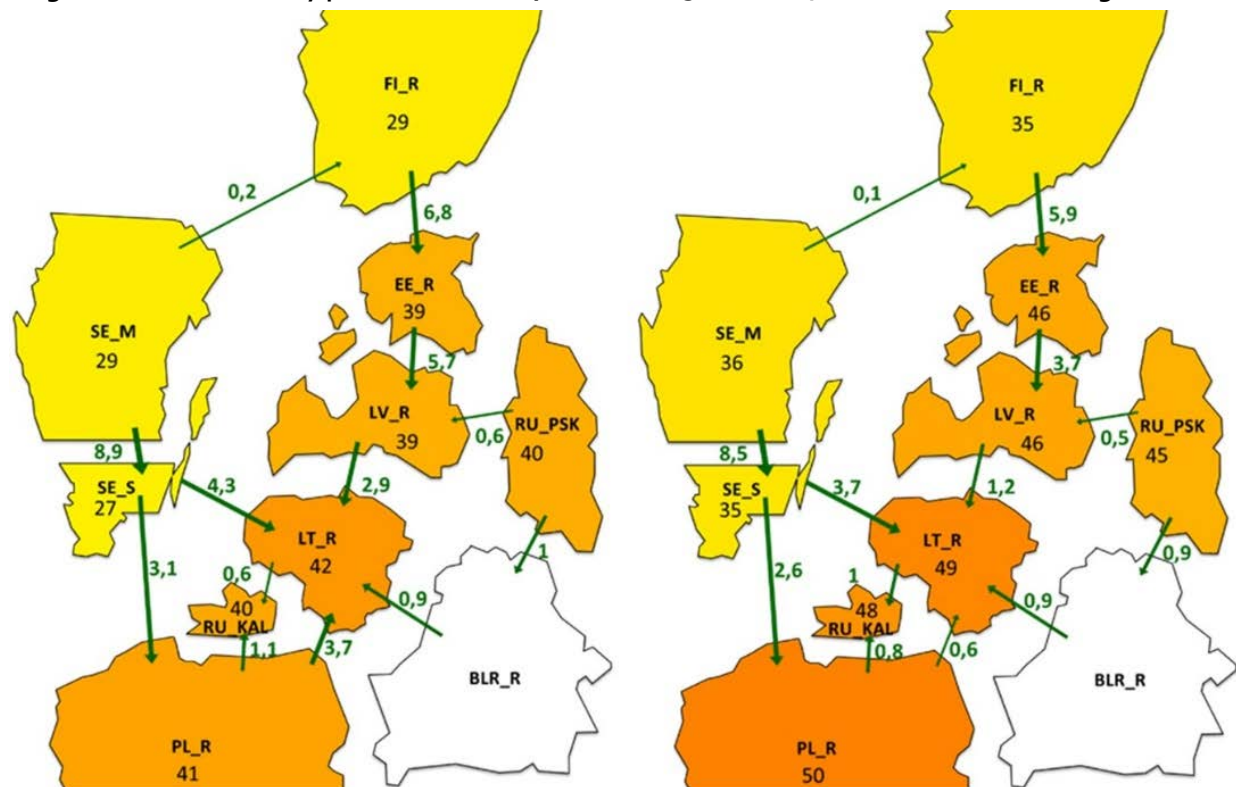

Key point(s): Electricity prices in the Baltic countries remain higher than in the Nordic countries in both the $4 \mathrm{DS}$ and $2 \mathrm{DS}$.

\subsubsection{How does a highly-renewable, highly-integrated electricity and heating system work?}

Figure 56 below shows the hourly variation in electricity production and electricity consumption accumulated for the three Baltic countries in a winter week in 2030 in the 2DS. Electricity prices are for comparison (black dashed line). Throughout this week, electricity prices are relatively high, with a clear day-night pattern. Night prices of around 50 EUR/MWh are close to the marginal cost of coal fired power plants, while the higher prices during day times of around 90-100 EUR/MWh are close to the marginal cost of natural gas fired power plants.

The classic electricity consumption (red line) varies according to a conventional diurnal pattern, namely high consumption during the day and low consumption at night. Total consumption (red dashed line), however, is more constant over the week, because electricity consumption for heating and pumping (pumped storage) increases at night, when electricity prices are low. Electricity generation from thermal power plants is almost constant over the week. Therefore, the balancing of the system mainly takes place via the interconnectors, by using pumped storage and by smart use of power to heat solutions. 
Figure 56: Operation of the Baltic system in a winter week (Week 1) in 2030 in the 2DS

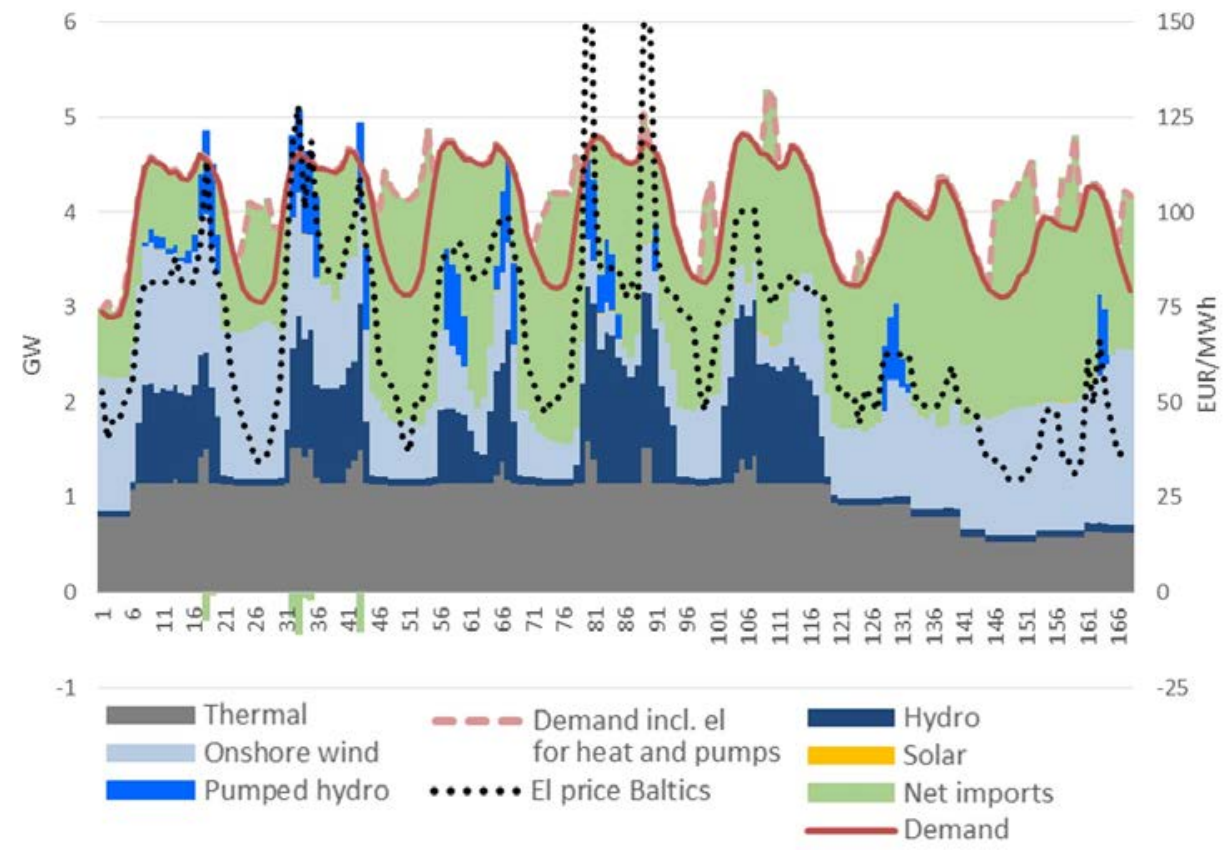

Key point(s): System is balanced by flexibility from interconnectors, pumped storage and flexible use of power to heat and pumped storage.

Note: $\quad$ Electricity price is shown is the average price for the three countries on the right axis. Simulations do not explicitly require certain ancillary services, such as spinning reserves to ensure N-1 criteria. However, a minimum generation of $200 \mathrm{MW}$ from dispatchable generators in three Baltic countries has been assumed. The technical methods to provide ancillary services will have to be developed beyond today's approach, as the European electricity system is moving towards high shares of variable renewable generation.

Figure 57 shows the similar operation picture for a spring week. In this situation, the price pattern is almost the opposite of the winter week. Electricity prices are low during the day as a results of high solar PV generation in the European market. This price signal is imported to the Baltic countries through the strong interconnectors to Poland. As a result, electricity consumption (pumped storage and electricity for heating) are increased and imports are decreased during these hours - and pumped storage mainly produces electricity in the evening hours and overnight. To a lesser extent, thermal power plants increase generation during evening hours and overnight. 
Figure 57: Operation of the Baltic system in a spring week (Week 21) in 2030 in the 2DS

5

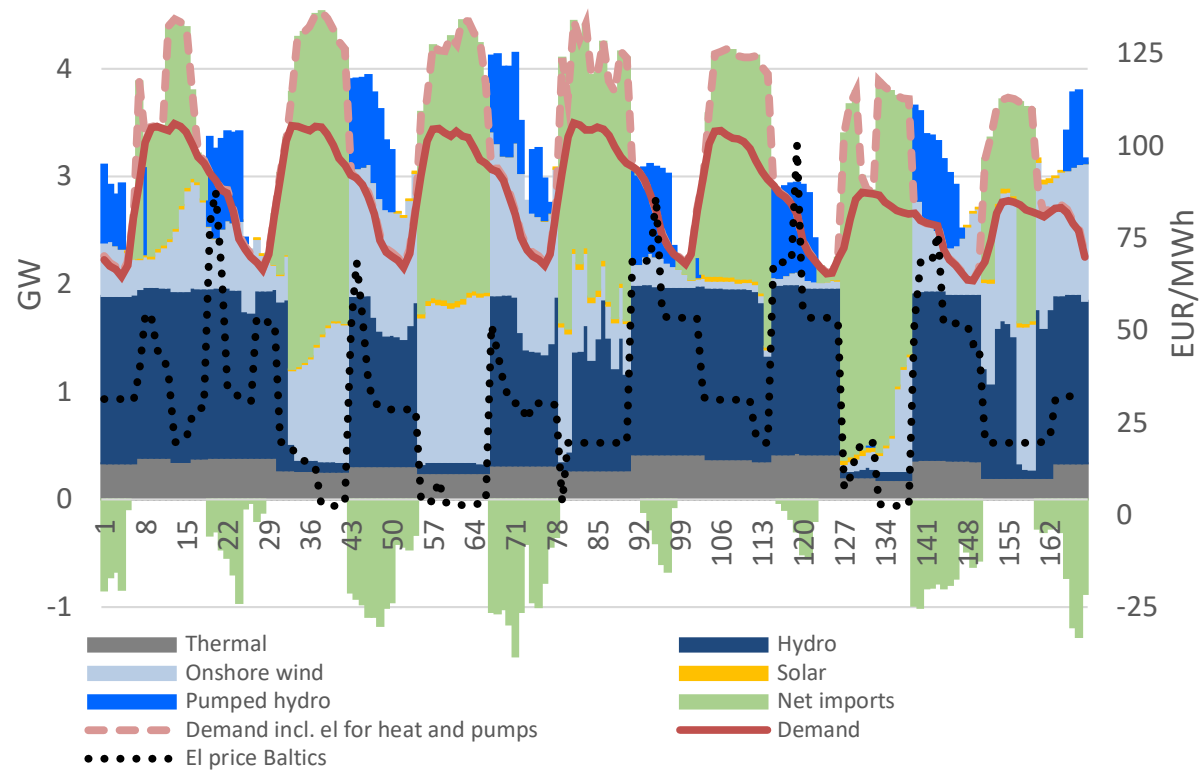

Key point(s): System is balanced by flexibility from interconnectors, pumped storage and flexible use of power to heat and pumped storage. Contrary to the winter week simulation, low electricity prices, and therefore increased consumption from flexible use of power to heat and pumped storage, occurs during day hours.

Note: $\quad$ Electricity price is shown is the average price for the three countries on the right axis.

\subsubsection{The heating system}

\section{Annual heat generation}

Historically, natural gas was the dominant fuel for district heating in the Baltic countries, but high gas prices and a political drive to reduce import dependency has prompted a development towards local biofuel in the last 5-10 years. Today, around $50 \%$ of the heat consumption in the Baltic countries is served by biomass, mainly wood chips and wood waste.

Towards 2030, the share of natural gas is reduced in all scenarios, as biomass, electric heat pumps and municipal solid waste gain increasing shares of the market (Figure 58). The development of heat pumps and municipal solid waste is driven by the economic competitiveness of heat pumps and the requirement to incinerate municipal solid waste. At the same time, efficiency measures reduce overall heat consumption in district heating systems. In both the BPO and 2DS, biomass plays a bigger role in district heating towards 2030 and beyond. This is due to the relatively cheap domestic biomass available to meet RE targets in the BPO. Biomass competitiveness is subject to uncertainty, if global biomass demand drives up prices. By 2050, heat pumps could supply up to $40 \%$ of the annual heat consumption in the 4 DS and BPO. In the $2 \mathrm{DS}$, 
higher electricity prices as a result of the higher $\mathrm{CO}_{2}$ prices reduce the contribution from heat pumps.

Figure 58: Annual heat generation by fuel in the Baltic countries for the $4 \mathrm{DS}, \mathrm{BPO}$ and $2 \mathrm{DS}$

$$
25
$$

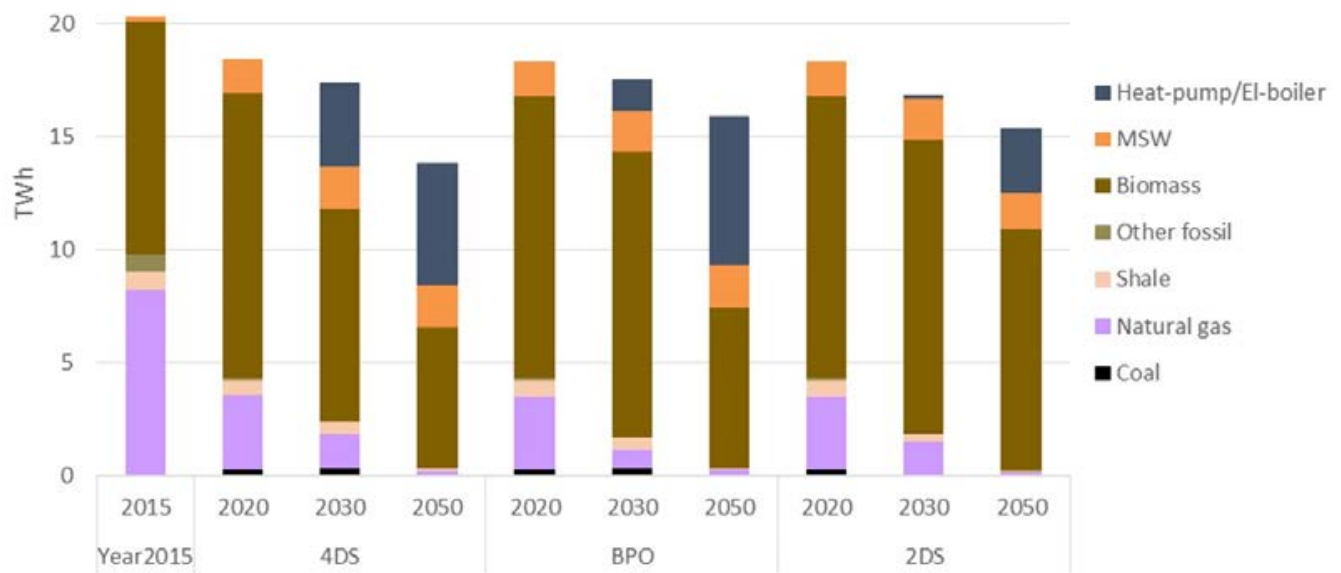

Key point(s): Reduced shares of natural gas, increased shares of heat pumps, biomass and municipal solid waste.

Source: Heat generation for 2015 estimated based on statistics and information from Baltic researchers: Input from LEl; Lithuanian Energy Institute, Utilitas and (Central Statistics Bureau of Latvia, 2018).

The contribution of heat pumps varies among the countries (Figure 59), and depends on the competition with existing technologies. According to Baltic researchers, a large proportion of the existing biomass boilers in Lithuania is expected to be decommissioned. In Estonia and Latvia, existing biomass boilers are expected to remain in operation in 2030. In all scenarios, the district heating sector dominates in these two countries in 2030 . The results show that heat pumps provide a competitive source of heat generation for district heating companies lacking capacity, whereas it is difficult for heat pumps to compete with the short-term costs of generating biomassbased heat.

It is important to note that the core scenarios assume that only quite modest efficiencies, expressed as Coefficient of Performance (COP), can be achieved. As investigated in sensitivity analyses later in the study, the potential for heat pumps could increase significantly if higher COPs can be obtained. 
Figure 59: Annual heat generation in 2030 for each Baltic country for the $4 \mathrm{DS}, \mathrm{BPO}$ and $2 \mathrm{DS}$

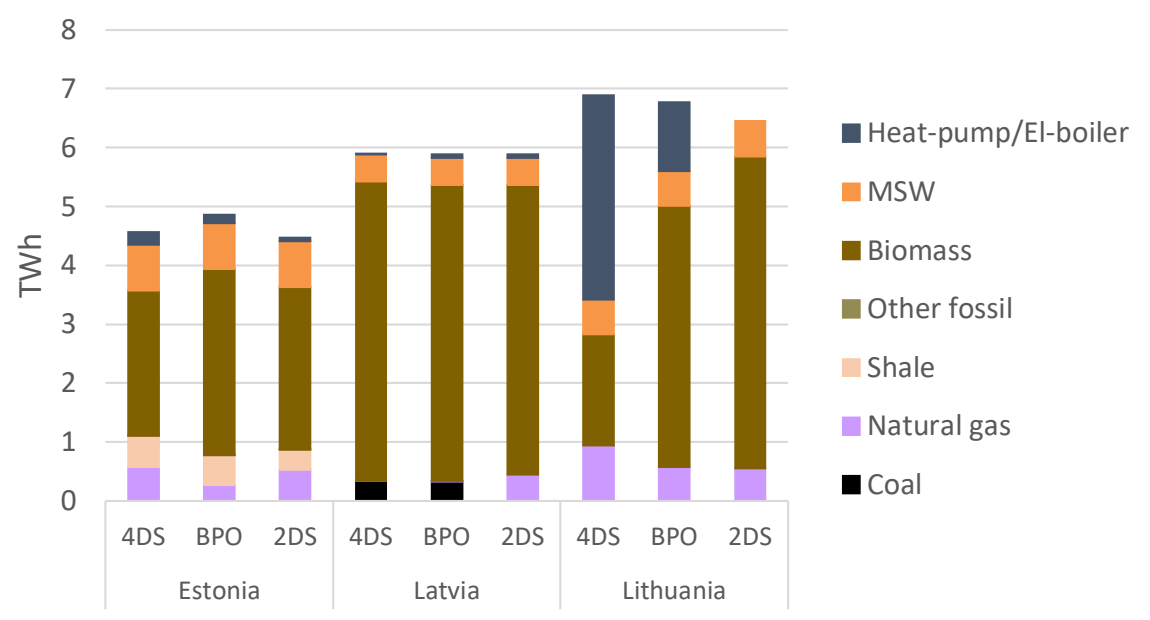

Key point(s): Electric heat pumps are a competitive option, where new generation capacity is needed (Lithuania), while they cannot provide a least cost option where existing biomass boilers are expected to be available in 2030 (Estonia and Latvia).

Heat pumps

All scenarios show options for using heat pumps for district heating. To date, heat pumps for district heating have only been used to a very limited extent in the Baltic countries. However, in the Nordic countries (especially Sweden), heat pumps are more commonly used for district heating on a larger scale. In the early 1990 , up to $35 \%$ of Swedish consumption of district heating was served by heat pumps and electric boilers. In 2013 however, contribution from heat pumps and electric boilers had been reduced to around $8 \%$ of the demand for district heating (Averfalk et. al 2017).

The competitiveness and subsequent deployment of heat pumps is subject to a number of uncertainties, related to both technical factors and financial circumstances. Technical uncertainties relate to achievable efficiencies (Coefficient of Performance, (OP). High efficiencies require both a good heat source and moderate temperatures in the district heating system. However, redesigning district heating systems for lower temperatures may require significant investments in both the district heating system itself and the end user installations, to ensure that the needed energy can be delivered on the coldest winter days. Another option is to install heat pumps closer to the end user in district heating systems where temperature requirements are lower, or to combine heat pumps with boilers, which can boost temperatures when necessary. 


$\begin{array}{ll}2.00 & 2.90 \\ 2.17 & 2.95 \\ 2.33 & 3.00 \\ 3.00 & 3.20\end{array}$

Key point(s): Baseline assumptions on COP for heat pumps are very conservative compared to international expectations and experiences.

Due to the limited experience with heat pumps in the Baltic countries, a very cautious assumption on average COP has been chosen. By 2020, an average COP of 2.0 is assumed for newly installed heat pumps. Efficiencies can be expected to be at their lowest when heat consumption is at its highest, since the heat source will also have lower temperatures. Hence, the COP is reduced to around 1.5 during the coldest months of the year. These values are well below the estimates in the Danish Energy Technology Data Catalogue, which predicts an average annual COP of around 3 by 2020 and international experiences also showcasing higher COPs, albeit dependent on the applied heat source (Figure 6o). Pilot projects in Estonia have also shown higher COPs of up to 2.5. Sensitivity analyses have therefore been prepared with higher COPs.

Figure 6o: International figures for realised COPs in heat pumps

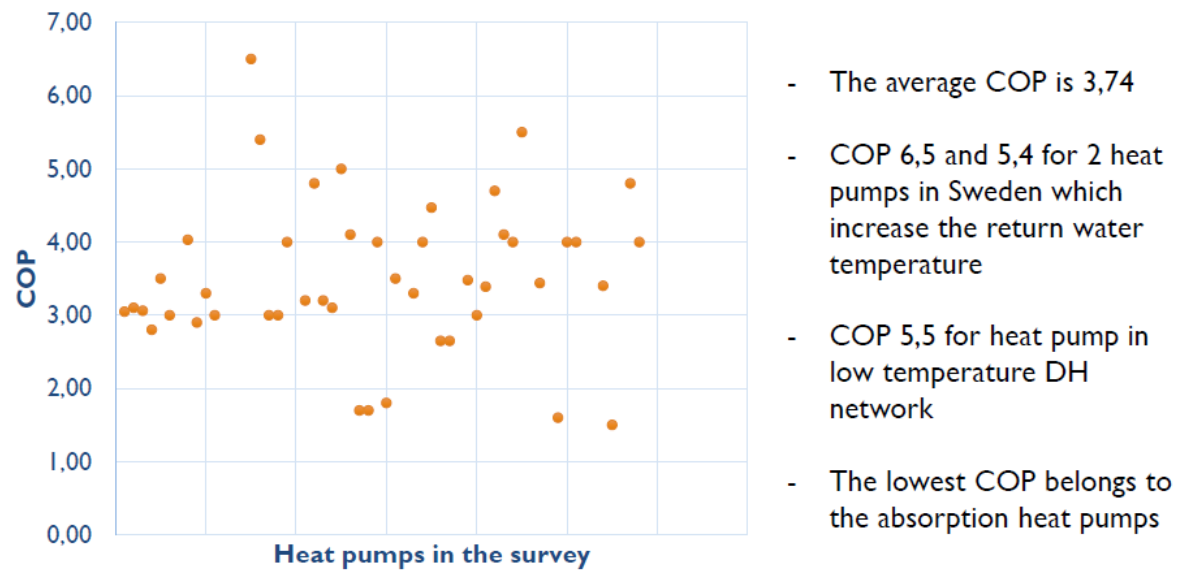

Key point(s): International experience shows higher achievable COPs under the right circumstances.

Source: $\quad$ (David 2016). 
The other very important factor for the economy of heat pumps is the cost of electricity. This concerns not only the electricity price in the wholesale market, but also electricity network tariffs for transmission, distribution, public service obligations (PSO) and possible taxes. Current network tariffs in the Baltic countries vary between 18 and 48 euros/MWh (info box on network tariffs in the Baltic countries). However, a large share of these payments is related to depreciation of the existing system, which can be regarded as a sunk cost from a socio-economic perspective. The socio-economic cost related to additional maintenance or investments in the transmission and distribution grid for the integration of heat pumps is likely to be well below the current tariffs. The cost will depend on the location of the heat pumps in the grid and the option for flexible usage of the heat pumps. Well-operated heat pumps can help manage local grid congestions, which implies a low socio-economic cost of transporting electricity. Defining the proper tariff level is of particular importance when the tariff risks distorting the optimal choice of technologies and fuels.

In the present model simulations, a general network tariff of 10 EUR/MWh for electricity used for district heating has been applied. This level is meant to reflect the socio-economic cost of investment and operation of the power system related to additional electricity consumption. The level acknowledges that new demand can impose costs for investing in and operating the electric transmission and distribution system. At the same time, the marginal cost of introducing new demand will be significantly lower than the average cost of capital and operation for the electric transmission and distribution system. ${ }^{4}$ A similar issue applies for transmission and distribution tariffs for natural gas. For natural gas, a total distribution and transmission tariff of 7 EUR/MWh has been applied in all the Baltic countries. ${ }^{5}$

\footnotetext{
4 The level of 10 EUR/MWh is not based on a detailed study of future prospects of the general level of network tariffs to cover overall cost of investing and operating the electricity network, but a proxy for the additional costs of introducing electricity demand for district heating generation in a system, that is developing towards high shares of variable renewable generation in any case.

${ }^{5}$ As for the electricity tariff, the level is meant as a proxy for the socio-economic cost of distributing natural gas. The level is based on information from the Lithuanian National Commission for Energy Control and Prices for 2017. Distribution tariff for group V (5.17 EUR/MWh (higher heating value)) and transmission tariff for users with annual consumption up to 10.4 TWh: 1.09 EUR/MWh (higher heating value). Sources: http://www.vkekk.It/en/Pages/ab-energijos-skirstymo-operatorius2017.aspx and http://www.vkekk.It/en/Pages/ab-amber-grid-2017.aspx. Capacity payments also apply. However, parts of the actual current payments in the Baltic countries are viewed as sunk costs, and capacity payments are therefore not included.
} 


\section{Electricity tariffs in the Baltic countries}

The level of payments for transmission and distribution tariffs and other taxes on electricity varies among the Baltic countries and different consumer groups. The table below provides an overview of the variable tariffs payable for consumers connected to the $10 \mathrm{kV}$ grid.

Table 14: Taxes and tariffs for electricity use for heat pumps in the Baltic countries for 2017. Capacity payments not included.

\begin{tabular}{lrrr} 
& Estonia & Lithuania & Latvia \\
\hline Transmission (EUR/MWh) & $9.6^{1}$ & 14.58 & 4.03 \\
Distribution (EUR/MWh) & & 8.30 & 17.63 \\
PSO (EUR/MWh) & 8.9 & 13.86 & 26.79 \\
Total (EUR/MWh) & 18.5 & $32.8^{2}$ & 48.45 \\
\hline
\end{tabular}

Key point(s): The current legislation on payments for electricity distribution and transmission tariffs can be an important barrier to using heat pumps for district heating and therefore hinder the introduction of cost-efficient renewable energy to the district heating sector.

Note: $\quad{ }^{1}$ Sum of distribution and transmission tariff.

${ }^{2}$ Ceiling of $24.5 € / \mathrm{MWh}$ applies to sum of transmission and PSO tariff.

Source: Estonia, Konkurentsiamet: http://www.konkurentsiamet.ee/file.php?28997

Estonian Transmission System Operator: https://elering.ee/taastuvenergia-tasu\#tabo

Lithuanian National Commission for Energy Control and Prices:

http://www.regula.It/en/Pages/price-ceilings-of-electricity-transportation-services-

and-public-energy-price-ceilings.aspx

Augstsprieguma tīkls AS, Latvian Independent Transmission System Operator:

http://www.ast.lv/eng/services_of_transmission_system/rate_of_transmission_service s/ Sadales tīkls Sadales tīkls AS, Latvian distribution system operator:

https://www.sadalestikls.Iv/files/tarifi/Jaunie_tarifi_ENG.pdf

Electricity tariffs and public service obligations payable by heat producers are subject to discussion in a number of countries. Apart from the socio-economic perspective, technical perspectives can also be a reason to introduce lower tariffs for heat pumps and electric boilers, as they can be interrupted and do not stress the system as much as other devices in congested situations. Lithuania has planned to introduce preferential tariffs for heat pumps in accordance with the Law on Energy from Renewable Sources (Article 11, 3) - The National Commission for Energy Control and Prices shall: Establish preferential rates for electricity used for the operation of heat pumps (with accounting of electricity supplied to the compressor). However, to date, the preferential tariffs have not been introduced. For reference, the issue has been a central part of the discussion on heat pumps in Denmark, where electricity use for heat pumps has not only been subject to payments for distribution and transmission tariffs (around 25 EUR/MWh), but also electricity taxes and PSO. There are plans to significantly reduce the latter two requirements toward 2022, when PSO (approximately 23 EUR/MWh $\mathrm{O}_{4}$ 2017) will be completely phased out and electricity taxes will be reduced to $20 \mathrm{EUR} / \mathrm{MWh}$ from the current level of around 54 EUR/MWh.

The cost of generating district heating using heat pumps is compared to other options in Figure 61. It appears that heat pumps are competitive with new biomass and gasbased generation, even with the low COP used as a standard assumption. 
Figure 61: Levelised cost of district heating generation in 2020 and 2030. All technologies are assumed to produce 5000 full load hours per annum. The economy of heat pumps is shown with a higher COP level (see Table 2) and a higher electricity tariff (зо EUR/MWh)

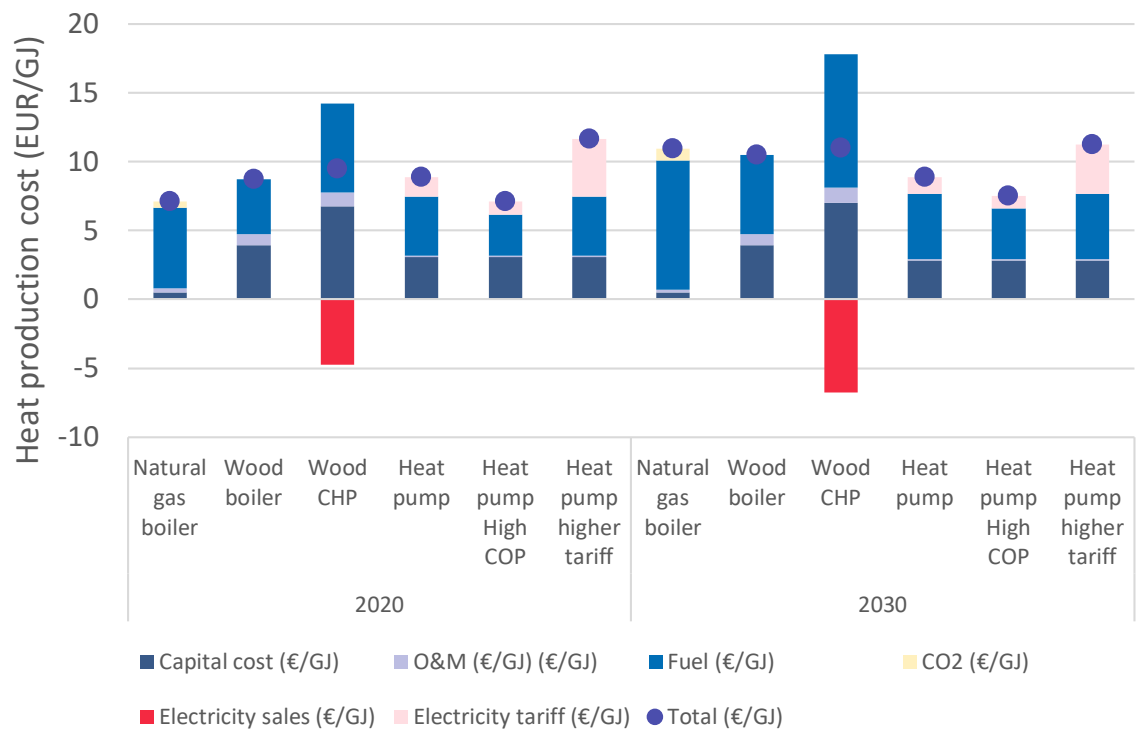

Key point(s): Heat pumps can provide a competitive alternative to biomass and gas boilers.

The opportunities for heat pumps in district heating have been investigated further in two sensitivity analyses, showing the effect of higher efficiencies and higher network tariffs (Figure 62). The higher COP increases the share of heat pumps from around $20 \%$ to $33 \%$ in 2030 in the $4 \mathrm{DS}$. Heat pumps will not be cost effective, when a network tariff of 30 EUR/MWh (or more) is applied. By 2050, heat pumps could supply up to around $40 \%$ of the heat consumption in the Baltic countries - and more than half of the consumption if higher COPs are achievable. However, network tariff levels of up to 30 EUR/MWh would limit heat supply from heat pumps to around $10 \%$. 
Figure 62: Annual heat generation by fuel in the Baltic countries for the $4 D S, 4 D S$ High COP and $4 D S_{30}$ EUR/MWh tariff

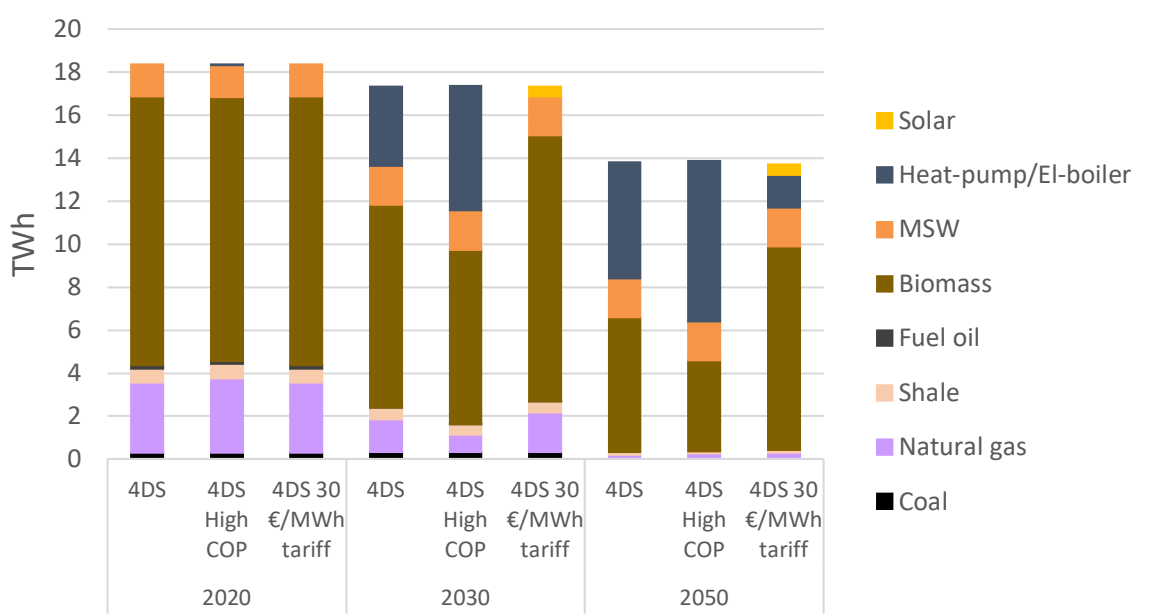

Key point(s): COP for heat pumps will influence the opportunities for heat pumps, but tariff and taxes on electricity use are the most important barrier to the introduction of heat pumps, which would be a cost-effective option in the district heating sector, also in the absence of RE goals (4DS). 


\section{Progressing towards low-carbon and renewable energy systems}

\subsection{Key Findings}

- GHG reductions should be led by electricity and district heating sectors, followed by transport, buildings, and other sectors. End-use sectors can reduce GHG emissions and increase the RE share through electrification only if the supplied electricity is $\mathrm{CO}_{2}$-free and renewable.

- The Baltic countries could achieve the proposed renewable energy targets using domestic resources. Energy efficiency measures, wind power, biomass, heat pumps, and solar power and heating are estimated to be the most cost-effective ways to increase the renewable energy share.

- The Baltic countries do not reach proposed Effort Sharing Sector (ESS) 2030 targets in the $4 \mathrm{DS}$. Especially Latvia will need additional reductions or flexibility measures to reach the target. The most cost-effective measures to reduce ESS emissions are to decrease oil consumption in ESS (most importantly in transport, buildings, and industrial plants that are not included in EU ETS) and to reduce fossil fuel use in smaller district heating plants that are not included in EU ETS.

- The Baltic countries increase their energy independence in the analysed scenarios largely due to national renewable energy and domestic electricity generation targets. In general, measures that reduce emissions increase the RE share, or increase energy efficiency also improve energy independence. The most notable exception is the use of shale oil, which is the only significant domestic fossil energy source.

- A large share of the non- $\mathrm{CO}_{2}$ emissions (from agriculture, industry processes, waste management) produced by the Baltic countries have more limited reduction options than $\mathrm{CO}_{2}$ emissions from energy use. The share of non- $\mathrm{CO}_{2}$ emissions increases from $25 \%$ in 2015 to $50 \%$ by 2050 in the BPO.

- The estimated additional energy system net costs of the BPO and 2DS are reasonably small. The additional costs compared to the $4 \mathrm{DS}$ range from $0 \%$ to $0.3 \%$ of GDP by 2030 and from $0.1 \%$ to $0.5 \%$ by 2050 . The BPO results indicate higher additional costs by 2030 than the 2DS. Presented costs do not include energy taxes or costs from $\mathrm{CO}_{2}$ prices. 


\subsection{Opportunities and threats}

- The Baltic countries are able to trade ESS emission allowances (2013-2030) and units of renewable energy through statistical transfers (until 2020) with other member states providing a potential source of extra income, if ESS emission development is more positive than in $4 \mathrm{DS}$.

- The Baltic countries have large biomass resources, which are exported, used to reduce emissions and increase the share of renewable energy in all energy consuming sectors. If bioenergy production grows less than assumed in the scenarios, the Baltic countries will require additional measures to reach their renewable energy targets and reduce their emissions.

- The Baltic countries face the risk of decreasing electricity generation capacity and increasing electricity imports due to ageing capacity, slightly poorer wind and solar resources, and RE subsidies in Central Europe and the Nordic countries. This development could put the renewable energy targets and domestic electricity generation targets at risk.

- The Baltic countries can avoid becoming large net importers of electricity. Modelled subsidy levels about 10 EUR/MWh for all domestic generation were sufficient to reduce annual net imports to zero by 2030 in a situation where wholesale power prices would be approx. 40 EUR/MWh. Wind and solar power provide the most cost-efficient way of reducing import dependency.

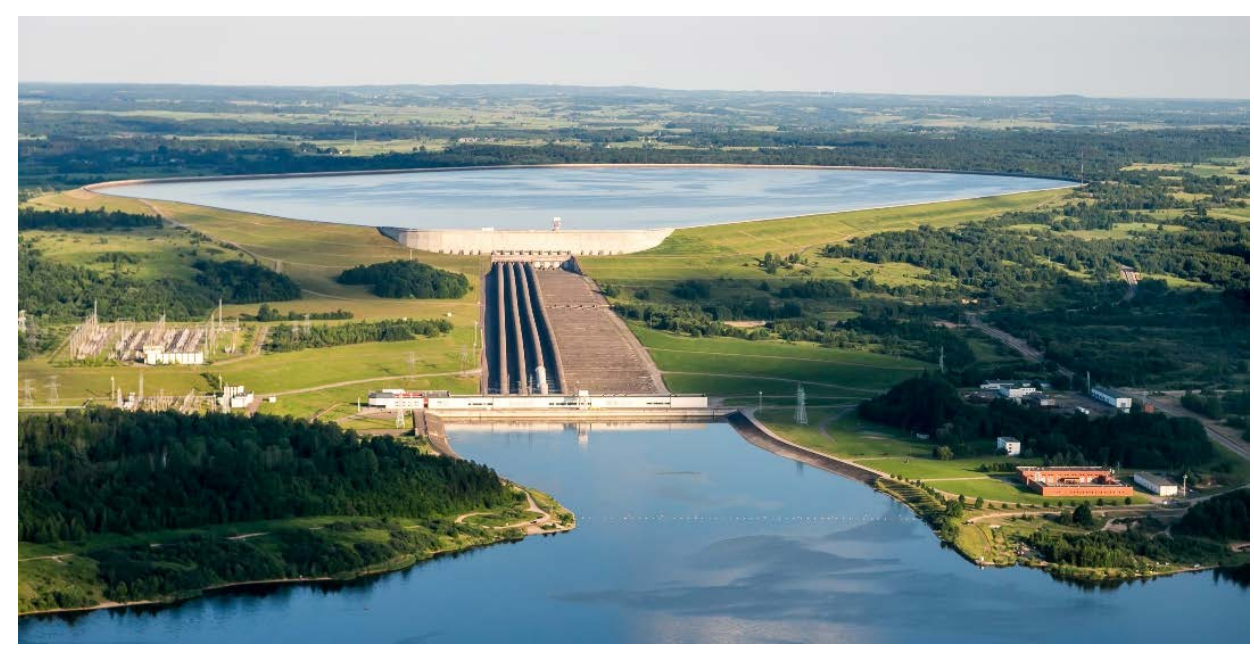

\subsection{GHG emissions}

Current policy measures and developing technology have already stopped the increase of GHG emissions in the Baltic countries (Figure 63). GHG emissions in the Nordic countries, EU and Baltic countries peaked around 2005 and have continued to decline despite increasing GDP. Future emissions trajectories in the scenarios indicate that these 3 groups of countries will follow very similar pathways. 
Figure 63: GHG emissions indexes (left) and GHG emissions per capita (right) in the Baltic countries, Nordic countries and EU
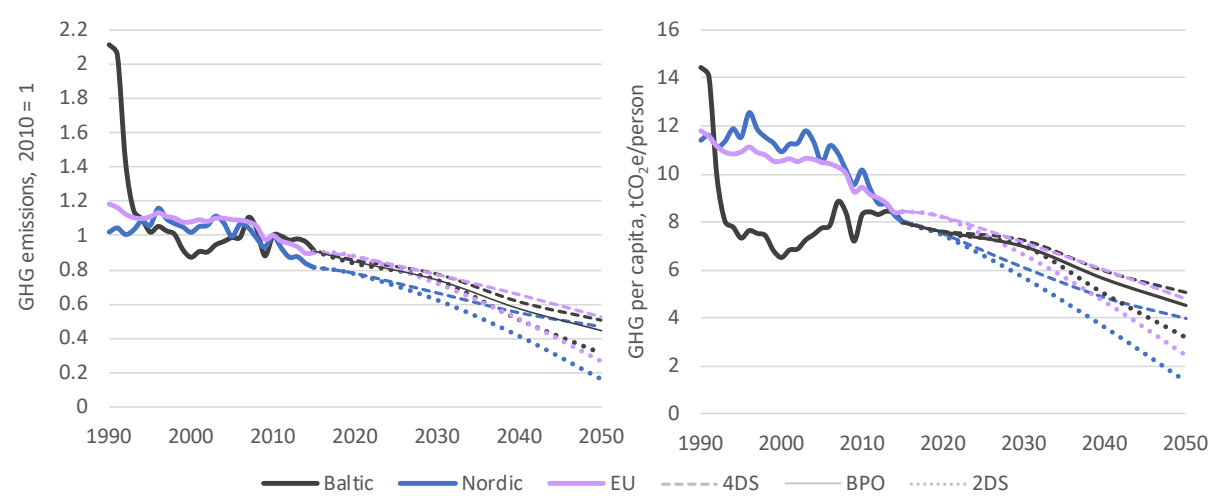

Key point(s): GHG emissions indexes and per-capita emissions of the Baltic countries are similar to the EU average; the Nordic countries are at a slightly lower level.

Note: $\quad$ GHG emissions excluding LULUCF and international bunkers.

Source: $\quad$ GHG emissions statistics from UNFCCC (2017), population statistics from WB (2017), GHG projections for the Baltic and Nordic countries in the TIMES-VTT modelling. EU projections are from PRIMES REF2016 (EC, 2016a) and 2050 Energy roadmap (EC, 2011).

The electricity and district heating sector reduces emissions before other sectors in the scenarios, because it has the most cost-effective emissions reduction potential, and models need $\mathrm{CO}_{2}$-free electricity to decarbonise other sectors (Figure 64). Emissions from electricity and district heating have decreased by $20 \%$ from 2010 to 2015 and the trend continues in the scenarios. In the $4 \mathrm{DS}$, the energy sector reaches a $55 \%$ reduction by 2030 compared to 2010 and $-90 \%$ to $-85 \%$ by 2050 compared to 2010 .

Low-carbon electricity generation offers other sectors the possibility of reducing emissions and increasing the renewable share through electrification. Transport sector emissions increased from 2010 to 2015, but the trend ought to be reversed. In the scenarios, transport sector emissions are reduced through energy efficiencies and alternative fuels (biofuels, electricity, biogas, and hydrogen). Blended biofuels are a quickly deployable measure that does not require investing in new cars. Electric vehicles are estimated to reach price parity with combustion engine vehicles around 2030, but government policies are likely required to build charging infrastructure.

Emissions from agriculture and industry processes are usually difficult to mitigate with current technologies. Deep emission reductions in these sectors require new technologies and solutions. Industry's $\mathrm{CO}_{2}$ from energy should be reduced through energy efficiency measures and fuel switching, but industry process emission reductions require new technologies and solutions. Despite small improvements, the emissions from these sectors increase, due to assumed growth in production. 
Figure 64: Sectoral GHG emissions trajectories in the Baltic countries in the BPO (excluding LULUCF and international bunkers)

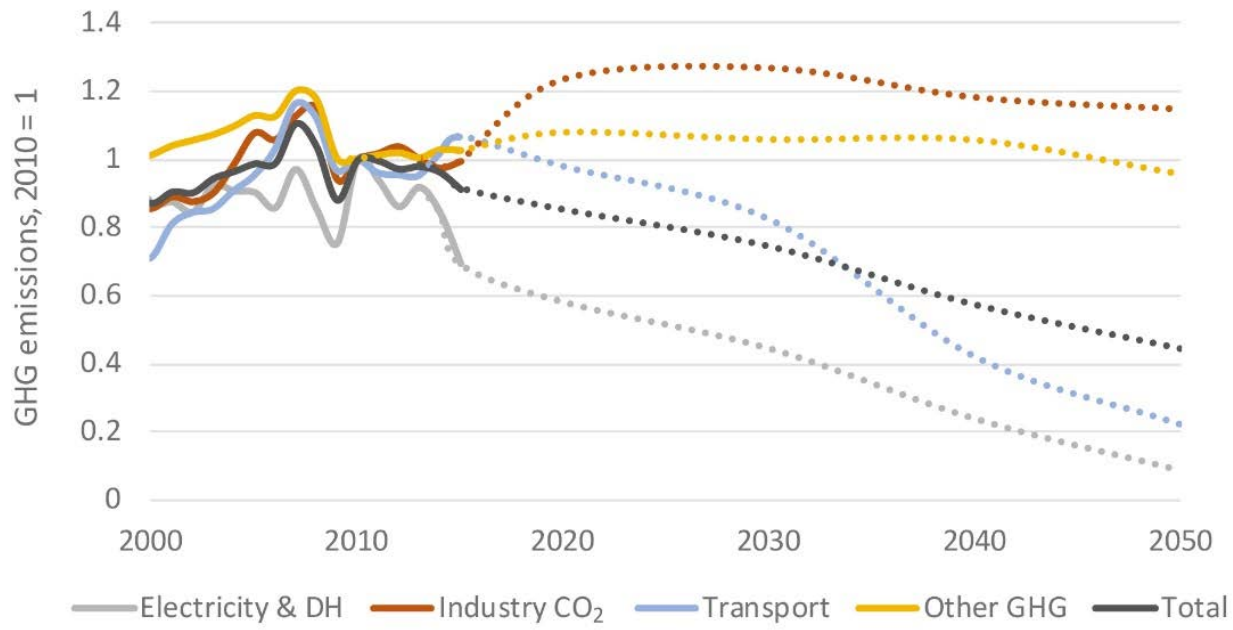

Key point(s): Electricity and district heating should reduce emissions first.

Source: $\quad$ GHG data from UNFCCC (2017).

All Baltic countries are projected to need additional measures or flexibilities to reduce emissions to reach 2030 ESS target (Figure 65). This is especially important for Latvia, where ESS emissions would be above the target pathway throughout the second ESS period from 2021 to 2030. Latvia needs $0.9 \mathrm{MtCO}_{2} \mathrm{e}$ more emission reductions in the ESS sector than takes place in the 4 DS in 2030 (additional 10\% from 2015 emissions).

In 4DS, Estonia's and Lithuania's ESS emissions decrease slightly from the current levels and remain below the target pathways until 2025. After this, ESS emissions in Lithuania and Estonia are above the target pathway in the $4 \mathrm{DS}$. Both are estimated to need $200 \mathrm{ktCO}_{2} \mathrm{e}$ additional reductions of flexibilities.

The emission projections presented here do not include flexibility measures. For Latvia, the proposed maximum flexibilities from LULUCF and Article 10(2) of the ESR total approximately $0.2 \mathrm{MtCO}_{2} \mathrm{e}$ annually from 2021 to 2030. For Lithuania, the same amount is $0.3 \mathrm{MtCO}_{2} \mathrm{e}$, and for Estonia the amount of these flexibilities are only 0.02 $\mathrm{MtCO}_{2} \mathrm{e}$. Additional flexibilities can be traded from or to other Member States and through banking of unused emission allowances from the earlier years within the same commitment period. 
Figure 65: ESS target pathways from 2013 to 2030 and ESS emissions in the 4 DS and BPO

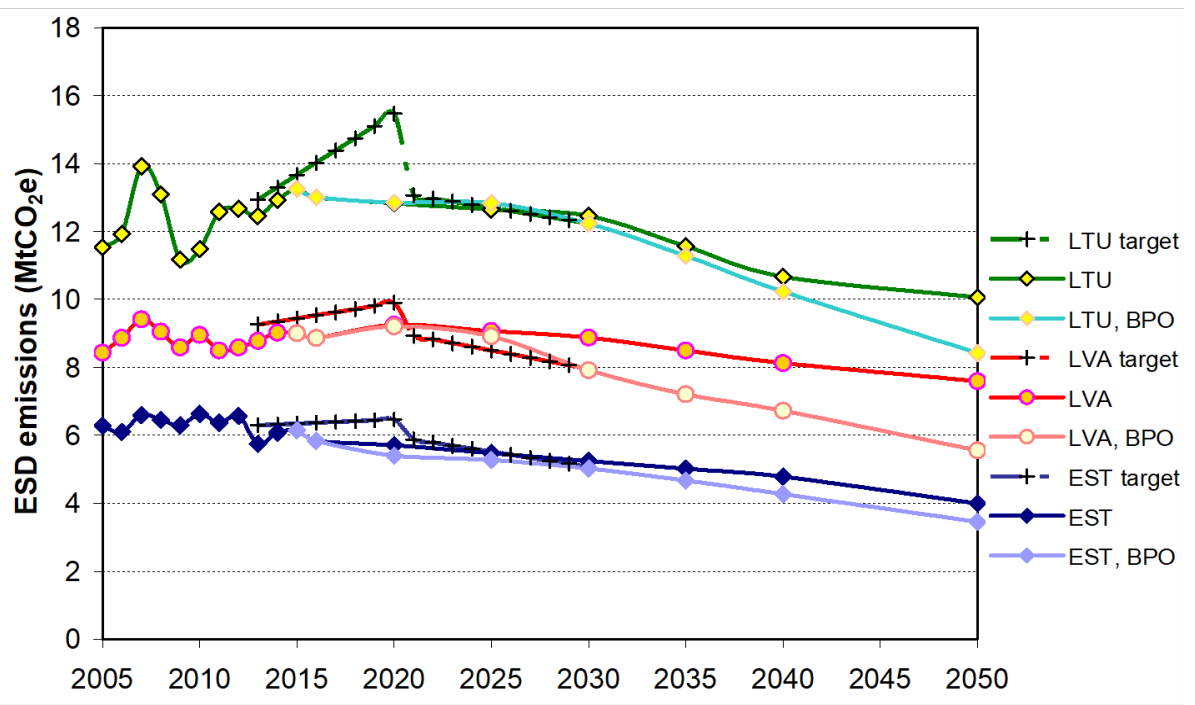

Key point(s): The Baltic countries do not reach their 2030 ESS targets in the $4 \mathrm{DS}$. Especially Latvia needs additional measures.

Source: $\quad$ ESS emissions statistics from EEA (2017b), target pathways from 2013/162/EU, 2013/634/EU, and EC (2016b).

The main measures to reduce ESS emissions from the $4 \mathrm{DS}$ to the BPO were to reduce the use of oil in ESS - most importantly to adopt alternative fuels in the transport sector (biofuels, electricity, natural gas, hydrogen buses, biogas), to reduce the use of heating oil (increasing biomass, heat pumps and solar heating), and to reduce the use of fossil fuels in smaller district heating plants that produce ESS emissions. It is likely that industry sector would hold additional potential to improve energy efficiency and to reduce emissions and more detailed assessments should be done in further studies.

Emissions in the waste management and agricultural sector were also reduced, because we assumed that they develop in the same way as in the WEM scenario in the PaMs reports in the ${ }_{4} \mathrm{DS}$ and in the WAM scenario in the PaMs reports in the BPO for 2017 (Ministry of the Environment of Estonia 2017, Ministry of the Environment of Latvia 2017, Ministry of the Environment of Lithuania 2017).

These estimates do not include flexibility measures from earlier years, from other countries or from the LULUCF sector. If a certain EU member state over performs (fewer emissions than target) in one year, those excess allowance units can be saved and used in later years. With this rule in place, both Estonia and Lithuania achieve their cumulative target for the period from 2021 to 2030 - but not the 2030 target - already in the $4 \mathrm{DS}$. According to the European Commission's estimates, the Baltic countries are likely to benefit from the LULUCF sector and don't have to achieve as low emissions as presented here (EC, 2016c).

EU member states are allowed to trade ESS allowance units. There could be relatively low-cost additional measures in Estonia and Lithuania, which could be sold to 
other EU member states, like the Nordic countries, which could avoid implementing their most expensive mitigation measures.

ESS emissions have relatively large annual variations, as can be seen from the historical data in Figure 66. In Estonia and Latvia, the annual variation from 2012 to 2016 was $\pm 3 \%$, but for Lithuania, the range was $\pm 5 \%$. These annual variations result from varying economic activity, heating degree days and transport demand. For Latvia and Lithuania, the variations are larger than the changes from 2015 to 2030 in the 4DS.

GHG emissions are reduced in all sectors towards 2050, but the shares of methane, nitrous oxides, and F-gases increase towards 2050, because those emissions are harder to mitigate than $\mathrm{CO}_{2}$ emissions (Figure 71 ). The share of non- $\mathrm{CO}_{2}$ emissions increases from $27 \%$ in 2015 to $50 \%$ by 2050 in the $4 \mathrm{DS}$ and to $72 \%$ by 2050 in the $2 \mathrm{DS}$.

Carbon Capture and Storage (CCS) is the biggest single emission reduction measure in 2DS in 2050 compared to BPO. We assume that CCS technology would be available by 2050 in the $2 \mathrm{DS}$ to mitigate $\mathrm{CO}_{2}$ emissions from industry processes, mainly cement manufacturing and oil refineries, for the Baltic countries. Additionally, bio-CCS could make it possible to produce negative emissions also in electricity and district heating. These technologies are adopted in the $2 \mathrm{DS}$ in 2050 when the $\mathrm{CO}_{2}$ price increases to up to $100 \mathrm{EUR} / \mathrm{tCO}$.

Latvia has potential $\mathrm{CO}_{2}$ storage sites. Alternatively, stored $\mathrm{CO}_{2}$ could be transported to Norwegian offshore sites with tanker ships. Bio-CCS technology is currently not commercially available, but some industry applications of Bio-CCS have already been demonstrated, such as using CCS with bioethanol production and steam methane reforming (SMR) (MIT, 2017).

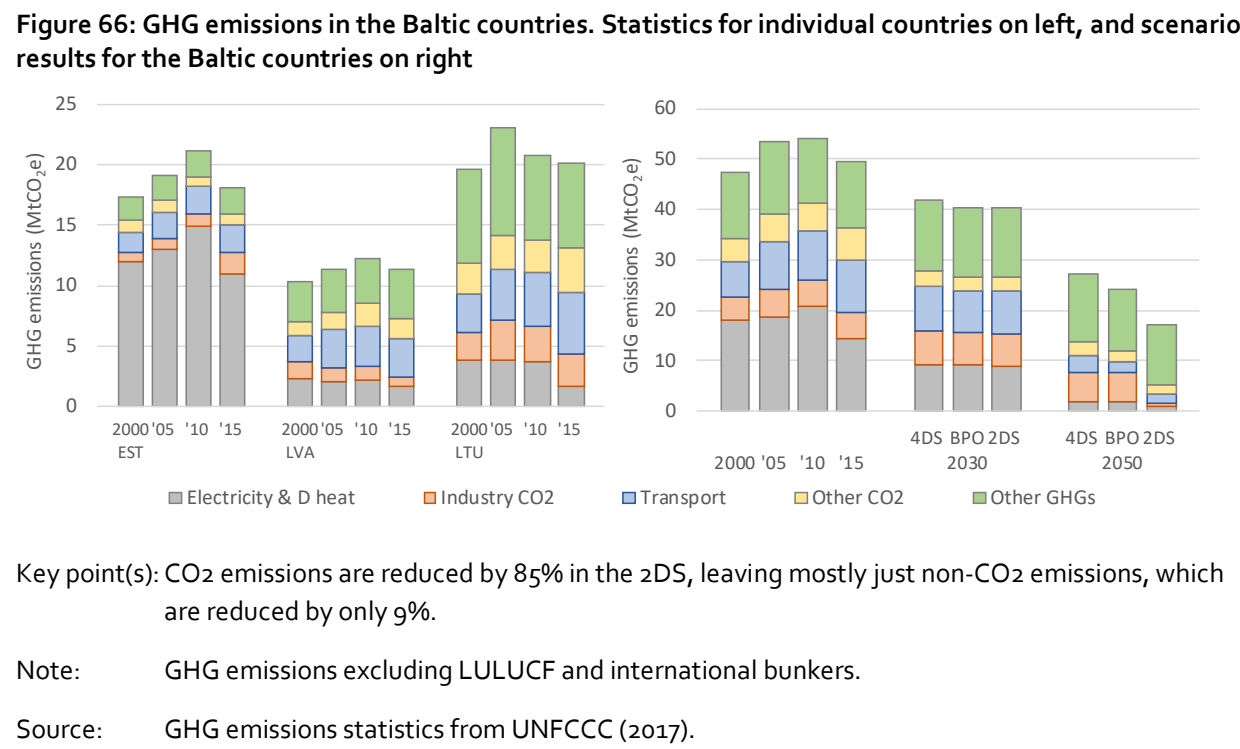




\subsection{Renewable energy}

The Baltic countries' national renewable energy targets would take the development to the 2DS pathway. The Baltic countries' RE share from final energy falls between that of the Nordic countries and the EU (Figure 67). The RE shares of these three groups of countries have been growing at a similar pace from 2005 to 2015. In the scenarios, the existing order remains unchanged, but the renewable levels of the Baltic countries would grow closer to those of the Nordic countries towards 2050.

Figure 67: Renewable energy share from final consumption in Baltic countries, Nordic countries, and EU

$$
100 \%
$$

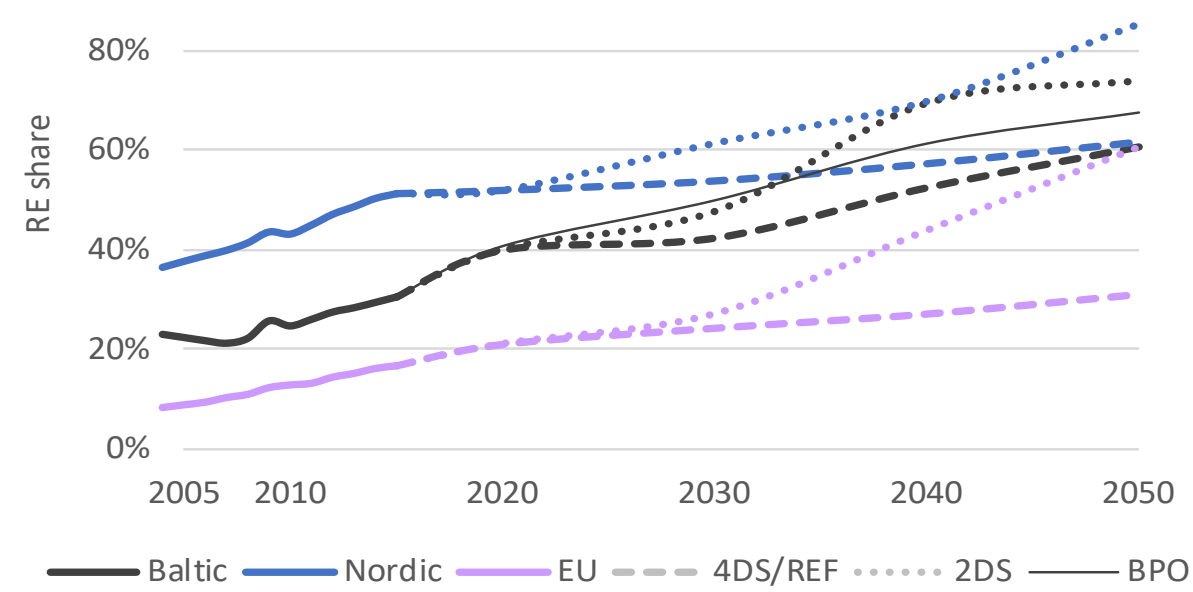

Key point(s): The Baltic countries' renewable energy targets take them to the 2DS pathway, but more targets are needed towards 2050 to remain on this pathway.

Source: $\quad$ Statistics from Eurostat (2017b). Projections for the Nordic countries calculated from NETP 2016 scenarios (NER, 2016). EU projections are from PRIMES REF2016 (EC, 2016a) and 2050 Energy roadmap (EC, 2011).

The Baltic countries' proposed 2030 targets for renewable energy are ambitious but achievable. Latvia came closest to the proposed 2030 target in $2015(39 \% / 50 \%)$ and reaches the target level in the 4DS (Figure 68). Estonia and Lithuania both need to increase their RE share by approximately $20 \%$ from 2015 to reach their proposed 2030 targets and do not achieve that level in the $4 \mathrm{DS}$. For Estonia and Lithuania, national RE targets are above the 2DS pathway and require early action. 
Figure 68: Renewable energy share (of final consumption) target pathways from 2013 to 2030 , and RE shares in the scenarios

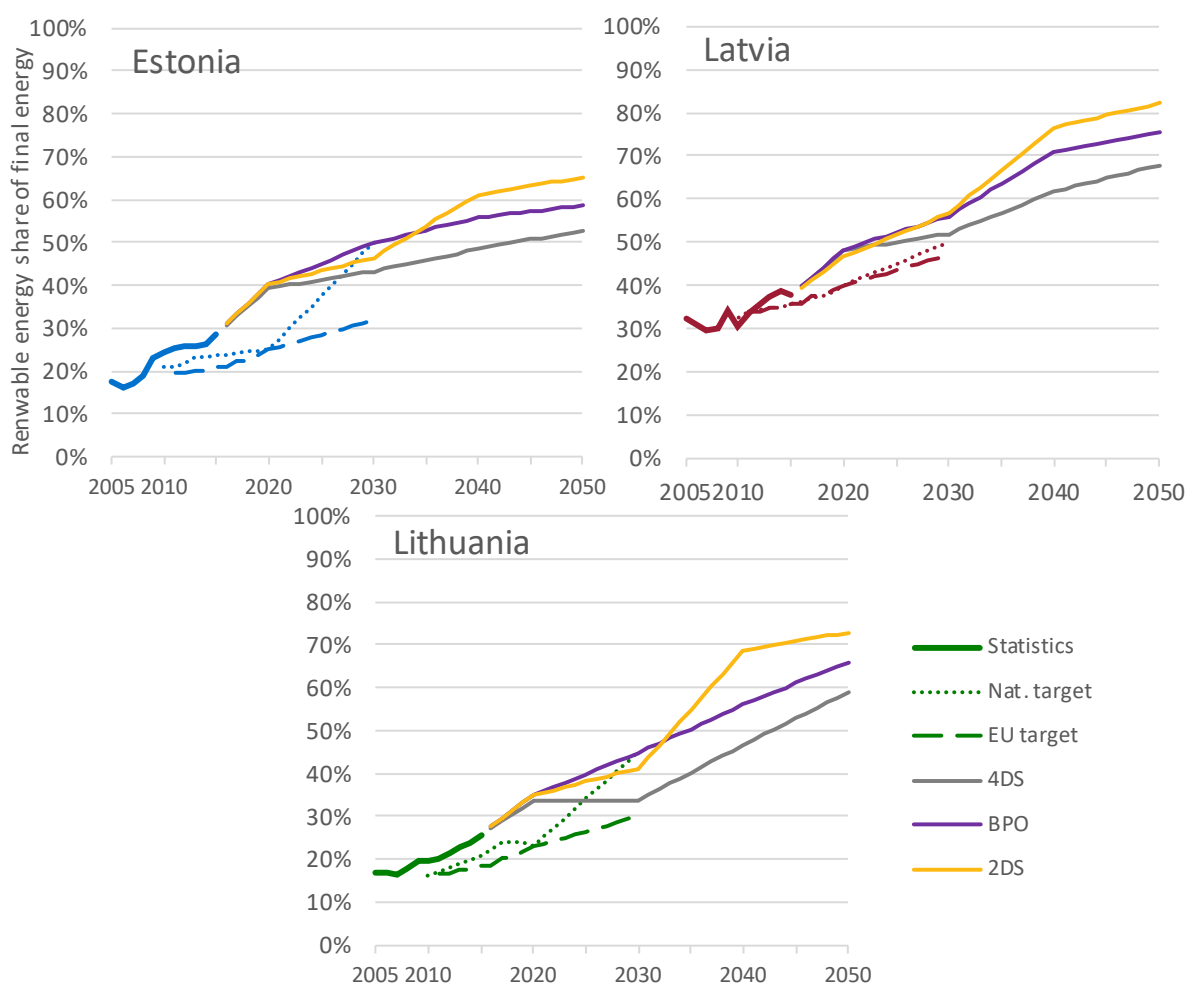

Key point(s): Renewable energy shares increase in the BPO due to renewable energy targets in Estonia and Lithuania, and ESS target in Latvia.

Source: $\quad$ Statistics from Eurostat (2017C), national target pathways from MKM (2017), Ministry of Economics Latvia (2013), Ministry of the Energy of Lithuania (2017). EU 2020 targets from EC (2009). EU 2030 proposal does not have national targets, but we calculated an indicative national target here that is $7 \%$ higher than each 2020 target.

Estonia and Lithuania need additional policies to reach national renewable energy targets. Wind, biofuels, biomass, heat pumps (for buildings and district heating), solar, and waste incineration seem to be the most attractive options to increase RE production. RE share can be increased also by reducing the use of fossil fuels through energy efficiency.

The Baltic countries have a good renewable energy potential and domestic resources are sufficient to achieve the renewable energy targets with domestic resources. The largest increase of renewable energy sources takes place in electricity and district heat production in all our scenarios (Figure 69). Direct consumption of biomass decreases mostly because of energy efficiency measures in buildings, but the amount of produced biomass increases. Biomass consumption shifts more to electricity and district heating, and to biofuel production in the scenarios. Biomass is an important cross-cutting issue linking electricity and district heating, buildings, transport, industry and material use targets. 
The share of biofuels in transport increases from the level of $3 \%$ in 2015 to $6 \%$ in 2020 and $7 \%$ in 2030 in the Baltic countries in the 4 DS. The amount of biofuels increases more in the BPO, where it is used to increase the RE share and to reduce ESS emissions. In the BPO, the share of biofuels increases to $12 \%$ in 2030 . If biofuels in transport are considered unwanted for reasons not assessed here, such as LULUCF emissions, the next options on the list would be to increase the share of wind power, solar power, heat pumps and biogas to higher levels than in these scenarios.

Figure 69: Renewable final energy use by renewable energy type and by sector in the Baltic countries
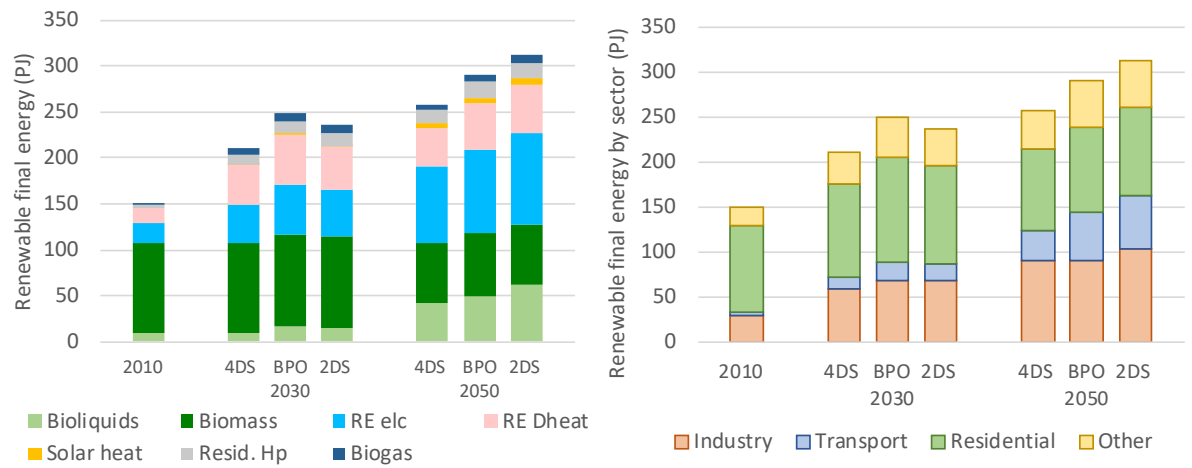

Key point(s): Renewable electricity and renewable heating provide the largest increases from renewable energy sources.

Source: $\quad$ Statistics from IEA Energy Balances (IEA, 2017).

There is strong competition from biomass, especially in the 2DS and across different domestic uses and exports. The Baltic countries have significant potential for harvesting agricultural biomass (residues + energy crops), but these are assumed to be more expensive than energy wood. Our assumptions for sustainable biomass and waste potentials are listed in Annex I. These are often more modest than assumptions in comparable European and national studies. Estimated potentials still lead to relatively large increases in biomass use, which leads to both increasing RE share and decreasing emissions already in the 4DS (Figure 70). 
Figure 70: Biomass production and trade balance

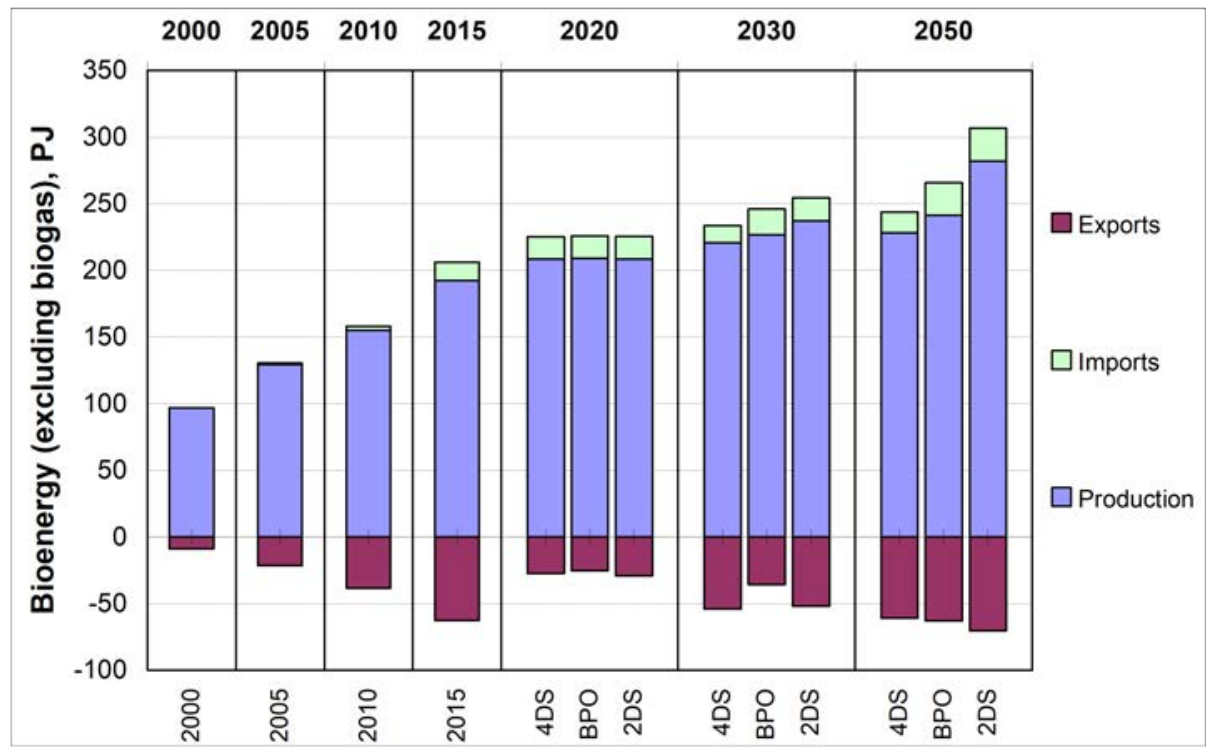

Key point(s): Biomass production has already increased from $100 \mathrm{PJ}$ in 2010 to $200 \mathrm{PJ}$ in 2015 in the Baltic countries. Production in the scenarios increases from 200 to 250 in $4 \mathrm{DS}$ and to $300 \mathrm{PJ}$ in $2 \mathrm{DS}$ in 2050.

Source: $\quad$ Statistics from IEA energy balances (IEA, 2017).

\subsection{Energy consumption}

The Baltic countries' primary energy supply is close to the EU average in the scenarios when measured by primary energy supply per person and by carbon intensity of primary energy (Figure 71). When measured by primary energy per GDP, the Baltic countries start developing towards the Nordic and EU averages, but don't reach the same level by 2050 . 
Figure 71: Comparing the Baltic countries' primary energy indicators to the Nordic countries and the EU

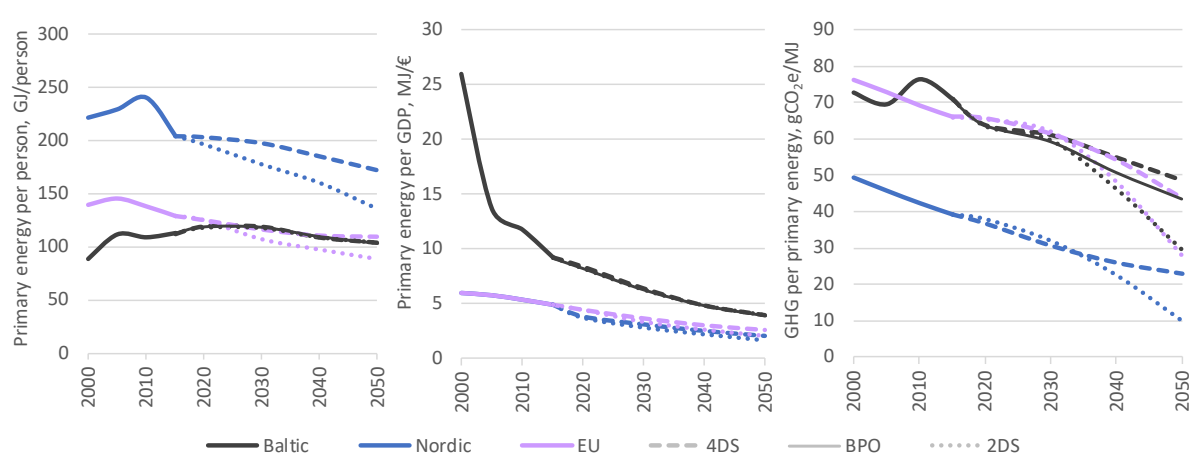

Note $\quad$ Figures for the Baltic countries are close to the EU average in primary energy per person and GHG per primary energy, but are higher in primary energy per GDP.

Source: Energy statistics from IEA energy Balances (IEA, 2017), GDP and population from WB (2017), Projections for EU from PRIMES REF2016 (EC, 2016a) and 2050 Energy Roadmap (EC, 2011). Projections for the Nordic countries from NETP 2016 (NER, 2016). See more details on projections for the Baltic countries in the supplementary input data file.

Eurostat and IEA define primary energy supply and final energy consumption slightly differently for energy transformation and industry. On average, IEA's statistics for primary and final energy for Lithuania are $20 \%$ higher than Eurostat's. For Estonia, the difference is smaller. In the IEA statistics, primary energy is $7 \%$ lower than in the Eurostat statistics, and final energy is $4 \%$ higher. For Latvia, these two statistics show almost the same numbers. The TIMES-VTT is developed based on IEA statistics, and the numbers in this report cannot be directly compared to studies or models based on Eurostat methodology.

Energy efficiency increases in all three scenarios. Figure 72 shows historical primary and final energy consumption in the Baltic countries and results from the three main scenarios. Solid lines from 2000 to $2015 / 2016$ are statistics, dotted lines from 2005 to 2020 are indicative EU target pathways. Thin lines from 2015 to 2050 are scenario results. We have adjusted the EU 2020 target levels to match the differences between Eurostat and IEA methodologies.

Electrification of end use sectors, renewable electricity production, and building energy efficiency measures bring significant energy savings in the scenarios. Primary energy supply experiences the strongest decrease in the scenarios due to the reduced use of oil in transformation, district heating, and transport. The natural gas use will also decrease. Biomass supply increases in the scenarios, but not enough to compensate for the decreased use of oil and natural gas.

The differences between the scenarios are quite small, because many existing measures and technology development bring significant gains already in the $4 \mathrm{DS}$. The BPO is quite similar to the $4 \mathrm{DS}$, but we only add the Baltic countries' national RE share and expected EU ESS targets for 2030. These two additional targets result in some energy efficiency measures, but have the biggest impact on RE share and emissions, as 
required by the targets. In addition, TIMES is a cost-minimising model that applies most energy efficiency measures due to cost minimisation already in the $4 \mathrm{DS}$.

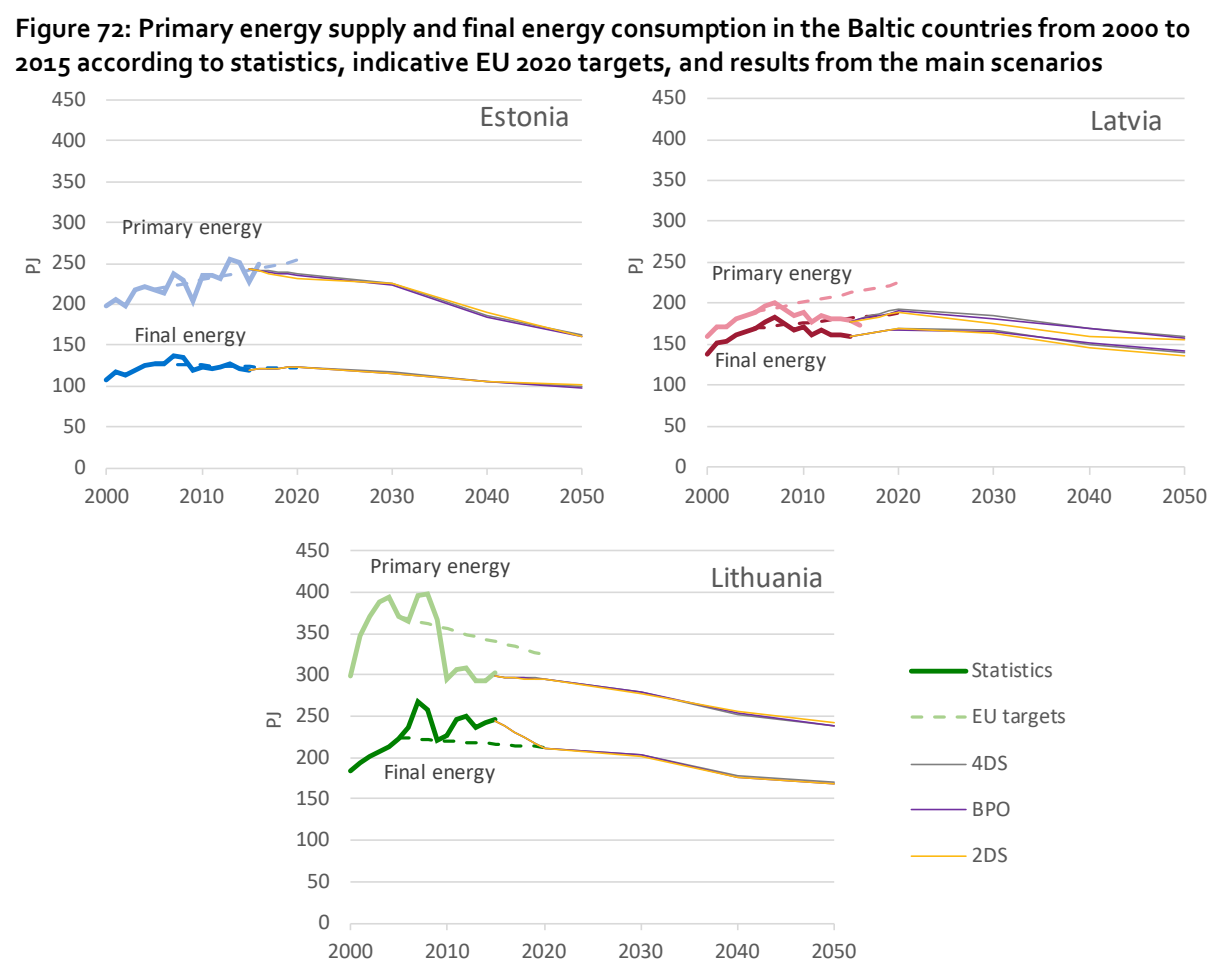

Key point(s): The differences between the scenarios are quite small, because most energy efficiency measures are assumed already in the $4 \mathrm{DS}$ and further improvements in the BPO and $2 \mathrm{DS}$ are defined through GHG savings and increasing RE share.

Source: $\quad$ Energy statistics from IEA energy balances (IEA, 2017), the methodology of which differs from the Eurostat methodology for calculating final and primary energy. National target pathways (EC, 2012) are scaled to match IEA statistics.

\subsection{Security of supply}

\subsubsection{Overall energy system}

The main energy import products in the Baltic countries are oil, natural gas and electricity. The security of supply should be sufficient for both annual needs (energy) and momentary needs (capacity). Oil and natural gas consumption decreases in the scenarios, but electricity net imports double in $4 \mathrm{DS}$. In the BPO and 2DS, there's less electricity net imports, but the Baltic countries would still be a net importer of electricity.

The main energy export product in the Baltic countries is biomass and the exports of biomass from the Baltic countries increase in all scenarios. 
Measures that reduce the use of fossil fuels or increase energy efficiency will also strengthen energy independence. The most notable exception in the Baltic countries are measures that decrease the use of shale oil in Estonia.

Electrification is a double-edged measure from the perspective of security of supply, because it reduces the use of fossil fuels, but it increases the use of electricity. Electricity consumption increased from $60 \%$ to $80 \%$ in the scenarios, due to assumed increases in production and consumption, and due to electrification. This increases the need to invest in new domestic generation capacity.

If assumed growths, e.g. in industry production, are not realised, the growth of electricity consumption will be lower. In addition, if modelled electrification rates do not come to fruition, electricity consumption may decrease due to efficiency improvements. If efficiency improvements are also not realised, electricity consumption could follow the status quo. All these assumption categories should be studied further.

All the Baltic countries improve their energy independence in the scenarios (Figure 73). Estonia's starting level in 2015 was already very good with only $7.5 \%$ of total energy consumption imported. Latvia's situation has also improved significantly since 1990 when net imports made up 90\% of all consumed energy. Lithuania imported $78 \%$ of all consumed energy in 2015. The sharp increase in 2010 was due to the shutdown of the Ignalina nuclear power plant.

The EU is projected to see an opposite trend compared to the Baltic countries. As the natural gas production in the EU decreases, renewable production might not increase fast enough and the overall energy dependence increases up to 2050 in the PRIMES Reference 2016 scenario. In the EU Energy Roadmap 2050, the energy dependence starts to ease from 2030 onwards.

Figure 73: Baltic countries energy dependence

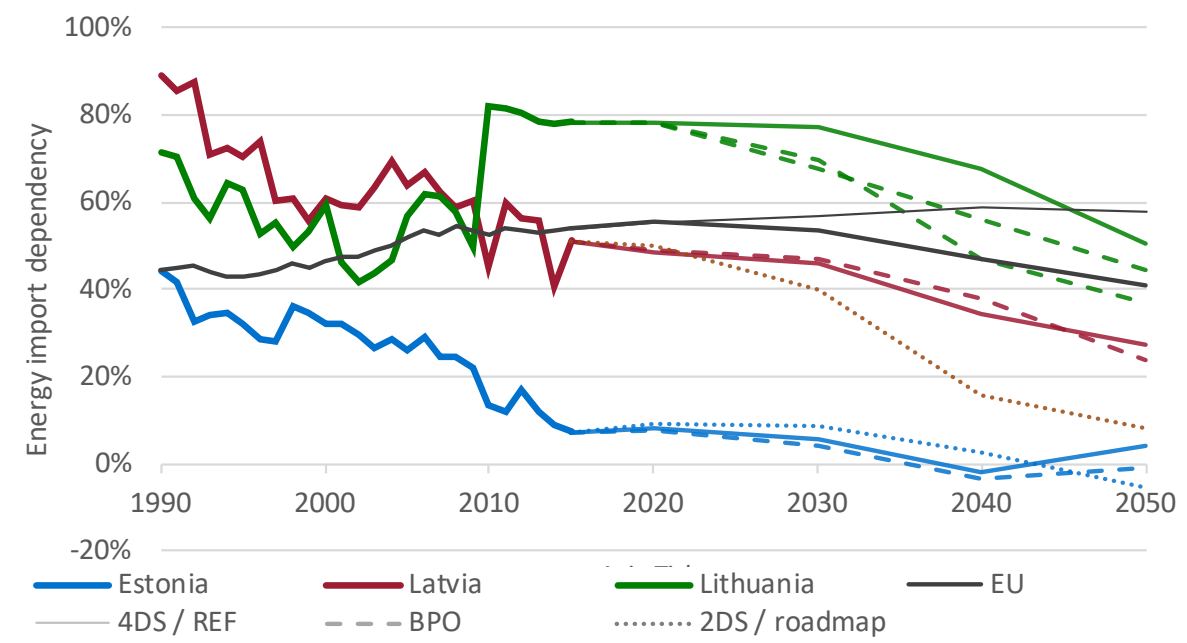

Key point(s): Energy independence improves mostly with the same measures that are needed to reduce GHG emissions, increase RE share or improve energy efficiency.

Source: $\quad$ Statistics from Eurostat (2017d). EU projections from PRIMES Reference 2016 (EC, 2016a) and 2050 Energy roadmap (EC, 2011). 


\subsubsection{Electricity and district heat}

In all three core scenarios, $4 \mathrm{DS}, \mathrm{BPO}$ and 2DS, the Baltic countries are net importers of electricity. The Baltic countries are not only importing electricity, their capacity balances are also increasingly becoming negative. In the $4 \mathrm{DS}$, all existing gas-fired generation capacity is shut down by 2030 and the Baltic countries are increasingly relying on imports to supply peak demand.

Four sensitivity analyses have been performed to examine what various selfsufficiency requirements will require in terms of additional generation capacity and investments. Two situations are considered: 1) an integrated approach to security of supply where the three Baltic countries cooperate on providing self-sufficiency and 2) a situation where each country complies with a domestic requirement. For each of the two situations, two cases are explored: 1) one where the self-sufficiency requirement only concerns energy imports and 2) one where the requirement both concerns energy self-sufficiency and capacity self-sufficiency. All four self-sufficiency scenarios are based on the $4 \mathrm{DS}$ framework:

1. 4DS C SS: As 4DS but each Baltic country has an energy-based self-sufficiency requirement of $100 \%$ from 2030 and onwards. This means that on an annual basis each Baltic country should produce as much electricity as it consumes.

2. 4 DS B SS: Same as 1) but in this case the Baltic countries as a whole have an energy-based self-sufficiency requirement of $100 \%$.

3. 4 DS C SS CM: Same as 1) but in addition to the energy-based self-sufficiency requirement, each Baltic country has a capacity requirement (capacity mechanism), corresponding to $105 \%$ of peak demand.

4. $4 \mathrm{DS}$ B SS CM: Same as 3) but in this case both capacity and energy requirements comply with the Baltic countries as a whole.

When determining the different technologies' contribution to the capacity balance, wind is attributed a capacity value of $7 \%$ and solar a value of $4 \%$. All other generation technologies have a capacity value of $90 \%$.

The self-sufficiency scenarios show that solar and wind provide the cheapest options to delivering energy security in all three countries (Figure 74). This is the case whether the self-sufficiency requirements are implemented individually for each country or for all three Baltic countries as a whole. The capacity requirement is mainly fulfilled by investments and re-investments in natural gas-fired capacity and shale oil capacity. While the thermal power plants also contribute to complying with the energy self-sufficiency requirement, their generation costs are still relatively high, and wind and solar are also the most important technologies to comply with the energy-based self-sufficiency target in this case. 
Figure 74: Development of power generation in the Baltic countries for the $4 \mathrm{DS}$ and four sensitivity analyses focusing on self-sufficiency

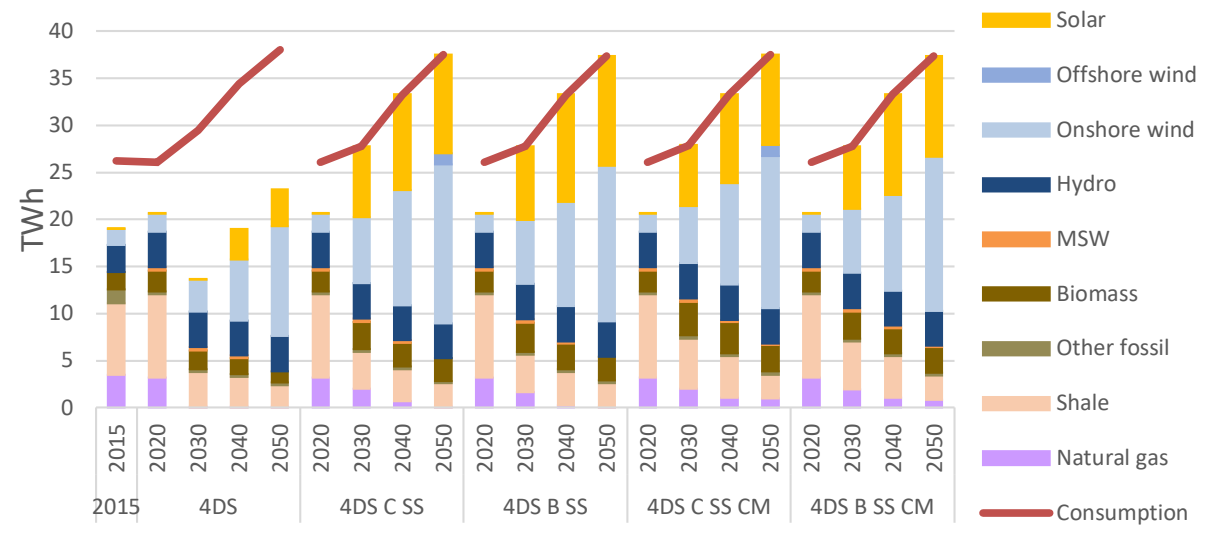

Key point(s): Solar and wind power provide the cheapest options for energy-based self-sufficiency.

Note: $\quad$ Scenario abbreviations: C SS: Energy self-sufficiency for each country, B SS: Energy selfsufficiency for Baltic countries, CM: Capacity mechanism.

It has not been within the scope of this project to undertake dedicated reliability analyses of the security of supply situation in the scenarios to test how vulnerable the project power systems are to tripping of power plants or failure of interconnectors. However, comparing peak load demand of all three Baltic countries with the available firm capacity indicates increasing dependence on imports. In the $4 \mathrm{DS}$, literally all existing gas-fired generation capacity will be shut down towards 2030. From 2030 the Baltic countries will rely on imports to supply peak demand in both the $4 \mathrm{DS}$ and the $2 \mathrm{DS}$ (Figure 75). This development is a result of both reductions in generation capacity (phasing-out of oil-shale power and natural gas capacity) and increasing peak demand. 
Figure 75: Development of power capacity compared to peak demand in the Baltic countries for the 4DS and four sensitivities

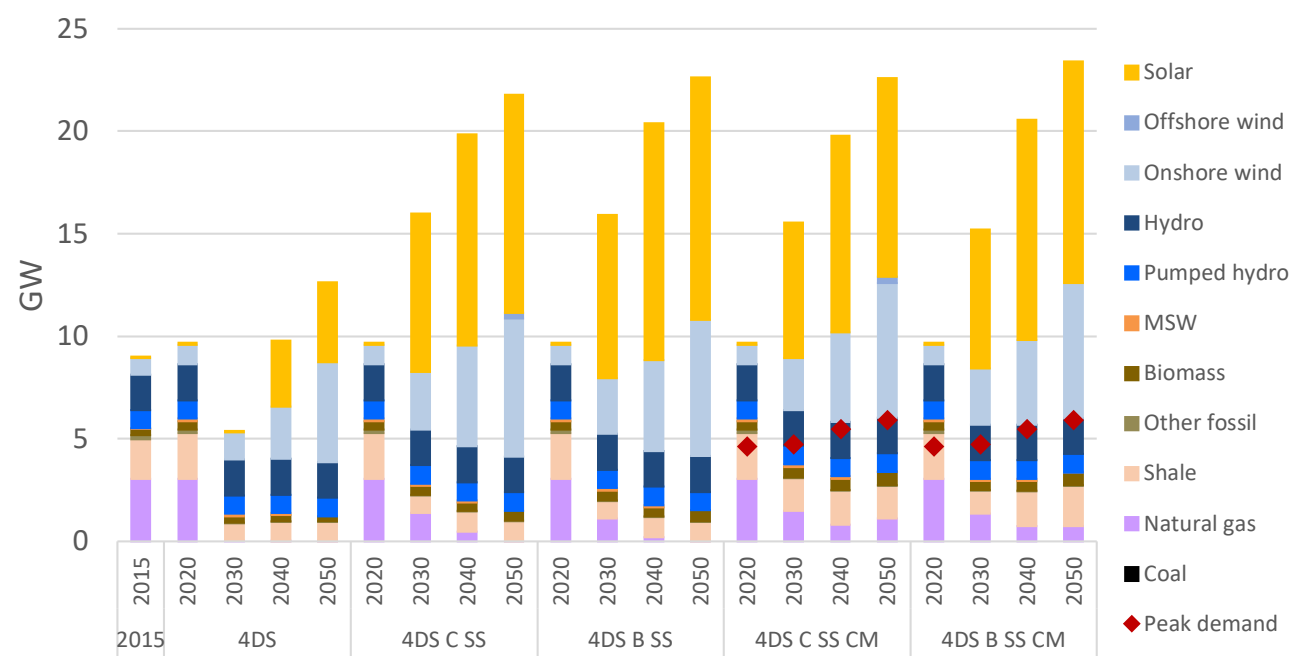

Key point(s): Introducing capacity requirements makes it feasible to maintain about $3 \mathrm{GW}$ of natural gas and shale oil capacity - without this requirement thermal capacity is reduced to approx. $1 \mathrm{GW}$.

Note: $\quad$ Scenarios abbreviations: C SS: Energy self-sufficiency for each country, B SS: Energy self-sufficiency for Baltic countries, CM: Capacity mechanism. Peak demand indicated on the graph does not include demand for electricity based heat generation or pumped storage since these demands would be interruptible. The indicated increases in shale capacity in the CM-scenarios in 2050 are due to investments in retort gas capacities. Investment cost are similar to natural gas power plants, which might be a more viable solution in practice, as availability of natural gas is easier to ensure. This will neither change the picture or the cost of the sensitivity analyses.

Table 15 shows the marginal cost of complying with the various self-sufficiency scenarios. If the energy self-sufficiency requirement is to be complied with on a national level, it would cost between 9 and 11 EUR/MWh by 2030, lowest in Lithuania and highest in Estonia. A common self-sufficiency scenario for the Baltic countries would cost around 10 EUR/MWh by 2030, indicating that synergies between the countries are limited in this case. The energy self-sufficiency requirements also have a positive impact on the power balance. For example, in the $4 \mathrm{DS}$ all gas fired capacity is phased out by 2030, whereas approx. 1,360 MW of capacity is maintained in the two energy self-sufficiency scenarios. Without maintaining this capacity, the capacity balance for the Baltic countries as a whole would be negative by 2030.

Adding national capacity self-sufficiency requirements will involve additional cost of around $27 \mathrm{EUR} / \mathrm{kW}$ for Estonia and $13 \mathrm{EUR} / \mathrm{kW}$ for Lithuania by 2030, whereas Latvia has sufficient generation capacity to comply with the requirement. Adding a capacity self-sufficiency requirement has a downward effect on the cost of energy selfsufficiency, because the power plants that are assigned to ensure sufficient capacity may also contribute to energy self-sufficiency. 


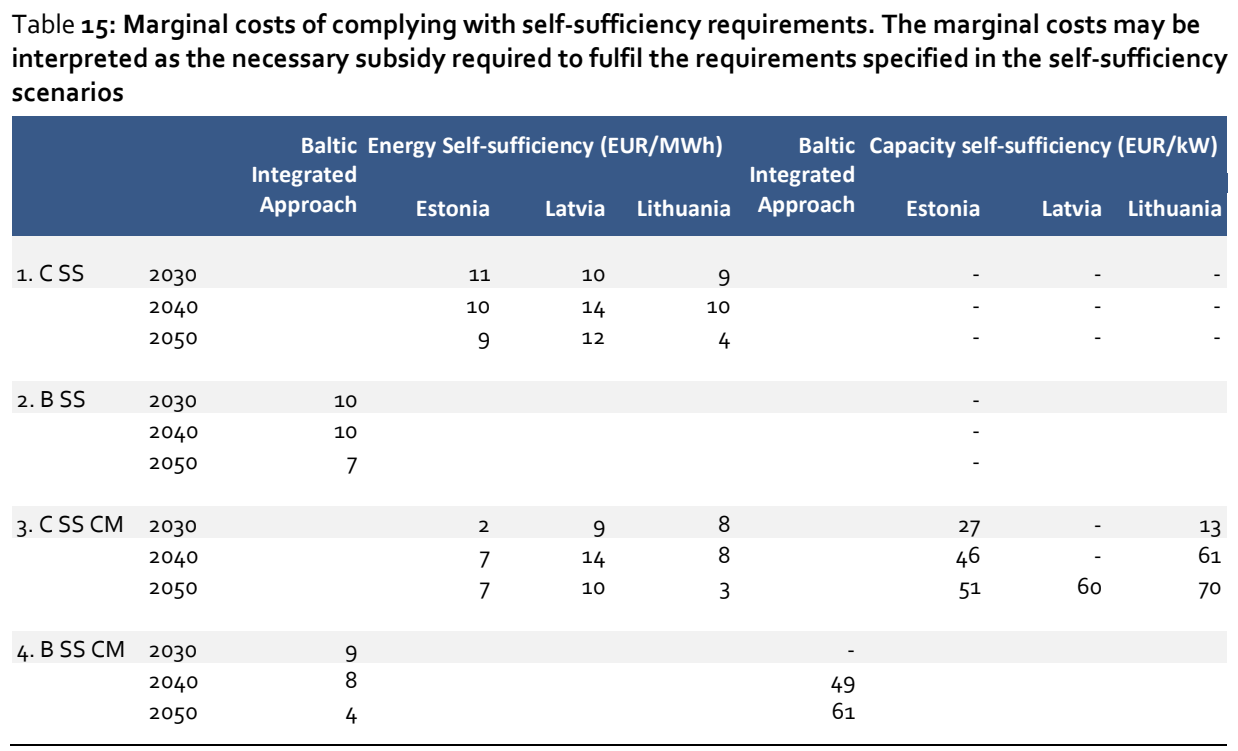

Key point(s): Baltic countries can avoid becoming large net-importers of electricity with subsidy levels about 10 EUR/MWh (energy self-sufficiency) by 2030.

Note: $\quad$ Scenarios with common requirements (B SS and B SS CM) have one common marginal cost of complying with the requirements.

\subsection{Additional cost of the BPO and the 2DS}

\subsubsection{Energy system overall}

Scenarios require investments, but they also bring savings due to reduced energy consumption and reduced energy imports. The estimated additional energy system net costs of BPO and 2DS are reasonably small. The additional costs compared to $4 \mathrm{DS}$ range from $0 \%$ to $0.3 \%$ of GDP at 2030 and from $0.1 \%$ to $0.5 \%$ at 2050 (Figure 76 ). The $\mathrm{BPO}$ results higher additional costs at 2030 than 2DS. Presented costs do not include energy taxes or costs from $\mathrm{CO}_{2}$ prices.

The additional costs of BPO scenarios are estimated to be higher in Latvia than other Baltic countries, due to strict ESS target that results to more expensive measures than the RE target of Estonia and Lithuania. The additional costs of 2DS are otherwise on a similar level between the Baltic countries, except at 2050 where the model chooses to invest to industrial CCS in Lithuania and bio-CCS in Latvia. These investments are made to avoid high $\mathrm{CO}_{2}$ costs.

Our scenarios do not include the flexibilities of the EU policies. It is possible to trade ESS units to countries that would otherwise require expensive measures to reach the strictest targets. The Baltic countries do not reach their 2030 ESS targets in the $4 \mathrm{DS}$, but if the actual development is more positive than in the $4 \mathrm{DS}$, there should be markets for ESS allowances towards 2030. 
Estimated costs exclude the costs associated with air pollution from energy use. Energy use contributes to local air pollution, such as small particulate matter (PM2.5) and nitrous oxides from diesel engines and PM2.5 from firewood. Most climate and energy policies considered in this study will reduce local air emissions - especially diesel engine emissions, but also emissions from firewood due to energy efficiency measures in buildings. But there are also exceptions, for an example, replacing natural gas in district heat with biomass probably points in opposite direction.

Reduced PM2.5 and NOx emissions will improve health, reduce healthcare costs, and reduce the damage to crops and buildings. WHO and the European Commission have estimated that the indirect cost savings would be larger than the additional costs of climate and energy policies, but there are significant uncertainties in the cost estimations (WHO 2015, EC 2013).

Figure 76: Increase of annual energy system costs compared to $4 \mathrm{DS}$. The figure shows average annual costs of the energy system from model periods 2025-2034 and 2045-2054
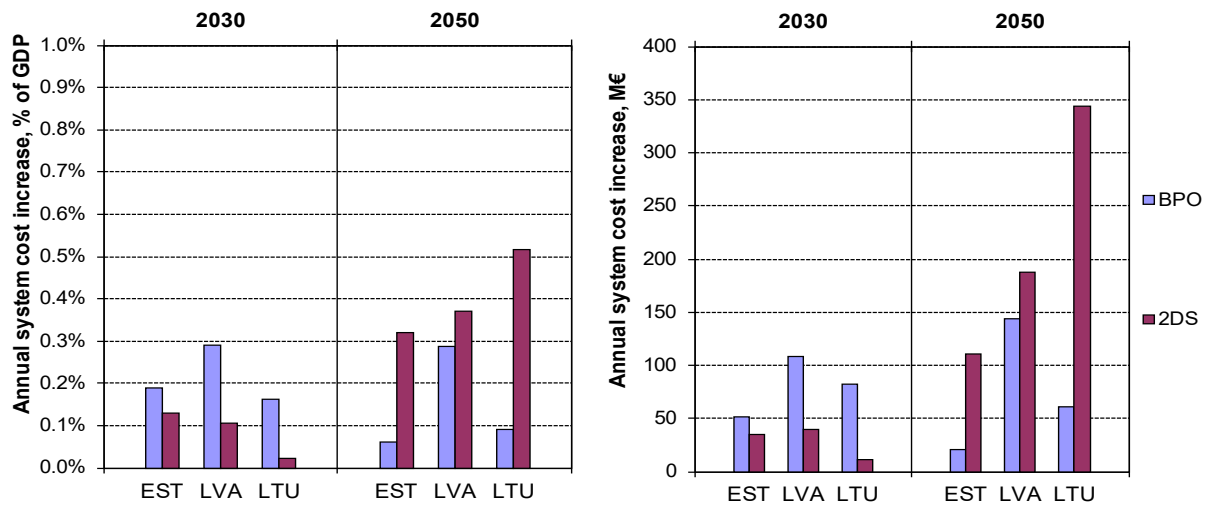

Key point(s): Additional annual costs compared to 4DS are moderate. Latvia's ESS target causes higher costs than for Estonia and Lithuania in the BPO. Lithuania's and Latvia's costs increase in 2DS due to modelled CCS investments.

\subsubsection{Electricity and district heat}

The economic impacts of the BPO are also analysed by calculating the total socioeconomic cost related to serving both district heating and electricity demand in the Baltic countries. The total socio-economic cost is derived from the capital cost of all new

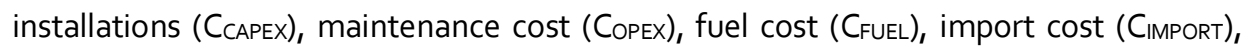
congestion rent ( $C_{\text {CONGEST }}$ ) and the socio-economic cost of $\mathrm{GHG}$ emissions ( $\mathrm{C}_{\mathrm{GHG}}$ ).

$$
C_{\text {tot }}=C_{\text {CAPEX }}+C_{\text {OPEX }}+C_{F U E L}+C_{I M P O R T}+C_{C O N G E S T}+C_{G H G}
$$

Capital cost is calculated using a real discount rate of $5 \%$ and a lifetime of 20 years for all technologies, corresponding to the economic requirements for new investments in the model run. For the GHG emissions, only differences in $\mathrm{CO}_{2}$ emissions are taken into account, while effects on other GHG emissions, particle emissions and other pollutants 
are disregarded. The cost of emissions is set equal to the applied ETS price in the $4 \mathrm{DS}$, which has a value of $8 \mathrm{EUR} /$ ton in 2020, increasing to 15 EUR/ton by 2030 and $40 \mathrm{EUR} /$ ton by 2050 .

Towards 2030, the cost of the additional RE requirement for electricity and district heating is limited to between $0.05 \%$ and $0.1 \%$ of GDP (Figure 77). Latvia is merely unaffected, as RE requirements do not change.

Figure 77: System costs for the electricity and district heating system in the BPO compared to the 4DS

$0,20 \%$

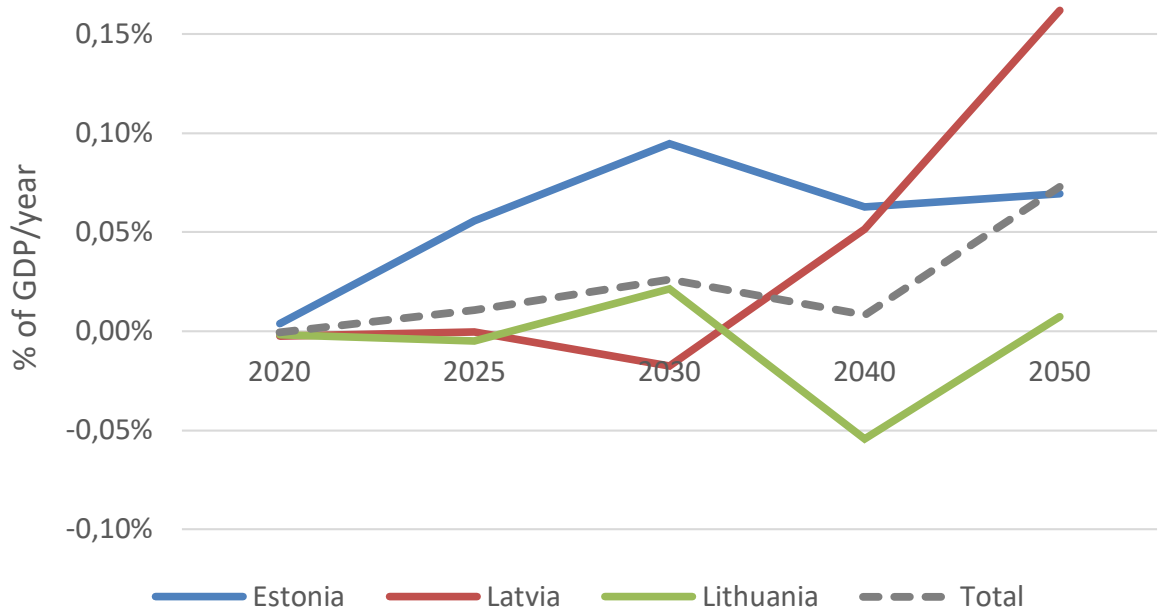

Key point(s): System costs increase in the three Baltic countries in the BPO, but stay below $0.1 \%$ of GDP on average.

Note: $\quad$ According to TIMES optimisation, district heating consumption changes in the BPO in 2050. (See total heat generation on Figure 59.). Therefore, the electricity and heating system is providing a higher service, which explains parts of the rising costs in electricity and district heating sector compared to the $4 \mathrm{DS}$.

The increased cost stems mainly from the increased capital cost (additional wind and solar installations) and fuel cost (biomass) (Figure 78). At the same time, the power balance is improved for Estonia and especially Lithuania, leading to a significant reduction in the cost for imported electricity. For Latvia slight increases in electricity imports lead to higher import cost. 
Figure 78: System cost components in the three Baltic countries in the BPO compared to the 4DS

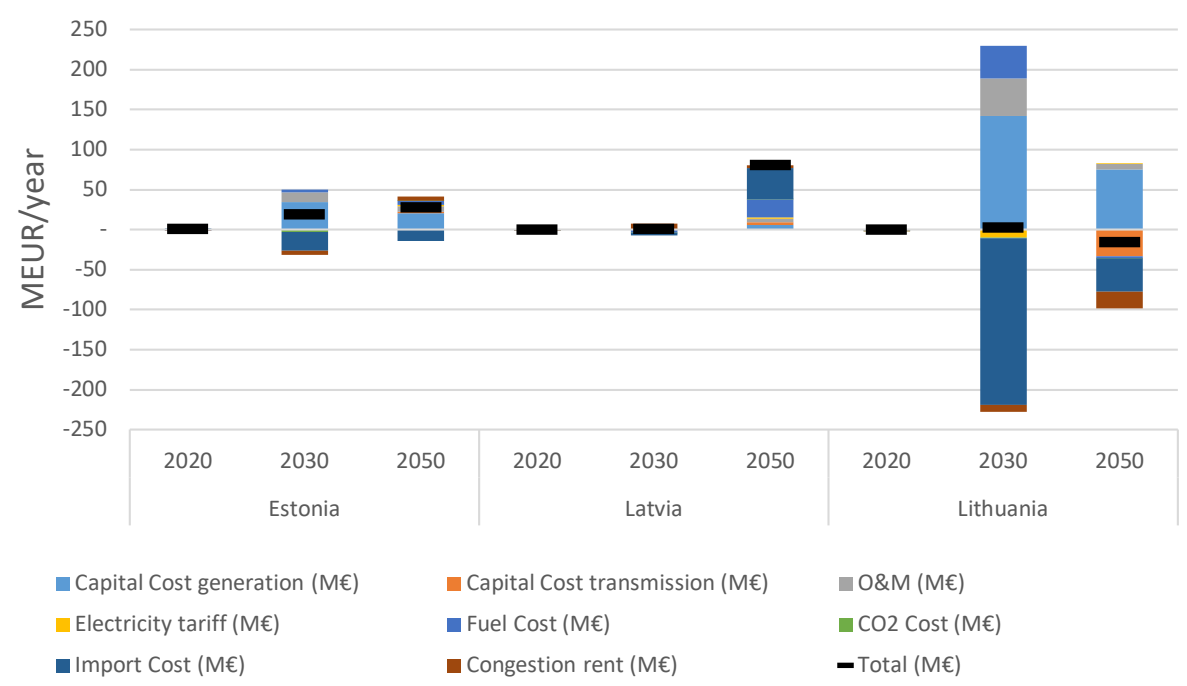

Key point(s): Largest impact on cost distribution in Lithuania. Main savings stem from the reduced import cost, while additional spending stems from the capital cost (wind and solar power) and the fuel cost (biomass).

Overall, the additional renewable energy in the electricity and district heating system is deployed at an average cost of between 6 and 7 EUR/MWh by 2030. These numbers reflect the marginal system cost of realising the renewable deployment, but required subsidy levels depend on the individual technology and have to ensure a balanced economy for the RE developers.

\subsection{Key uncertainties}

The presented scenarios are the results of many assumptions: sectoral drivers (e.g. industry production, transport demand, and floor areas), technology development, fuel prices, policies, and the cost-optimal behaviour of the models. Changes in any of these could lead to slightly different results. The following list contains the most important assumptions in our modelling by sector, but we acknowledge that the list does not cover all the work and could be extended both to further details and to topics not covered by this project. See chapter 4.7 for suggestion of research topics for further studies.

- General: GDP, population, potential of domestic energy resources

- Transport: passenger transport demand (current and projection, passenger-km), freight demand within country borders (current and projection, tonne-km), vehicle efficiency of each vehicle type (current and projection, passenger-km or 
tonne-km / MJ), investment cost of new vehicles, vehicle lifetime, price of fossil fuels and biofuels, infrastructure costs of new technologies such as EVs.

- Buildings: Building stock (by type, age group, heating technology, and thermal efficiency), future energy efficiency standards for new and renovated buildings, projected changes in the building stock (amount of new, renovated, and demolished buildings), heating fuel switch potential and costs.

- Industry: Energy and emission statistics by industry branch by ETS/ESS split, production by industry branch (current and projection), energy saving and fuel switch potential, available process emission mitigation measures, potential for district heat from industry including waste heat sources.

- Fuel refining: assumptions on future production reflecting the amount of e.g. oil consumption in the scenarios, energy saving potential, potential for alternative feedstocks e.g. biomass.

- Agriculture: amount of animals, field area, and produced crops. Potential and costs of emission saving measures.

- Waste management: Municipal waste generation per person, share of landfilled waste, $\mathrm{CH}_{4}$ emissions from landfilled waste (waste fractions). Potential and costs of emission reduction measures in landfills, waste water treatment, and other waste management facilities.

- Electricity and district heating: socio-economic costs of existing and new generation capacity (capital costs, O\&M, fuel, $\mathrm{CO}_{2}$, taxes and tariffs, infrastructure costs, profits from sales, etc.), potential of renewable technologies (wind, solar, biomass, heat pumps, biogas, etc.), lifetime of existing plants, demand projections from end-use sectors, socio-economic costs of existing and new transmission capacity, and secondary effects from the development in the neighbouring countries.

Recent years have shown that the technology development rate is difficult to project, even just a few years ahead, and some technologies have developed faster than assumed (e.g. solar PV, wind power, and EVs) while others have advanced more slowly (e.g. CCS and nuclear). We have updated our models to match the best current understanding, but it is almost certain that some trends are either over- or underestimated. Our technology assumptions and links to sources have been listed in each chapter.

New technologies might need a little push. Some new technologies, such as transport biofuels and wind and solar power up to a certain share, can be applied to existing infrastructure, but some low-carbon technologies require varying degrees of infrastructure investments. EVs require charging points and a large volume of electric vehicles might require strengthening the electricity grid. Variable renewable electricity generation might require strengthening the existing grid - especially in Lithuania, where wind resources are located along the coast but most consumption is inland.

Uncertainties may curb investments and halt development. Unpredictable policy targets and measures are a risk from the perspective of private companies. Many 
energy sector investments have a long repayment period and require a stable operation environment. Even if policies and measures would be predictable, global energy and carbon markets might be too unpredictable for companies to want to commit to investments.

Scenarios include significant improvements in energy efficiency in all sectors, especially in buildings and transport. It requires a lot of effort to achieve the estimated potential in practice. Typical barriers to energy efficiency investments are demand for short payback periods, conflicts of interest between investor and the one who benefits from savings (e.g. landlord and tenant), conflicting information or information overload, requirement for many small solutions instead of one large solution, structural limitations (e.g. lack of skills), and cultural resistance within societies and companies. Specific studies are required to overcome these barriers. National Energy Efficiency Action Plans (EC, 2017l) outline some of the extensive work done towards meeting the energy efficiency targets.

\subsection{Things to improve in further studies}

Further improvements should be split between improving and updating the data and assumptions used in this study, and studying those aspects that were not included in this project. Considering the topics of this project, the most important topics to improve include:

- Transport statistical data and projections, including car stock, demand within country borders (passenger- $\mathrm{km}$, tonne- $\mathrm{km}$ ) and vehicle efficiency. There were quite large variations between the Baltic countries in calculated efficiencies (MJ/passenger-km, MJ/tonne- $\mathrm{km}$ ) at 2015. The calibrated efficiency influences the statistics, but also the future emissions, because part of the existing cars will be used for a decade or two. Assumed growth rates and future vehicle efficiencies have direct effects on future energy demand and emissions.

- Detailed view of current electricity consumption sector by sector, and reasons for increase and/or decrease. The Baltic countries' own projection were either in line (Estonia), higher (Lithuania), or lower (Latvia) than projection of electricity consumption in this study. The differences should be studied in detail starting from the statistics and continuing to assumptions and projections.

- Heat pump potential and socio-economic costs. Potential of high temperature heat sources for large heat pumps, cost-efficiency of large sea water heat pumps, potential for heat pumps in the end-use sectors. The study shows that heat pumps are very promising option in buildings and in district heat production in a future energy system with high share of variable electricity generation. Large scale district heat pumps are already used in commercial operation in the Nordic countries when there is a suitable high temperature heat source available or need for both district heating and cooling. Future studies could map the available and 
economical potential of heat pumps in buildings and high temperature waste heat sources in the Baltic countries. After this, the cost-efficiency of large sea water heat pumps could be explored further.

- Statistics of energy and GHG emissions in industry, and potential for emission reductions and fuel switch, especially in the ESS industry. Many emission categories in ESS are reported individually in the national inventory reports, but in energy production and industry, these are mixed with EU ETS emissions. Our estimates are based on publicly available information, but these should be further defined with national statistics centres. Industry emission reduction potential could be studied also in cooperation with the largest companies, for an example in cooperation with Energy Saving Companies (ESCOs). Also changes in the industry structure, e.g. new industry installations, should be updated.

- Wind and solar PV potential classified by $F L H$, region, and distance to grid. Wind and solar integration could be studied with additional details if there would be better estimates of their potentials classified at least by FLH but preferably also by region, and distance to grid.

- Buildings database, including classification by age, specific consumption, and fuel for heating. Building sector estimates could be improved if buildings could be a) classified to more specific groups than single-dwelling buildings, multi-dwelling buildings, and service buildings, b) each group's age distribution, heating fuels, and energy consumption could be estimated.

- Improved modelling the oil shale refining. The energy flows of oil shale refining technology was modelled in detail, but less detailed modelled of the actual costs, possible subsidies, and market prices for the products prevented the optimization of the amount of oil shale refining. In these projections, the oil shale refining volumes followed exogenous assumptions which could be improved in the following studies.

- Modelling larger regions. Baltic countries energy systems are affected by the development of the neighboring countries especially in the electricity sector. In the current scenarios the Nordic countries are modelled simultaneously with Baltic countries, but the assumptions are static for Nordic countries where there have been calculated several sensitivity analysis for the Baltic countries. Varying the assumptions and adopted policies of Nordic and Baltic countries in the scenarios would bring additional insight to the results of both these regions.

The scope of this study could be extended and the conclusions double-checked against power sector reliability analysis, macro-economic analysis, LULUCF modelling including ESS flexibilities, and air quality assessments. These are all important factors affecting the overall conclusions. 



\section{References}

Aasness, M.A., Odeck, J., 2015; The increase of electric vehicle usage in Norway-incentives and adverse effects; https://link.springer.com/article/10.1007/s12544-015-0182-4

Airbus, 2017; Airbus, Rolls-Royce, and Siemens team up for electric future Partnership launches E-Fan X hybrid-electric flight demonstrator; http://www.airbus.com/newsroom/pressreleases/en/2017/11/airbus--rolls-royce--and-siemens-team-up-for-electric-future-par.html

Averfalk et. Al 2017; Large heat pumps in Swedish district heating systems, Renewable and Sustainable Energy Reviews 79 (2017) 1275-1284

Baltasam 2017; Main Themes and Activities of the Baltic Assembly under Estonian Presidency in 2017; http://baltasam.org/images/2017/Working-activities-2017a.pdf

Baltic course, 2017; Estonia does not support synchronization agreement between Lithuania, Poland. The Baltic Course, Tallinn, 06.09.2017. Link: http://www.balticcourse.com/eng/energy/?doc $=132941$

BSOWF 2017; The Baltic Sea Declaration. High wind, low waves - A favourable place for offshore wind power; https://www.offshore-stiftung.de/sites/offshorelink.de/files/Baltic-SeaDeclaration.pdf

Bu, C., 2015; "Experience to date with EV policy in Norway", presentation at KAPSARC workshop: Drivers of Transportation Fuel Demand: Is Policy Expanding the Research of Alternative and Fuel Efficient Vehicles? King Abdullah Petroleum Studies and Research Center (9 November).

Cabinet of Ministers of Latvia, 2016; Guidelines of Energy Development for 2016-2020.

Available: https://likumi.lv/ta/id/280236-par-energetikas-attistibas-pamatnostadnem-20162020-gadam

Cambridge Economics, 2013; An Economic Assessment of Low Carbon Vehicles;

https://europeanclimate.org/documents/Cars-Economic-assessment-vehicles-FINAL.pdf

Central Statistics Bureau of L-atvia (2017a); population statistics;

http://data.csb.gov.Iv/pxweb/en/Sociala/Sociala_ikgad_iedz_iedzskaits/

Central Statistics Bureau of Latvia (2017b); registered vehicles;

http://www.csb.gov.Iv/en/statistikas-temas/metodologija/registered-vehicles-38762.html

Central Statistics Bureau of Latvia (2018); Environment and Energy - ENG15;

http://data.csb.gov.Iv/pxweb/en/vide/vide__ikgad_energetika/ENo150.px/table/tableViewLa yout $2 /$ ?rxid=cdcb978c-22bo-416a-aacc-aa65odze2ceo

CleanTtechnica, 2017; 7 Countries That May Ban Gas \& Diesel Cars; https://cleantechnica.com/2017/08/10/7-countries-may-ban-gas-diesel-cars/

David, 2016 ; Large heat pumps in European district heating systems, 4th International DHC + Student Awards, Frankfurt 20. April 2016, https://www.euroheat.org/wpcontent/uploads/2016/04/160420_1600_1730_2nd-place_Andrei-David_presentation.pdf DEA 2016; Danish Energy Agency; Technology Data for Individual Heating Plants and Energy Transport Updated chapters, August 2016; https://ens.dk/sites/ens.dk/files/Analyser/technology_catalogue_individual_heating_plants_e nergy_transport_aug16.pdf

DEA 2016a; Levelized Cost of Energy (LCOE) calculator, Danish Energy Agency, https://ens.dk/en/our-responsibilities/global-cooperation/levelized-cost-energy-calculator

EA, 2013; Long-term energy scenarios for Estonia; SCENARIOS FOR 2030 AND 2050; https://energiatalgud.ee/img_auth.php/9/92/Scenario_report_final.pdf 
EC, 2009; Directive 2009/28/EC of the European Parliament and of the Council of 23 April 2009 on the promotion of the use of energy from renewable sources and amending and subsequently repealing Directives 2001/77/EC and 2003/30/EC

EC, 2011; SEC (2011) 1565 final; Impact Assessment of Energy Roadmap 2050; https://ec.europa.eu/energy/sites/ener/files/documents/roadmap2050_ia_20120430_en_o.pdf

EC, 2012; Directive 2012/27/EU of the European Parliament and of the Council of 25 October 2012 on energy efficiency; https://ec.europa.eu/energy/en/topics/energy-efficiency/energyefficiency-directive

EC, 2013; SWD (2013) 531; Impact assessment of air quality package; http://ec.europa.eu/environment/archives/air/pdf/Impact_assessment_en.pdf

EC, 2016a; EU Reference Scenario 2016 - Energy, transport and GHG emissions trends to 2050

EC, 2016b; Factsheet on the Commission's proposal on binding greenhouse gas emission reductions for Member States (2021-2030); http://europa.eu/rapid/press-release_MEMO-162499_en.htm

EC, 2016c; SWD (2016) 249 final; Accompanying the document; Proposal for a REGULATION OF THE EUROPEAN PARLIAMENT AND OF THE COUNCIL on the inclusion of greenhouse gas emissions and removals from land use, land-use change and forestry into the 2030 climate and energy framework and amending Regulation No 525/2013 of the European Parliament and the Council on a mechanism for monitoring and reporting greenhouse gas emissions and other information relevant to climate change

EC, 2017a; Baltic Energy Market Interconnection Plan; https://ec.europa.eu/energy/en/topics/infrastructure/baltic-energy-market-interconnectionplan

EC, 2017b; 2030 climate \& energy framework; https://ec.europa.eu/clima/policies/strategies/2030_en

EC, 2017C; The EU Emissions Trading System (EU ETS); https://ec.europa.eu/clima/sites/clima/files/factsheet_ets_en.pdf

EC, 2017d; Effort sharing regulation, 2021-2030 - Limiting Member States' carbon emissions; http://www.europarl.europa.eu/RegData/etudes/BRIE/2016/589799/EPRS_BRI(2016)589799_ EN.pdf

EC, 2017e; Renewable energy - Moving towards a low carbon economy; https://ec.europa.eu/energy/en/topics/renewable-energy

EC, 2017f; Second agreement on statistical transfers of renewable energy amounts between Estonia and Luxembourg; https://ec.europa.eu/info/news/second-agreement-statisticaltransfers-renewable-energy-amounts-between-estonia-and-luxembourg-2017-nov-13_en

EC, 2017g; Proposal for updated sustainability criteria for biofuels, bioliquids and biomass fuels; https://ec.europa.eu/energy/en/topics/renewable-energy/biofuels/sustainability-criteria

EC, 2017h; Energy Efficiency Directive; https://ec.europa.eu/energy/en/topics/energyefficiency/energy-efficiency-directive

EC, 2017i; National Energy Efficiency Action Plans and Annual Reports; https://ec.europa.eu/energy/en/topics/energy-efficiency/energy-efficiency-directive/nationalenergy-efficiency-action-plans

EC, 2017j; Land use and forestry proposal for 2021-2030; https://ec.europa.eu/clima/policies/forests/lulucf_en

EC 2017k; Statistical pocketbook 2017; https://ec.europa.eu/transport/factsfundings/statistics/pocketbook-2017_en

EC, 2017l; National Energy Efficiency Action Plans and Annual Reports; https://ec.europa.eu/energy/en/topics/energy-efficiency/energy-efficiency-directive/nationalenergy-efficiency-action-plans

EC, 2017m; Agreement on statistical transfers of renewable energy amounts between Lithuania and Luxembourg; https://ec.europa.eu/info/news/agreement-statistical-transfers-renewableenergy-amounts-between-lithuania-and-luxembourg-2017-oct-26_en 
EEA 2017a; Overview of electricity production and use in Europe;

https://www.eea.europa.eu/data-and-maps/indicators/overview-of-the-electricityproduction-2/assessment

EEA 2017b; Greenhouse gas emissions under the Effort Sharing Decision (ESD); https://www.eea.europa.eu/data-and-maps/data/esd-1

EEA 2017c; EEA database on climate change mitigation policies and measures in Europe; http://pam.apps.eea.europa.eu

Elering, 2014; Estonian Long-Term Power Scenarios; Eesti pikaajalised elektritootmisstsenaariumid; https://energiatalgud.ee/img_auth.php/6/6d/ENMAK_2030._Eesti_pikaajalised_elektritootmi sstsenaariumid.pdf

Energy central, 2017; Synchronization of Baltic power grid through Poland is best option. Energy Central, April 13, 2017. Link: http://www.energycentral.com/news/synchronizationbaltic-power-grid-through-poland-best-option

ENTSO-E, 2016; Ten Year network Development Plan

ENTSO-E, 2017; Baltic Synchronisation. Entsoe.eu. Link: http://tyndp.entsoe.eu/insightreports/baltic-synchronisation/

ENTSO-E, 2018; Power Statistics - Monthly Domestic values; https://www.entsoe.eu/data/statistics/Pages/monthly_domestic_values.aspx

EurObserv'ER 2017; Wind Energy Barometer 2017

Eurostat 2017a; Employment Statistics; http://ec.europa.eu/eurostat/statisticsexplained/index.php/Employment_statistics

Eurostat, 2017b; Household energy consumption and Heating Degree Days (HDD) statistics; http://ec.europa.eu/eurostat/web/energy/data

Eurostat, 2017c; Energy from renewable sources; http://ec.europa.eu/eurostat/web/energy/data/shares

Eurostat, 2017d; Energy dependence; http://ec.europa.eu/eurostat/tgm/table.do?tab=table\&init=1\&language=en \&pcode=tsdcc310 \&plugin $=1$

Figenbaum, E., 2017; Perspectives on Norway's supercharged electric vehicle policy; https://www.sciencedirect.com/science/article/pii/S2210422416301162

Financial observer, 2017; For the Baltic States the cheapest option will be to connect with Poland. Financialobserver.eu, 25.09.2017. Link: https://financialobserver.eu/poland/for-thebaltic-states-the-cheapest-option-will-be-to-connect-with-poland/

Fraunhofer ISE, 2018; Electricity production and spot prices in Germany, https://www.energycharts.de/price.htm

Global Wind Atlas 2.0, a free, web-based application developed, owned and operated by the Technical University of Denmark (DTU) in partnership with the World Bank Group, utilizing data provided by Vortex, with funding provided by the Energy Sector Management Assistance Program (ESMAP). For future information: https://globalwindatlas.infoHancher, L. and Winters, B.M., 2017; The EU Winter Package - Briefing Paper; http://fsr.eui.eu/wpcontent/uploads/The-EU-Winter-Package.pdf

Holthe, J. F. (2015), "Speech on Norway's EV policy framework", delivered 8 December at COP 21 High-Level Event on Zero-Emission Vehicles.

Holtsmark, B. and A. Skonhoft (2014), The Norwegian Support and Subsidy Policy of Electric Cars. Should It Be Adopted by Other Countries? Environmental Science \& Policy, Vol. 42, Elsevier.

Huld T., Müller R., Gambardella A., 2012. A new solar radiation database for estimating PV performance in Europe and Africa. Solar Energy, 86, 1803-1815.

ICE, 2017; EUA FUTURES data; https://www.theice.com/products/197/EUA-Futures/data

IEA, 2017; IEA World Energy Statistics and Balances; http://www.oecdilibrary.org/energy/data/iea-world-energy-statistics-and-balances_enestats-data-en 
IMF 2017; World Economic Outlook Database;

http://www.imf.org/external/pubs/ft/weo/2017/02/weodata/weoselgr.aspx

IPE, 2017; Institute of Physical Energetics; Drivers used in the MARKAL modelling.

Independent, 2017; UK plans to halt production of petrol cars by 2040;

http://www.independent.co.uk/news/uk/politics/uk-petrol-diesel-cars-stop-production-2040climate-change-plan-a7842056.htmlKurnitski, Jan; 2014; Buildings in Estonian ENMAK 2030+ energy strategy - cost optimal energy savings;

http://www.edlig.org/fileadmin/user_upload/projektseiten/edlig/Technical_Day_Tallinn/Buildi

ngs_in_Estonian_ENMAK_2030_energy_strategy_-_cost_optimal_energy_savings_-

_Kurnitski.pdf

JRC (Joint Research Center), 2017; Integration of the Baltic States into the EU electricity system. A technical and economic analysis: executive summary. Joint Research Centre (European Commission), 2017. Link: https://publications.europa.eu/en/publication-detail//publication/8d3b7da2-562e-11e7-a5ca-01aa75ed71a1/language-en/format-PDF/source31392329

LEI, 2015; LIETUVOS ENERGETIKOS SEKTORIAUS PLĖTROS TYRIMAS; 1 DALIS; TECHNINE் EKONOMINĖ ENERGETIKOS SEKTORIAUS PLE்TROS ANALIZE்;

http://www.lei.It/_img/_up/File/atvir/2016/NES/2-

Technine_ekonomine_energetikos_sektoriaus_pletros_analize-2015.11.16.pdf

Litgrid, 2017a; Litgrid. Strategic projects; www.litgrid.eu.

Litgrid, 2017b; Electricity Transmission Grid Ten-Year Development Plan 2017-2026. Litgrid, 2017. Link (In Lithuanian): http://www.litgrid.eu/index.php/tinklo-pletra/lietuvos-elektrosperdavimo-tinklo-10-metu-pletros-planas/113

LSM, 2018; Riga Transport gets EUR6om loan to buy trams, hydrogen-powered buses; https://eng.Ism.Iv/article/economy/transport/riga-transport-gets-6om-loan-to-buy-low-floortrams-hydrogen-powered-buses.a243834/

Ministry of Economics Latvia, 2013; Informative Report; Long-Term Energy Strategy of Latvia 2030 - Competitive Energy for the Society;

http://vvc.gov.lv/image/catalog/dokumenti/Informative_Report_Long-

Term_Energy_Strategy_of_Latvia_2030.doc

Ministry of Economy Latvia, 2014; Long-Term Strategy for Building Renovation. Riga 2014. https://ec.europa.eu/energy/sites/ener/files/documents/2014_article4_en_latvia.pdf

Ministry of Economy of Latvia, 2015; Ex ante evaluation. European Union funds for the 2014 2020 planning period. Financial availability for the increased energy efficiency in apartment buildings; https://em.gov.Iv/files/es_fondi/Ex\%2oante\%2oizvertejums.pdf

Ministry of Foreign Affairs of Estonia, 2017; Baltic Cooperation; http://vm.ee/en/balticcooperation

Ministry of Interior Estonia 2017;

https://www.siseministeerium.ee/sites/default/files/dokumendid/Rahvastiku-

statistika/eesti_elanike_arv_kov_01.01.2017.pdf

Ministry of the Environment of Estonia (2017); Report pursuant to Articles 13 and 14 of Regulation (EU) 525/2013

Ministry of the Environment of Latvia (2017); REPORTING ON POLICIES AND MEASURES UNDER ARTICLE 13 AND ON PROJECTIONS UNDER ARTICLE 14 OF REGULATION (EU) NO 525/2013 OF THE EUROPEAN PARLAMENT AND OF THE COUNCIL

Ministry of the Environment of Lithuania (2017); Policies \& Measures and Projections of Greenhouse Gas Emissions in Lithuania; http://www.am.It/VI/files/File/Klimato\%2okaita/Prognoziu\%2oataskaitos/Report.pdf

Ministry of the Energy of Lithuania (2017); NACIONALINĖ ENERGETINÉS

NEPRIKLAUSOMYBĖS STRATEGIJA (National Energy Independence Strategy, in Lithuanian); https://enmin.Irv.It/uploads/enmin/documents/files/2017\%2010\%2016\%2oEnergetikos\%20str ategijos\%2oprojektas\%2o(pateiktas\%2oLRV).pdf 
MIT, 2017; Massachusetts Institute of Technology; CCS Project Database, Industrial CCS Projects; https://sequestration.mit.edu/tools/projects/us_ccs_background.html

MKM 2017; Ministry of Economic Affaris and Communications of Estonia; The approved Energy Sector Development Plan ensures Estonia's energy supply;

https://www.mkm.ee/en/news/approved-energy-sector-development-plan-ensures-estoniasenergy-supply

NER, 2016; Nordic Energy Research; Nordic Energy Technology Perspectives 2016; http://www.nordicenergy.org/project/nordic-energy-technology-perspectives/

Nord pool spot, 2018; Market data, https://www.nordpoolspot.com/Marketdata1/\#/nordic/map

Parliament of Estonia, 2017; Resolution of the Riigikogu - General Principles of Climate Policy until 2050; https://www.envir.ee/sites/default/files/low_carbon_strategy_until_2050.pdf

Parliament of Latvia, 2010; Sustainable Development Strategy of Latvia until 2030; http://www.pkc.gov.lv/sites/default/files/images-legacy/LV2030/LIAS_2030_en.pdf

Parliament of Lithuania, 2012; National Energy Independence Strategy (unofficial translation); https://gamyba.le.lt/sites/default/files/media/dynamic/files/481/nationalenergyindependences trategy.pdf

Popular Mechanics, 2017; Boeing-Backed Electric Plane Could Fly in 2020s; http://www.popularmechanics.com/flight/news/a28540/boeing-backed-electric-plane-fly2020s/

Regulation 383/2013 of Latvia; Regulation of the Republic of Latvia No 383. Regulation on the energy certification of building. The official Publisher of the Republic of Latvia "Latvijas Vēstnesis" 2013;138 (4844)

Road Administration Estonia, 2017; Sõidukite statistika; https://www.mnt.ee/et/ametist/statistika/soidukite-statistika

Siemens, 2017; Setting a Course for Carbon-Free Shipping; https://www.siemens.com/innovation/en/home/pictures-of-the-future/mobility-andmotors/electromobility-electric-ferries.html

SSB, 2017; Registered vehicles statistics database; http://www.ssb.no/en/statbank/list/bilreg?rxid=eoa48oag-8aec-4d7e-8fe2-a28854532a18

Statistics Lithuania (2017a); population statistics; https://osp.stat.gov.It

Statistics Lithuania, 2017b; Kelių transporto priemonių rodiklia (Road vehicle indicators); https://osp.stat.gov.It/statistiniu-rodikliu-analize\#/

Šúri M., Huld T.A., Dunlop E.D. Ossenbrink H.A., 2007. Potential of solar electricity generation in the European Union member states and candidate countries. Solar Energy, 81, 1295-1305, http://re.jrc.ec.europa.eu/pvgis/

Tuohy, E., Bulakh, A., Tsarik, Y.. 2017; Desynch or Sink - A Political Analysis of Baltic Electricity Desynchronization. International Centre for Defence and Security, Tallin, Estonia. ISSN 22282076. Link:

https://www.icds.ee/fileadmin/media/icds.ee/doc/ICDS_Analysis_Desynch_or_Sink_TuohyBulakh-Tsarik_May_2017.PDF

UNFCCC 2017a; GHG emissions data viewer; http://di.unfccc.int/time_series

UNFCCC 2017b, National Inventory Submissions 2017;

http://unfccc.int/national_reports/annex_i_ghg_inventories/national_inventories_submissions /items/10116.php

Virbickas, D. 2017; Synchronization of Baltic countries. Presentation by D. Virbickas (Litgrid CEO), 2017. Link (In Lithuanian):

http://www.Ista.It/files/events/170514_Glasgow/2017\%2005\%2025_Sinchronizacijos\%2oprista tymas\%2oLMA_final.pdf

WHO, 2015; Economic cost of the health impact of air pollution in Europe; http://www.euro.who.int/_data/assets/pdf_file/o004/276772/Economic-cost-health-impactair-pollution-en.pdf

World Bank (2017); World Bank Open Data; https://data.worldbank.org/ 



\section{Sammendrag}

Baltic Energy Technology Scenarios 2018 (BENTE) er en scenariobasert energisystemanalyse som utforsker fremtidige endringer $\mathrm{i}$ de Baltiske landenes energisystemer. Hva er driverne og konsekvensene de neste tiårene? Hva må til for at de Baltiske landene skal oppnå sine klima- og energimålsetninger for 2030, og hvilken utvikling er nødvendig for at Baltikum skal være på vei mot togradersmålet i 2050?

Rapporten viser at de Baltiske landene kan klare å oppnå sine foreslåtte fornybarmålsetninger ved å ta i bruk sine egne fornybarressurser. Mer fornybar energi (både for elektrisitet, varme og i drivstoff) lar forbrukssektorene redusere sine klimagassutslipp og øke fornybarandelen. Men, til tross for økt bruk av fornybare energikilder i 4-graders scenarioet, når ikke de Baltiske landene sine klimagassreduksjonsforpliktelser i 2030 (innenfor "Effort Sharing Sector's (ESS)"). Rapporten viser også at det er sannsynlig at de Baltiske landene vil bli store nettoimportører dersom det ikke lanseres virkemidler som fremmer lokal, fornybar elektrisitetsproduksjon.

Noen hovedfunn er:

- Elektrisitetsproduksjons- og fjernvarmesektoren bør lede an i å redusere utslipp av klimagasser, fulgt av transport, bygninger og andre sektorer.

- De Baltiske landene når ikke sine "Effort Sharing Sector's (ESS)014"-mål i 2030 i 4graders scenarioet.

- De Baltiske landene kan klare å oppnå sine fornybarmålsetninger ved å ta i bruk egne fornybare ressurser.

- Elektrisitetsforbruket vil øke som følge av økt etterspørsel og økt elektrifisering av sektorer som i dag tar i bruk fossil energi.

- Den europeiske kraftsektoren vil endres til et system med høyere andeler fornybar energi i de kommende tiårene, noe som vil påvirke de Baltiske landene, uavhengig av de Baltiske landenes egne veivalg.

- $\quad \varnothing k t$ utbygging av lokal fornybar energiproduksjonskapasitet vil senke importavhengigheten til de Baltiske landene, og kan fungere som en "hedge" mot høye elektrisitetspriser. 



\section{Annex I. TIMES-VTT model}

TIMES-VTT provides a constructive and systematic method to analyse energy markets and emissions. It is used to analyse energy and climate policies, market potential of technologies, low carbon scenarios, market uncertainty, etc. The model is capable of Finnish, Nordic, Baltic, European and global analysis.

TIMES-VTT is a partial equilibrium model based on linear optimisation. Assuming efficient markets and perfect foresight, the model calculates a market equilibrium solution through cost minimisation for energy production, transformation and end-use under the given energy demand projections, technology assumptions and policies (e.g. targets for emission levels or global temperature increase).

TIMES-VTT is a bottom-up model of the energy system and it includes a large database of energy technologies. The production chain starts from the extraction of energy resources, continues through transformation and distribution steps, and ends at energy end-use where final energy is used for a wide variety of energy services in five end-use sectors (industry, residential, transportation, commercial and agriculture). A simplified outline of this structure is presented in Figure 79.

Figure 79: A simplified structure of the energy system in the TIMES-VTT model in each model region

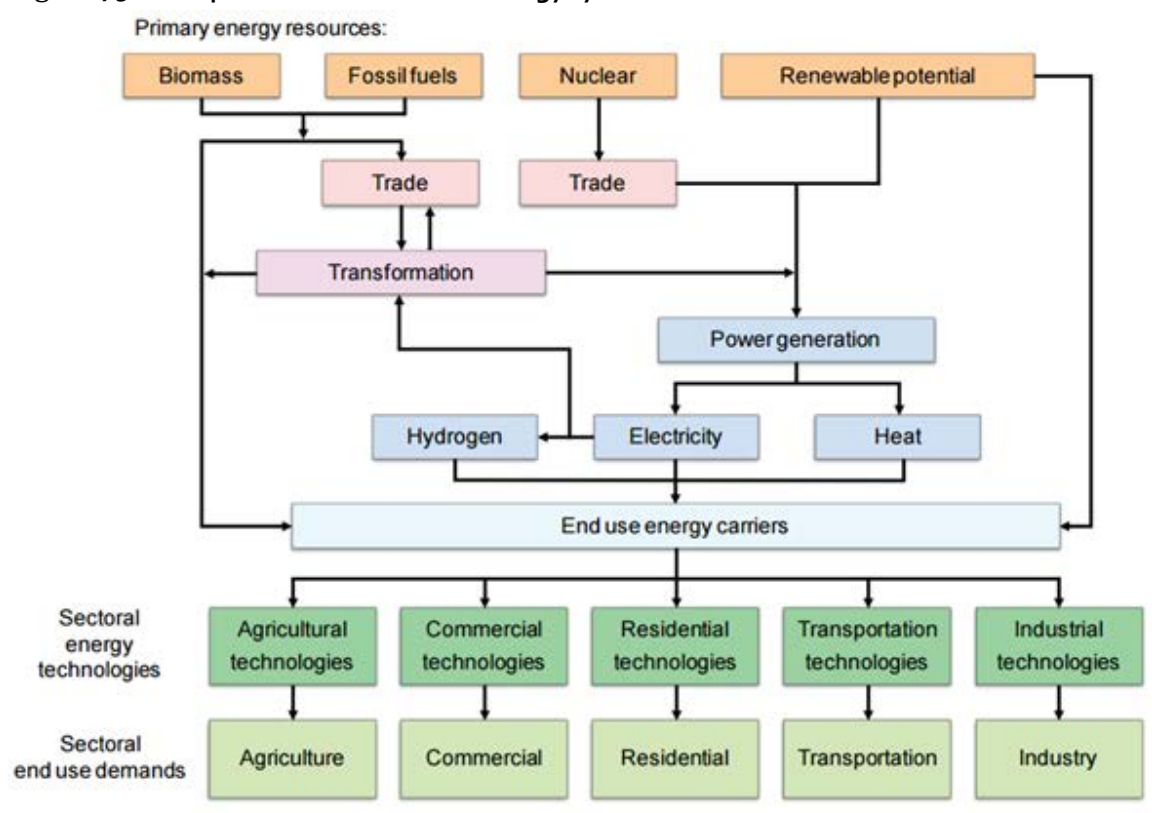


The model uses the TIMES modelling approach, and is originally based on the TIMES integrated assessment model (Loulou et al. 2016), to which a number of modifications have been made at VTT. TIMES-VTT and its input data have also been documented in several studies (Matthews et al. 2015 and Kallio et al. 2015).

The main model inputs are:

- Energy resources: quantities, marginal cost-extraction costs.

- Energy and emission reduction technologies: investment costs, lifetimes, O\&M costs, efficiencies, availability factors, emission factors, etc.

- Future sectoral activities, such as transport demand, building stock, etc.

- Energy and environmental/climate policy: taxes, emissions targets, etc.

The main model outputs are:

- Flows of energy and emissions, per energy form/emission type, region and time step.

- Investments, fixed O\&M, variable costs, and decommissioning costs for each technology and region.

- Trade in energy commodities and emissions between regions in each period.

- Energy import expenditures and export revenues by commodity, region and period.

- Climatic variables: atmospheric GHG concentration, radiative forcing, temperature increase.

- Marginal values of different energy forms/emission types (as shadow prices from the optimisation); these values correspond to long-term equilibrium prices.

It is also possible to set various constraints, e.g. emission reduction targets, prices for emission allowances and limitations on certain types of technologies, where these are relevant to the definition of scenarios.

The model runs in 10-year time steps. In this BENTE project, we run the model up to 2060 , though scenario results are shown up to 2050 . TIMES has intra-year variability on the production or consumption of selected technologies and energy forms (e.g. daynight variation with solar power). In total, the model has 24 time slices for every year modelling the changing seasons ( 4 seasons), weekdays (weekday or weekend), and daytime (day, night, peak demand).

Specific assumptions used in this study are compiled in the supplementary input data excel. Modelling results are compiled in the supplementary results excel. 


\section{Annex II. Balmorel model}

\section{II.1. Overview}

Balmorel is a detailed techno-economical partial equilibrium model suited for analyses of electricity as well as combined district heating and electricity markets. It is capable of both investment and dispatch optimisation. In investment mode, it is able to simultaneously determine the optimal level of investments, refurbishment and decommissioning of electricity and heat generation and storage technologies, as well as the transmission capacity between predefined regions.

In dispatch optimisation mode, it determines the optimal use of available generation and transmission capacity for the market. It is capable of both timeaggregated and hourly modelling, which allows for a high level of geographical, technical and temporal detail. It is particularly strong in addressing the interdependence between heat and electricity production of combined heat and power (CHP) generators.

The mathematical principle behind Balmorel is based on finding a least-cost solution for the dispatch and investments within the relevant interrelated electricity and district heating markets. Doing so, Balmorel takes into account developments in electricity and heat demand, grid constraints, technical and economic characteristics for each kind of production unit, fuel prices, spatial and temporal availability of primary renewable energy, etc.

Figure 80: Inforgraphic on the concept of the Balmorel model

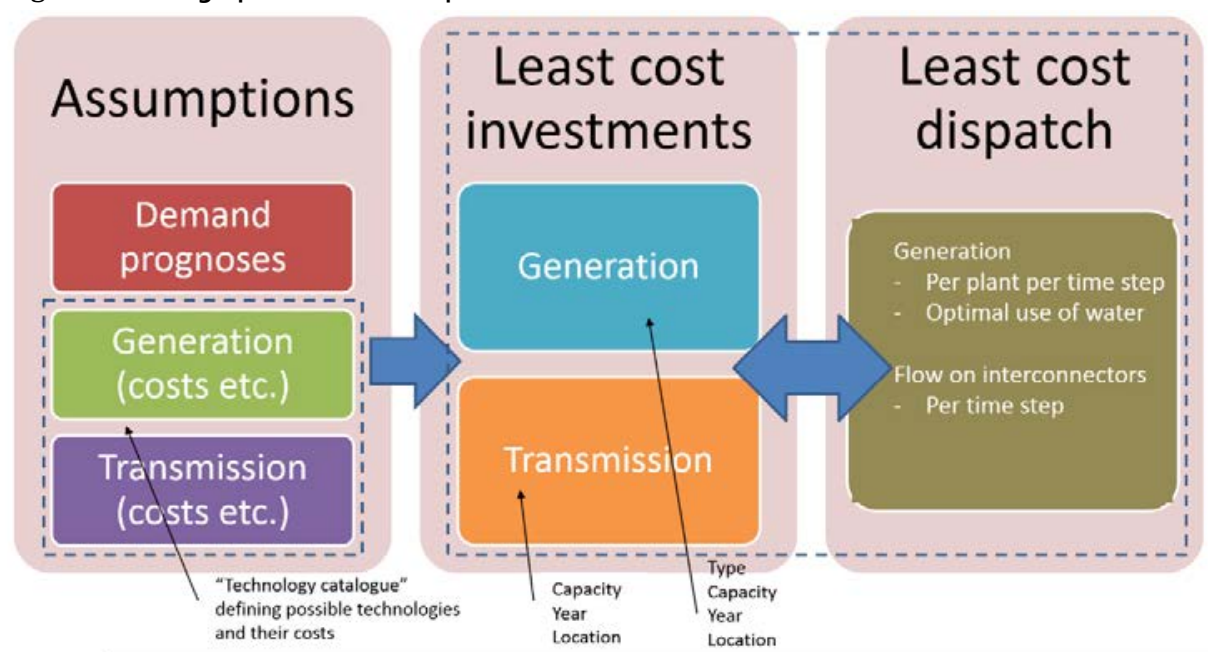

Both societal and stakeholder perspectives can be analysed based on the results of the model. 
Open source code provides transparency and credibility

The model has been developed and distributed under open source principles since 2001. The GAMS-based source code and its documentation is available for download on www.balmorel.com. The Balmorel developers are active members of the open energy modelling initiative (www.openmod-initiative.org), an international platform for knowledge exchange and the promotion of open source and open data within the energy modelling sector.

The representation of the transmission grid

Transmission lines are represented by the total capacity available to the market between bidding zones (net transfer capacity).

\section{Detailed representation of heating markets and combined heat and power}

The model allows for detailed simulation of the heating market, which is particularly important in countries and regions where combined heat and power is noticeable.

$\mathrm{CPH}$ units are represented by two types of technology: extraction units and backpressure units. The capacities in the model are given as net capacities for either power or heat. For extraction units, the capacity is given as the electrical capacity in condensing mode; while the power capacity for backpressure units is given in the cogeneration mode. In full cogeneration mode, the $\mathrm{Cb}$-value specifies the ratio between power and heat. For extraction units, the Cv-value specifies the loss in electricity when producing heat for maintained fuel consumption. The fuel efficiencies in the model are for CHP units given as the fuel efficiency in condensing mode for extraction units and the total fuel efficiency in CHP mode for backpressure units.

The model also includes heat-only generation technologies without simultaneous electricity generation, for example heat-only boilers and electricity-to-heat units (heat pumps, electric boilers). With increasing shares of renewable energy in electricity systems, electricity-to-heat technologies become important for system integration.

\section{Investment module}

The model has a technology catalogue with a set of new power generation technologies that it can invest in according to the input data. The investment module allows the model to invest in a range of different technologies, including coal power, gas power (combined cycle plants and gas engines), straw and wood-based power plants, wind power (on- and off-shore) and solar PV. The model is also able to rebuild existing thermal power plants from one existing fuel to another. At a lower cost than building a new power station, the model can choose to rebuild a coal-fired plant into a wood pellet or woodchip plant, and convert a natural gas-fired plant into biogas.

The technology assumptions will develop between now and 2050, which means that costs and efficiencies develop according to learning curves for the specific technology. 
Technology assumptions are largely based on the Danish Energy Agency's technology catalogues (https://ens.dk/en/our-services/projections-and-models/technology-data )

\section{Decommissioning of power plants}

The decommissioning of thermal power plants can happen both exogenously and endogenously in the model. The exogenous approach is based on data about the year of commissioning the power plant and assumptions about typical technical lifetime. Moreover, the model can decide to decommission a power plant when it is no longer profitable to operate (endogenous decommissioning).

\section{II.2. General assumptions}

\section{Geographical scope}

The Balmorel simulations are carried out over a model area which comprises the Baltic countries, the Nordic countries, the most western parts of Russia, Belarus (transit-area only), Poland, Germany, the Benelux countries, Great Britain, Ireland, France, Switzerland, Austria, the Czech Republic and Italy.

\section{Electricity demand}

Demand development until 2030 based on ENTSO-E estimates suggests a limited increase between 2015 and 2020 (4.5\%), after which efficiency measures reduce demand towards 2030 by $3 \%$. Beyond 2030, no further developments in electricity demands are implemented. For Denmark, the electricity demand until 2030 is based on assumptions from the Danish TSO Energinet.dk (includes introduction of EVs and individual heat pumps).

Figure 81: Electricity demand in Europe in the $4 \mathrm{DS}$. Baltic demand is dependent on TIMES output. In the $2 \mathrm{DS}$, all countries except the Baltic countries see an $8 \%$ and $25 \%$ increase for 2040 and 2050 , respectively, compared to 2030 , to account for electrification of the energy system

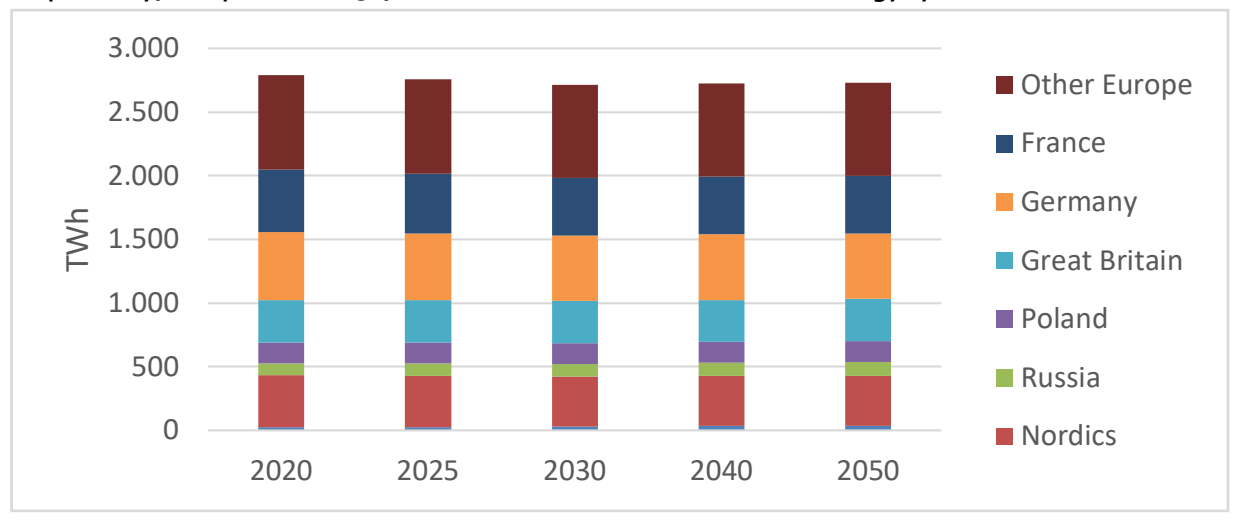




\section{Demand flexibility}

Demand flexibility (demand response) can be an important measure for integration of renewable energy in the electricity system. However, current experiences with demand flexibility are limited and projections are highly uncertain.

As a cautious assumption, it is assumed here that $10 \%$ of the average nominal demand throughout the year is flexible and can shift by up to 4 hours. This leads to a demand response capacity of $30 \mathrm{GW}$ by 2050 and the option to "store" $120 \mathrm{GWh}$.

\section{Heat demand}

District heating areas with related heat demand is modelled for selected countries: the Baltic countries, the Nordic countries, Poland and Germany.

Figure 82: Heat demand in Europe in the 4DS. Baltic demand is dependent on TIMES output

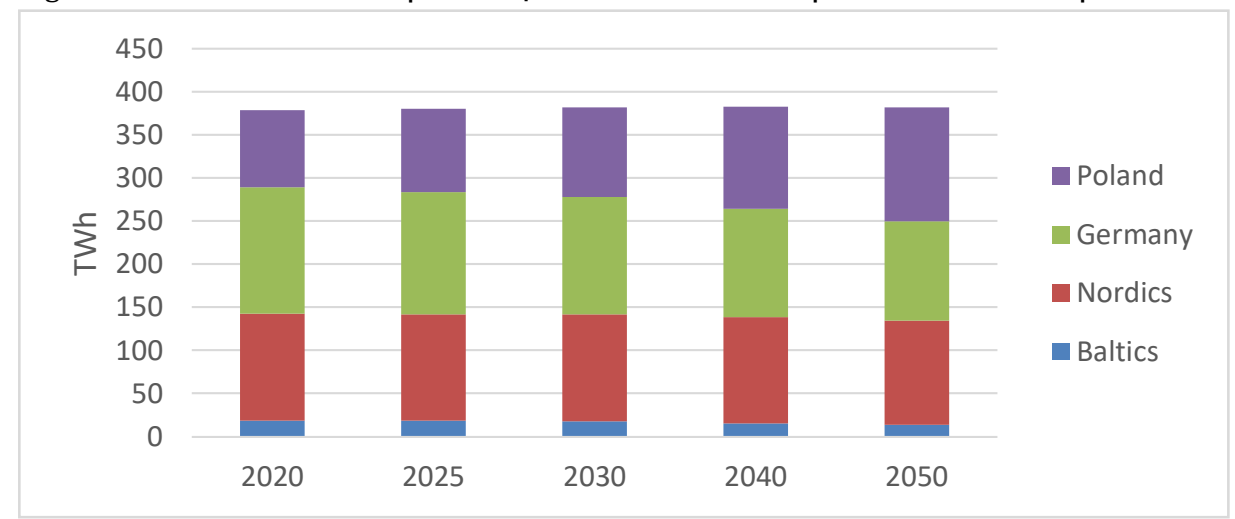

\section{Exogenous capacity}

Development of the existing generation capacity is subject to uncertainty. The reason is that, similar to new investment, the lifetime of existing capacities is subject to economic optimisation and thus dependent on the development of electricity prices. However, other factors also play a role, and these can be harder to reflect in the model optimisation. They include: environmental legislation on emissions that effectively rule out older power plants; various national subsidies to support certain power plants or types of power plants due to either concerns about the security of supply or national priorities (e.g. importance of power plants for regional economy and labour); and optimisation of fixed costs as a result of changing operational patterns.

The overall approach to the development of existing capacities is that planned phase outs are implemented exogenously, while the remaining capacity is held constant, and the lifetime is subject to economic optimisation (power plants have to recover fixed costs). Some exceptions are mentioned below. Wind and solar capacity have relatively low fixed operational costs, and are therefore assumed to be decommissioned after the end of the technical lifetime. 


\section{Minimum RE roll-out}

In some scenarios, a minimum RE roll-out is assumed for all modelled European countries except the Baltic countries. They are mainly based on ENTSO-E estimates until 2025, with linear extrapolation to 2030. Where better data has been available, national sources are used. For Germany, projections based on the Renewable Energy Act until 2020 and the NEP 2015 until 2030 have been implemented. The development for Denmark until 2030 is based on assumptions from the Danish TSO Energinet.dk.

Figure 83: Minimum RE roll-out for the modelled system. Implemented in the $4 \mathrm{DS}$ and BPO

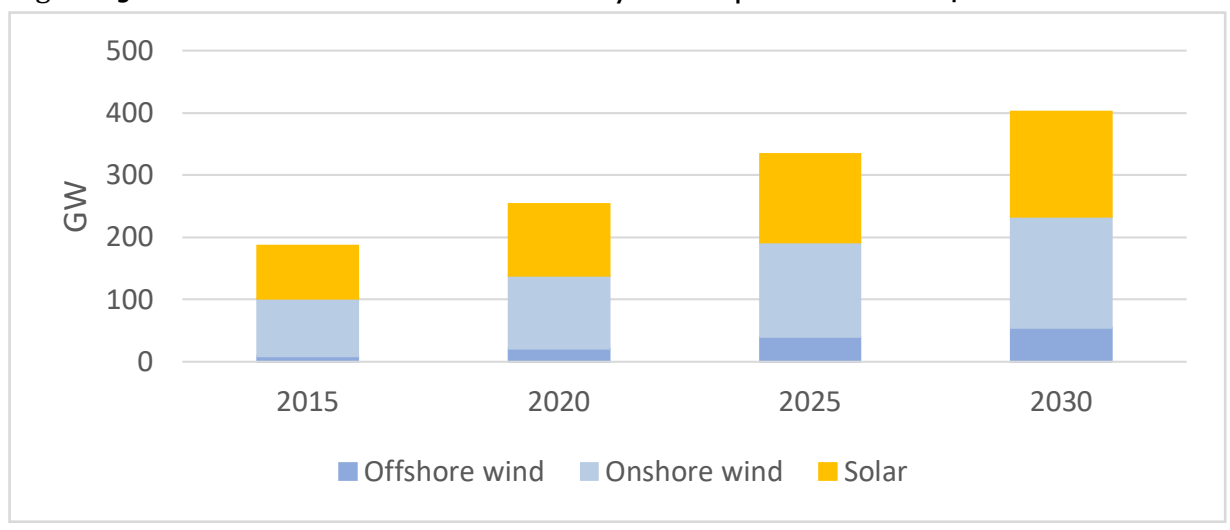

RE subsidies

In the $4 \mathrm{DS}$ and $\mathrm{BPO}$, electrical power from renewable sources receives a technologyneutral subsidy of 7.5 EUR/MWh. This level is meant to reflect a continuation of the current trend of national approaches that support renewable energy. Therefore, the level should be seen as linked to the modest $\mathrm{CO}_{2}$ prices. As renewable policies have been more moderate in some countries in the past, subsidies are assumed to be $50 \%$ lower in the Czech Republic, Poland and Russia.

\section{Taxes}

In the Baltic countries, electricity for heating (heat pumps or electric boilers) is taxed with 10 EUR/MWh in the baseline scenarios.

\section{Fossil fuel prices}

Until 2020, the fossil fuel prices in the model are based on fuel price futures. From 2030, the International Energy Agency (IEA) - World Energy Outlook 2016 (WEO16) fuel price projections have been used. Between 2020 and 2030, the prices converge from future prices to WEO 16 prices. For the $4 \mathrm{DS}$ and the BPO, IEA's New policies scenario was used. For the 2DS, IEA's 450 ppm scenario was used. 
Figure 84: Fossil fuel prices in the $4 \mathrm{DS}$ and $2 \mathrm{DS}$. The BPO uses the same prices as the $4 \mathrm{DS}$

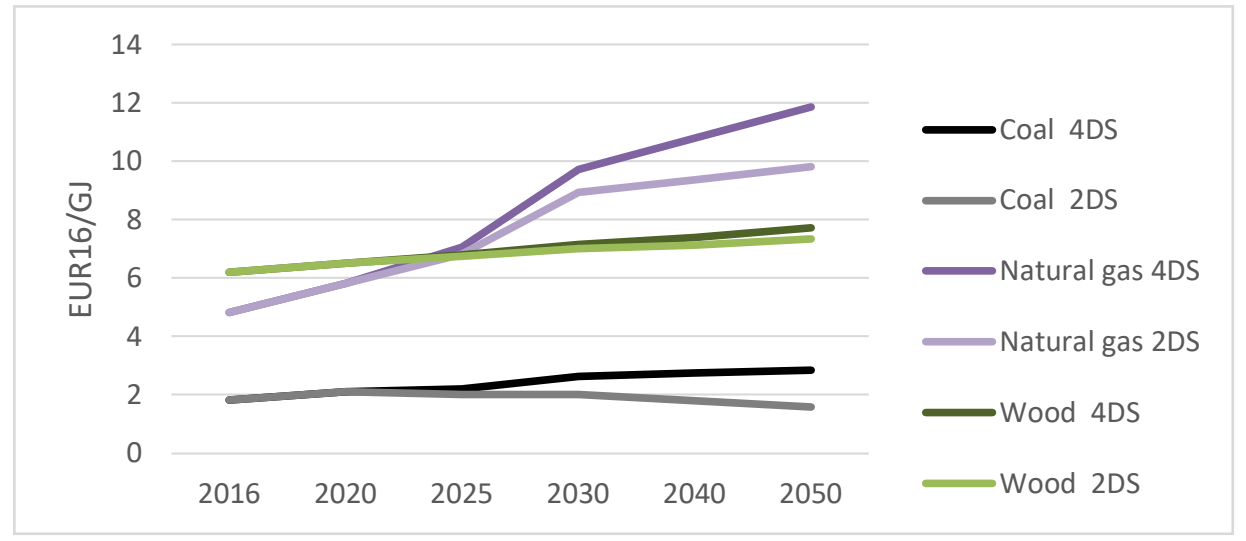

Baltic fuel prices are adjusted compared to those shown in Figure 84. Historically, natural gas prices have been higher in the Baltic countries, compared to Western European countries. This difference is estimated to roughly 2.2 EUR/MWh. Convergence of natural gas markets is assumed to lead to a phaseout of this difference by 2025 . Additionally, transport cost for natural gas (transmission and distribution) are assumed to be higher in the Baltic countries by a margin of another 3.9 EUR/MWh compared to the prices in Figure 84.

Domestic biomass resources in the Baltic countries currently lead to lower biomass prices, as reported by the Lithuanian biomass exchange baltpool.eu for example. For the 2017 price level, domestic wood chips are estimated to be $50 \%$ cheaper compared to European prices. In the longer term, further exploitation of export opportunities may lead to converging prices, and by 2030 , the difference is assumed to decrease to $15 \%$, corresponding to the estimated transport cost to reach European markets. Wood pellets are assumed to be $15 \%$ cheaper in the Baltics for all years.

Russian natural gas prices are currently much lower than European prices (52\% cheaper). By 2030, a gradual convergence has been assumed, so the difference is only $15 \%$.

\section{Transmission system}

Transmission Grid developments are based on the Ten-Year Network Development Plan 2016, developed by the transmission system operators within ENTSO-E. Where updated information is available, this has been used. Mid-term and long-term projects were included, while future projects were excluded since they are more uncertain and involve longer timespans.

The German internal grid is based on the TSO's latest grid development plan (NEP 2014), scenario B. Data until 2020 was directly implemented; expansion beyond 2020 appeared optimistic with regards to the controversial ongoing discussions. Therefore, the most controversial expansion corridors were assumed to be delayed until 2025. Transmission capacity between North West DE and South DE increases 
significantly between 2020 and 2025. Further expansion beyond 2025 between South and North DE are added.

Figure 85: The model area in the Balmorel and transmission lines in 2030 (GW)

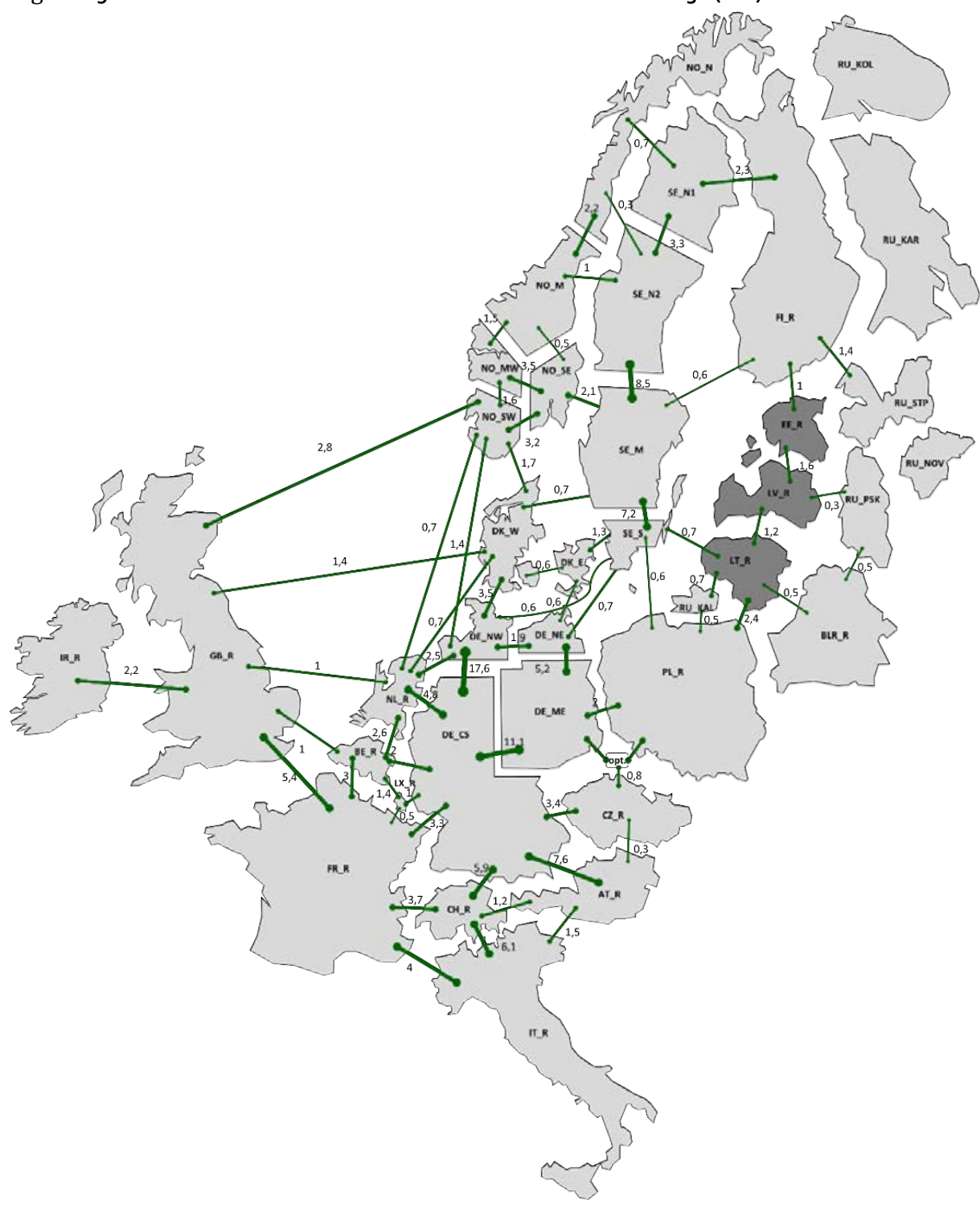

\section{Endogenous investments and decommissioning}

The capacity in the electricity system develops according to the least-cost optimisation pathway in the Balmorel model. The model invests in generation capacity if it is profitable, and decommissions capacity if it is not, from an electricity system perspective. The model both invests and decommissions myopically, i.e. only based on the information for the given year, not taking into account estimates for the future. This applies to parameters such as fuel and $\mathrm{CO}_{2}$ prices. 
- Investments: The model invests in a technology when its projected annual revenue can cover all costs, including capital costs and fixed O\&M. The model investments have been allowed after 2016, the base year of the model runs.

- Decommissioning: The model decommissions a technology when the revenue can no longer recover fixed O\&M. Exogenous capacity is kept constant (except if better data for the expected decommissioning year is available) unless it is decommissioned by the model. The model has been allowed to decommission capacity after 2020 .

Table 16: Model investment approach. The minimum RE development depends on the scenario modelled (See Annex II.3. Scenario description)

\section{Renewable capacity}

Denmark

Germany

Other EU countries

Decommissioning

Transmission after 2020

Allowed after 2020
Minimum development until 2030 (estimates based on Energinet.dk). Investments above the minimum after 2020

Minimum development until 2030 (estimates based on Renewable Energy Act). Investments above the minimum

Minimum development until 2030 (estimates based on ENTSO-E). Investments above the minimum after 2020.

Exogenous until 2030 (TYNDP 2016). Investments after 2030
Other capacity

Investments after 2016

Investments after 2016 Nuclear: Exogenous

Investments after 2016 Nuclear: Exogenous

Exogenous until 2030 (TYNDP 2016).

Investments after 2030 .

Technology assumptions are mainly based on the Technology Catalogue, published by Danish Transmission System operator Energinet and the Danish Energy Agency. ${ }^{6}$ The details are listed in Table 17.

${ }^{6}$ https://ens.dk/en/our-services/projections-and-models/technology-data 
Table 17: Technology assumptions

\begin{tabular}{|c|c|c|c|c|c|c|c|c|}
\hline Name & Type & Period & Fuel & Power efficiency & Heat efficiency or COP & $\begin{array}{r}\text { Investment cost } \\
\text { EUR/kW }\end{array}$ & $\begin{array}{r}\text { Fixed O\&M cost } \\
\text { EUR/kW }\end{array}$ & $\begin{array}{r}\text { Variable O\&M cost } \\
\text { EUR/MWh }\end{array}$ \\
\hline Coal refurbishment: Narva-EJ-TG8 & Condensing & $2020-2050$ & Coal & $33 \%$ & - & 118 & 40,56 & 3,32 \\
\hline Coal refurbishment: Auvere-EJ-TG1 & Condensing & $2020-2050$ & Coal & $40 \%$ & - & 118 & 40,56 & 3,32 \\
\hline Wood refurbishment: Narva-EJ-TG8 & Condensing & $2020-2050$ & Wood & $33 \%$ & - & 462 & 64,90 & 3,32 \\
\hline Wood refurbishment: Auvere-EJ-TG1 & Condensing & $2020-2050$ & Wood & $40 \%$ & - & 462 & 64,90 & 3,32 \\
\hline Wood pellet refurbishment: Narva-EJ-TG8 & Condensing & $2020-2050$ & Wood pellets & $33 \%$ & - & 197 & 48,68 & 3,32 \\
\hline Wood pellet refurbishment: Auvere-EJ-TG1 & Condensing & $2020-2050$ & Wood pellets & $40 \%$ & - & 197 & 48,68 & 3,32 \\
\hline Gas turbine - condensing CC & Condensing & $2020-2029$ & Natural gas & $60 \%$ & - & 812 & 16,23 & 2,34 \\
\hline Gas turbine - condensing CC & Condensing & $2030-2049$ & Natural gas & $62 \%$ & - & 803 & 16,23 & 2,34 \\
\hline Gas turbine - condensing CC & Condensing & 2050 & Natural gas & $62 \%$ & - & 783 & 16,23 & 2,34 \\
\hline Gas turbine - condensing & Condensing & $2020-2050$ & Natural gas & $46 \%$ & - & 594 & 16,23 & 1,59 \\
\hline Gas turbine - condensing & Condensing & $2020-2050$ & Retort gas & $46 \%$ & - & 594 & 16,23 & 1,59 \\
\hline Oil Shale turbine - condensing & Condensing & $2020-2050$ & Shale & $36 \%$ & - & 2.354 & 67,82 & 2,42 \\
\hline Gas turbine - backpressure & Backpressure & $2020-2050$ & Natural gas & $52 \%$ & $39 \%$ & 1.596 & 20,28 & 0,90 \\
\hline Steam turbine - backpressure & Backpressure & $2020-2050$ & Straw & $29 \%$ & $72 \%$ & 4.404 & 91,27 & 0,83 \\
\hline Steam turbine - backpressure & Backpressure & $2020-2029$ & Wood & $37 \%$ & $66 \%$ & 2.752 & 81,13 & 0,86 \\
\hline Steam turbine - backpressure & Backpressure & $2020-2050$ & Wood & $29 \%$ & $77 \%$ & 4.404 & 81,13 & 0,79 \\
\hline Steam turbine - backpressure & Backpressure & $2030-2050$ & Wood & $39 \%$ & $64 \%$ & 2.587 & 81,13 & 0,92 \\
\hline Steam turbine - extraction & Extraction & $2020-2029$ & Coal & $49 \%$ & $58 \%$ & 2.235 & 50,70 & 2,42 \\
\hline Coal refurbishment: Narva-EJ-TG11 & Extraction & $2020-2050$ & Coal & $33 \%$ & $39 \%$ & 118 & 50,70 & 3,37 \\
\hline Wood refurbishment: Narva-EJ-TG11 & Extraction & $2020-2050$ & Wood & $33 \%$ & $39 \%$ & 462 & 81,13 & 3,37 \\
\hline Wood pellets refurbishment: Narva-EJ-TG11 & Extraction & $2020-2050$ & Wood pellets & $33 \%$ & $39 \%$ & 197 & 60,84 & 3,37 \\
\hline Engine- extraction & Extraction & $2020-2029$ & Natural gas & $46 \%$ & $51 \%$ & 1.376 & 20,28 & 5,07 \\
\hline Engine- extraction & Extraction & $2030-2049$ & Natural gas & $49 \%$ & $54 \%$ & 1.376 & 20,28 & 5,07 \\
\hline Engine-extraction & Extraction & 2050 & Natural gas & $49 \%$ & $54 \%$ & 1.376 & 20,28 & 5,07 \\
\hline Steam turbine - extraction & Extraction & $2030-2049$ & Coal & $52 \%$ & $51 \%$ & 2.191 & 50,70 & 2,42 \\
\hline Steam turbine - extraction & Extraction & 2050 & Coal & $54 \%$ & $53 \%$ & 2.081 & 50,70 & 2,42 \\
\hline Waste to Energy - extraction & Extraction & $2020-2050$ & MSW & $22 \%$ & $73 \%$ & 11.057 & 309,67 & 25,63 \\
\hline Gas turbine - extraction & Extraction & $2020-2029$ & Natural gas & $60 \%$ & $34 \%$ & 903 & 20,28 & 2,75 \\
\hline Steam turbine - extraction & Extraction & $2020-2050$ & Natural gas & $47 \%$ & $66 \%$ & 1.431 & 20,28 & 0,90 \\
\hline Gas turbine - extraction & Extraction & $2020-2050$ & Natural gas & $46 \%$ & $43 \%$ & 661 & 20,28 & 1,87 \\
\hline Gas turbine-extraction & Extraction & $2030-2049$ & Natural gas & $62 \%$ & $35 \%$ & 892 & 20,28 & 2,75 \\
\hline Gas turbine - extraction & Extraction & 2050 & Natural gas & $62 \%$ & $35 \%$ & 870 & 20,28 & 2,75 \\
\hline Oil Shale turbine - extraction & Extraction & $2020-2050$ & Shale & $36 \%$ & $42 \%$ & 2.354 & 67,82 & 2,42 \\
\hline Steam turbine - extraction & Extraction & $2020-2029$ & Wood & $47 \%$ & $85 \%$ & 2.268 & 81,13 & 2,42 \\
\hline Steam turbine - extraction & Extraction & $2030-2050$ & Wood & $49 \%$ & $80 \%$ & 2.180 & 81,13 & 2,42 \\
\hline Steam turbine - extraction & Extraction & $2020-2029$ & Wood pellets & $49 \%$ & $58 \%$ & 2.235 & 60,84 & 2,42 \\
\hline Steam turbine - extraction & Extraction & $2030-2049$ & Wood pellets & $52 \%$ & $51 \%$ & 2.191 & 60,84 & 2,42 \\
\hline Steam turbine - extraction & Extraction & 2050 & Wood pellets & $54 \%$ & $53 \%$ & 2.081 & 60,84 & 2,42 \\
\hline Heat only boiler & Heat-only & $2020-2050$ & MSW & - & $98 \%$ & 1.681 & 77,42 & 5,05 \\
\hline Heat only boiler & Heat-only & $2020-2050$ & Natural gas & - & $101 \%$ & 110 & 2,04 & 0,68 \\
\hline Heat only boiler & Heat-only & $2020-2050$ & Straw & - & $103 \%$ & 881 & 6,61 & 2,20 \\
\hline
\end{tabular}




\begin{tabular}{|c|c|c|c|c|c|c|c|c|}
\hline Name & Type & Period & Fuel & Power efficiency & Heat efficiency or COP & $\begin{array}{r}\text { Investment cost } \\
\text { EUR/kW }\end{array}$ & $\begin{array}{r}\text { Fixed O\&M cost } \\
\text { EUR/kW }\end{array}$ & $\begin{array}{r}\text { Variable O\&M cost } \\
\text { EUR/MWh }\end{array}$ \\
\hline Heat only boiler & Electric boiler & $2020-2050$ & Electricity & - & $99 \%$ & 83 & 1,21 & 0,55 \\
\hline HeatPump & Heatpump & $2020-2024$ & Electricity & - & 2,00 & 694 & 2,01 & 0,33 \\
\hline HeatPump & Heatpump & $2025-2029$ & Electricity & - & 2,17 & 663 & 2,01 & 0,33 \\
\hline HeatPump & Heatpump & $2030-2049$ & Electricity & - & 2,33 & 633 & 2,01 & 0,33 \\
\hline HeatPump & Heatpump & 2050 & Electricity & - & 3,00 & 578 & 2,01 & 0,33 \\
\hline HeatPump - geothermal & Geothermal HP & $2020-2050$ & Electricity & - & 4,68 & 2.638 & 18,72 & 2,67 \\
\hline Heat storage & Heat storage & $2020-2050$ & Heat & - & $95 \%$ & 3 & 0,00 & 0,00 \\
\hline Solar heating & Solar heat & $2020-2024$ & Solar & - & - & o & - & 0,63 \\
\hline Solar heating & Solar heat & $2025-2029$ & Solar & - & - & o & - & 0,63 \\
\hline Solar heating & Solar heat & $2030-2050$ & Solar & - & - & o & - & 0,63 \\
\hline Solar PV & Photovoltaic & $2020-2024$ & Solar & - & - & 507 & 6,07 & - \\
\hline Solar PV & Photovoltaic & $2025-2029$ & Solar & - & - & 459 & 5,44 & - \\
\hline Solar PV & Photovoltaic & $2030-2039$ & Solar & - & - & 411 & 4,81 & - \\
\hline Solar PV & Photovoltaic & $2040-2049$ & Solar & - & - & 364 & 4,29 & - \\
\hline Solar PV & Photovoltaic & 2050 & Solar & - & - & 317 & 3,78 & - \\
\hline Onshore wind & Wind power & $2020-2024$ & Onshore wind & - & - & 987 & 23,95 & 2,50 \\
\hline Onshore wind & Wind power & $2025-2029$ & Onshore wind & - & - & 948 & 23,14 & 2,40 \\
\hline Onshore wind & Wind power & $2030-2049$ & Onshore wind & - & - & 908 & 22,34 & 2,30 \\
\hline Onshore wind & Wind power & 2050 & Onshore wind & - & - & 836 & 21,24 & 2,10 \\
\hline Onshore wind (expensive) & Wind power & $2020-2024$ & Onshore wind & - & - & 1.086 & 23,95 & 2,50 \\
\hline Onshore wind (expensive) & Wind power & $2030-2049$ & Onshore wind & - & - & 999 & 22,34 & 2,30 \\
\hline Onshore wind (expensive) & Wind power & $2025-2029$ & Onshore wind & - & - & 1.043 & 23,14 & 2,40 \\
\hline Onshore wind (expensive) & Wind power & 2050 & Onshore wind & - & - & 919 & 21,24 & 2,10 \\
\hline Offshore wind & Wind power & $2020-2024$ & Offshore wind & - & - & 2.266 & 47,52 & 3,53 \\
\hline Offshore wind & Wind power & $2025-2029$ & Offshore wind & - & - & 2.106 & 43,84 & 3,25 \\
\hline Offshore wind & Wind power & $2030-2049$ & Offshore wind & - & - & 1.946 & 40,16 & 2,98 \\
\hline Offshore wind & Wind power & 2050 & Offshore wind & - & - & 1.695 & 35,14 & 2,61 \\
\hline Far offshore wind & Wind power & $2020-2024$ & Offshore wind & - & - & 2.570 & 53,70 & 3,98 \\
\hline Far offshore wind & Wind power & $2025-2029$ & Offshore wind & - & - & 2.389 & 49,54 & 3,68 \\
\hline Far offshore wind & Wind power & $2030-2049$ & Offshore wind & - & - & 2.208 & 45,38 & 3,37 \\
\hline Far offshore wind & Wind power & 2050 & Offshore wind & - & - & 1.924 & 39,71 & 2,95 \\
\hline Near offshore wind & Wind power & $2020-2024$ & Offshore wind & - & - & 2.130 & 39,59 & 2,91 \\
\hline
\end{tabular}


Table 18: Investment options in the Baltic countries

\begin{tabular}{|c|c|c|c|c|c|c|c|c|}
\hline Name & Type & Period & Fuel & Power efficiency & Heat efficiency or COP & $\begin{array}{l}\text { Investment cost } \\
\text { EUR/kW }\end{array}$ & $\begin{array}{l}\text { Fixed O\&M cost } \\
\text { EUR/kW }\end{array}$ & $\begin{array}{l}\text { Variable } O \& M \text { cost } \\
\text { EUR/MWh }\end{array}$ \\
\hline Coal refurbishment: Narva-EJ-TG8 & Condensing & $2020-2050$ & Coal & $33 \%$ & & 118 & 40,56 & 3,32 \\
\hline Coal refurbishment: Auvere-EJ-TG1 & Condensing & $2020-2050$ & Coal & $40 \%$ & - & 118 & 40,56 & 3,32 \\
\hline Wood refurbishment: Narva-EJ-TG8 & Condensing & $2020-2050$ & Wood & $33 \%$ & - & 462 & 64,90 & 3,32 \\
\hline Wood refurbishment: Auvere-EJ-TG1 & Condensing & $2020-2050$ & Wood & $40 \%$ & - & 462 & 64,90 & 3,32 \\
\hline Wood pellet refurbishment: Narva-EJ-TG8 & Condensing & $2020-2050$ & Wood pellets & $33 \%$ & - & 197 & 48,68 & 3,32 \\
\hline Wood pellet refurbishment: Auvere-EJ-TG1 & Condensing & $2020-2050$ & Wood pellets & $40 \%$ & - & 197 & 48,68 & 3,32 \\
\hline Gas turbine - condensing CC & Condensing & $2020-2029$ & Natural gas & $60 \%$ & - & 812 & 16,23 & 2,34 \\
\hline Gas turbine - condensing CC & Condensing & $2030-2049$ & Natural gas & $62 \%$ & - & 803 & 16,23 & 2,34 \\
\hline Gas turbine - condensing CC & Condensing & 2050 & Natural gas & $62 \%$ & - & 783 & 16,23 & 2,34 \\
\hline Gas turbine - condensing & Condensing & $2020-2050$ & Natural gas & $46 \%$ & - & 594 & 16,23 & 1,59 \\
\hline Gas turbine - condensing & Condensing & $2020-2050$ & Retort gas & $46 \%$ & - & 594 & 16,23 & 1,59 \\
\hline Oil Shale turbine - condensing & Condensing & $2020-2050$ & Shale & $36 \%$ & - & 2.354 & 67,82 & 2,42 \\
\hline Gas turbine - backpressure & Backpressure & $2020-2050$ & Natural gas & $52 \%$ & $39 \%$ & 1.596 & 20,28 & 0,90 \\
\hline Steam turbine - backpressure & Backpressure & $2020-2050$ & Straw & $29 \%$ & $72 \%$ & 4.404 & 91,27 & 0,83 \\
\hline Steam turbine - backpressure & Backpressure & $2020-2029$ & Wood & $37 \%$ & $66 \%$ & 2.752 & 81,13 & 0,86 \\
\hline Steam turbine - backpressure & Backpressure & $2020-2050$ & Wood & $29 \%$ & $77 \%$ & 4.404 & 81,13 & 0,79 \\
\hline Steam turbine - backpressure & Backpressure & $2030-2050$ & Wood & $39 \%$ & $64 \%$ & 2.587 & 81,13 & 0,92 \\
\hline Steam turbine - extraction & Extraction & $2020-2029$ & Coal & $49 \%$ & $58 \%$ & 2.235 & 50,70 & 2,42 \\
\hline Coal refurbishment: Narva-EJ-TG11 & Extraction & $2020-2050$ & Coal & $33 \%$ & $39 \%$ & 118 & 50,70 & 3,37 \\
\hline Wood refurbishment: Narva-EJ-TG11 & Extraction & $2020-2050$ & Wood & $33 \%$ & $39 \%$ & 462 & 81,13 & 3,37 \\
\hline Wood pellets refurbishment: Narva-EJ-TG11 & Extraction & $2020-2050$ & Wood pellets & $33 \%$ & $39 \%$ & 197 & 60,84 & 3,37 \\
\hline Engine - extraction & Extraction & $2020-2029$ & Natural gas & $46 \%$ & $51 \%$ & 1.376 & 20,28 & 5,07 \\
\hline Engine - extraction & Extraction & $2030-2049$ & Natural gas & $49 \%$ & $54 \%$ & 1.376 & 20,28 & 5,07 \\
\hline Engine - extraction & Extraction & 2050 & Natural gas & $49 \%$ & $54 \%$ & 1.376 & 20,28 & 5,07 \\
\hline Steam turbine - extraction & Extraction & $2030-2049$ & Coal & $52 \%$ & $51 \%$ & 2.191 & 50,70 & 2,42 \\
\hline Steam turbine - extraction & Extraction & 2050 & Coal & $54 \%$ & $53 \%$ & 2.081 & 50,70 & 2,42 \\
\hline Waste to Energy - extraction & Extraction & $2020-2050$ & MSW & $22 \%$ & $73 \%$ & 11.057 & 309,67 & 25,63 \\
\hline Gas turbine - extraction & Extraction & $2020-2029$ & Natural gas & $60 \%$ & $34 \%$ & 903 & 20,28 & 2,75 \\
\hline Steam turbine - extraction & Extraction & $2020-2050$ & Natural gas & $47 \%$ & $66 \%$ & 1.431 & 20,28 & 0,90 \\
\hline Gas turbine - extraction & Extraction & $2020-2050$ & Natural gas & $46 \%$ & $43 \%$ & 661 & 20,28 & 1,87 \\
\hline Gas turbine - extraction & Extraction & $2030-2049$ & Natural gas & $62 \%$ & $35 \%$ & 892 & 20,28 & 2,75 \\
\hline Gas turbine - extraction & Extraction & 2050 & Natural gas & $62 \%$ & $35 \%$ & 870 & 20,28 & 2,75 \\
\hline Oil Shale turbine - extraction & Extraction & $2020-2050$ & Shale & $36 \%$ & $42 \%$ & 2.354 & 67,82 & 2,42 \\
\hline Steam turbine - extraction & Extraction & $2020-2029$ & Wood & $47 \%$ & $85 \%$ & 2.268 & 81,13 & $2,4^{2}$ \\
\hline Steam turbine - extraction & Extraction & $2030-2050$ & Wood & $49 \%$ & $80 \%$ & 2.180 & 81,13 & 2,42 \\
\hline Steam turbine - extraction & Extraction & $2020-2029$ & Wood pellets & $49 \%$ & $58 \%$ & 2.235 & 60,84 & 2,42 \\
\hline Steam turbine - extraction & Extraction & $2030-2049$ & Wood pellets & $52 \%$ & $51 \%$ & 2.191 & 60,84 & 2,42 \\
\hline Steam turbine - extraction & Extraction & 2050 & Wood pellets & $54 \%$ & $53 \%$ & 2.081 & 60,84 & 2,42 \\
\hline Heat only boiler & Heat-only & $2020-2050$ & MSW & - & $98 \%$ & 1.681 & 77,42 & 5,05 \\
\hline Heat only boiler & Heat-only & $2020-2050$ & Natural gas & 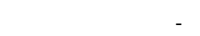 & $101 \%$ & 110 & 2,04 & 0,68 \\
\hline
\end{tabular}




\begin{tabular}{|c|c|c|c|c|c|c|c|c|}
\hline Name & Type & Period & Fuel & Power efficiency & Heat efficiency or COP & $\begin{array}{r}\text { Investment cost } \\
\text { EUR/kW }\end{array}$ & $\begin{array}{r}\text { Fixed O\&M cost } \\
\text { EUR/kW }\end{array}$ & $\begin{array}{r}\text { Variable O\&M cost } \\
\text { EUR/MWh }\end{array}$ \\
\hline Heat only boiler & Heat-only & $2020-2050$ & Straw & - & $103 \%$ & 881 & 6,61 & 2,20 \\
\hline Heat only boiler & Heat-only & $2020-2050$ & Wood & - & $108 \%$ & 881 & 8,92 & 2,97 \\
\hline Heat only boiler & Heat-only & $2020-2050$ & Wood pellets & - & $95 \%$ & 440 & 4,46 & 1,49 \\
\hline Heat only boiler & Electric boiler & $2020-2050$ & Electricity & - & $99 \%$ & 83 & 1,21 & 0,55 \\
\hline HeatPump & Heatpump & $2020-2024$ & Electricity & - & 2,00 & 694 & 2,01 & 0,33 \\
\hline HeatPump & Heatpump & $2025-2029$ & Electricity & - & 2,17 & 663 & 2,01 & 0,33 \\
\hline HeatPump & Heatpump & $2030-2049$ & Electricity & - & 2,33 & 633 & 2,01 & 0,33 \\
\hline HeatPump & Heatpump & 2050 & Electricity & - & 3,00 & 578 & 2,01 & 0,33 \\
\hline HeatPump - geothermal & Geothermal HP & $2020-2050$ & Electricity & - & 4,68 & 2.638 & 18,72 & 2,67 \\
\hline Heat storage & Heat storage & $2020-2050$ & Heat & - & $95 \%$ & 3 & 0,00 & 0,00 \\
\hline Solar heating & Solar heat & $2020-2024$ & Solar & - & - & 0 & - & 0,63 \\
\hline Solar heating & Solar heat & $2025-2029$ & Solar & - & - & 0 & - & 0,63 \\
\hline Solar heating & Solar heat & $2030-2050$ & Solar & - & - & o & - & 0,63 \\
\hline Solar PV & Photovoltaic & $2020-2024$ & Solar & - & - & 507 & 6,07 & - \\
\hline Solar PV & Photovoltaic & $2025-2029$ & Solar & - & - & 459 & 5,44 & - \\
\hline Solar PV & Photovoltaic & $2030-2039$ & Solar & - & - & 411 & 4,81 & - \\
\hline Solar PV & Photovoltaic & $2040-2049$ & Solar & - & - & 364 & 4,29 & - \\
\hline Solar PV & Photovoltaic & 2050 & Solar & - & - & 317 & 3,78 & - \\
\hline Onshore wind & Wind power & $2020-2024$ & Onshore wind & - & - & 987 & 23,95 & 2,50 \\
\hline Onshore wind & Wind power & $2025-2029$ & Onshore wind & - & - & 948 & 23,14 & 2,40 \\
\hline Onshore wind & Wind power & $2030-2049$ & Onshore wind & - & - & 908 & 22,34 & 2,30 \\
\hline Onshore wind & Wind power & 2050 & Onshore wind & - & - & 836 & 21,24 & 2,10 \\
\hline Onshore wind (expensive) & Wind power & $2020-2024$ & Onshore wind & - & - & 1.086 & 23,95 & 2,50 \\
\hline Onshore wind (expensive) & Wind power & $2030-2049$ & Onshore wind & - & - & 999 & 22,34 & 2,30 \\
\hline Onshore wind (expensive) & Wind power & $2025-2029$ & Onshore wind & - & - & 1.043 & 23,14 & 2,40 \\
\hline Onshore wind (expensive) & Wind power & 2050 & Onshore wind & - & - & 919 & 21,24 & 2,10 \\
\hline Offshore wind & Wind power & $2020-2024$ & Offshore wind & - & - & 2.266 & 47,52 & 3,53 \\
\hline Offshore wind & Wind power & $2025-2029$ & Offshore wind & - & - & 2.106 & 43,84 & 3,25 \\
\hline Offshore wind & Wind power & $2030-2049$ & Offshore wind & - & - & 1.946 & 40,16 & 2,98 \\
\hline Offshore wind & Wind power & 2050 & Offshore wind & - & - & 1.695 & 35,14 & 2,61 \\
\hline Far offshore wind & Wind power & $2020-2024$ & Offshore wind & - & - & 2.570 & 53,70 & 3,98 \\
\hline Far offshore wind & Wind power & $2025-2029$ & Offshore wind & - & - & 2.389 & 49,54 & 3,68 \\
\hline Far offshore wind & Wind power & $2030-2049$ & Offshore wind & - & - & 2.208 & 45,38 & 3,37 \\
\hline Far offshore wind & Wind power & 2050 & Offshore wind & - & - & 1.924 & 39,71 & 2,95 \\
\hline Near offshore wind & Wind power & $2020-2024$ & Offshore wind & - & - & 2.130 & 39,59 & 2,91 \\
\hline
\end{tabular}




\section{II.3.Scenario description}

Three main scenarios are modelled by Balmorel, the $4 \mathrm{DS}$ representing a scenario with low RE ambitions, the BPO where the Baltic countries have an additional RE share requirement, and the $2 \mathrm{DS}$ with more ambitious targets for curbing GHG emissions.

For all three scenarios, the electricity and heat demand are given by TIMES. In the BPO, the RE shares are also TIMES outputs for the Baltic countries.

Table 19: Scenario overview. WEO16 NP: New policies scenario in the World Energy Outlook 2016, IEA.WEO16 450 ppm: 450 ppm scenario in the World Energy Outlook 2016, IEA

\begin{tabular}{|c|c|c|c|}
\hline & 2020 & 2030 & 2050 \\
\hline \multirow[t]{9}{*}{$4 D S$} & Baltics -2020 targets & Baltics -2020 targets & Baltics -2020 targets \\
\hline & No subsidies & No subsidies & No subsidies \\
\hline & RE roll-out: None & RE roll-out: None & \\
\hline & $E U-2020$ targets & $E U-2030$ targets & $E U-2030$ targets \\
\hline & RE subsidies & RE subsidies & RE subsidies \\
\hline & RE roll-out: ENTSO-E & RE roll-out: Min. ENTSO-E & \\
\hline & All & All & All \\
\hline & Fuel prices: futures & Fuel prices: WEO 16 NP & Fuel prices: WEO 16 NP \\
\hline & $\mathrm{CO}_{2}$-price: $8.2 \mathrm{EUR} /$ tonne & $\mathrm{CO}_{2}$-price: $15 \mathrm{EUR} /$ tonne & $\mathrm{CO}_{2}$-price: $40 \mathrm{EUR} /$ tonne \\
\hline \multirow[t]{9}{*}{$B P O$} & Baltics -2020 targets & Baltics -2030 targets & Baltics - 2050 targets \\
\hline & TIMES RE shares & TIMES RE shares & TIMES RE shares \\
\hline & RE roll-out: None & RE roll-out: None & \\
\hline & $E U-2030$ targets & $E U-2030$ targets & $E U-2050$ targets \\
\hline & RE subsidies & RE subsidies & RE subsidies \\
\hline & RE roll-out: ENTSO-E & RE roll-out: Min. ENTSO-E & \\
\hline & All & All & All \\
\hline & Fuel prices: futures & Fuel prices: WEO 16 NP & Fuel prices: WEO 16 NP \\
\hline & $\mathrm{CO}_{2}$-price: $8.2 \mathrm{EUR} /$ tonne & $\mathrm{CO}_{2}$-price: $15 \mathrm{EUR} /$ tonne & $\mathrm{CO}_{2}$-price: $40 \mathrm{EUR} /$ tonne \\
\hline \multirow[t]{9}{*}{$2 D S$} & Baltics - 2020 optimisation & Baltics - 2030 optimisation & Baltics - 2050 optimisation \\
\hline & No subsidies & No subsidies & No subsidies \\
\hline & RE roll-out: None & RE roll-out: None & \\
\hline & EU-2020 optimization & EU - 2030 optimization & EU - 2050 optimization \\
\hline & No subsidies & No subsidies & No subsidies \\
\hline & RE roll-out: ENTSO-E & RE roll-out: None & Higher electricity demand \\
\hline & All & All & All \\
\hline & Fuel prices: futures & Fuel prices: WEO16 450ppm & Fuel prices: WEO16 45oppm \\
\hline & $\mathrm{CO}_{2}$-price: 8.2 EUR/tonne & $\mathrm{CO}_{2}$-price: $30 \mathrm{EUR} /$ tonne & $\mathrm{CO}_{2}$-price: $100 \mathrm{EUR} /$ tonne \\
\hline
\end{tabular}





\section{Annex III. Energy system modelling in Estonia}

Various models and methodologies have been used over the years to facilitate longterm energy system planning in Estonia. Complete energy sector models, such as LEAP and MARKAL, have sometimes been utilised. In other cases, rudimentary models or specific analyses have been used for single-sector studies before being combined (where applicable) into a holistic energy sector analysis. Balmorel has been a popular model for electricity and district heating sector analysis, especially in the recent years.

The Estonian electricity system development plan 2008-2018 is an example of a sectoral analysis which was then used (along with other sectoral studies) in the Estonian energy system development plan 2020. The LEAP model was used in the Estonian energy system development plan 2020 to assess the environmental impacts.

An example of applying a holistic energy sector model can be observed in a study published in 1999, which conducted an extensive investigation of the energy sector using MARKAL and MARKAL-MACRO as the tools for analysis [1]. In the study, a baseline and high energy demand scenarios were investigated alongside subcases for $\mathrm{CO}_{2}$ and oil shale prices. An overview of the overall projected energy system primary fuel supply in the baseline demand scenario can be observed in figures 82 and 83 . Pathways to a lower carbon-intensive energy sector were investigated alongside their potential impacts. The main opportunities for GHG mitigation were found to be: reducing oil shale combustion in electricity generation, newer and more efficient fossil generation technologies, wider usage of CHP and renewables, possible usage of nuclear power, and reducing grid losses.

MARKAL and MARKAL-MACRO have not been used in recent studies, however, due to a declining expertise of these models in Estonia since approximately 2005. 
Figure 86: Primary fuel use in different scenarios as MARKAL output

Baseline primary fuel supply

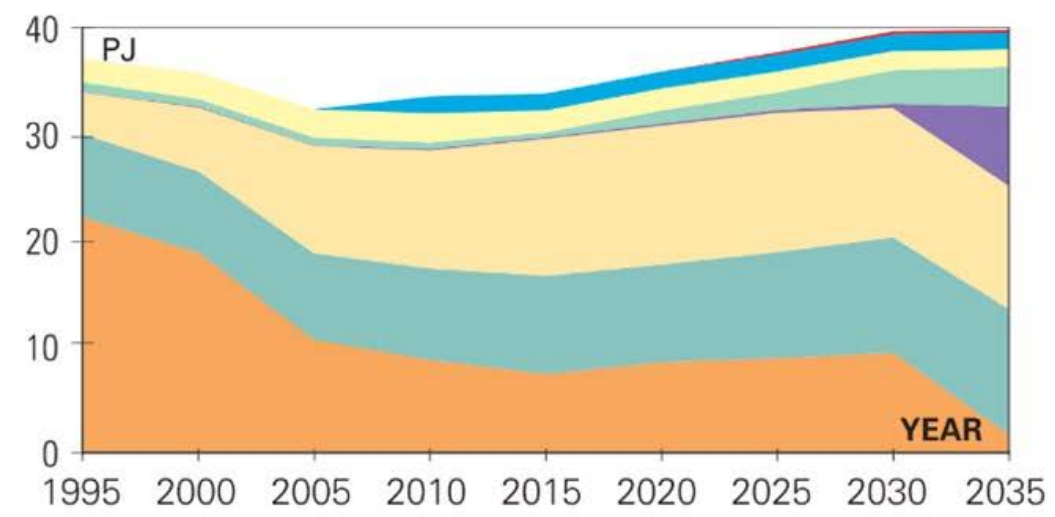

\section{Primary fuel supply under Low $\mathrm{CO}_{2} \mathrm{Tax}+$} Baseline Demand scenario

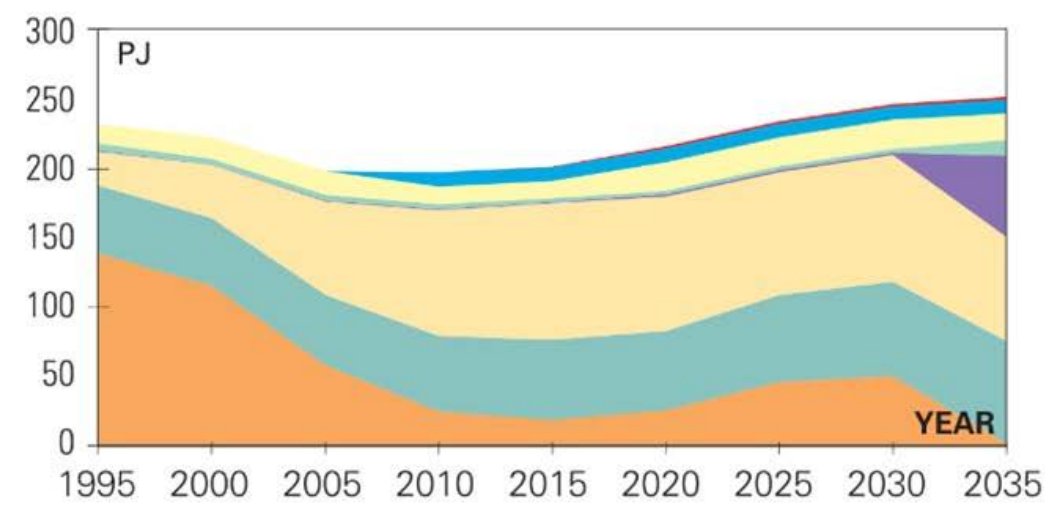

Primary fuel supply under High $\mathrm{CO}_{2} \mathrm{Tax}+$ Baseline Demand scenario

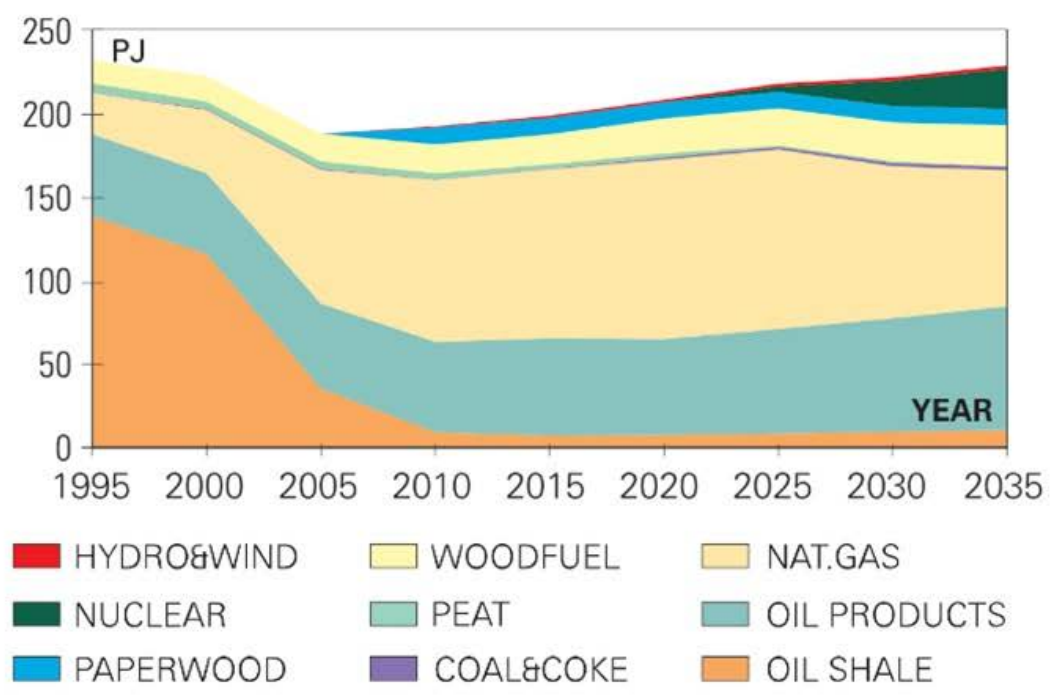


Figure 87: $\mathrm{CO}_{2}$ emissions in different scenarios as MARKAL output

Total $\mathrm{CO}_{2}$ emissions from energy system under Baseline Energy Demand

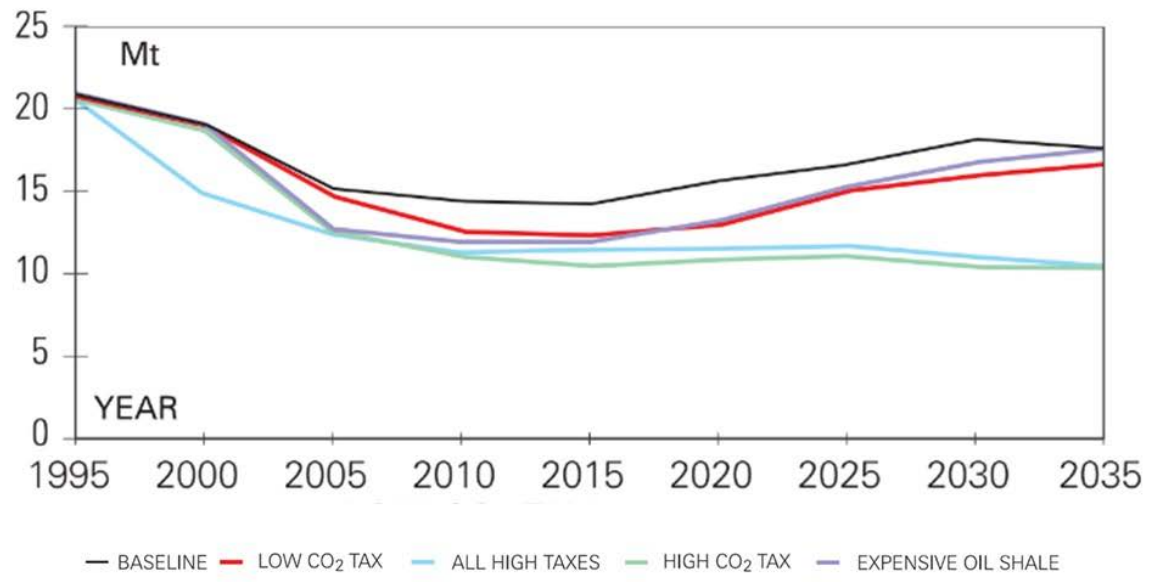

ENMAK and KPP

Among more recent studies, the Estonian National Development Plan of the Energy Sector until 2030 (ENMAK 2030+) and climate policy principles through 2050 (KPP) should be mentioned. In both of these studies, in-depth sectoral analysis was conducted while the Balmorel model was used for electricity and district heating sector analysis. The sectoral analysis was combined by merging the sectoral scenarios to form holistic energy sector scenarios.

In ENMAK 2030+, Balmorel was used to investigate the effects of strategic national choices in the power sector on the electricity market. Among the cases studied were: the choice between shale oil production and oil shale combustion in power plants; ambitious renewable energy targets; security of supply targets; and complete cessation of fossil fuel investments in the country.

Being the more recent of the two studies, KPP used the inputs and results of ENMAK 2030+ extensively to expand upon. Sectoral scenarios were combined into several pathways to identify how the European Union climate policy targets could be achieved. The chosen pathway towards an $80 \%$ reduction in emissions by 2050 can be observed in figure 88 . The study paid close attention to the possible effects of climate targets on the economy. The analysis indicated that the impact of emission reduction measures on the state of the economy and overall GDP would be mostly positive. The overall effect on GDP was estimated to be about 440 MEUR/year, which would largely be brought about by an increase in labour productivity and a positive impact of renewable transport fuels on the national trade balance. 
Figure 88: Sectoral emission estimates in the KPP study in order to meet the $80 \%$ emission reduction target [2]

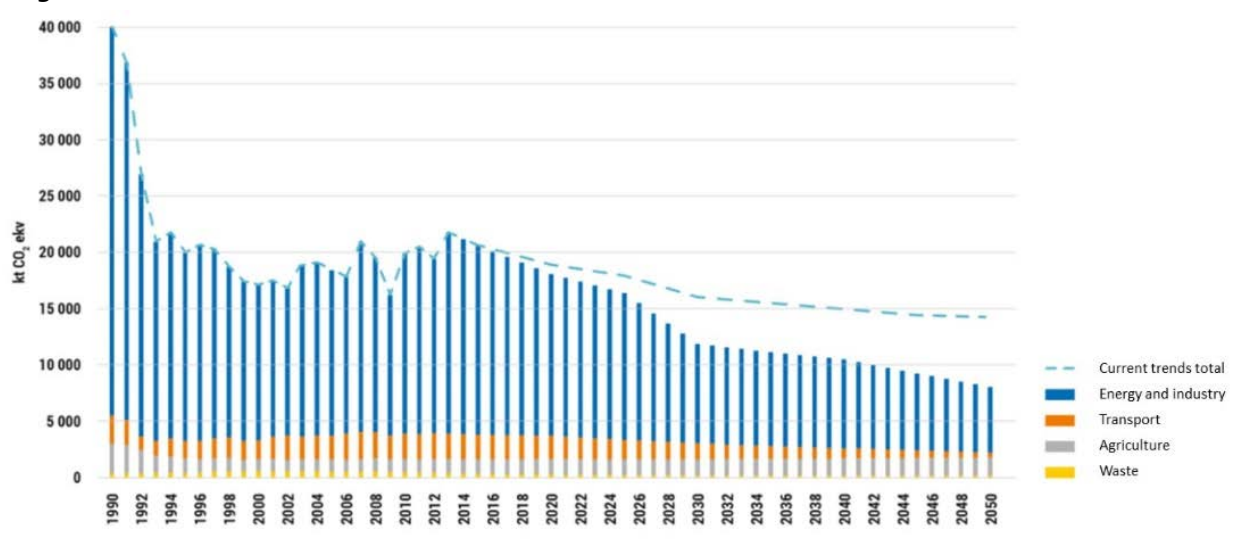

\section{References}

[1] SEI Tallinn, Possible Energy Sector Trends in Estonia, Tallinn: SEI Tallinn, 1999.

[2] Ministry of Environment, „Kliimapoliitika põhialused aastani 2050", Ministry of Environment, Tallinn, 2016. 


\section{Annex IV. Energy system modelling in Latvia}

To analyse the energy system, several analysis tools have been used in Latvia, e.g. EFOM multi-period linear programming optimisation model used from 1994-2000 in research projects focusing on electricity and district heating. Few studies have been done using MESSAGE, BALMOREL, MESAP (PlaNet), and ENPEP-BALANCE models. Since 1995 MARKAL has been used for energy and environmental system analysis in Latvia, e.g. GHG emission and pollutant projections for National Communications and Biennial Reports under the UNFCCC and Convention on Long-range Transboundary Air Pollution. The model covers the entire energy system of Latvia (energy balance with further final demand disaggregation) and other IPCC CRF sectors represented at the GHG emission level.

Example of using MARKAL to assess existing end-use energy efficiency policies In one of the research projects using the MARKAL-Latvia model, the Institute of Physical Energetics (IPE) evaluated the impact of an implemented energy efficiency policy on energy consumption and GHG emissions.

To assess the impact of the existing energy efficiency policy and measures upon the primary energy consumption, two scenarios were modelled - the scenario without the existing policy and measures (BASE) and the scenario including the existing policy and measures - to reach the targets set for 2020 (BASE-HE). End-use energy savings for the period 2007-2015 were calculated using top-down and bottom-up approaches.

Figure 89: Sectoral energy consumption and the modelled effect of the energy efficiency measures with and without existing energy efficiency policies

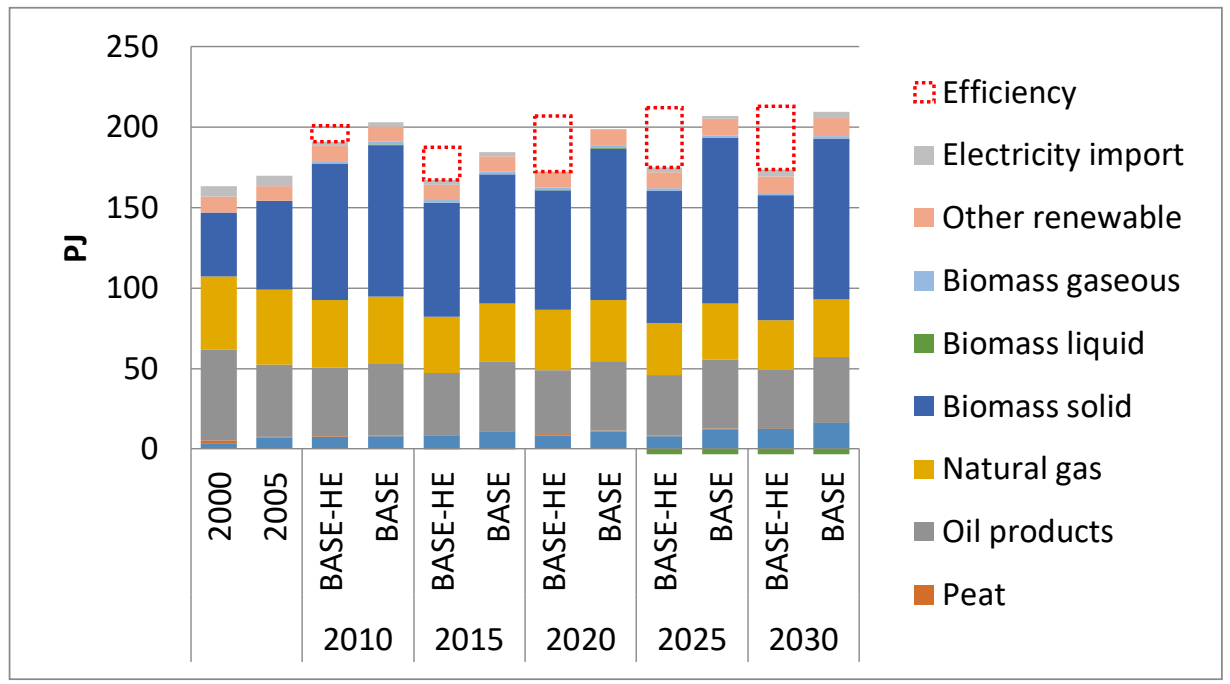


Model assessing primary energy savings from the implementation of energy efficiency policy up to 2030

The modelling results reveal that failing to implement the existing energy efficiency policy would result in an increase in consumption of primary energy by $34 \mathrm{PJ}$ and $39 \mathrm{PJ}$ in 2020 and 2030, respectively. The energy efficiency policy contributes to GHG emission reductions in the energy sector as well. The results show that GHG emissions in the energy sector would increase by $875 \mathrm{kt} \mathrm{CO}_{2}$ eq in 2020 and by $1390 \mathrm{kt} \mathrm{CO}{ }_{2}$ eq in 2030.

Figure 9o: GHG emission reductions of the assessed energy efficiency measures

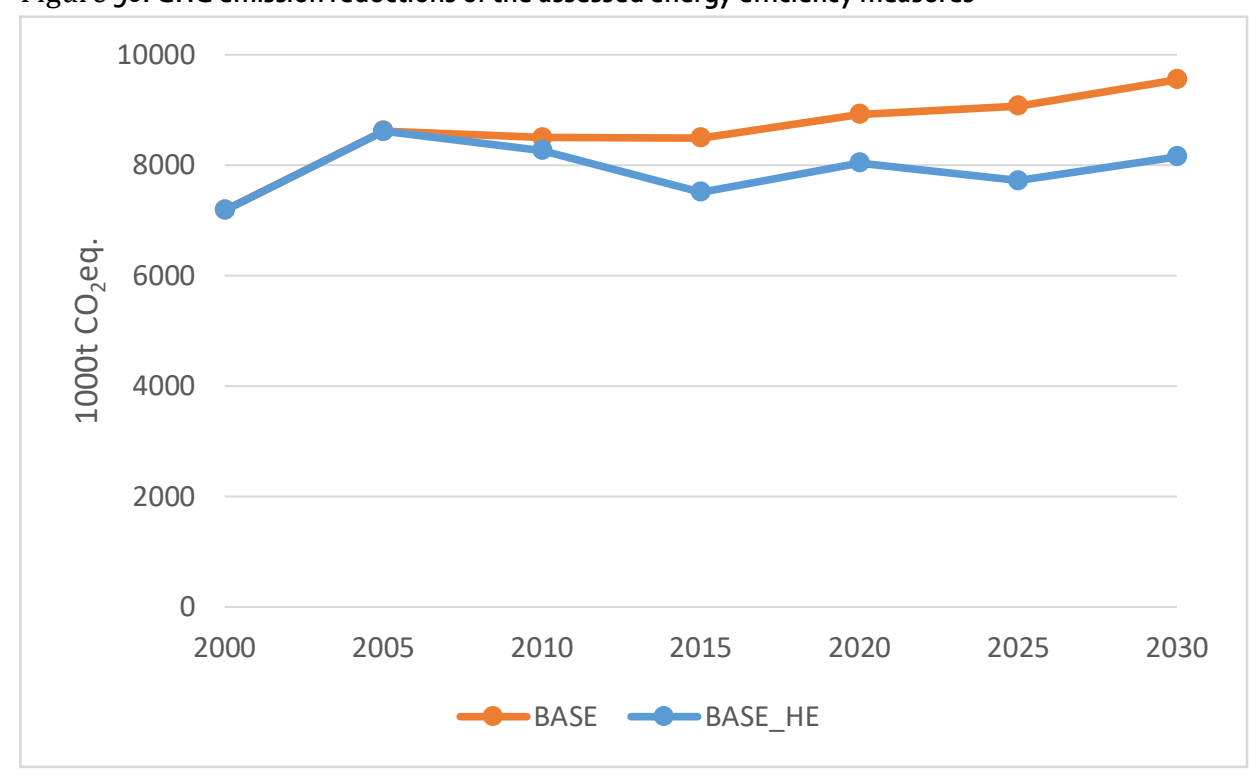

Model assessing GHG emission reductions from the implementation of the energy efficiency policy up to 2020

Modelling scenarios allow us to assess the impact of energy efficiency measures on the total costs in the energy sector. The modelling results reveal that implementation of the energy efficiency policy reduces the average of total annual costs by $0.9 \%-2.5 \%$ of GDP. Moreover, the assessment shows that the energy efficiency measures reduce the total system costs of imported fuels and energy average by 62-143 MEUR(2000)/year. At the same time, household expenses for energy are reduced by 44288 MEUR(2000)/year on average. The given calculation takes investments, operation and maintenance costs into account, as well as fuel costs. It should be noted that this approach allows us to assess the average impact on the sector or the whole system and provides an insight into the main trends in the energy efficiency policy regarding the impact. The level of the economic agent is not assessed here, because the assessment cannot be directly attributed to a definite energy consumer of households or other sectors. 


\section{Annex V. Energy system modelling in Lithuania}

Laboratory experts in energy systems research from the Lithuanian Energy institute (LEI) were recently involved in preparing the National Energy Independence Strategy draft, which defines the main provisions of the State in developing the energy sector until 2030 and presents guidelines until 2050. Prospective development directions of the Lithuanian energy sector and scenarios of rational energy sector development in the long-term perspective were justified by the analysis of the results of the mathematical modelling. Very important factors influencing the development and security of the national energy sector were chosen to prepare scenarios that differ in terms of the required installed capacity of power plants or local electricity production level, volumes of imported electricity and shares of renewable energy resources in the country's energy balance. After the analysis of the obtained results, the main rational and stable technological solutions for the energy sector were identified [1-2].

In 2014, a three-year long project "Assessment of perspectives for broader use of renewable energy sources in Lithuania taking into account interdependencies among energy water and climate change" in coordination with the International Atomic Energy Agency (IAEA) as part of the research project "Assessing Interdependencies between Energy, Water, Land-use and Climate Change" [3] was completed. This research provides guidelines for modelling of sustainable development of the Lithuanian energy sector, land, and water use. For this objective the optimisation model was created in order to analyse the entire chain of energy flows (including the use of non-renewable energy sources), starting from the use of natural energy resources such as land, and finishing with separate energy types obtained from these resources seeking to meet societal demands.

On the sectoral level, recommendations for the national programme for development of the district heating sector in 2014-2020 was prepared. Perspective development and functioning of district heating supply systems were analysed by applying a mathematical model created for this purpose. The district heat supply system was addressed as an integral and inseparable part of the energy sector, tightly related to the electricity system by technological and energy flow relations, fuel supply and other systems. Complex modelling made it possible to determine the most efficient heat generation technologies in the largest cities, capacities of heat and electricity generation in thermal power plants, the volume of fuel consumption, costs and volume of necessary investments, etc. [4].

The model for analysis of energy system development in the Baltic countries was created by experts of LEI $[5,6]$. Other models analysing energy sector development on the regional level have also been developed by LEl. For example, in order to assess how 
the Baltic countries' electricity sector may change in the future, depending on the different fossil fuel prices and European Union's carbon dioxide emission reduction objectives, analysis was carried out on the prospective development of the power sector in 9 Baltic region countries (Denmark, Estonia, Latvia, Lithuania, Norway, Finland, Sweden, Germany, Poland). Analysis is based on a mathematical optimisation model created using MESSAGE software. A few possible scenarios differing by fuel prices, possible technological development, environmental limitations, etc. were analysed in the time period from 2016 to 2045. Further developments and improvements are being made to this model.

The multiregional model incorporating Lithuanian, Latvian, Estonian and Polish power system models is being developed by LEI as part of the BRILLIANT project [7]. The model created for the analysis of energy system development and operation for each Baltic country and Poland should help the investigation of technical and economical attractiveness of electricity generation from nuclear fuel, as well as with the examination of power system behaviour having large nuclear units. Capacity building of personnel involved in the planning of power system development and operation is also one of the main objectives of these tasks.

\section{References}

The analysis of Lithuanian energy sector perspective development (In Lithuanian). Lithuanian Energy institute, 201511 16. Available online (In Lithuanian):

http://www.lei.It/_img/_up/File/atvir/2016/NES/2-

Technine_ekonomine_energetikos_sektoriaus_pletros_analize-2015.11.16.pdf

Norvaiša E., Galinis A. Future of Lithuanian energy system: Electricity import or local generation? (dx.doi.org/10.1016/j.esr.2016.03.001) // Energy Strategy Reviews. ISSN 2211-467X. Vol. 10. 2016. p. 29-39.

Planning \& Economic Studies. International Atomic Energy Agency. https://www.iaea.org/OurWork/ST/NE/Pess/crps.html

Recommendations for the National program for development of heat sector in 2014-2020. Presentation by A. Galinis on 201402 20, Lithuanian Energy institute. Available online (In Lithuanian):

http://www.lei.lt/_img/_up/File/atvir/2014/naujienos/Pranesimai_20140220/Pas_pletros_1 dalis.pdf

Analyses of Energy Supply Options and Security of Energy Supply in the Baltic States // Vienna, Austria: International Atomic Energy Agency, 2007. 323 p. IAEA-TECDOC-1541, ISBN 92-0-101107-5. ISSN 1011-4289. Available online :

http://www-pub.iaea.org/MTCD/publications/PDF/te_1541_web.pdf

Future development of the Baltic power system in 2010-2030. Under contract with RWE, 2008.

Baltic Region Initiative for Long Lasting Innovative Nuclear Technologies. The BRILLIANT project (2015-2018) homepage: http://balticbrilliantproject.eu/index.html 
Nordic Council of Ministers

Nordens Hus

Ved Stranden 18

DK-1061 Copenhagen $\mathrm{K}$

www.norden.org

\section{Baltic Energy Technology Scenarios 2018}

Baltic Energy Technology Scenarios 2018 (BENTE) is a scenario-based energy system analysis that explores the changes in the Baltic countries' energy systems. What are the drivers and their impacts in the following decades? What would be required for the Baltic countries to meet their climate and energy targets in 2030, and what development would lead the Baltics towards a $2^{\circ} \mathrm{C}$ pathway?

The report finds that the Baltic countries' proposed renewable energy (RE) targets can be achieved using domestic resources. More renewable energy (electricity, heat and fuels) lets energy demanding sectors reduce GHG emissions and increase the RE share. However, the Baltic countries still do not reach their Effort Sharing Sector's 2030 targets in the $4^{\circ} \mathrm{C}$ Scenario (4DS). Without policies to stimulate local renewable energy generation, the Baltics are likely to become large net importers of electricity. 